\title{
The fundamentals of a dedicated palliative approach to care for people with dementia
}

Citation for published version (APA):

Bolt, S. R. (2021). The fundamentals of a dedicated palliative approach to care for people with dementia. [Doctoral Thesis, Maastricht University]. Maastricht University. https://doi.org/10.26481/dis.20210922sb

Document status and date:

Published: 01/01/2021

DOI:

10.26481/dis.20210922sb

Document Version:

Publisher's PDF, also known as Version of record

\section{Please check the document version of this publication:}

- A submitted manuscript is the version of the article upon submission and before peer-review. There can be important differences between the submitted version and the official published version of record.

People interested in the research are advised to contact the author for the final version of the publication, or visit the DOI to the publisher's website.

- The final author version and the galley proof are versions of the publication after peer review.

- The final published version features the final layout of the paper including the volume, issue and page numbers.

Link to publication

\footnotetext{
General rights rights.

- You may freely distribute the URL identifying the publication in the public portal. please follow below link for the End User Agreement:

www.umlib.nl/taverne-license

Take down policy

If you believe that this document breaches copyright please contact us at:

repository@maastrichtuniversity.nl

providing details and we will investigate your claim.
}

Copyright and moral rights for the publications made accessible in the public portal are retained by the authors and/or other copyright owners and it is a condition of accessing publications that users recognise and abide by the legal requirements associated with these

- Users may download and print one copy of any publication from the public portal for the purpose of private study or research.

- You may not further distribute the material or use it for any profit-making activity or commercial gain

If the publication is distributed under the terms of Article $25 \mathrm{fa}$ of the Dutch Copyright Act, indicated by the "Taverne" license above, 


\section{The fundamentals of a}

\section{DEDICATED}

palliative approach to care for people with dementia 
The fundamentals of a DEDICATED palliative approach to care for people with dementia 
The research presented in this thesis was conducted at CAPHRI Care and Public Health Research Institute, Department of Health Services Research, of Maastricht University. CAPHRI participates in the Netherlands School of Public Health and Care Research CaRe. This research was conducted within the Living Lab in Ageing and Long-Term Care and funded by The Netherlands Organisation for Health Research and Development (ZonMw, grant number 844001405).

\section{The fundamentals of a DEDICATED palliative approach to care for people with dementia}

PROEFSCHRIFT

The front cover image is a painting by Irene Geertruida Bolt - de Klerk, my grandmother, oma Rien. She had Alzheimer's disease. She made this painting in one of her creative therapy sessions in 2014. It is called 'Vogel' ('Bird').

The painting symbolizes living 'in the moment'. Painting helped oma Rien to express her emotions and to relief physical and mental distress. The process of painting was not result-driven, it was not demanding. It allowed her to focus only on shapes and colors.

Layout: Ilse Modder, www.ilsemodder.nl

Printing: Gildeprint, www.gildeprint.nl

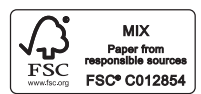

Financial support for printing this thesis was kindly provided

by Alzheimer Nederland.

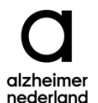

door

(C) Copyright Sascha Bolt, 2021

All rights are reserved. No part of this book may be reproduced or transmitted in any form or by any means, without the written permission from the author or, where appropriate, from the publishers of the publications.

Ter verkrijging van de graad van doctor aan de Universiteit Maastricht,

op gezag van de Rector Magnificus, Prof. dr. Rianne M. Letschert, volgens het besluit van het College van Decanen, in het openbaar te verdedigen

op woensdag 22 september 2021 om 16.00 uur

Sascha Rianne Bolt 


\section{PROMOTORES}

Prof. dr. S.M.G. Zwakhalen

Prof. dr. J.M.G.A. Schols

\section{COPROMOTORES}

Dr. J.M.M. Meijers

Dr. J.T. van der Steen (Leids Universitair Medisch Centrum)

\section{BEOORDELINGSCOMMISSIE}

Prof. dr. F.R.J. Verhey (voorzitter)

Prof. dr. H. Verbeek

Prof. dr. M.H.J. van den Beuken-van Everdingen

Prof. dr. S.C.C.M. Teunissen (Universitair Medisch Centrum Utrecht)

Prof. dr. G.G. Cummings (University of Alberta, Canada) 


\section{CONTENTS}

CHAPTER 1

General introduction

Adapted chapter of The practical handbook of dementia, accepted

Impact

Dankwoord

About the author

Publications

Living Lab in Ageing and Long-Term Care
International Journal of Nursing Studies, 2019

CHAPTER 3 Nursing staff needs in providing palliative care for persons with dementia at home or in nursing homes: A survey Journal of Nursing Scholarship, 2020

CHAPTER 4 Practical nursing recommendations for palliative care for people with dementia living in long-term care facilities during the COVID-19 pandemic: A rapid scoping review International Journal of Nursing Studies, 2019

CHAPTER 5 Families' experiences with end-of-life care in nursing homes and associations with dying peacefully with dementia Journal of the American Medical Directors Association, 2019

CHAPTER 6 What do relatives value most in end-of-life care for people with dementia?

International Journal of Palliative Nursing, 2019

CHAPTER 7 Trends in quality of care and dying perceived by family caregivers of nursing home residents with dementia between 2005-2019

Palliative Medicine, accepted for publication

CHAPTER 8 The perspectives of people with dementia on their future, end of life, and on being cared for by others:

A qualitative study

Journal of Clinical Nursing, 2021

CHAPTER 9 General discussion 


\section{CHAPTER 1}

\section{General introduction}

Sascha R Bolt 


\section{A CLOAK OF COMFORT: PALLIATIVE CARE}

In palliative care, we aim to alleviate symptoms, regardless of whether we can treat the underlying disease. The term palliative care originates from the Latin word pallium, which means cloak. Figuratively speaking, we put a cloak around persons with incurable conditions to provide them with warmth, comfort and a sense of safety. The purpose of palliative care is to improve the quality of life of people with serious health-related suffering (i.e., suffering related to any type of illness or injury that carries a high risk of mortality, negatively affects quality of life, or involves burdensome symptoms or treatments) and their families. ${ }^{1}$ Palliative care is holistic, which means that it focuses on the entire person by recognizing physical, psychological, social and spiritual needs. Nowadays more than 100 countries worldwide provide palliative care services. Despite growing efforts, the rising needs for high-quality palliative care are still unmet in many parts of the world. ${ }^{2}$ Although it eventually incorporates terminal care, contemporary palliative care is much broader. Palliative care could refer to specialized services such as a palliative care team, specialized nurses or specialized treatments. However, palliative care also refers to a general philosophy and approach to care. ${ }^{3}$ Essentially, this is generalist care, and every healthcare professional should be able to apply palliative care principles. Palliative care is for people across all ages with any type of life-limiting condition and it applies to all health care settings, from primary to tertiary care. ${ }^{1}$ It is not restricted by time and may cover weeks, months or years. Moreover, palliative care may be provided alongside therapies that prolong life or modify the disease. ${ }^{1}$

People with a variety of life-limiting conditions, and people with frailty in general, may benefit from a palliative approach to care. ${ }^{1,4}$ This dissertation focuses specifically on palliative care for people with dementia and explores what constitutes high-quality palliative dementia care from different perspectives. This chapter introduces the applicability of a palliative approach to care for people with dementia and their family caregivers, outlines common challenges, and describes nursing staff as the primary group of professional caregivers for people with dementia until the end of life. The aims and content of this dissertation are outlined at the end of this chapter.

\section{DEMENTIA AND THE PALLIATIVE APPROACH TO CARE}

Meet Mrs. Fiona Scott. Fiona is 83 years old and she has dementia of the Alzheimer's type. Fiona lives at home with her husband, Mr. Paul Scott, 78 years old. Paul underwent several treatments for cancer. He calls himself 'a very bright man with some physical defects'. Although they argue at times, Paul thinks that he and Fiona make a great team together. Their daughter Millie visits them regularly.
Dementia is a neurodegenerative syndrome caused by underlying single or mixed pathologies in the brain. ${ }^{5}$ The predominant form of dementia among older people is Alzheimer's disease. In 2015, the estimated worldwide number of people living with dementia was 46.8 million and the estimated healthcare costs for dementia entailed 818 billion US dollars. ${ }^{6}$ Alzheimer's Disease International anticipates that these numbers will have nearly tripled by $2050 .{ }^{6}$ To date, however, evidence concerning the increase in the global prevalence of dementia is ambiguous. ${ }^{7,8}$ Despite the long-standing and costly worldwide pursuit to find a cure or disease-modifying therapy, there is no cure available for dementia today. ${ }^{9,10}$ In most forms of dementia, disease progression is irreversible and impairments increase over time. Thus, dementia is a chronic condition that persists until the end of life. A central characteristic of dementia is that it affects cognitive functions, such as memory, language, attention and planning. ${ }^{11}$ This implies that, over time, people like Fiona may lose their ability to think or talk about their wishes. Eventually they may also lose self-care abilities and the ability to walk, or to eat and drink without the assistance of others..$^{12} \mathrm{~A}$ palliative approach to care recognizes the progressive nature of dementia. Goals of care focused on comfort and symptom relief may be particularly important in the more advanced stages. ${ }^{13}$ Nonetheless, awareness of the life-shortening and terminal nature of dementia may help to prepare for potential future problems and early anticipation should support the adequate provision of future palliative care ${ }^{13}$ In an early stage, palliative care may support coping with the disease and the anticipated, often gradual, decline.

Although an integrated palliative care approach is a vital element of highquality dementia care, ${ }^{14,15}$ previous studies highlight a wide variety of barriers to the provision of palliative care for people with dementia. ${ }^{16,17}$ Dementia is not always recognized as a terminal illness and people with dementia are less likely to receive palliative care services compared to people with other terminal conditions. ${ }^{18}$ Another barrier involves communication..$^{16}$ This refers to insufficient communication between healthcare professionals, insufficient communication with the person with dementia and their family caregivers, and poor collaboration between all these stakeholders. On the contrary, ideally palliative care for people with dementia should facilitate communication and collaboration to allow for shared decision-making, personcentered and relationship-centered care ${ }^{13}$ According to Kitwood's theory of personcentered dementia care, healthcare professionals should invest in trustful and respectful relationships with people with dementia to preserve personhood and to promote well-being. ${ }^{19}$ This aligns with Nolan's definition of relationship-centered care, in which he stresses the importance of recognizing the interdependence of individuals in social interactions. ${ }^{20}$ Relationship-centered care aims to incorporate the needs of all involved parties and contributes to a shared understanding among people with dementia, their family caregivers and professional caregivers. In the Netherlands, the 
estimated number of family caregivers or other informal caregivers currently caring for someone with dementia is $800,000 .{ }^{21}$ On average, their caregiving role takes up 40 hours per week. Thus, families provide substantial care for people with dementia. Their important role continues after nursing home placement and up to the end of life..$^{22}$ Family caregivers like Paul and Millie should be involved in early palliative care, as they are likely to become proxy-decision makers for Fiona someday. ${ }^{23}$

Fiona notices increasing difficulties in making decisions and clearly expressing herself. Fiona once signed a form stating that she does not want to be resuscitated. 'There is no need for all that', she told Millie and her family physician at the time. 'If my time here is up, let it be that way."

Palliative care provision and decision-making in more advanced stages of dementia can be challenging due to communication difficulties with the person with dementia. ${ }^{24,25}$ Therefore, it is often stressed that people with dementia should be offered timely opportunities to discuss future care, while they are capable of weighing preferences and expressing their thoughts. ${ }^{13,26}$ Advance care planning (ACP) is a communication process, in which healthcare professionals discuss goals of care and wishes for future care with persons with dementia and their family caregivers. ${ }^{27}$ Discussing care plans in advance may help and reduce stress for family caregivers, once they have to make proxy decisions ${ }^{28}$ In the context of palliative care, healthcare professionals have an important role in informing people like Fiona, Paul, and their daughter on the prognosis of dementia and the potential benefits of ACP conversations in an early stage. ${ }^{26}$ Nonetheless, introducing conversations about future or end-of-life care and finding the right time for these conversations is often challenging for healthcare professionals..$^{29,30}$ Moreover, people with dementia and their family caregivers may be hesitant themselves to talk about end-of-life topics. ${ }^{31}$ Guiding people with dementia and their families towards accepting the inevitable decline associated with dementia may facilitate conversations about future wishes. ${ }^{31}$ As an individual's wishes regarding care and treatment may change over time, ACP requires regular updating. ${ }^{27}$

Fiona enjoys strolling in the forest. Although she prefers not to think about this, Fiona might slip or fall and risk a fracture. Fiona already told Paul and Millie several times that she does not want to go to a hospital.

The documentation of care preferences in advance directives is a specific and concrete goal of having ACP conversations. Yet, there are many other underlying goals of ACP, such as improving autonomy of persons with dementia, preparing them for the end of life and reducing unwanted and unnecessary treatments. ${ }^{32}$ Shared decision-making about the place of care can be challenging, ${ }^{33}$ as older people often prefer to stay in their own familiar environment until the end of life. ${ }^{34}$ Feelings of guilt, shame or loss, but also relief, are common among family caregivers after a relative's transition to residential care ${ }^{35}$ Family caregivers therefore require adequate support by healthcare professionals when relinquishing care for a relative with dementia to a nursing home. ${ }^{35}$

Paul sometimes worries about caring for Fiona if the dementia gets worse. It may become difficult for Fiona to stay at home when her needs grow beyond Paul's capacities. Paul thinks it would feel like 'giving up' if he would let Fiona move to a nursing home.

\section{WHO PROVIDES PALLIATIVE DEMENTIA CARE IN THE NETHERLANDS?}

In the Netherlands, the majority (79\%) of people with dementia live in the community, ${ }^{21}$ where they mostly receive care from family caregivers and home care professionals. ${ }^{36}$ Dutch policy stimulates ageing in place and only very frail and highly dependent people qualify for placement in nursing homes, which offer 24-hour care. ${ }^{37,38}$ Holistic palliative care requires an interdisciplinary approach, and interprofessional collaboration is needed to ensure continuity. ${ }^{13}$ Well-coordinated, interprofessional care may help postpone or prevent admissions to a nursing home or hospital. ${ }^{39}$ Yet, around $70 \%$ of the persons with dementia eventually die in a nursing home..$^{40}$ To avoid fragmented care and to promote continuity of care after transitions, former professionals should communicate care plans to new professionals, involving people with dementia and their families. ${ }^{13}$ Both care settings need skilled and knowledgeable staff to establish a palliative approach to care for people with dementia. However, insufficient knowledge and competences among professionals who provide this care is a commonly described barrier. ${ }^{41,42}$

It is six o'clock in the morning when Aisha's alarm goes off. She is working the early shift today. Aisha is a certified nurse assistant on a secure dementia unit. She loves her job, even though it is not always easy. She wants to provide the best possible care for each of the residents, but it can be difficult at times to really understand what they want or need. Sometimes, family members can be very helpful companions in discovering those needs.

The largest workforce providing formal care for people with dementia at home and in nursing homes consists of nurse assistants (helpenden), certified nurse assistants (verzorgenden), vocationally trained registered nurses (MBO-verpleegkundigen), and bachelor educated registered nurses (HBO-verpleegkundigen). ${ }^{43,44}$ Curricula for the 
basic education of both registered nurses and nurse assistants lack an in-depth focus on palliative care. ${ }^{45}$ The need among Dutch nurses and nursing students to develop and improve palliative care knowledge and skills has persisted for years, especially among home care workers. ${ }^{46}$ In a recent survey among Dutch nurses and certified nurse assistants working in different settings, $85 \%$ of the respondents reported that they experienced at least one barrier to ideal palliative care ${ }^{47}$ Roughly $40 \%$ reported that they experienced more than five barriers. Palliative care for people with dementia requires a particular set of skills and a certain sensitivity that may help to alleviate the person's symptoms and to optimize quality of life. Core competencies include, among others: applying a person-centered and family-centered approach by responding to the person's and family caregiver's individual needs, supporting people with dementia and their families in planning for the future, and adopting a holistic approach to the treatment of symptoms ${ }^{13}$ Especially in the advanced stages of dementia, when impaired cognition and communication are often evident, care professionals experience difficulties in providing high-quality care. ${ }^{16,24,48}$ Yet, even in advanced dementia, skilled staff and tailored psychosocial approaches may help to build social and emotional connections. ${ }^{49}$

Fiona is now 88 years old and lives in a nursing home. Paul, now 83 years old still says he is 'a bright fellow'. Paul visits Fiona daily and Millie visits them weekly. Aisha and the other nursing staff do their best to provide warm care for Fiona every day. Over the past weeks, Fiona has become nearly completely care dependent: she does not get out of bed nor eat by herself. Paul and Millie feel that they have an important role in voicing Fiona's needs now that her end of life is nearing. Aisha wishes that she can contribute to a peaceful end of life for Fiona.

\section{FAMILY CAREGIVERS AND THE END OF LIFE WITH DEMENTIA}

Palliative care aims to optimize the quality of life and eventually, the quality of dying. ${ }^{1}$ Although the meaning of a 'good death' is debatable, people generally wish to die peacefully and comfortably. Being at peace at the end of life involves a sense of tranquility, inner harmony, well-being, and closeness to one's family. ${ }^{50}$ Care for family caregivers, and actively involving them, is an important part of end-of-life care. ${ }^{18}$ The families' perspective is valuable to professional caregivers when trying to hear and understand the voice of persons with dementia at the end of life. ${ }^{51}$ Moreover, witnessing a relative approaching the end of life may bring along feelings of loss and grief for family caregivers. ${ }^{52}$ Relatives of people with dementia often lack knowledge concerning the disease trajectory, prognosis, and dying process. ${ }^{52}$ Formal caregivers have an important role to evaluate their understanding and to support them accordingly and in a sensible manner. Family caregivers need support throughout the care trajectory and until their relative's end of life to help them deal with multiple losses and anticipatory grief, and their need for support may continue after bereavement. ${ }^{18,52}$ Family caregivers of people with dementia are important stakeholders in the evaluation of quality of care at the end of life, and quality of dying..$^{53}$ Several validated instruments exist that can be used to measure these outcomes. ${ }^{54}$ De Roo and colleagues found that only half (56\%) of the family caregivers of residents with dementia in Dutch nursing homes indicated that their relative had died peacefully. ${ }^{50}$ One of the factors that increased the odds of a resident dying peacefully according to their family member was the families' perception that enough nurses were available. Families' assessments of the quality of end-of-life care and the quality of dying provide information on opportunities to improve palliative care at the end of life with dementia. ${ }^{5.5}$

When the end of life is approaching, goals of care should focus mainly on comfort as this becomes more important than prolonging life..$^{13}$ Continuity in care relationships and dedicated, familiar staff are needed to optimize comfort for people with dementia in the terminal phase. ${ }^{56}$ Nursing staff have a key role to recognize and manage discomfort and to respond to unmet care needs. ${ }^{57}$ Although physical care is indispensable to manage burdensome symptoms such as pain, equal attention should be paid to the psychological, social and spiritual aspects of end-of-life care. ${ }^{51}$

Ideally, every member of the healthcare team that provides care for people with dementia should be skilled to apply the basics of a palliative care approach. ${ }^{13}$ As the white paper of the European Association for Palliative Care (EAPC) describes: increasing competences of healthcare professionals is one of the key domains of optimal palliative care in dementia. ${ }^{13}$ This was acknowledged in a Dutch policy program (National Program Palliative Care) that was established in 2014 to improve palliative care. ${ }^{58}$ One of the program's goals stated that all professional caregivers, throughout the care chain, should integrate palliative care. Nursing staff feel that they lack sufficient knowledge and skills to provide palliative care and end-of-life care. ${ }^{59}$ To improve palliative dementia care provided by nursing staff specifically, their education and ongoing training should be tailored to their specific needs. ${ }^{60}$ It is important to increase knowledge and skills of nursing staff to contribute to high-quality palliative care for people with dementia until the end of life, and their families. To improve tailored care provision from the ground up, we need a deeper understanding of what constitutes high-quality palliative dementia care, as perceived by its primary stakeholders. In this dissertation, these stakeholders are people with dementia, their family caregivers and nursing staff. Knowledge concerning the fundamentals of palliative dementia care provides a starting point for developing interventions that contribute to the required competences of nursing staff. 


\section{THE DEDICATED PROJECT}

The studies in this dissertation are part of a larger project entitled DEDICATED: Desired Dementia Care Towards End of Life. The overall aim of the DEDICATED project is to improve palliative care for people with dementia and their family caregivers. The project consists of two parts. Part 1 focuses on palliative dementia care provision by nursing staff, working in the community or in nursing homes, and on end-of-life communication. Part 2 focuses on interprofessional collaboration in palliative dementia care in the community, in nursing homes, and in transition between these settings. Although both parts of the project have their own specific research focus, the parts are complementary and the themes addressed overlap in practice. DEDICATED uses an iterative and cocreative method to develop a 'DEDICATED approach', in collaboration with nurses, other healthcare professionals, and nurse education experts. The DEDICATED approach in its entirety entails both parts of the project and consists of support materials for healthcare professionals. Initially, several studies were performed to explore what is needed in palliative dementia care as a basis for the subsequent development of support materials.

\section{AIMS AND OUTLINE}

The aim of this dissertation is to explore and describe what constitutes high-quality palliative care for people with dementia. The studies in this dissertation take into account the perspective of nursing staff, family caregivers and people with dementia themselves. The findings from this exploration function as a basis for the development of a 'DEDICATED approach' to palliative care for people with dementia. More specifically, this dissertation describes:

1. The needs of nursing staff in providing palliative dementia care and how they may do so in times of a pandemic (COVID-19). - Chapters 2, 3, and 4

2. The association between family caregivers' experiences with palliative care at the end of life of a relative with dementia and peaceful dying, an exploration of family caregivers' experiences and trends in family caregivers' assessments of the quality of end-of-life care and the quality of dying. - Chapters 5, 6, and 7

3. The perspectives of people with dementia themselves on their future and the end of life, and on being cared for by others. - Chapter 8
Accordingly, the chapters can be grouped into three parts:

Part 1. The nurse perspective - Chapter 2 describes a scoping review to map the needs of nursing staff in providing palliative care for people with dementia. Chapter 3 reports on a survey among Dutch nursing staff to explore their support needs and their preferred forms of support in providing palliative dementia care. Chapter $\mathbf{4}$ formulates practical recommendations for nursing staff on how to provide palliative dementia care in times of COVID-19, based on a rapid scoping review.

Part 2. The family perspective - Chapter $\mathbf{5}$ analyses family caregivers' experiences with end-of-life care and the association with a peaceful death of their relative with dementia. Chapter 6 explores how bereaved family caregivers of people with dementia experienced palliative care provided to their relative at the end of life. Chapter 7 analyses trends in family caregivers' assessments of the quality of end-of-life care and quality of dying of nursing home residents with dementia, over a 14-year period (20052019)

Part 3. The perspective of the person with dementia - Chapter 8 explores how people with dementia themselves regard their future and the end of life, and how they perceive being cared for by others.

Chapter 9 summarizes these studies' main findings and elaborates on theoretical implications, methodological considerations, and implications for future research, practice, and policy. 


\section{REFERENCES}

1. Radbruch L, De Lima L, Knaul F, Wenk R, Ali Z, Bhatnaghar S, et al. Redefining Palliative Care-A New Consensus-Based Definition. Journal of Pain and Symptom Management. 2020;60(4):754-64.

2. Connor SR, Sepulveda Bermedo MC. Global atlas of palliative care at the end of life. 2014.

3. Sawatzky R, Porterfield P, Lee J, Dixon D, Lounsbury K, Pesut B, et al. Conceptual foundations of a palliative approach: a knowledge synthesis. BMC Palliative Care. 2016;15(1):5.

4. Stow D, Spiers G, Matthews FE, Hanratty B. What is the evidence that people with frailty have needs for palliative care at the end of life? A systematic review and narrative synthesis. Palliat Med. 2019;33(4):399414.

5. James BD, Bennett DA. Causes and Patterns of Dementia: An Update in the Era of Redefining Alzheimer's Disease. Annual Review of Public Health. 2019;40(1):65-84.

6. Alzheimer's Disease International. World Alzheimer Report. The global impact of dementia: An analysis of prevalence, incidence, cost and trends. 2015.

7. Prince M, Ali G-C, Guerchet M, Prina AM, Albanese E, Wu Y-T. Recent global trends in the prevalence and incidence of dementia, and survival with dementia. Alzheimer's Research \& Therapy. 2016;8(1):23.

8. Stephan BCM, Birdi R, Tang EYH, Cosco TD, Donini LM, Licher S, et al. Secular Trends in Dementia Prevalence and Incidence Worldwide: A Systematic Review. Journal of Alzheimer's Disease. 2018;66:653-80.

9. Wong G, Knapp M. Should we move dementia research funding from a cure to its care? Expert Review of Neurotherapeutics. 2020;20(4):303-5.

10. Cummings J, Lee G, Ritter A, Sabbagh M, Zhong K. Alzheimer's disease drug development pipeline: 2019. Alzheimer's \& dementia (New York, N Y). 2019;5:272-93,

11. Hugo J, Ganguli M. Dementia and cognitive impairment: epidemiology, diagnosis, and treatment. Clinics in geriatric medicine. 2014;30(3):421-42.

12. Mitchell SL, Teno JM, Kiely DK, Shaffer ML, Jones RN, Prigerson HG, et al. The clinical course of advanced dementia. The New England journal of medicine. 2009;361(16):1529-38.

13. van der Steen JT, Radbruch L, Hertogh CM, de Boer ME, Hughes JC, Larkin P, et al. White paper defining optimal palliative care in older people with dementia: a Delphi study and recommendations from the European Association for Palliative Care. Palliat Med. 2014:28(3):197-209.

14. Nakanishi M, Nakashima T, Shindo Y, Miyamoto Y, Gove D, Radbruch L, et al. An evaluation of palliative care contents in national dementia strategies in reference to the European Association for Palliative Care white paper. International Psychogeriatrics. 2015;27(9):1551-61

15. Durepos P, Wickson-Griffiths A, Hazzan AA, Kaasalainen S, Vastis V, Battistella L, et al. Assessing Palliative Care Content in Dementia Care Guidelines: A Systematic Review. Journal of Pain and Symptom Management. 2017;53(4):804-13.

16. Erel M, Marcus EL, Dekeyser-Ganz F. Barriers to palliative care for advanced dementia: a scoping review. Ann Palliat Med. 2017;6(4):365-79.

17. Sachs GA, Shega JW, Cox-Hayley D. Barriers to excellent end-of-life care for patients with dementia. J Gen Intern Med. 2004;19(10):1057-63.

18. Broady TR, Saich F, Hinton T. Caring for a family member or friend with dementia at the end of life: A scoping review and implications for palliative care practice. Palliat Med. 2018;32(3):643-56.

19. Kitwood TM. Dementia Reconsidered: The Person Comes First. Buckingham: Open University Press; 1997.

20. Nolan MR, Davies S, Brown J, Keady J, Nolan J. Beyond person-centred care: a new vision for gerontological nursing.J Clin Nurs. 2004;13(3a):45-53.

21. Alzheimer Nederland. Factsheet cijfers en feiten over dementie 2021 [cited 202124 March]. Available from: https://www.alzheimer-nederland.nl/factsheet-cijfers-en-feiten-over-dementie.

22. Brodaty H, Donkin M. Family caregivers of people with dementia. Dialogues in clinical neuroscience. 2009;11(2):217-28

23. Kwak J, De Larwelle JA, Valuch KO, Kesler T. Role of Advance Care Planning in Proxy Decision Making Among Individuals With Dementia and Their Family Caregivers. Res Gerontol Nurs. 2016;9(2):72-80.

24. Midtbust MH, Alnes RE, Gjengedal E, Lykkeslet E. A painful experience of limited understanding: healthcare professionals' experiences with palliative care of people with severe dementia in Norwegian nursing homes. BMC Palliative Care 2018:17(1):25.

25. Birch D, Draper I A critical literature review exploring the challenges of delivering effective palliative care to older people with dementia. Journal of Clinical Nursing. 2008;17(9):1144-63.

26. Harrison Dening K, Sampson EL, De Vries K. Advance care planning in dementia: recommendations for healthcare professionals. Palliative Care: Research and Treatment. 2019;12:1178224219826579.

27. Rietjens JAC, Sudore RL, Connolly M, van Delden JJ, Drickamer MA, Droger M, et al. Definition and recommendations for advance care planning: an international consensus supported by the European Association for Palliative Care. Lancet Oncol. 2017;18(9):e543-e51.

28. Sudore RL, Fried TR. Redefining the "planning" in advance care planning: preparing for end-of-life decision making. Ann Intern Med. 2010;153(4):256-61

29. Robinson L, Dickinson C, Bamford C, Clark A, Hughes J, Exley C. A qualitative study: Professionals experiences of advance care planning in dementia and palliative care, 'a good idea in theory but ...' Palliat Med. 2013;27(5):401-8.

30. Ryan T, Amen K, McKeown J. The advance care planning experiences of people with dementia, family caregivers and professionals: a synthesis of the qualitative literature. Ann Palliat Med. 2017;6(4):380-9.

31. Sellars M, Chung O, Nolte L, Tong A, Pond D, Fetherstonhaugh D, et al. Perspectives of people with dementia and carers on advance care planning and end-of-life care: A systematic review and thematic synthesis of qualitative studies. Palliat Med. 2019;33(3):274-90

32. Fleuren N, Depla MFIA, Janssen DJA, Huisman M, Hertogh CMPM. Underlying goals of advance care planning (ACP): a qualitative analysis of the literature. BMC Palliative Care. 2020;19(1):27.

33. Ducharme F, Couture M, Lamontagne J. Decision-making process of family caregivers regarding placement of a cognitively impaired elderly relative. Home Health Care Serv Q. 2012;31(3):197-218

34. De Roo ML, Miccinesi G, Onwuteaka-Philipsen BD, Van Den Noortgate N, Van den Block L, Bonacchi A, et al. Actual and preferred place of death of home-dwelling patients in four European countries: making sense of quality indicators. PLOS ONE. 2014;9(4):e93762.

35. Graneheim UH, Johansson A, Lindgren BM. Family caregivers' experiences of relinquishing the care of a person with dementia to a nursing home: insights from a meta-ethnographic study. Scand J Caring Sci. 2014;28(2):215-24

36. Alzheimer Nederland. Cijfers en feiten over dementie. 2017.

37. Maarse JA, Jeurissen PP. The policy and politics of the 2015 long-term care reform in the Netherlands. Health Policy. 2016;120(3):241-5.

38. Sanford AM, Orrell M, Tolson D, Abbatecola AM, Arai H, Bauer JM, et al. An international definition for “nursing home".J Am Med Dir Assoc. 2015;16(3):181-4.

39. Hirschman KB, Hodgson NA. Evidence-Based Interventions for Transitions in Care for Individuals Living With Dementia. The Gerontologist. 2018;58(suppl_1):S129-S40.

40. Joling KJ, Janssen O, Francke AL, Verheij RA, Lissenberg-Witte BI, Visser PJ, et al. Time from diagnosis to institutionalization and death in people with dementia. Alzheimers Dement. 2020;16(4):662-71.

41. Ryan T, Gardiner C, Bellamy G, Gott M, Ingleton C. Barriers and facilitators to the receipt of palliative care for people with dementia: The views of medical and nursing staff. Palliat Med. 2012;26(7):879-86.

42. Dening KH, Greenish W, Jones L, Mandal U, Sampson EL. Barriers to providing end-of-life care for people with dementia: a whole-system qualitative study. BMJ Support Palliat Care. 2012;2(2):103-7.

43. Backhaus R. Thinking beyond numbers: nursing staff and quality of care in nursing homes. Maastricht: Maastricht University; 2017

44. Hallberg IR, Cabrera E, Jolley D, Raamat K, Renom-Guiteras A, Verbeek H, et al. Professional care providers in dementia care in eight European countries; their training and involvement in early dementia stage and in home care. Dementia. 2016;15(5):931-57.

45. Courtens A, Vaessen G, Bour A, van Pol A, van den Beuken-van Everdingen M. Basiscompetenties palliatieve zorg voor verzorgenden en verpleegkundigen. Onderwijs en Gezondheidszorg. 2019;43(4):26-9.

46. Francke AL, Albers G, de Veer AJ, Onwuteaka-Philipsen B. Nog steeds veel behoefte aan extra scholing levenseindezorg. TvZ Tijdschrift voor verpleegkundigen. 2012;122(2):27-40.

47. Uitdehaag MJ, Stellato RK, Lugtig P, Olden T, Teunissen S. Barriers to ideal palliative care in multiple care settings: the nurses' point of view. Int J Palliat Nurs. 2019;25(6):294-305.

48. Pennbrant S, Hjorton C, Nilsson C, Karlsson M. "The challenge of joining all the pieces together" - Nurses' 
experience of palliative care for older people with advanced dementia living in residential aged care units. Journal of Clinical Nursing. 2020;29(19-20):3835-46.

49. Nicholls D, Chang E, Johnson A, Edenborough M. Touch, the essence of caring for people with end-stage dementia: A mental health perspective in Namaste Care. Aging \& Mental Health. 2013;17(5):571-8.

50. De Roo ML, van der Steen JT, Galindo Garre F, Van Den Noortgate N, Onwuteaka-Philipsen BD, Deliens L, et al. When do people with dementia die peacefully? An analysis of data collected prospectively in long-term care settings. Palliat Med. 2014;28(3):210-9.

51. Perrar KM, Schmidt H, Eisenmann Y, Cremer B, Voltz R. Needs of people with severe dementia at the endof-life: a systematic review. Journal of Alzheimer's Disease. 2015;43(2):397-413.

52. Peacock SC. The experience of providing end-of-life care to a relative with advanced dementia: An integrative literature review. Palliative and Supportive Care. 2013;11(2):155-68.

53. van Soest-Poortvliet MC, van der Steen JT, Zimmerman S, Cohen LW, Munn J, Achterberg WP, et al. Measuring the Quality of Dying and Quality of Care When Dying in Long-Term Care Settings: A Qualitative Content Analysis of Available Instruments. Journal of Pain and Symptom Management. 2011;42(6):852-63.

54. van Soest-Poortvliet MC, van der Steen JT, Zimmerman S, Cohen LW, Reed D, Achterberg WP, et al. Selecting the Best Instruments to Measure Quality of End-of-Life Care and Quality of Dying in Long Term Care. ournal of the American Medical Directors Association. 2013;14(3):179-86.

55. Teno JM, Clarridge BR, Casey V, Welch LC, Wetle T, Shield R, et al- Family perspectives on end-of-life care at the last place of care. Jama. 2004;291(1):88-93.

56. van der Steen JT, Lemos Dekker N, Gijsberts M-JHE, Vermeulen LH, Mahler MM, The BA-M. Palliative care for people with dementia in the terminal phase: a mixed-methods qualitative study to inform service development. BMC Palliative Care. 2017;16(1):28.

57. McCleary L, Thompson GN, Venturato L, Wickson-Griffiths A, Hunter P, Sussman T, et al. Meaningful connections in dementia end of life care in long term care homes. BMC Psychiatry. 2018;18(1):307.

5. Nationaal Programma Palliatieve Zorg. Over NPPZ 2014. Available from: https://www. nationaalprogrammapalliatievezorg.nl/Over-NPPZ

59. Francke AL, Albers G, de Veer AJE, Onwuteaka-Philipsen BD, V\&V P. Panel V\&V: nog steeds veel behoefte aan extra scholing levenseindezorg. TVZ: Tijdschrift voor Verpleegkundigen. 2012;122(2):37-40.

60. Smythe A, Jenkins C, Galant-Miecznikowska M, Bentham P, Oyebode J. A qualitative study investigating training requirements of nurses working with people with dementia in nursing homes. Nurse Educ Today. 2017:50:119-23. 


\section{CHAPTER 2}

Nursing staff needs in providing palliative care for people with dementia at home or in long-term care facilities:

A scoping review 


\section{ABSTRACT}

\section{Background}

Nursing staff caring for people with dementia have a crucial role in addressing palliative care needs and identifying changes in health status. Palliative care for people with dementia is complex and requires specific competences. A lack thereof may lead to unnecessary hospitalizations, poor symptom control, and undesirable burdensome treatments. Understanding what nursing staff need to provide palliative care specifically for people with dementia facilitates the development of tailored and feasible interventions.

\section{Objective}

To investigate what is known from the literature regarding the needs in providing palliative dementia care as perceived by nursing staff working in home care or in longterm care facilities and to establish an integrated conceptualization of these needs.

\section{Design}

A scoping review method combined with thematic analysis methods.

\section{Data sources}

Bibliographic databases of PubMed, CINAHL and PsycINFO were searched for primary research studies.

\section{Review methods}

Guidelines from the Joanna Briggs Institute were utilized as a framework for setting up and conducting the scoping review. Eligible articles considered nursing staff's perceived needs in providing palliative dementia care at home or in long-term care facilities. Two authors assessed eligibility based on title and abstract, assessed full texts for selected records, and assessed the quality of included articles. Thematic analysis methods were used to identify themes from relevant study findings, which were integrated to form a conceptualization.

\section{Results}

Of the 15 articles that were included, most used qualitative methods ( $\mathrm{N}=13)$ and were conducted in long-term care facilities $(\mathrm{N}=14)$. Themes reflecting nursing staff needs on a direct care-level concern recognizing and addressing palliative care needs (such as comfort), verbal and non-verbal communication, challenging behavior, and familiarity: knowing and understanding the person with dementia. On more distant levels, themes involve a need for interdisciplinary collaboration, training and education, and organizational support.

\section{Conclusion}

A comprehensive overview of nursing staff perspectives on providing palliative care for people with dementia demonstrates interdependent needs related to recognizing and addressing palliative care needs, communicating, handling challenging behavior, and building close care relationships. These care-related needs occur within workplace and organizational contexts. Organizational support is considered insufficient. Yet, healthcare organizations have the authority to fulfil a facilitating role in implementing nursing interventions tailored to nursing staff needs. Areas for further research include home care settings, the psychosocial and spiritual domains of palliative dementia care, advance care planning, and family involvement. 


\section{BACKGROUND}

Dementia is a progressive, irreversible, and life-limiting condition for which there is currently no cure. ${ }^{1,2}$ Yet, palliative care for people with dementia has not received much attention for long, as opposed to palliative oncological care. ${ }^{3,4} \mathrm{~A}$ white paper defining optimal palliative care for older people with dementia suggests that for people in moderate to severe stages of the disease, maintaining functioning and maximizing comfort are appropriate goals of care. ${ }^{5}$ Rather than life prolongation, the suggested care goals focus on optimizing quality of life and are therefore compatible with palliative care. ${ }^{5}$ Palliative care should improve the quality of life of people with a life-limiting illness and their families through addressing physical, psychosocial and spiritual needs..$^{5-8}$ As a combination of problems in these domains often arises, the palliative care needs of people with dementia may be particularly complex and heterogeneous. ${ }^{9,10}$ Severe cognitive deficits, such as memory loss, apraxia, and aphasia are manifest in advanced dementia, as well as comorbid disease, infections, and burdensome symptoms such as dyspnea, pain, and agitation. ${ }^{11}$ Hence, it is important that people with dementia have the opportunity, along with their loved ones, to discuss their preferences and wishes for future care timely. ${ }^{5,12}$

In Western countries, typically more than half of people with dementia ultimately die in long-term care facilities. ${ }^{13,14}$ In the Netherlands, this proportion reaches approximately $92 \%$. Nursing staff working in home care or long-term care facilities usually provide most of the daily care to people with advanced dementia, which allows them to familiarize themselves with usual behavioral patterns, routines, and preferences of the people whom they care for. This also indicates they have an important role in the early identification and acting upon changes in the person's physical and cognitive status, to prevent or alleviate suffering..$^{15}$ Especially at the end of life of people with dementia, the availability of nursing staff to provide personal attention may contribute to a good quality of dying. ${ }^{16}$ When aiming to optimize quality of life and ultimately support a 'good death' for people with dementia, there is much to gain in optimizing care provided by nursing staff.

Specific training focusing on palliative care for people with dementia is needed in nursing curricula and practice. ${ }^{2,17,18}$ Previous studies have indicated that professional caregivers lack knowledge and skills to enforce principles of palliative care in dementia care, lack knowledge about the disease and its prognosis, and insufficiently assess and manage pain. ${ }^{19-21}$ Professionals' descriptions of other barriers to palliative care for people with dementia involve staff shortages, disconnection between services, the absence of advance directives, and staff's lack of self-confidence and self-efficacy. ${ }^{17,22}$ These studies demonstrate gaps in knowledge, skills, and organizational aspects related to palliative care for people with dementia.

Inferring nursing staff needs from knowledge tests or informant information may be valuable, as incompetence might exist unconsciously or perceptions of one's own competence might be biased. Nonetheless, mere measurement of knowledge and skills does not suffice to address nursing staff's own specific needs in providing palliative dementia care. We need a better understanding of the actual perceived needs of nursing staff to provide high-quality palliative care specifically for people with dementia. Therein, 'needs' may also include perceived 'barriers' to delivering high-quality palliative care, as barriers arise when certain needs are not met, or barriers may induce needs. Solutions built to overcome barriers and to adhere to needs may be viewed as 'facilitators' for high-quality palliative dementia care. An integral understanding of nursing staff needs facilitates the development of tailored interventions that fit daily practices and routines. This may in turn motivate nursing staff to apply these interventions and thereby support real-world implementation.

The main research question of this scoping review is: 'What are the perceived needs of nursing staff in providing palliative care for people with dementia in home care or in long-term care facilities?' In addition, we aimed to establish an integrated conceptualization of these needs that may inform the development of a tailored intervention for nursing staff.

\section{METHODS}

The current scoping review is part of the research project 'DEDICATED: Desired Dementia Care Towards End of Life', which aims to improve palliative care for people with dementia and their loved ones. The review was conducted according to an adapted framework proposed by the Joanna Briggs Institute, ${ }^{23}$ which builds on previously established guidelines. ${ }^{24}$ Moreover, we adhered to the PRISMA statement for systematic review protocols where possible. ${ }^{25}$ For instance, we created a flow chart as proposed in the statement and we assessed the methodological quality of included articles.

\section{Search strategy}

The literature search for this scoping review was carried out in December (22nd) 2017. The search strategy comprised three subsequent steps, as proposed in the Joanna Briggs Institute manual. ${ }^{23}$ First, the databases of CINAHL, PubMed, PsycINFO and the search engine Google Scholar were searched to identify relevant keywords and synonyms regarding the subject. Second, these terms were used to build an elaborated search string. An information specialist and two palliative care and dementia experts helped define terminology and broaden definitions in the search strategy, and the search string was discussed with all authors. The search strategy was improved to increase its sensitivity and reduce the risk of missing relevant studies. ${ }^{24} \mathrm{An}$ inclusive approach is recommended for scoping reviews, even though a broad search might result in an increased number 
of irrelevant articles (i.e., lower specificity). As opposed to systematic reviews, scoping reviews tend to seek breadth rather than depth. ${ }^{24}$ The databases of CINAHL, PubMed, and PsycINFO were used to search for literature in a stepwise fashion (Table 1). Third, the Joanna Briggs Institute manual recommends hand-searching reference lists of all studies found through database searching. ${ }^{23}$ For feasibility, we searched included articles that fitted our inclusion criteria for references to other relevant articles. We also searched reviews for relevant references to original studies.

Table 1. Steps and detailed search terms used in the PubMed search.

Step Search terms

$1 \quad$ Subject area I: Dementic

("Dementia"[Mesh] OR “dementias" [Title/Abstract] OR "dementia"[Title/Abstract] OR "alzheimer disease" [MeSH Terms] OR “Alzheimer" [Title/Abstract] OR Alzheimers[Title/Abstract] OR ("alzheimer"[Title/Abstract] AND “disease"[Title/Abstract]) OR "alzheimer disease"[Title/Abstract])

2 Subject area II: Palliative care ("palliative care" [MeSH Terms] OR ("palliative"[Title/Abstract] AND "care"[Title/Abstract])
OR "palliative care"[Title/Abstract] OR "palliative treatment"[Title/Abstract] OR "palliative therapy"[Title/Abstract] OR "palliative therapies" [Title/Abstract] OR “Nursing home"[Title/abstract] OR "Home care services" [MeSH Terms] OR "Hospice and Palliative Care Nursing" [Mesh] OR "Hospice Care"[Mesh] OR ("Palliative"[Title/Abstract] AND "Nursing"[Title/Abstract]) OR ("hospice"[Title/ Abstract] AND "nursing"[Title/Abstract]) OR ("hospice"[Title/Abstract] AND "care"[Title/Abstract]) OR "hospice care" TTitle/Abstract] OR "terminal care"[MeSH Terms] OR ("terminal"[Title/Abstract] AND "care" [Title/Abstract]) OR terminal care"[Title/Abstract] OR ("end of life"[Title/Abstract] AN "care" [Title/Abstract]) OR "end of life care [Title/Abstract] OR Tong-term care" [MeSH] OR (

3 Subject area III: Nurses

["Nurses"[MeSH Terms] OR "nurses"[Title/Abstract] OR "nurse"[Title/Abstract] OR

("registered"[Title/Abstract] AND "nurses"[Title/Abstract]) OR "registered nurses"[Title/Abstract]

OR "nursing staff" [MeSH Terms] OR ("nursing" [Title/Abstract] AND "staff” [Title/Abstract]) OR

"nursing staff"[Title/Abstract] OR “Nurses' aides"[MeSH] OR ("nurses"[Title/Abstract] AND

“aides"[Title/Abstract]) OR “Nurses aides"[Title/Abstract] OR ("nursing"[Title/Abstract] AND "personnel"[Title/Abstract]) OR "nursing personnel"[Title/Abstract] OR "nursing aide"[Title/ Abstract] OR "nursing aides" [Title/Abstract] OR "nursing assistant" [Title/Abstract] OR "nursing assistants" [Title/Abstract] OR attendant [Hitle/Abstract] OR attendants" [Title/Abstract] OR "caregiver"[Title/Abstract] OR "caregivers" [Title/Abstract] OR "caregivers" [MeSH Terms] OR "Healt

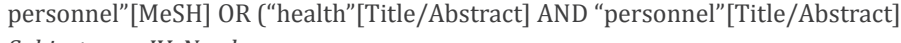

Subjectarea IV: Needs

("Attitude of health personnel"[MeSH] OR "Need"[Title/Abstract] OR "needs"[Title/Abstract] OR "demand" [Title/Abstract] OR "demands" [Title/Abstract] OR "barrier"; [Title/Abstract] OR "barriers" [Title/Abstract] OR "difficulty" [Title/Abstract] OR "difficulties" [Title/Abstract] OR "facilitator" [Title/Abstract] OR "facilitators" "attitudes"[Title/Abstract] OR "views"[Title/Abstract] OR "perception"[Title/Abstract] OR "perceptions" [Title/Abstract] OR "obstacle"[Title/Abstract] OR "obstacles"; Title/Abstract] OR "challenge" [Title/Abstract] OR "challenges" [Title/Abstract] OR "knowledge"[Title/Abstract] OR "skills"[Title/Abstract] OR "communication" [Title/Abstract])

$5 \quad$ All subject areas

\section{Study selection process}

Identified records were imported into EndNote X8 for further investigation and selection. The inclusion criteria for selecting articles were established a priori (Table 2).

Studies involving a subset of relevant study participants, along with other participants (for instance, other healthcare professionals, informal carers, nurses working in other settings) were considered for inclusion if results were specified for the population of interest. We sought for studies conducted in countries where palliative care services are at least at a preliminary stage of integration into general healthcare provision, as defined in the Global Atlas of Palliative Care at the End of Life. ${ }^{26}$ This mainly entails Australia, New Zealand, and countries in Europe, the Northern Americas, and Asia.

Initially, author S.B. screened titles and abstracts for possible eligibility. This process was carried out in collaboration with author S.P. to increase reliability. Both authors screened a random selection of 100 titles and abstracts. Any divergences were discussed to reach a consensus, and if in doubt, inclusion was discussed with the other authors. After achieving agreement, author S.B. continued title-abstract screening. After screening titles and abstracts, records that were deemed eligible were obtained as full texts. When there was no online access, authors of the articles were emailed or articles were requested via inter-library loan services. S.B. and S.P. judged eligibility of a random selection of 20 articles. They reached full agreement, whereupon the first author continued with fulltext assessment. The reasons for excluding full-text articles were recorded. An expert in palliative care and dementia research evaluated the final list of included articles to verify that the important literature had been identified through the search.

Table 2. In and exclusion criteria for selecting articles.

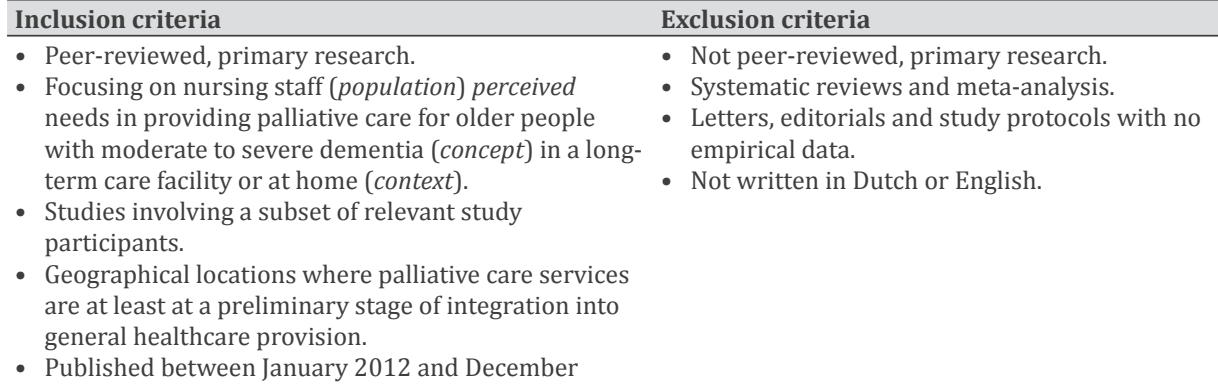

\section{Quality appraisa}

We included primary research articles and we were interested in the quality of the research and the reporting. We used the quality assessment form developed by Kmet et al., ${ }^{27}$ as it allows for rating both quantitative and qualitative studies. It involves two 
separate checklists with scoring manuals developed to assess the internal validity of studies. The checklist for qualitative research comprises 10 items and the checklist for quantitative research comprises 14 items. The items cover study characteristics reflecting methodological quality (e.g., clarity of objective and procedures, appropriate design, reporting of bias) and, upon presence, are scored with a 2 ('yes'), 1 ('partial') or 0 ('no'). A summary score represents the total divided by the maximum score. For the purpose of the current scoping review, there was no cut-off point for inclusion of articles. Quality was assessed after inclusion of articles to explore possible methodological hiatuses that need closer consideration in future research. The quality assessment was carried out by three researchers and an assessment of weighted kappa between each pair of assessors (respectively $\kappa=0.399,95 \% \mathrm{CI} .141$ to $.657, p<.00, \kappa=0.284,95 \% \mathrm{CI}$, .008 to $.560, p<.05, \kappa=0.258,95 \% \mathrm{CI},-.019$ to $.535, p<.05$ ) indicated fair agreement. ${ }^{28}$ Overall agreement between the three assessors was fair, as indicated by Fleiss' kappa $(\kappa=0.279,95 \% \mathrm{CI}, .141$ to $.417, p<.00)$. Any interrater discrepancies were discussed to reach consensus and improve the quality of the procedures.

\section{Synthesis, thematic analysis and conceptualization}

One author (S.B.) extracted data from the included studies using a data charting form adapted from Joanna Briggs Institute recommendations. ${ }^{23}$ This form comprised the following elements: authors, year, country, population demographics, study aims and focus, design and methodology. For each article, we added to the form the quality score and findings that were relevant to answer the current research question. For the one quantitative study, this merely concerned findings that the article's authors derived from open-ended questions inquiring about nurses' learning needs.

We read the included articles thoroughly to familiarize ourselves with the content of the studies. During a second reading, the research question as defined a priori guided identification and flagging of findings relevant to the research question. The parts of the text that described findings related to perceived needs were then copied onto the data extraction form. Qualitative analysis software Nvivo 11 was used to assist the qualitative analysis. Author S.B. identified themes from the relevant text passages of the included studies using a thematic analysis applying Braun and Clarke's paradigm. ${ }^{29}$ The first step involved initial open coding of the extracted texts reflecting needs and barriers. Thereafter, codes were clustered into themes. Synthetizing themes from the data was an iterative process, guided by the review question, and further informed and refined by regular discussions with all authors. Memos were written throughout this process. Recurring themes and apparent links between themes were discussed with all authors for further interpretation, integrating each team member's knowledge and perspective. This process contributed to establishing a comprehensive conceptualization of nursing staff needs in providing palliative care for people with dementia.

\section{RESULTS}

Literature search

After removal of duplicates, the final updated search of the bibliographic databases CINAHL, PsycINFO, and PubMed resulted in 1230 articles. After title and abstract screening, 1029 articles were excluded. Full texts of 200 articles were accessed and screened for eligibility. One article was unavailable and therefore excluded. Figure 1 shows the reasons for excluding full-text articles. Ultimately, 15 articles were included in the scoping review. No additional eligible records were identified through screening reference lists of included articles or the reference lists of systematic reviews.
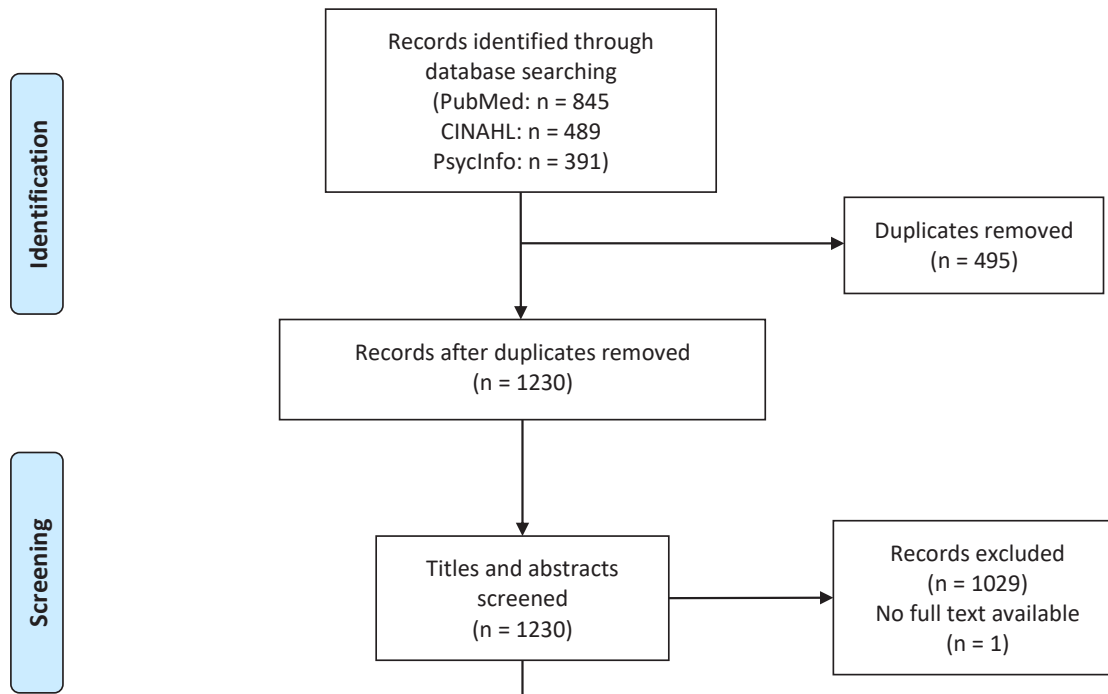
$(n=1230)$
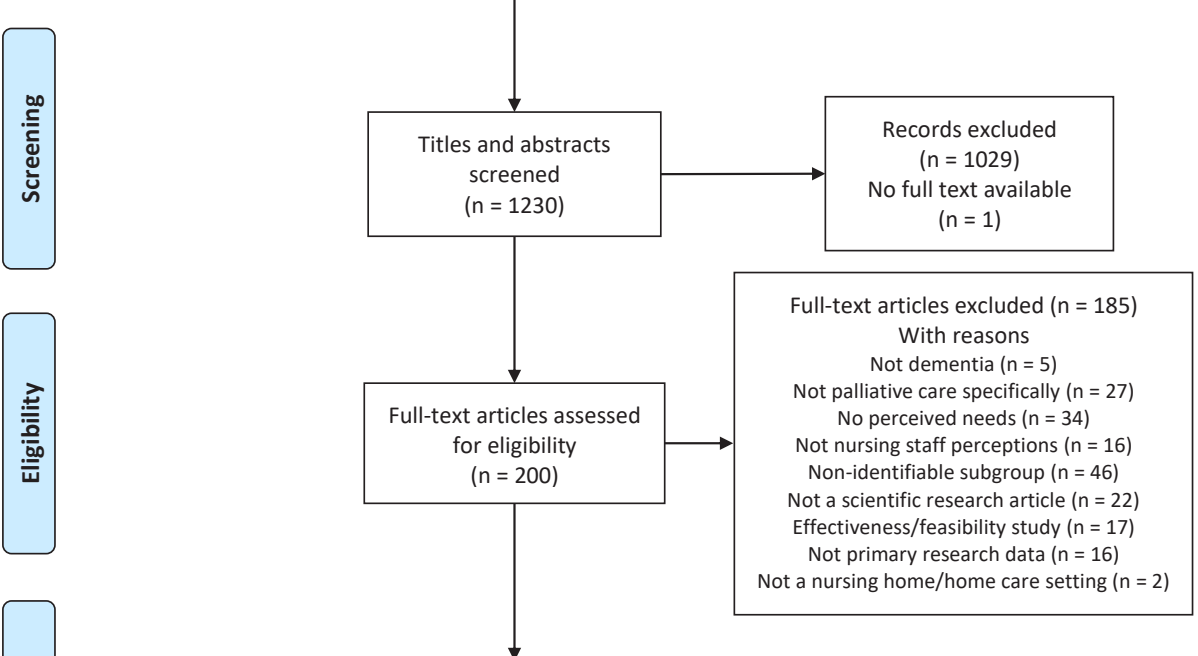


\section{Article information}

The 15 included articles were written in English..$^{15,30-43}$ The majority concerned qualitative studies ( $\mathrm{N}=13)$, one study used mixed methods and one article described a quantitative study. All articles described distinct studies. The studies were conducted in Europe $(\mathrm{N}=8)$, the Northern Americas $(\mathrm{N}=4)$, Australia $(\mathrm{N}=1)$, and Asia $(\mathrm{N}=2)$. Participants in these studies were nursing assistants $(\mathrm{N}=4)$, registered nurses $(\mathrm{N}=4)$, registered and licensed practical nurses $(\mathrm{N}=2)$, registered nurses and nursing assistants $(\mathrm{N}=1)$, or all three groups $(\mathrm{N}=4)$. One article described a study conducted in a home care setting, ${ }^{39}$ the other articles involved institutional long-term care settings (mostly nursing homes). Appendix 1 presents a summary of the characteristics of the included articles.

\section{Methodological quality appraisal}

Methodological quality scores ranged from 0.65 to 0.95 , with a mean score of 0.85 indicating overall good quality. Most items from the checklists were scored with either 'yes' or 'partial'; only two items were scored with 'no' for two different articles. The items 'question/objective sufficiently described?' and 'connection to a theoretical framework/ wider body of knowledge?' obtained the optimal score ('yes') in most studies. The items 'sampling strategies described, relevant and justified?', 'conclusions supported by the results?' and 'reflexivity of the account?' (i.e., the description of possible sources influencing the data or causing bias) were frequently scored as 'partial'

\section{Narrative summary of themes}

Notions reflecting needs in palliative care provision were clustered into the following seven themes: 1) recognizing and addressing palliative care needs; 2) verbal and nonverbal communication; 3) dealing with challenging behavior; 4) familiarity: knowing and understanding the person; 5) interdisciplinary collaboration; 6) education and training; and 7) organizational support. Table 3 demonstrates examples of citations referring to the seven themes. Appendix 2 presents more elaborate examples of phrases per theme and per article.
Table 3. Example phrases from included studies per theme.

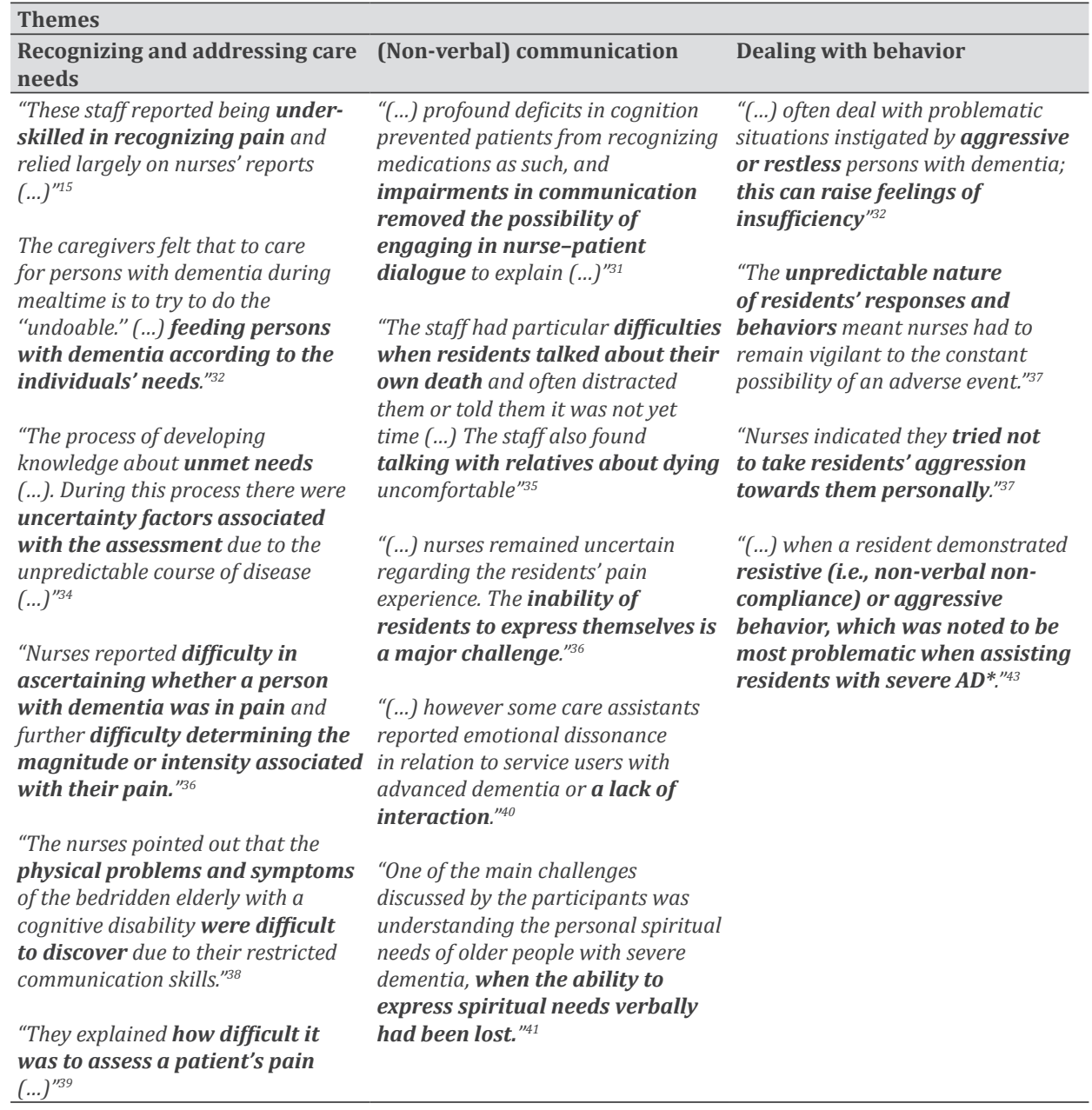

${ }^{*} \mathrm{AD}=$ Alzheimer's Diseas 
Table 3 (continued). Example phrases from included studies per theme.

\begin{tabular}{|c|c|c|c|}
\hline \multicolumn{4}{|l|}{ Themes (continued) } \\
\hline Familiarity & $\begin{array}{l}\text { Interdisciplinary } \\
\text { collaboration }\end{array}$ & Education/training & Organizational support \\
\hline $\begin{array}{l}\text { "Understanding the } \\
\text { residents for whom they } \\
\text { cared was perceived to be } \\
\text { critical (...) iffficulties and } \\
\text { limitations in recognizing } \\
\text { pain in residents } \\
\text { with whom they were } \\
\text { unfamiliar." } \\
\text { "Several factors were } \\
\text { identified that may } \\
\text { assist in clarifying if } \\
\text { resident with dementia is } \\
\text { experiencing pain. (...) and } \\
\text { knowing the resident } \\
\text { over an extended period } \\
\text { of time. }{ }^{.36} \\
\text { "(...) they spoke about } \\
\text { the importance of } \\
\text { 'knowing' } \\
\text { individual resh } \\
\text { history and persts' life } \\
\text { preferences." }\end{array}$ & $\begin{array}{l}\text { "Five participants } \\
\text { employed in nursing homes } \\
\text { reported problematic } \\
\text { relationships with } \\
\text { nursing staff and/or } \\
\text { physicians." } \\
\text { "Difficult nurse- } \\
\text { physician relationships } \\
\text { were reported by both } \\
\text { nursing home and acute } \\
\text { care nurses." }{ }^{21} \\
\text { "Feeling abandoned is also } \\
\text { in relation to the absence } \\
\text { of nursing staff, as one's } \\
\text { own competence as a } \\
\text { nursing aid is not always } \\
\text { enough."32 }\end{array}$ & $\begin{array}{l}\text { "When nurses were } \\
\text { asked to identify their } \\
\text { learning needs; pain } \\
\text { management at end of life } \\
\text { in dementia, knowledge } \\
\text { of analgesic choice, and } \\
\text { a better understanding } \\
\text { pain assessment tools were } \\
\text { identified."30 } \\
\text { "All respondents } \\
\text { believed that access to } \\
\text { ongoing professional } \\
\text { development was critical } \\
\text { (...)." } \\
\text { "All nurses reported } \\
\text { training in } \\
\text { pharmacology was } \\
\text { required (...)."31 }\end{array}$ & $\begin{array}{l}\text { "(...) professional and } \\
\text { practice development } \\
\text { were often limited for } \\
\text { acute care and nursing } \\
\text { home nurses due to } \\
\text { constraints on staff time, } \\
\text { heavy workload (....)."31 } \\
\text { "(...) struggling between } \\
\text { knowing what is best to do } \\
\text { and the organizational } \\
\text { structures that } \\
\text { interfere.".32 } \\
\text { (...) concern about lack of } \\
\text { time, overwork, the pace } \\
\text { of work or routinization } \\
\text { of tasks as impediments to } \\
\text { relationships."33 }\end{array}$ \\
\hline
\end{tabular}

Recognizing and addressing palliative care needs

An important need in providing palliative care for people with dementia concerns assessing symptoms and recognizing care needs. Nursing staff experienced difficulties in attending to patients' basic care needs and in optimizing comfort. In particular, recognizing and managing pain and physical discomfort (e.g., stiff muscles, digestive problems, bed sores) in people with dementia is challenging for them; pain may therefore be undertreated. . $^{15,30,31,33,34,36,38,39,42}$ In one article, nurses reported that family members are important partners in assessing physical comfort, but that involvement of family may also pose ethical challenges (e.g., balancing family members' wishes and patients' needs) when considering administering analgesics. ${ }^{36}$ Besides identifying pain, providing psychological support ${ }^{33}$ and recognizing the spiritual ${ }^{41}$ and emotional needs ${ }^{42}$ of people with dementia was concerning nursing staff. Lastly, attending to the individual need for assistance with feeding of persons with moderate to severe dementia during mealtimes was perceived as difficult, leaving nursing staff concerned about nutritional health. $^{32}$

Verbal and non-verbal communication

Nursing staff often linked challenges in responding to care needs of people with dementia to the patients' limited ability to communicate and difficulties in understanding the meaning of non-verbal signs. ${ }^{15,34,36,38,39,41,42}$ Limited possibilities for communication also hindered them in explaining to patients why they would need certain treatments, which sometimes resulted in refusal or resistant behavior. ${ }^{31}$ Staff reported limited alertness in people with severe dementia ${ }^{43}$ and regarded a lack of interaction as a barrier to effective care. ${ }^{40}$ In one article, nursing staff reported difficulties communicating about death and advance care plans with people with dementia and their relatives. ${ }^{35}$

\section{Dealing with challenging behavior}

Nursing staff mentioned exposure to certain behavior, such as non-compliance and resistive or aggressive behavior, when providing daily care for people with moderate to severe dementia. ${ }^{32,35,37}$ They regarded this behavior as challenging when trying to provide high-quality care. Nursing staff reported that encountering challenging behavior sometimes raised feelings of insufficiency. ${ }^{32}$ Despite attempts not to take such behaviors personally, they described feelings of hurt and frustration. Moreover, they reported concerns about organizational support, and families and managers not respecting and valuing their demanding work. ${ }^{37}$ Patient refusal was also an apparent issue in managing pain through administering analgesia, which nursing staff assumed resulted from patients' anxiety and lack of understanding of medication use. ${ }^{31}$ To deal with challenging behavior, nursing staff need knowledge on individual triggers and preferences of patients and ways to communicate with them. ${ }^{37,43}$

Familiarity: knowing and understanding the person

To overcome difficulties in recognizing and addressing palliative care needs, communication or challenging behavior, nursing staff often reported that they need to be familiar with the person. Nursing staff felt that building a close care relationship is beneficial for both themselves and the person with dementia, as it helps to recognize needs and to individualize palliative care. Learning about the history and preferences of the person with dementia and building a good care relationship through caring for them over an extended period of time were frequently mentioned as prerequisites to providing good care. ${ }^{15,33,34,36-38,41,43}$ In nursing homes, the importance of knowing a person's life story and involving family is increasing as people with dementia are generally admitted rather late in the course of the disease due to ageing in place policies. ${ }^{34}$ Knowledge 
about the individual aids decoding non-verbal signals, recognizing changes in, and triggers of, behavior, and identifying nursing problems beyond merely the medical aspects. Nursing staff stressed that building close companionship and obtaining this knowledge takes considerable time.

Interdisciplinary collaboration

Nursing staff reported poor collaboration with other disciplines (physicians/other nursing staff members) as a barrier to effective palliative care provision. ${ }^{15,31,32}$ Nursing assistants reported feelings of being unsupported by other staf ${ }^{32}$ and being excluded from multidisciplinary team meetings, which raised concerns about missing out on critical information about patients from other disciplines. ${ }^{15}$ Nursing staff emphasized the necessity of interdisciplinary collaboration..$^{34,36}$

Education and training

Nursing staff frequently mentioned a need for training and education. . $^{1530,31,34,35,39,40}$ They stressed that general dementia training does not suffice in developing skills specifically in caring for people with advanced dementia. ${ }^{40}$ Nursing staff wished to acquire skills and knowledge on pain recognition and management, entailing monitoring and reporting treatment response and side effects, the use of assessment tools, and choice of medication. Further, they reported a wish to acquire skills through training in advance care planning, artificial nutrition/hydration, and in communicating with families about these matters. Nursing staff preferred opportunities for case-based discussion or mentoring by more experienced staff members. ${ }^{31}$

\section{Organizational support}

Nursing staff reported several factors occurring at the organizational level to be barriers to providing high-quality, person-centered palliative care. ${ }^{15,31-33,37,40} \mathrm{Hence}$, this theme comprised divergent elements concerning limited support from the organization towards its employees. This involves understaffing, a heavy workload, limited time to provide care and attend to individual patients, forced task-centered rather than person-centered care, and cuts to services delivered by lifestyle staff and allied health staff. Moreover, nursing staff reported inadequate opportunities for professional development, incomplete exchange of information exchange among nursing staff members, insufficient emotional support, and feeling undervalued or unrecognized.

\section{An integrated conceptualization}

From these themes, we inferred an integrated conceptualization to outline what nursing staff need in providing palliative care for people with dementia (Figure 2). Issues arise that directly relate to daily care provision and interaction between nursing staff and the person with dementia (depicted in circles). Beyond these practical concerns, needs arise on a more distant workplace level as preconditions for nursing staff in providing palliative dementia care. These prerequisites exist within the healthcare organization itself (depicted in triangles). When the organization fails to provide nursing staff with sufficient resources to meet their fundamental needs, this likely incites experiencing barriers in daily care practice. Healthcare organizations are well positioned and authorized to establish supportive policies.

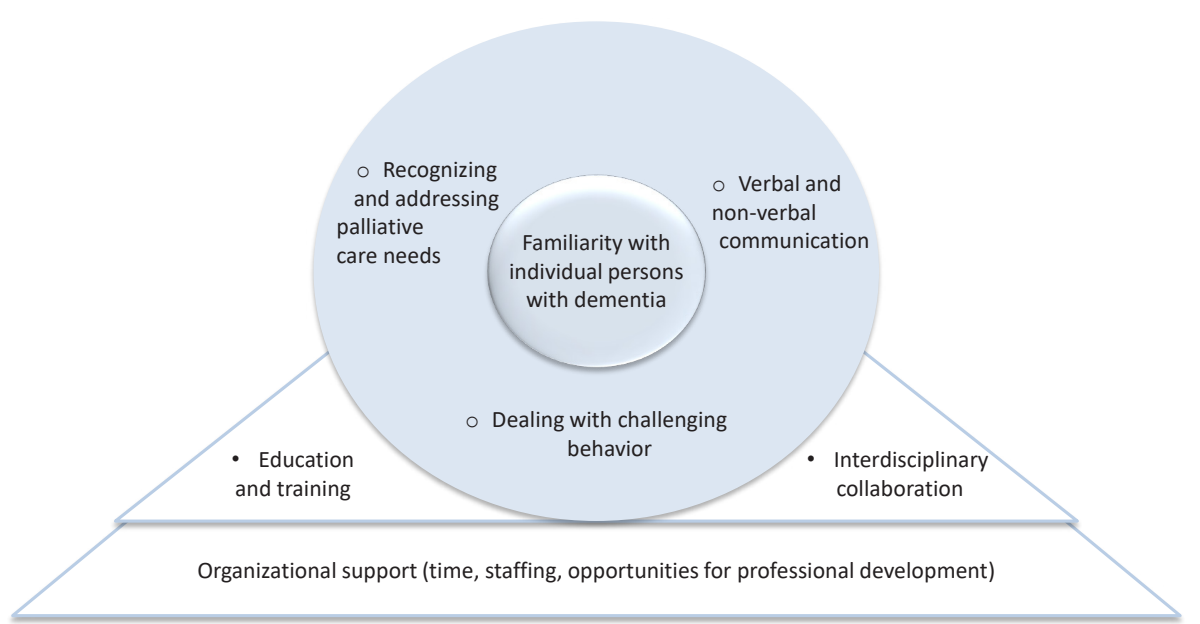

Figure 2. An integrated conceptualization of nursing staff needs in providing palliative care for people with dementia. The circular elements reflect needs on a direct care-level, whereas the triangular elements reflect needs concerning more distant workplace and organizational levels.

\section{DISCUSSION}

To our knowledge, this scoping review is the first to provide an overview of perceived needs of nursing staff in providing palliative care for people with dementia, at home or in long-term care facilities. It should be noted that terms reflecting 'needs' and 'barriers' are used interchangeably across and within articles. We conceptualized barriers as needs. Therefore, reported barriers to high-quality palliative dementia care (such as difficulties in managing care needs or organizational restraints) were regarded as inverted needs for these aspects to be in place. Nursing staff needs in providing palliative care for people with dementia involve recognizing and addressing care needs (mostly physical pain), verbal and non-verbal communication, and dealing with challenging behavior. To aid these direct care-related matters, nursing staff need to become familiar with, and learn to understand the people for whom they care. Needs that are more distant from direct care provision include training and education, and 
sufficient interdisciplinary collaboration and information exchange with colleagues. Nursing staff have unmet needs related to organizational support. Inadequate time and staffing and limited opportunities for professional development are a concern. The majority of the included studies were conducted in Western countries and most used qualitative methods, investigating long-term care facilities. Most obtained high quality scores. However, sometimes the rationale for choosing a specific purposive sample was missing, notions in the discussion or conclusion could not be traced back directly to reported results, or claims of generalization were not substantiated with existing literature. Articles rarely mentioned the researchers' personal viewpoints as a possible source of influence on the data. These hiatuses in reporting may reflect points of consideration for future studies.

The importance of familiarity and a familiar environment has been stressed by others ${ }^{7,44}$ and is in line with a person-centered approach; one of the key domains recommended for palliative care for people with dementia. ${ }^{5}$ Communication is another core competency needed in addressing the social needs of people with dementia ${ }^{7}$ and in establishing person-centered care, shared decision-making, and advance care planning. ${ }^{5}$ However, nursing staff report that they experience difficulties related to verbal and non-verbal communication with individuals with dementia. Furthermore, nursing staff experience complications in recognizing and addressing physical needs and managing physical discomfort. Yet, these are pivotal elements when providing palliative care in the physical domain.,

Nursing staff struggle to apply a palliative approach according to the established domains of palliative care in dementia. Previous research indicates that nursing staff may lack sufficient competences, sensitive awareness, and an appropriate personal attitude to deal with the complex, multifaceted palliative care demands of people with dementia. ${ }^{17,45-47}$ The failure to deliver high-quality nursing care may result in adverse outcomes for both people with dementia and their formal caregivers. People with dementia may have unmet psychosocial and spiritual needs and face poor symptom control, unnecessary hospitalizations, and burdensome interventions. ${ }^{47,48}$ At the end of life, maintaining human dignity may involve a 'mirrored experience', meaning that dignity of the person with dementia is interrelated with the caregiver's own dignity. ${ }^{49}$ Consequently, nursing staff may feel undignified or demoralized themselves if barriers to the delivery of high-quality palliative care cannot be overcome. Factors hindering nursing staff from realizing their personal values in the care they provide may cause strain and burnout. . $^{50,51}$

Measures of competence or knowledge do not directly translate into tailored solutions that would facilitate nursing staff to overcome barriers. This review adds to known challenges in dementia care as it reflects needs extracted from nursing staff's own accounts. The added value of narrating nursing staff's own expressed needs over measuring their knowledge or skills is that interdependencies between needs and also the context in which they occur are exposed. For instance, recognizing pain is closely linked with learning to interpret non-verbal signals, which requires knowing the person, which in turn may be hampered by having insufficient time. Nursing staff's expressed need for knowing the person with dementia may be a key element in relation to addressing other care issues, which fits in the more general vision that the traditional nursing profession requires treating someone as a whole person. ${ }^{52} \mathrm{~A}$ holistic approach to nursing may help nursing staff to build meaningful care relationships and nurture personhood while recognizing losses associated with dementia. ${ }^{53}$ This review also shows that to improve holistic palliative care for people with dementia, we need to consider not only specific care-related issues encountered by staff, but also workplace and organizational set-up. Considering Maslow's hierarchy of needs, ${ }^{54}$ a facilitating work environment that fulfils physiological and safety needs may allow nursing staff to build close care relationships, feel recognized and self-efficacious, and actualize one's personal values in the nursing profession. Fulfilling nursing staff's occupational needs may increase their motivation, job satisfaction, and the quality of care they provide..$^{55}$ To pursue impact of nursing interventions, we recommend developing them in close collaboration and agreement with care organizations to facilitate effective integration in daily nursing practice.

The review also exposes gaps in the current knowledge about nursing staff needs in providing palliative dementia care. Advance care planning from a nursing perspective has not received much attention from the scientific community. Nursing staff providing daily care may often (informally) receive signals that are important to future care. However, they may be unaware of a potential role in care planning or feel that it is not their responsibility or priority to actively engage. ${ }^{56,57}$ Although all articles are about care for people with moderate to severe stages of dementia, palliative care is not always mentioned explicitly. A more explicit palliative approach in future nursing research might trigger greater awareness around the end of life of people with dementia, stimulating nursing staff to express their needs in supporting advance care planning. The same might be true for expressing needs in offering spiritual and psychological support. These domains were referred to only to a limited extent. In a previous ethnographic study, nurses were unaware that in fact they did attend to spiritual needs. ${ }^{58}$ This suggests that a lack of reporting on spiritual matters does not necessarily indicate nursing staff do not provide spiritual care.

It is notable that only one of the included studies concerned a home care setting. Palliative dementia care provided at home may be an under-studied area ${ }^{59} \mathrm{Nevertheless,}$ home care services are important as living and dying at one's place of preference is an important element in end-of-life care, and home is often considered a preferred place for people with dementia to reside until the end of life. ${ }^{45,46,48}$ Community-based palliative care for people with dementia is gaining increasing attention; services require further exploration. ${ }^{48}$ The current conceptualization of nursing staff needs draws largely upon 
findings from studies conducted in long-term care facilities. Nonetheless, the article concerning home care ${ }^{39}$ did not appear to differ substantially in terms of themes. Thus, nursing staff working in long-term care facilities and home care may face similar challenges in their daily work, underpinned by similar fundamental needs. Similarities and differences in the particular needs perceived by nursing home staff compared to home care staff requires further study.

Lastly, nursing staff needs in providing care for families have not been studied extensively, inducing the need for future research. Starting early in the dementia process when still receiving care at home, providing support for families of people with dementia continues to be an important element of palliative care after admission to long-term care. ${ }^{5,60}$ Upon admission to a long-term care facility, individuals may already have advanced dementia, limiting opportunities for nursing staff to become acquainted with the person. ${ }^{34}$ This highlights the importance of involving family.

\section{Strengths and limitations}

The current scoping review has several strengths, including its focus on recent research, as the landscape of palliative dementia care is subject to rapid change. Three researchers evaluated the methodological quality of studies, addressing weaknesses that may require attention in future studies. It should be noted that initially there was only 'fair' interrater agreement observed from the quality assessment tool, indicating proneness to bias. Two authors carried out the screening of titles and abstracts, and fulltext articles for a random selection and after reaching agreement one author continued. The coding of texts from articles and classifying of codes into themes was performed by one author and may therefore have been prone to researcher bias. However, written memos and triangulation by discussing and fine-tuning interpretations with all authors increased objectivity and reduced the influence of the researcher's personal viewpoint. Moreover, relevant information may have been overlooked as studies were only included if they were written in English or Dutch, and grey literature was not searched for. Lastly, a limitation of the included articles is that none addressed cultural or gender differences that may influence nursing staff needs. Future research may consider these factors.

\section{Conclusions and implications}

This review provides an overview and comprehensive summary of primary research findings concerning nursing staff needs in providing palliative care for people with dementia at home or in long-term care facilities. A conceptualization of these findings shows the interdependency of nursing staff needs, occurring within an organizational context. Reaching the primary goal of the overarching DEDICATED project to improve palliative care for people with dementia and their loved ones, may require addressing educational and organizational issues to support daily caregiving. Areas recommended for further research on nursing staff needs in palliative care for people with dementia include home care settings, psychosocial and spiritual domains, advance care planning, and family involvement. An integrated understanding of nursing staff needs in providing palliative care for people with dementia may support integration of tailored and feasible interventions in everyday nursing practice, increasing competences to improve quality of care and quality of life of people with dementia. 


\section{REFERENCES}

1. Blom K, van den Elsen GAH, Koek HL, Sanders JB, Kruithof HC, Claassen JAHR. Stand van zaken: Behandeling van dementie. Nederlands Tijdschrift voor Geneeskunde. 2017;161(38/39):52-8.

2. Sachs GA, Shega JW, Cox-Hayley D. Barriers to excellent end-of-life care for patients with dementia. J Gen Intern Med. 2004;19(10):1057-63.

3. Iliffe S, Davies N, Vernooij-Dassen M, van Riet Paap J, Sommerbakk R, Mariani E, et al. Modelling the landscape of palliative care for people with dementia: a European mixed methods study. BMC Palliat Care. 2013;12(1):30.

4. Sampson EL. Palliative care for people with dementia. British medical bulletin. 2010;96(1):159-74.

5. van der Steen JT, Radbruch L, Hertogh CM, de Boer ME, Hughes JC, Larkin P, et al. White paper defining optimal palliative care in older people with dementia: a Delphi study and recommendations from the European Association for Palliative Care. Palliat Med. 2014;28(3):197-209.

6. World Health Organization. WHO Definition of palliative care 2018 [cited 201811 April]. Available from: http://www.who.int/cancer/palliative/definition/en/.

7. Perrar KM, Schmidt H, Eisenmann Y, Cremer B, Voltz R. Needs of people with severe dementia at the endof-life: a systematic review. J Alzheimers Dis. 2015;43(2):397-413.

8. IKNL/Palliactief. Netherlands Quality Framework for Palliative Care. 2017.

9. Haaksma ML, Leoutsakos JS, Bremer JA, Aalten P, Ramakers IH, Verhey FR, et al. The clinical course and interrelations of dementia related symptoms. Int Psychogeriatr. 2017:1-8.

10. Odbehr L, Kvigne K, Hauge S, Danbolt LJ. Nurses' and care workers' experiences of spiritual needs in residents with dementia in nursing homes: a qualitative study. BMC Nurs. 2014;13:12

11. Hendriks SA, Smalbrugge M, Galindo-Garre F, Hertogh CM, van der Steen JT. From admission to death: prevalence and course of pain, agitation, and shortness of breath, and treatment of these symptoms in nursing home residents with dementia. J Am Med Dir Assoc. 2015;16(6):475-81.

12. Dening KH, Jones L, Sampson EL. Advance care planning for people with dementia: a review. Int Psychogeriatr. 2011;23(10):1535-51.

13. Houttekier D, Cohen J, Bilsen J, Addington-Hall J, Onwuteaka-Philipsen BD, Deliens L. Place of death of older persons with dementia. A study in five European countries. J Am Geriatr Soc. 2010;58(4):751-6.

14. Reyniers T, Deliens L, Pasman HR, Morin L, Addington-Hall J, Frova L, et al. International variation in place of death of older people who died from dementia in 14 European and non-European countries. J Am Med Dir Assoc. 2015;16(2):165-71

15. de Witt Jansen B, Brazil K, Passmore P, Buchanan H, Maxwell D, Mcllfatrick SJ, et al. Exploring healthcare assistants' role and experience in pain assessment and management for people with advanced dementia towards the end of life: a qualitative study. BMC Palliat Care. 2017;16(1):6.

16. De Roo ML, van der Steen JT, Galindo Garre F, Van Den Noortgate N, Onwuteaka-Philipsen BD, Deliens L, et al. When do people with dementia die peacefully? An analysis of data collected prospectively in long-term care settings. Palliat Med. 2014;28(3):210-9.

17. Erel M, Marcus EL, Dekeyser-Ganz F. Barriers to palliative care for advanced dementia: a scoping review. Ann Palliat Med. 2017;6(4):365-79.

18. Hirakawa Y, Kuzuya M, Uemura K. Opinion survey of nursing or caring staff at long-term care facilities about end-of-life care provision and staff education. Arch Gerontol Geriatr. 2009;49(1):43-8.

19. Burns M, Mcllfatrick S. Palliative care in dementia: literature review of nurses' knowledge and attitudes towards pain assessment. Int J Palliat Nurs. 2015;21(8):400-7.

20. Chen IH, Lin KY, Hu SH, Chuang YH, Long CO, Chang CC, et al. Palliative care for advanced dementia: Knowledge and attitudes of long-term care staff. J Clin Nurs. 2017.

21. Robinson A, Eccleston C, Annear M, Elliott KE, Andrews S, Stirling C, et al. Who knows, who cares? Dementia knowledge among nurses, care workers, and family members of people living with dementia. J Palliat Care. 2014;30(3):158-65

22. Davies N, Maio L, Vedavanam K, Manthorpe J, Vernooij-Dassen M, Iliffe S. Barriers to the provision of high-quality palliative care for people with dementia in England: a qualitative study of professionals experiences. Health Soc Care Community. 2014;22(4):386-94.
23. Peters M, Godfrey C, McInerney P, Soares C, Khalil H, Parker D. The Joanna Briggs Institute reviewers' manual 2015: methodology for JBI scoping reviews. 2015

24. Arksey H, O'Malley L. Scoping studies: towards a methodological framework. International Journal of Social Research Methodology. 2005;8(1):19-32.

25. Moher D, Liberati A, Tetzlaff J, Altman DG. Preferred reporting items for systematic reviews and metaanalyses: the PRISMA statement. PLoS Med. 2009;6(7):e1000097.

26. Connor SR, Bermedo MCS. Global atlas of palliative care at the end of life: Worldwide Palliative Care Alliance; 2014.

27. Kmet LM, Lee RC, Cook LS. Standard quality assessment criteria for evaluating primary research papers from a variety of fields: Alberta Heritage Foundation for Medical Research Edmonton; 2004

28. Landis JR, Koch GG. The measurement of observer agreement for categorical data. Biometrics. 1977;33(1):159-74

29. Clarke V, Braun V. Thematic analysis. Encyclopedia of critical psychology: Springer; 2014. p. 1947-52.

30. Burns M, Mcllfatrick S. Nurses' knowledge and attitudes towards pain assessment for people with dementia in a nursing home setting. Int J Palliat Nurs. 2015;21(10):479-87.

31. de Witt Jansen B, Brazil K, Passmore P, Buchanan H, Maxwell D, Mcllfactrick SJ, et al. Nurses' experiences of pain management for people with advanced dementia approaching the end of life: a qualitative study.J Clin Nurs. 2017;26(9-10):1234-44.

32. Hammar LM, Swall A, Meranius MS. Ethical aspects of caregivers' experience with persons with dementia at mealtimes. Nursing Ethics. 2016;23(6):624-35.

33. Hunter PV, Hadjistavropoulos T, Kaasalainen S. A qualitative study of nursing assistants' awareness of person-centred approaches to dementia care. Ageing \& Society. 2016;36(6):1211-37.

34. Koppitz A, Bosshard G, Kipfer S, Imhof L. Decision-making in caring for people with dementia at the end of life in nursing homes. Int J Palliat Nurs. 2016;22(2):68-75.

35. Livingston G, Pitfield C, Morris J, Manela M, Lewis-Holmes E, Jacobs H. Care at the end of life for people with dementia living in a care home: A qualitative study of staff experience and attitudes. Int J Geriatr Psychiatry. 2012;27(6):643-50.

36. Monroe TB, Parish A, Mion LC. Decision Factors Nurses Use to Assess Pain in Nursing Home Residents With Dementia. Arch Psychiatr Nurs. 2015;29(5):316-20.

37. Ostaszkiewicz J, Lakhan P, O'Connell B, Hawkins M. Ongoing challenges responding to behavioural and psychological symptoms of dementia. Int Nurs Rev. 2015;62(4):506-16

38. Park MS, Lim SY, Kim EY, Lee SJ, Chang SO. Examining practical nursing experiences to discover ways in which to retain and invigorate the remaining functions of the elderly with a demented and complex disability in nursing homes. Jpn J Nurs Sci. 2017

39. Smith L, Amella EJ, Nemeth L. Perceptions of home health nurses regarding suffering, artificial nutrition, and hydration in late-stage dementia. Home Healthcare Now. 2016;34(9):478-84.

40. Talbot R, Brewer G. Care assistant experiences of dementia care in long-term nursing and residential care environments. Dementia: The International Journal of Social Research and Practice. 2016;15(6):1737-54.

41. Toivonen K, Charalambous A, Suhonen R. Supporting spirituality in the care of older people living with dementia: a hermeneutic phenomenological inquiry into nurses' experiences. Scand J Caring Sci. 2017.

42. Wang IJ Hsieh PF, Wang CJ. Long-term care nurses' communication difficulties with people living with dementia in Taiwan. Asian Nurs Res (Korean Soc Nurs Sci). 2013;7(3):99-103.

43. Wilson R, Rochon E, Leonard C, Mihailidis A. Formal caregivers' perceptions of effective communication strategies while assisting residents with Alzheimer's disease during activities of daily living. Canadian Journal of Speech-Language Pathology and Audiology. 2012;36(4):314-31.

44. Midtbust MH, Alnes RE, Gjengedal E, Lykkeslet E. A painful experience of limited understanding: healthcare professionals' experiences with palliative care of people with severe dementia in Norwegian nursing homes. BMC Palliat Care. 2018;17(1):25.

45. Harris D. Forget me not: palliative care for people with dementia. Postgrad Med J. 2007;83(980):362-6.

46. van der Steen JT, Lemos Dekker N, Gijsberts MHE, Vermeulen LH, Mahler MM, The BA. Palliative care for people with dementia in the terminal phase: a mixed-methods qualitative study to inform service development. BMC Palliat Care. 2017;16(1):28.

47. van Riet Paap J, Mariani E, Chattat R, Koopmans R, Kerherve H, Leppert W, et al. Identification of the 
palliative phase in people with dementia: a variety of opinions between healthcare professionals. BMC Palliat Care. 2015;14:56.

48. Lloyd-Williams M, Mogan C, Dening KH. Identifying palliative care needs in people with dementia. Curr Opin Support Palliat Care. 2017;11(4):328-33.

49. Pols J, Pasveer B, Willems D. The particularity of dignity: relational engagement in care at the end of life. Medicine, Health Care and Philosophy. 2018;21(1):89-100

50. Duffy B, Oyebode JR, Allen J. Burnout among care staff for older adults with dementia:The role of reciprocity, self-efficacy and organizational factors. Dementia. 2009;8(4):515-41.

51. Edberg AK, Bird M, Richards DA, Woods R, Keeley P, Davis-Quarrell V. Strain in nursing care of people with dementia: nurses' experience in Australia, Sweden and United Kingdom. Aging Ment Health. 2008;12(2):236-43.

52. Fitch MI, Fliedner MC, O'Connor M. Nursing perspectives on palliative care 2015. Ann Palliat Med. 2015;4(3):150-5.

53. Touhy TA. Dementia, personhood, and nursing: learning from a nursing situation. Nurs Sci Q. 2004;17(1):43-

54. Maslow AH. A theory of human motivation. Psychological review. 1943:50(4):370.

55. Liu Y, Aungsuroch $Y$, Yunibhand J. Job satisfaction in nursing: a concept analysis study. Int Nurs Rev. 2016;63(1):84-91.

56. Robinson L, Dickinson C, Bamford C, Clark A, Hughes J, Exley C. A qualitative study: professionals' experiences of advance care planning in dementia and palliative care, 'a good idea in theory but ....' Palliat Med. 2013;27(5):401-8,

57. Ke LS, Huang X, O'Connor M, Lee S. Nurses' views regarding implementing advance care planning for older people: a systematic review and synthesis of qualitative studies. J Clin Nurs. 2015;24(15-16):2057-73.

58. Gijsberts MJ, van der Steen JT, Muller MT, Hertogh CM, Deliens L. Spiritual end-of-life care in Dutch nursing homes: an ethnographic study. J Am Med Dir Assoc. 2013;14(9):679-84.

59. D’Astous V, Abrams R, Vandrevala T, Samsi K, Manthorpe J. Gaps in understanding the experiences of homecare workers providing care for people with dementia up to the end of life: A systematic review. Dementia (London). 2017:1471301217699354.

60. Brodaty H, Donkin M. Family caregivers of people with dementia. Dialogues Clin Neurosci. 2009;11(2):217-

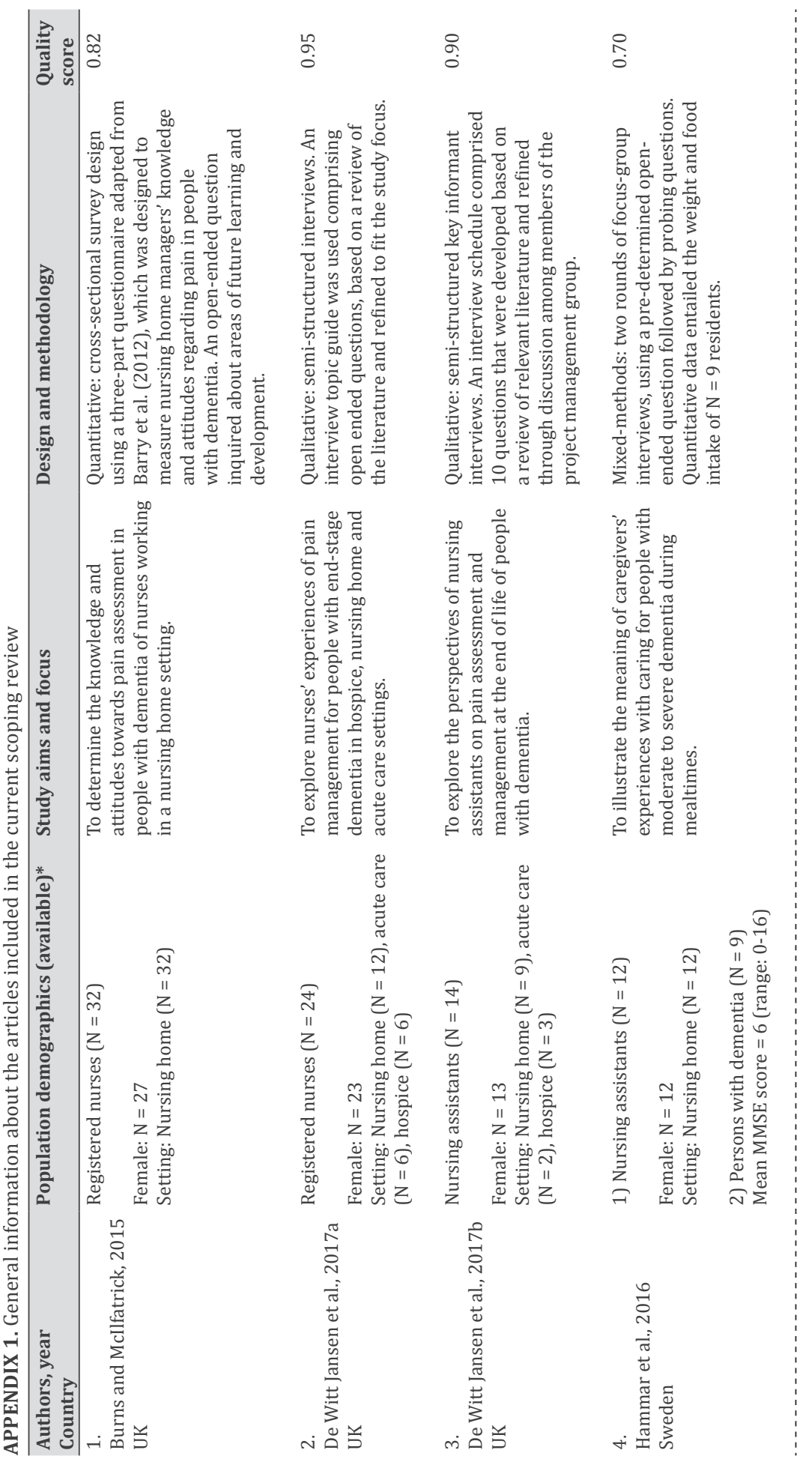

DEDICATED | $4 \mathbf{7}$ 

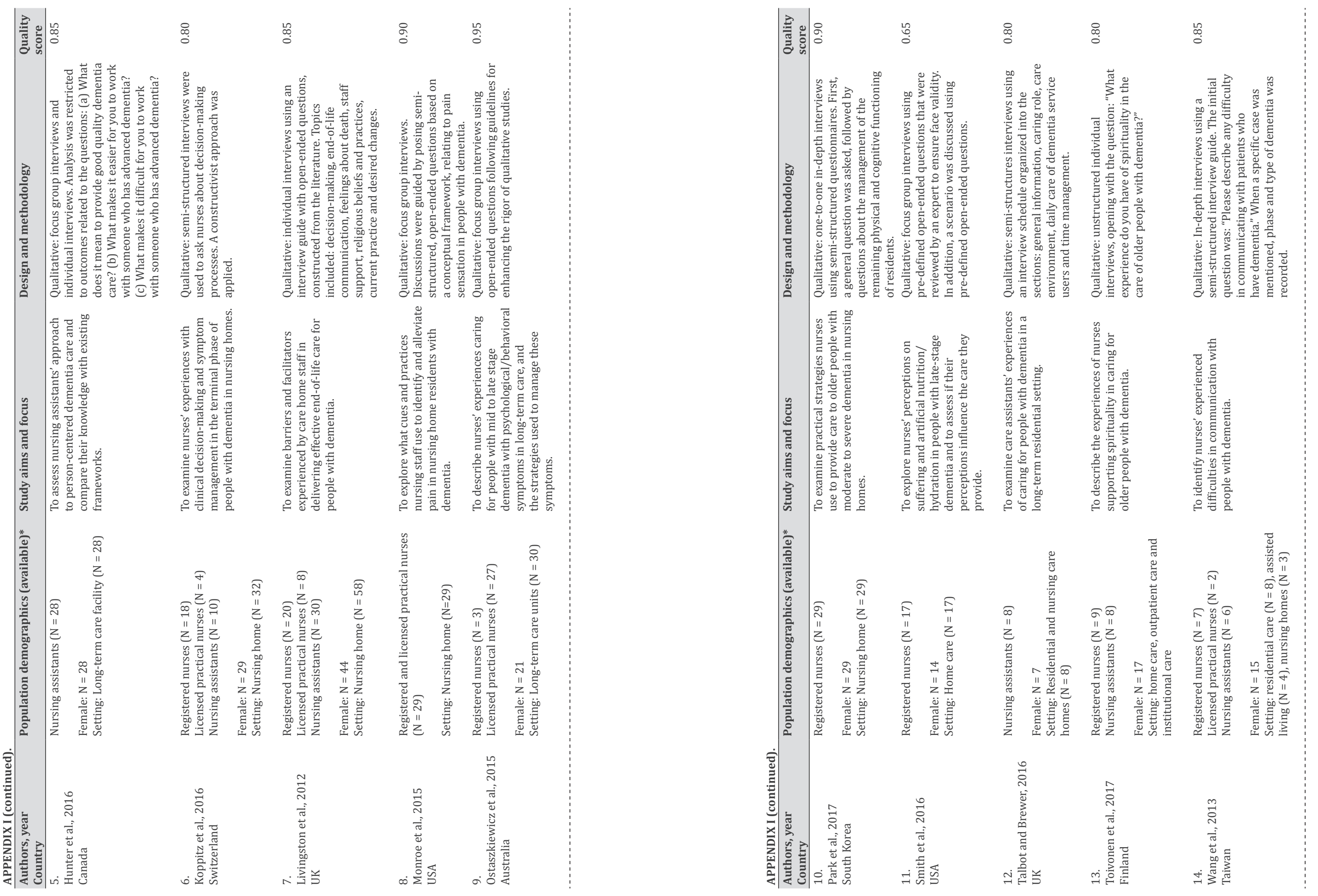

48 | CHAPTER 2 

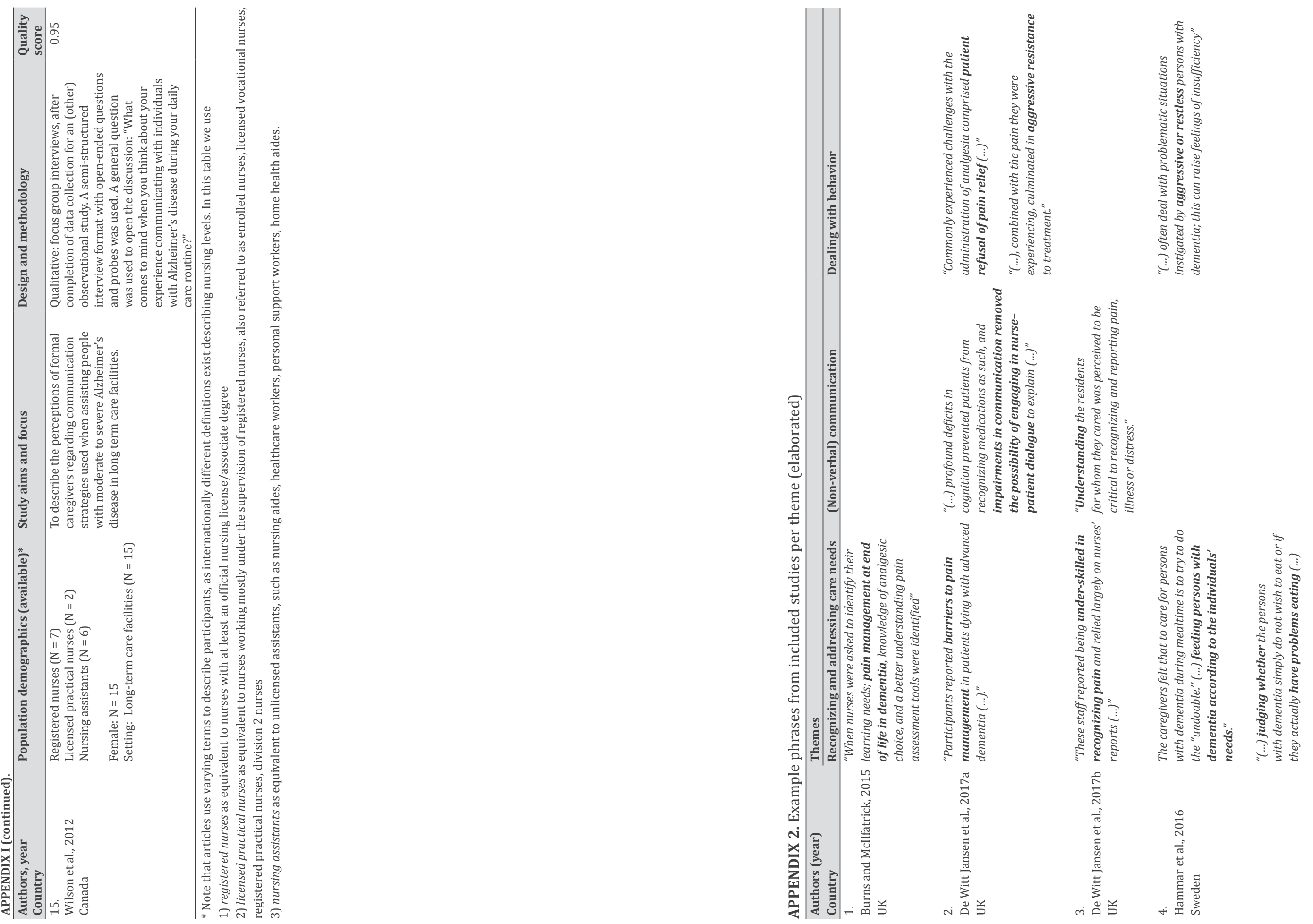

50 | CHAPTER 2 

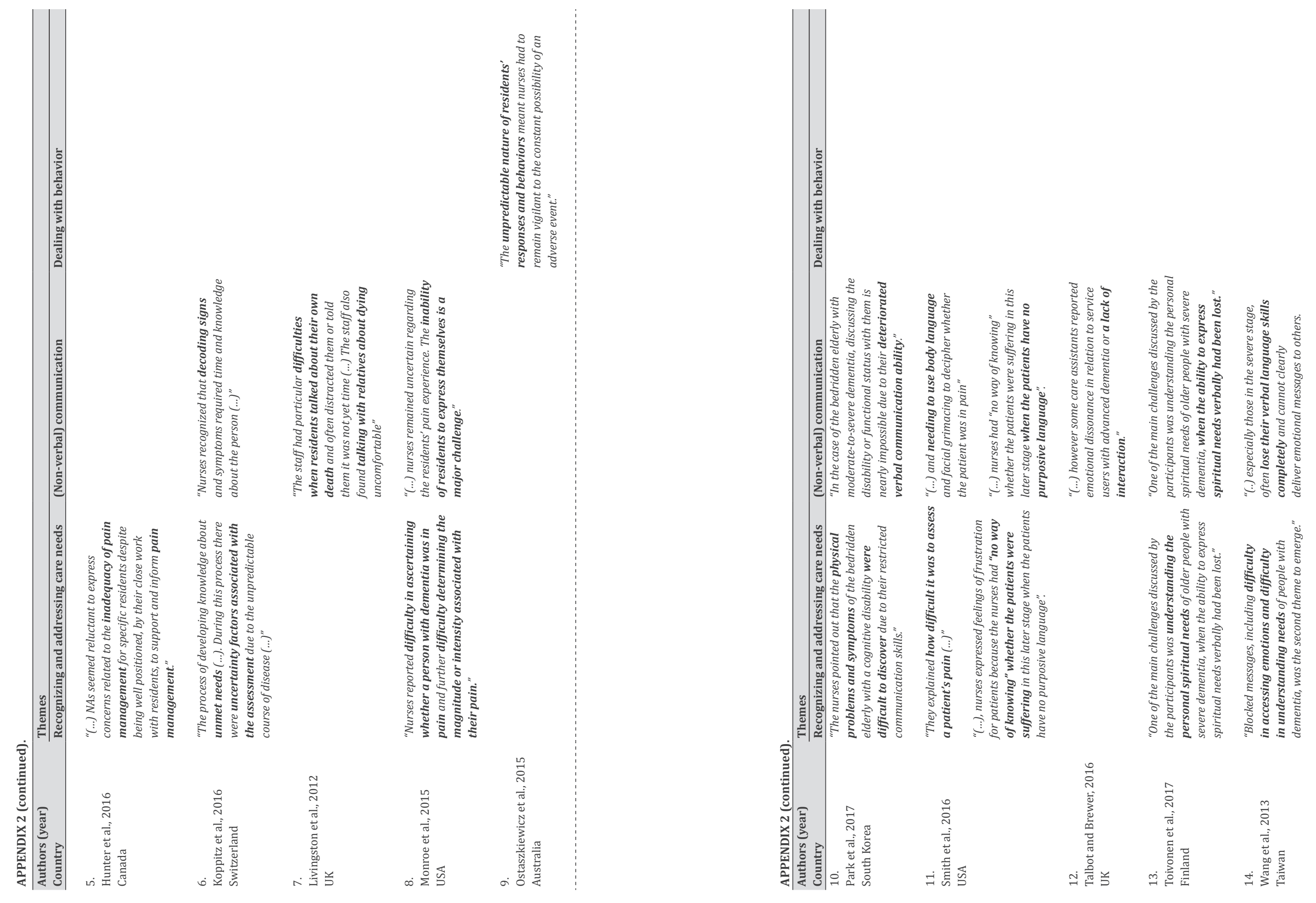

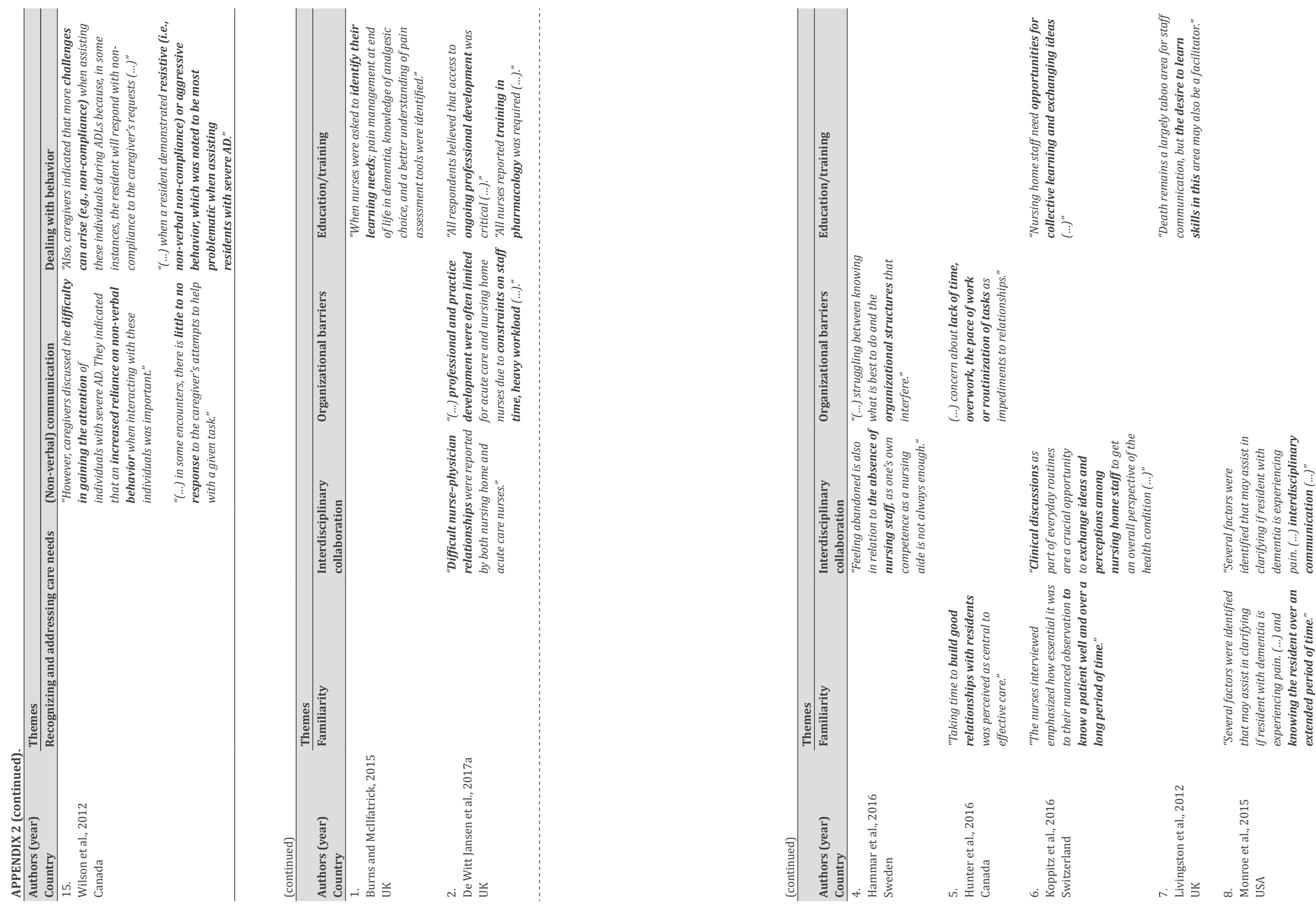


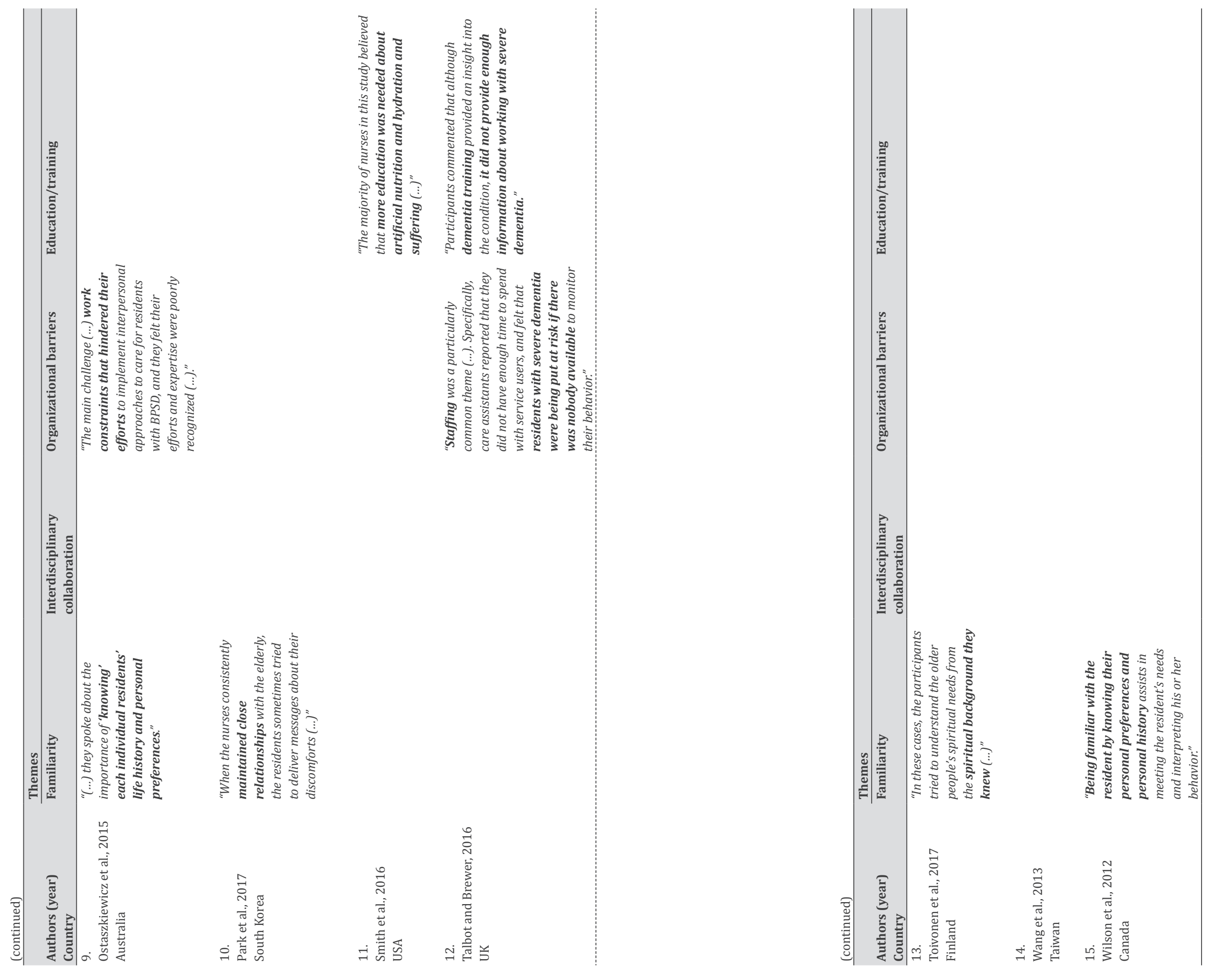




\section{CHAPTER 3}

Nursing staff needs in providing palliative care for persons with dementia at home or in nursing homes: A survey

Sascha R Bolt Judith MM Meijers Jenny T van der Steen

Jos MGA Schols Sandra MG Zwakhalen 


\section{ABSTRACT}

Purpose

This study aimed to evaluate what types and forms of support nursing staff need in providing palliative care for persons with dementia. Another aim was to compare the needs of nursing staff with different educational levels and working in home care or in nursing homes.

Design

A cross-sectional, descriptive survey design was used.

\section{Methods}

A questionnaire was administered to a convenience sample of Dutch nursing staff working in the home care or nursing home setting. Data were collected from July through October 2018. Quantitative survey data were analyzed using descriptive statistics. Data from two open-ended survey questions were investigated using content analysis.

\section{Findings}

The sample comprised 416 respondents. Nursing staff with different educational levels and working in different settings indicated largely similar needs. The highest ranking needs for support were in dealing with family disagreement in end-of-life decisionmaking (58\%), dealing with challenging behaviors (41\%), and recognizing and managing pain (38\%). The highest ranking form of support was peer-to-peer learning (51\%). If respondents would have more time to do their work, devoting personal attention would be a priority.

\section{Conclusions}

Nursing staff with different educational levels and working in home care or in nursing homes endorsed similar needs in providing palliative care for persons with dementia and their loved ones.

\section{Clinical Relevance}

It is critical to understand the specific needs of nursing staff in order to develop tailored strategies. Interventions aimed at increasing the competence of nursing staff in providing palliative care for persons with dementia may target similar areas to support a heterogeneous group of nurses and nurse assistants, working in home care or in a nursing home.

\section{BACKGROUND}

Home care and nursing home staff have an important role in providing palliative care for persons with dementia and their families. ${ }^{1}$ Palliative care is aimed at optimizing the quality of life of persons facing a life-threatening illness and their families. ${ }^{2}$ Dementia is an incurable, neurodegenerative disease and a palliative approach to care is recommended for persons with dementia. ${ }^{3}$ In the Netherlands, direct nursing staff includes registered nurses, certified nurse assistants (i.e., licensed nurses), and nurse assistants. ${ }^{4}$ Nursing staff have a prominent role in daily caregiving, and they are generally more accessible than physicians. ${ }^{5,6}$ Thereby, they are conveniently positioned to discuss care wishes, identify burdensome symptoms, and to increase quality of life. ${ }^{3}$ However, nursing staff may not feel competent to provide adequate palliative care for persons with dementia; they report difficulties in recognizing and addressing physical, psychosocial, and spiritual care needs, dealing with challenging behaviors, and communicating with persons with dementia.

Palliative care for persons with dementia is often complex, and heterogeneous care needs may arise, ${ }^{8}$ especially in the advanced stages. ${ }^{9,10}$ Lacking skills and knowledge among nursing staff may adversely affect the quality of palliative care. ${ }^{10-12}$ In the Netherlands, only persons needing 24-hr care qualify for nursing home care, which implies that persons with dementia in nursing homes are highly reliant on nursing staff. ${ }^{13}$ The majority of persons with dementia live in the community and they require appropriate services to support living at home. ${ }^{14}$ Nursing staff working in home care or in nursing homes should be competent to safeguard the quality of (palliative) care. Today, there is limited knowledge about the specific competency needs that may help to close the knowledge and skills gap in the dementia workforce. ${ }^{15}$

Interventions aimed at increasing the competence of nursing staff should be tailored to their needs and preferences. ${ }^{1,16}$ The needs of nursing staff in providing palliative care for persons with dementia, particularly in the home care setting, have not been assessed in depth. ${ }^{17}$ Moreover, research investigating and comparing the needs of nursing staff with different educational backgrounds and from different settings in providing palliative care for persons with dementia is scarce. Therefore, the purpose of this study was to evaluate the needs of nursing staff in providing palliative care for persons with dementia. The study aimed to compare nursing staff with different educational levels and nursing staff working in home care or in nursing homes. Moreover, the study aimed to investigate what forms of support (e.g., digital, educational, emotional) nursing staff prefer. 


\section{METHODS}

This cross-sectional, descriptive study is part of the Desired Dementia Care Towards End of Life (DEDICATED) project carried out in The Living Lab in Ageing \& Long-Term Care in Limburg. ${ }^{18}$ DEDICATED aims to develop a tailored intervention to empower nursing staff in providing palliative care for persons with dementia. A web-based questionnaire was administered to explore the needs of nursing staff in several aspects of palliative care in dementia. Data were collected in the Netherlands from July through October 2018, using Qualtrics (Provo, Utah, USA) online survey software. The Medical Ethics Committee approved the study (Zuyderland, METCZ20180079).

\section{Sample, Recruitment, and Procedure}

A convenience sample was recruited, and respondents from different sociodemographic areas and organizations were approached to increase representativeness. Eligible participants were: (a) nursing staff members; (b) who had been employed for at least 6 months; (c) currently working in home care or in a nursing home; (d) providing care for older persons ( $\geq 65$ years of age) with dementia. The investigators shared a hyperlink granting access to the Qualtrics questionnaire with the main contact persons within the collaborating organizations. The contact persons then distributed the invitation with an information letter and a hyperlink to the consent form. Figure 1 provides an overview of the regional and national organizations that distributed the questionnaire. Participation was voluntary. Participants provided written informed consent for anonymous processing of data before they could access the questionnaire by checking a box stating 'agreed' and submitting the answer. At the beginning of the questionnaire, participants confirmed they met the inclusion criteria and they were asked to indicate via which route the questionnaire had reached them.

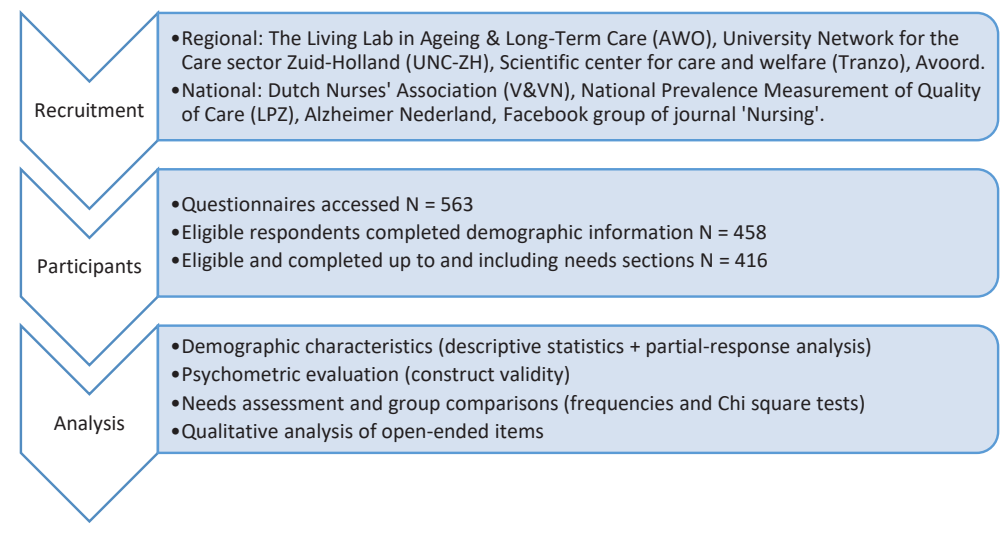

Figure 1. Flowchart of the study process.

\section{Questionnaire Design}

Because no instrument that matched this study's specific aims existed, a questionnaire was designed to explore the needs of nursing staff in providing palliative care for persons with dementia. The questionnaire included items covering the main focus areas of the DEDICATED project: palliative caregiving and end-of-life communication, and interprofessional collaboration and transitions of care. This article focuses on the sections regarding palliative caregiving and end-of-life communication.

Initial item development was informed by results of earlier work to investigate needs in palliative caregiving for persons with dementia.,19,20 Moreover, the main literature sources used throughout the DEDICATED project involve a white paper established by the European Association for Palliative Care, with recommendations for palliative care for persons with dementia ${ }^{3}$ and a systematic review of the palliative care needs of persons with dementia. ${ }^{8}$ Lastly, the End-of-life Professional Caregiver Survey ${ }^{21}$ informed item development. Three investigators (J.M., S.P., and S.B.) developed items and discussed them with all members of the research team to reach consensus. To establish face and content validity, the investigators invited a group of key informants (i.e., healthcare professionals, nurse education specialists, and patient representatives) to carefully review the questionnaire and to provide recommendations for improvement. From three local collaborating care organizations, separate test panels of nursing staff (two registered nurses, two certified nurse assistants, and two uncertified nurse assistants per organization) piloted the questionnaire for feasibility and provided feedback for final improvement. Improvements were mainly in language usage.

The questionnaire asked about the demographic and work-related characteristics: age, sex, location of work (province), current work setting, current job title, years of experience in dementia care, additional training in dementia or palliative care, and self-perceived competence (on a scale from 0 to 10) in providing palliative care for persons with dementia. Thereafter, needs in palliative caregiving and in end-of-life communication were examined, presenting item lists of potential needs. The last section showed items on preferred forms of support. Respondents could select multiple items. The questionnaire finished with two optional open-ended items: "Are there any other aspects of palliative care for persons with dementia in which you need support?" and "If you had more time to do your work, what would you use it for?"

\section{Analysis}

Quantitative analyses were performed using IBM SPSS version 25 (IBM Corp., Armonk, NY, USA). Responses were included if completed at least up to and including the section asking about needs for support in palliative caregiving and end-of-life communication. A partial-response analysis was performed, comparing available characteristics of eligible participants that did and did not complete the questionnaire to this point. Chi- 
square tests and independent t-tests were used. Descriptive statistics were used to present demographic and work-related characteristics, which were compared using chisquare tests. Respondents' self-perceived competence in providing palliative dementia care was compared between the different educational levels and the different settings using analysis of variance and an independent $t$ test, respectively; $p$ values of less than .05 were considered to be statistically significant. Pearson's correlations between the respondents' self-perceived competence and summed needs in palliative caregiving (16 items) and end-of-life communication (8 items) were calculated to explore the questionnaire's construct validity. Cronbach's alpha for internal consistency was not calculated, as the items were designed to explore a variety of needs rather than a single construct.

For each item concerning support needs and preferred forms of support, frequencies of the item being endorsed were counted. Chi-square tests were used to explore differences in item endorsement by educational level and work setting. Holm's sequential Bonferroni procedure was applied to adjust for multiple testing. ${ }^{22}$ Therein, the smallest $p$ value of a series of tests is significant at $p<.05$ per number of test items. The second smallest $p$ value is significant at $p<.05$ per number of test items -1 , the third at $\mathrm{p}<.05$ per number of test items -2 , and so forth. Assumptions underlying the statistical analyses were tested using Levene's test and Q-Q plots.

Content analysis was used to explore answers to both open-ended questions ${ }^{23}$ using NVivo 11 software (QSR International Pty Ltd, headquarters in Doncaster, Victoria, Australia). Initial coding and clustering codes into categories was performed by one researcher (S.B.). Recurring categories were discussed with the research team to allow cross-validation. After fine tuning with the team, a final list of main categories was used to analyze the data a second time to ensure these covered all answers. Frequencies of answers reflecting the established main categories were counted.

\section{RESULTS}

The sample included in the analyses comprised 416 respondents, of whom 192 (46\%) worked in a home setting and $224(54 \%)$ in a nursing home setting (Table 1). Their mean age was 45.5 (SD 12.1, range 18.0-65.0) years, and they had a mean of 15.6 ( $S D$ 10.9 , range 0.8-43.0) years of experience in dementia care. Respondents rated their own competence in providing palliative care for persons with dementia with an average score of 7.5 (SD 1.3, range $0-10)$, indicating an overall good score. ${ }^{24}$ Nursing home staff scored higher (mean 7.9, $S D$ 1.2) than home care staff did (mean 7.2, $S D$ 1.4); $t(414)=$ $-4.8, p<.001$. No differences were found between educational levels (registered nurses, certified nurse assistants, and uncertified nurse assistants).

Considering construct validity, there was a negative correlation between respondents' self-perceived competence and summed needs in caregiving $(r=-.30, p$ $<.001)$ and end-of-life communication $(r=-.14, p=.003)$. Thus, respondents who feel less competent report more support needs. Respondents' needs were rank ordered by frequencies (Table 2). Most needs did not differ between educational levels and settings (Appendix 1)

Table 1. Summary of respondents' characteristics

\begin{tabular}{|c|c|c|}
\hline Respondent characteristics ( $\mathrm{N}=416$ ) & $\mathbf{N}$ & $\%$ \\
\hline \multicolumn{3}{|l|}{ Gender } \\
\hline Female & 401 & 96 \\
\hline Male & 15 & 4 \\
\hline \multicolumn{3}{|l|}{ Nursing degree/educational level } \\
\hline Registered nurse $^{a}$ & 164 & 40 \\
\hline Certified nurse assistant & 218 & 52 \\
\hline Uncertified nurse assistant & 34 & 8 \\
\hline \multicolumn{3}{|l|}{ Primary work setting } \\
\hline Nursing home & 224 & 54 \\
\hline Home care & 192 & 46 \\
\hline \multicolumn{3}{|l|}{ Additional training in dementia care $^{\mathrm{d}}$} \\
\hline Yes & 201 & 48 \\
\hline No & 215 & 52 \\
\hline \multicolumn{3}{|l|}{ Additional training ${ }^{c}$ in palliative care ${ }^{e}$} \\
\hline Yes & 186 & 44 \\
\hline No & 230 & 56 \\
\hline \multicolumn{3}{|l|}{ Providing palliative care is...f } \\
\hline ...a standard task for all nursing and care staff with a basic education & 308 & 74 \\
\hline ...a task for nursing and care staff specialized in palliative care & 108 & 26 \\
\hline
\end{tabular}

.... standard task for all nursing and care staff with a basic educa

. ${ }^{b}$ Significant differences between educational levels (Chi-square $=32.35, p<0.001$ )

'Additional training was defined as an educational effort of at least 2 hours outside of one's basic nursing curriculum.

${ }^{\mathrm{d}}$ Significant differences between work settings (more often in nursing homes; Chi-square $=17.60, p<0.001$ ) but not educational levels.

eSignificant differences between educational levels (Chi-square $=7.39, p<0.05$ ) but not work setting ${ }^{\mathrm{f}} \mathrm{No}$ differences found between educational levels or work setting

\section{Needs for Support in Palliative Caregiving and End-of-Life Communication}

The highest ranking needs for support in caregiving were recognizing and dealing with challenging behaviors (41\%), pain (38\%), and emotions (34\%); providing guidance in the dying phase (34\%); and communicating with persons with severe dementia (33\%). The highest ranking needs for support in end-of-life communication were dealing with family disagreement (58\%) and involving persons with dementia in end-of-life decisionmaking (41\%). There were significant differences between settings in support needs in "communicating with persons with severe dementia", which was endorsed by $42 \%$ of the home care respondents and $23 \%$ of nursing home respondents (chi-square $=15.95$, 
$p<.001)$. Needs in "feeling comfortable when caring for persons with dementia" was endorsed by $13 \%$ of the home care respondents and $3 \%$ of nursing home respondents (chi-square $=13.78, p<.001$ ). Nursing staff with different educational levels differed in support needs in "providing daily care/assisting self-care (ADL and IADL)," which was endorsed by $2 \%$ of the registered nurses, $9 \%$ of the certified nurse assistants, and $21 \%$ of the uncertified nurse assistants (chi-square $=17.43, p<.001$ ). Moreover, "involving persons with dementia in end-of-life decision-making" was endorsed by $48 \%$ of the registered nurses, $40 \%$ of the certified nurse assistants, and $15 \%$ of the uncertified nurse assistants (chi square $=13.30, p=.001$ ).

Table 2. Frequencies for each item regarding needs in palliative caregiving and end-of-life communication, in descending order (total $\mathrm{N}=416$ )

\begin{tabular}{ll}
\hline & $\mathrm{N}(\%)$ \\
\hline Needs in palliative caregiving & \\
Recognizing and dealing with certain behavior, such as agitation or aggression & $169(41)$ \\
Recognizing discomfort and dealing with pain & $156(38)$ \\
Guiding persons with dementia and their loved ones in the dying phase & $143(34)$ \\
Recognizing and dealing with emotions, such as sadness, anxiety, or anger & $141(34)$ \\
Communicating with persons with severe dementia & $139(33)^{\mathrm{a}}$ \\
Recognizing (the start of) the dying phase & $129(31)$ \\
Using (validated) instruments, e.g. for measuring symptoms & $113(27)$ \\
Opportunities to get to know the person with dementia and their loves ones well & $109(26)$ \\
My personal contribution to meaningful activities for persons with dementia & $107(26)$ \\
Involving loved ones in the entire care process & $103(25)$ \\
Recognizing and optimizing physical comfort & $89(21)$ \\
Dealing with religious and existential questions & $84(20)$ \\
Supporting loved ones after bereavement & $75(18)$ \\
Feeling more comfortable interacting with loved ones & $41(10)$ \\
Feeling more comfortable when caring for persons with dementia & $36(9)^{\mathrm{a}}$ \\
Providing daily care/assisting self-care (ADL and IADL) & $29(7)^{\mathrm{b}}$ \\
Needs in end-of-life communication & \\
Dealing with disagreement between loved ones about end-of-life care & $240(58)$ \\
Involving people with dementia in end-of-life decision-making & $171(41)^{\mathrm{b}}$ \\
Guiding people with dementia and their loved ones to document end-of-life wishes & $165(40)$ \\
Having a conversation about the end of life & $136(33)$ \\
Involving loved ones in end-of-life decision-making & $130(31)$ \\
Being able to retrieve documented end-of-life wishes & $118(28)$ \\
Deciding on the right time to initiate end-of-life communication & $116(28)$ \\
Feeling comfortable talking about the end of life with people with dementia and their loved ones & $101(24)$
\end{tabular}

Feeling comfortable talking about the end of life with people with dementia and their loved ones 101 (24)

${ }^{a}$ Significant differences between settings. Details are shown in Appendix 1.

${ }^{b}$ Significant differences between educational levels. Details are shown in Appendix

\section{Preferred Forms of Support}

Nursing staff chiefly preferred support in the form of peer-to-peer learning ( $51 \%$, Table

3 ). Also frequently endorsed were joint case discussions (48\%) and classical education

(45\%). The fourth-ranking form involved organizational support (43\%). Frequencies were mostly similar across settings and educational levels (Appendix 2). Jointly discussing cases differed between registered nurses (54\%), certified nurse assistants $(49 \%)$, and uncertified nurse assistants $(13 \%$, chi-square $=17.62, \mathrm{p}<.001)$

Table 3. Frequencies of reported forms of support in descending order (total $\left.N=366^{a}\right)$

\begin{tabular}{lc} 
& $\mathrm{N}(\%)$ \\
\hline Preferred forms of support & $185(51)$ \\
Exchanging experiences with colleagues ('peer-to-peer learning') & $176(48)^{\mathrm{b}}$ \\
Jointly discussing cases & $164(45)$ \\
Classical education (e.g., clinical lessons) & $158(43)$ \\
General organizational support (e.g., sufficient time, resources, staffing) & $131(36)$ \\
A palliative care expert or team to ask for advise & $112(30)$ \\
E-learning & $106(29)$ \\
Coaching/supervision on the work floor ('coaching on the job') & $71(19)$ \\
Electronic client or patient files with access by all involved caregivers & $63(17)$ \\
Care processes depicted in care paths (e.g., care path dying phase) & $63(17)^{\mathrm{c}}$ \\
A guide to or overview of available care providers & $54(15)$ \\
Digital communication medium with access by all involved caregivers & $46(13)$ \\
Digital support on the work floor (e.g., measuring instruments, checklists) & $46(13)$ \\
Collaboration agreements within own organization & $43(12)$ \\
Emotional support from direct colleagues & $41(11)$ \\
More opportune moments to consult a palliative care expert or team & $35(10)^{\mathrm{b}}$ \\
Collaboration agreements with professionals outside own organization & $35(10)$ \\
Mobile apps & $34(9)$ \\
Digital informative movies, animations, or podcasts & $30(8)$ \\
Training by means of actors or puppets & $25(7)$ \\
Emotional support from the organization (e.g., trustees) & $16(4)$ \\
Serious gaming (games with an educative goal) & $7(2)$ \\
(Being referred to) professional emotional support & athe \\
aThe preferred forms of support section was at the end of the questionnaire. The smaller sample size is du
\end{tabular}

aThe preferred forms of support section was at the end of the questionnaire. The smaller sample size is due to respondents that prematurely withdrew from completing the questionnaire, after finishing at least the caregiving and end-of-life communication items.

${ }^{b}$ Significant differences between educational levels. Details are shown in Appendix 2.

cSignificant differences between educational levels and settings. Details are shown in Appendix 2.

\section{Open-Ended Questions}

Additional issues that were raised beyond the survey items included wishes for specific knowledge and skills in palliative dementia care (e.g., caring for specific groups, such as people with aphasia or with another ethnical background, applying complementary therapies), general awareness about palliative care, family involvement and support, and dealing with ethical matters. If respondents had more time to do their work, the main priority would be to devote more personal attention by making a connection, being present and "in the moment," investing in a close care relationship, and learning about the individual person (Table 4). Moreover, extra time would be invested in supporting families, safeguarding quality of care, deepening one's knowledge, and exchanging and 
devote personal attention and make a connection with the individual further supports previous statements about the importance of a person-centered approach in dementia care $^{29}$ and in palliative care for persons with dementia. ${ }^{3,7}$ However, as in this study, nursing staff previously expressed concerns on how to achieve this with increasing work demands, scarce resources, and a lack of time. ${ }^{1,30}$ Initiatives aimed at increasing competence and person-centered palliative care may require reconsideration of the organizational culture of long-term care and awareness about palliative care for persons with dementia to be successful. ${ }^{30-32}$

Dealing with disagreement between family members in decision-making about care and treatment was a prominent issue for nursing staff from both settings. Nursing staff may encounter families that are unwilling to comply with advance directives or decisions that are not in the person's best interest as perceived by staff. ${ }^{33} \mathrm{~A}$ comparison of six European countries demonstrated that achieving full consensus (as perceived by nurses) about end-of-life care and treatments of nursing home residents among all involved in care agreements ranged from $60 \%$ in Finland to $86 \%$ in England, with the Netherlands rating in between with $78 \%{ }^{34}$ Conflict between family members or between staff and family may result from poor communication or families' lack of understanding or disagreement about appropriate care and treatment, and forms a barrier to effective palliative care for persons with dementia. ${ }^{11,35}$ Current findings also highlight a particular need for competencies in dealing with family conflicts in end-oflife decision-making emotionally. This underexposed topic is an important direction for future research and for the development of interventions.

Overall, home care staff felt less competent than nursing home staff in providing palliative care for persons with dementia. Moreover, home care staff less frequently indicated that they had had additional training in dementia care, and they reported more support needs in communicating with and feeling comfortable in caring for persons with (severe) dementia. These findings are important, and they point out that more training on dementia and end-of-life care is needed, in particular for home care staff. ${ }^{17}$ The population cared for at home might differ from the nursing home population, possibly requiring different levels of competence from nursing staff. Nonetheless, Hasson and Arnetz found that in Sweden both settings involve similar care tasks and that staff from both settings have similar development needs. ${ }^{36}$ Correspondingly, the current findings point to similar needs across the settings, which may have important implications for the development of interventions that target both settings.

Self-perceived competence did not differ between the different educational levels. Similarly, a previous study found that educational level did not predict self-perceived competence among home care staff. ${ }^{37}$ Self-assessment of competence is valued in nursing. ${ }^{38}$ Nonetheless, the concept of competence is ill defined, and it has been argued that nurses cannot judge what they ought to know and what they do and do not know. ${ }^{39}$ Higher-educated nursing staff are generally more trained in self-reflection and might 
be more conscious of their own competence and incompetence, which may explain the findings.

In both settings, the rapid digitalization of health care challenges nursing staff's technological skills and induces changes in care practice. ${ }^{40}$ Considering forms of support, instead of endorsing the use of apps or other technological aides, nursing staff emphasize the need for having "real" conversations and exchanging knowledge and experiences with colleagues. This is an important finding considering the contemporary digital era. There is sufficient literature highlighting the value of peer learning among undergraduate nurses, suggesting it contributes to critical thinking, facilitates a safe learning environment, and raises feelings of being emotionally supported. ${ }^{41}$ Less is known about formal and informal peer-to-peer learning among employed nursing staff. Particularly when caring for people with complex care needs, sharing experiences and reflecting with peers might be essential for emotional and informational support and to overcome challenges in caregiving. Future research may explore the shaping of efficient peer learning among nursing staff within an increasingly technology-driven work environment.

\section{Limitations}

This study is limited by its nonrandom sampling technique, which was administered to comply with the General Data Protection Regulation. ${ }^{42}$ Self-selection bias might have occurred (e.g., a special interest in palliative care or dementia), diminishing generalizability of the findings to the entire population of interest. ${ }^{43}$ Nonetheless, a partial-response analysis suggests that partial responders (who may share characteristics with non-responders) were similar, although more experienced and certified or registered staff were more likely to respond fully. The representation of certified nurse assistants is consistent with the general staffing levels in Dutch longterm care. ${ }^{44,45}$ The mean age and proportion of females in the sample are comparable to national statistics. ${ }^{44}$ This study does not provide information on the reliability of the questionnaire. The goal of the current study was to rank nursing staff's needs by counting item frequencies, rather than measuring a single construct for individual needs. Different forms of reliability (i.e., internal consistency, inter-rater, test-retest) were considered unsuitable, and parallel form reliability data were not obtained in this study as no equivalent instrument existed.

\section{Conclusion}

Nursing staff with varying educational levels and working in the nursing home or home setting reported similar support needs in providing palliative care for persons with dementia. Dealing with challenging behaviors, pain, and family conflict were the most pressing support needs for proper caregiving. Nursing staff expressed a desire to connect with persons with dementia when imagining they would be given more time for caregiving. Organizational support and awareness is needed to enable nursing staff to devote personal attention and to establish meaningful care relationships. Nursing staff preferred and emphasized the need for peer-to-peer learning and exchanging knowledge and experiences with colleagues. Professionalizing palliative care for persons with dementia in both settings requires consideration of explicit needs and preferences for support. To increase the competence of nursing staff in providing palliative care for persons with dementia, interventions with a similar focus may address the needs of a heterogeneous group of nurses and nurse assistants, working in the home or nursing home setting. 


\section{REFERENCES}

1. Smythe A, Jenkins C, Galant-Miecznikowska M, Bentham P, Oyebode J. A qualitative study investigating training requirements of nurses working with people with dementia in nursing homes. Nurse Educ Today. 2017;50:119-23.

2. World Health Organization (WHO). WHO definition of palliative care. Available from: http://www.who. int/cancer/palliative/definition/en/.

3. van der Steen JT, Radbruch L, Hertogh CM, de Boer ME, Hughes JC, Larkin P, et al. White paper defining optimal palliative care in older people with dementia: A Delphi study and recommendations from the European Association for Palliative Care. Palliative Medicine. 2014;28(3):197-209.

4. Backhaus R. Thinking beyond numbers: nursing staff and quality of care in nursing homes. Maastricht: Maastricht University; 2017.

5. Albers G, Francke AL, de Veer AJ, Bilsen J, Onwuteaka-Philipsen BD. Attitudes of nursing staff towards involvement in medical end-of-life decisions: a national survey study. Patient Educ Couns. 2014;94(1):4-9.

6. Toles M, Song M-K, Lin F-C, Hanson LC. Perceptions of family decision-makers of nursing home residents with advanced dementia regarding the quality of communication around end-of-life care. Journal of the American Medical Directors Association. 2018;19(10):879-83.

7. Bolt SR, van der Steen JT, Schols JMGA, Zwakhalen SMG, Pieters S, Meijers JMM. Nursing staff needs in providing palliative care for people with dementia at home or in long-term care facilities: a scoping review. Int J Nurs Stud. 2019;96:143-52.

8. Perrar KM, Schmidt H, Eisenmann Y, Cremer B, Voltz R. Needs of people with severe dementia at the endof-life: a systematic review. Journal of Alzheimer's Disease. 2015;43(2):397-413.

9. Hendriks SA, Smalbrugge M, Galindo-Garre F, Hertogh CMPM, van der Steen JT. From admission to death: Prevalence and course of pain, agitation, and shortness of breath, and treatment of these symptoms in nursing home residents with dementia. Journal of the American Medical Directors Association. 2015;16(6):475-81:

10. Mitchell SL, Teno JM, Kiely DK, Shaffer ML, Jones RN, Prigerson HG, et al. The clinical course of advanced dementia. The New England journal of medicine. 2009;361(16):1529-38.

11. Erel M, Marcus E-L, Dekeyser-Ganz F. Barriers to palliative care for advanced dementia: a scoping review. Annals of Palliative Medicine. 2017;6(4):365-79.

12. Robinson A, Eccleston C, Annear M, Elliott KE, Andrews S, Stirling C, et al. Who knows, who cares? Dementia knowledge among nurses, care workers, and family members of people living with dementia. J Palliat Care. 2014;30(3):158-65

13. Maarse JAM, Jeurissen PP. The policy and politics of the 2015 long-term care reform in the Netherlands. Health Policy. 2016;120(3):241-5.

14. Saks K, Tiit EM, Verbeek H, Raamat K, Armolik A, Leibur J, et al. Most appropriate placement for people with dementia: individual experts' vs. expert groups' decisions in eight European countries. J Adv Nurs. 2015;71(6):1363-77

15. Surr CA, Gates C, Irving D, Oyebode J, Smith SJ, Parveen S, et al. Effective dementia education and training for the health and social care workforce: A systematic review of the literature. Rev Educ Res. 2017:87(5):9661002.

16. Whittaker E, George Kernohan W, Hasson F, Howard V, McLaughlin D. The palliative care education needs of nursing home staff. Nurse Educ Today. 2006;26(6):501-10.

17. D'Astous V, Abrams R, Vandrevala T, Samsi K, Manthorpe J. Gaps in understanding the experiences of homecare workers providing care for people with dementia up to the end of life: A systematic review. Dementia (London). 2017:1471301217699354.

18. Verbeek H, Zwakhalen SMG, Schols JMGA, Hamers JPH. Keys to successfully embedding scientific research in nursing homes: A win-win perspective. Journal of the American Medical Directors Association. 2013;14(12):855-7

19. Bolt SR, van der Steen JT, Schols JMGA, Zwakhalen SMG, Meijers JMM. What do relatives value most in endof-life care for people with dementia? Int J Palliat Nurs. 2019;25(9):432-42.

20. Bolt SR, Verbeek L, Meijers JMM, van der Steen JT. Families' experiences with end-of-life care in nursing homes and associations with dying peacefully with dementia.J Am Med Dir Assoc. 2019;20(3):268-72.

21. Lazenby M, Ercolano E, Schulman-Green D. McCorkle R Validity of the end-of-life professional caregiver survey to assess for multidisciplinary educational needs. J Palliat Med. 2012;15(4):427-31,

22. Abdi H. Holm's sequential Bonferroni procedure. Encyclopedia of research design. 2010;1(8):1-8.

23. Bengtsson M. How to plan and perform a qualitative study using content analysis. NursingPlus Open. 2016;2:8-14

24. Nuffic. Grading systems in the Netherlands, the United States and the United Kingdom. The Netherlands organisation for international cooperation in higher education., 2013.

25. Malara A, De Biase GA, Bettarini F, Ceravolo F, Di Cello S, Garo M, et al. Pain assessment in elderly with behavioral and psychological symptoms of dementia. J Alzheimer's Dis. 2016;50(4):1217-25.

26. Pieper MJ, van Dalen-Kok AH, Francke AL, van der Steen JT, Scherder EJ, Husebo BS, et al. Interventions targeting pain or behaviour in dementia: a systematic review. Ageing Res Rev. 2013;12(4):1042-55.

27. Midtbust MH, Alnes RE, Gjengedal E, Lykkeslet E. A painful experience of limited understanding: healthcare professionals' experiences with palliative care of people with severe dementia in Norwegian nursing homes. BMC Palliat Care. 2018;17(1):25.

28. Monroe TB, Parish A, Mion LC. Decision factors nurses use to assess pain in nursing home residents with dementia. Arch Psychiatr Nurs. 2015;29(5):316-20.

29. Kitwood T, Bredin K. Towards a theory of dementia care: personhood and well-being. Ageing Soc. 1992;12:269-87

30. Midtbust MH, Alnes RE, Gjengedal E, Lykkeslet E. Perceived barriers and facilitators in providing palliative care for people with severe dementia: the healthcare professionals' experiences. BMC Health Serv Res. 2018;18(1):709.

31. Kaplan HC, Brady PW, Dritz MC, Hooper DK, Linam WM, Froehle CM, et al. The influence of context on quality improvement success in health care: a systematic review of the literature. Milbank Q. 2010;88(4):500-59.

32. Sommerbakk R, Haugen DF, Tjora A, Kaasa S, Hjermstad MJ. Barriers to and facilitators for implementing quality improvements in palliative care - results from a qualitative interview study in Norway. BMC Palliat Care. 2016;15:61.

33. Hill E, Savundranayagam MY, Zecevic A, Kloseck M. Staff Perspectives of barriers to access and delivery of palliative care for persons with dementia in long-term care. Am J Alzheimers Dis Other Demen. 2018;33(5):284-91.

34. ten Koppel M, Pasman HRW, van der Steen JT, van Hout HPJ, Kylänen M, Van den Block L, et al. Consensus on treatment for residents in long-term care facilities: perspectives from relatives and care staff in the PACE cross-sectional study in 6 European countries. BMC Palliat Care. 2019;18(1):73.

35. Lopez RP. Suffering and dying nursing home residents: Nurses' perceptions of the role of family members. Hosp Palliat Nurs. 2007;9(3):141-9

36. Hasson H, Arnetz JE. Nursing staff competence, work strain, stress and satisfaction in elderly care: a comparison of home-based care and nursing homes. J Clin Nurs. 2008;17(4):468-81.

37. Grönroos E, Perälä ML. Self-reported competence of home nursing staff in Finland. J Adv Nurs. 2008;64(1):27-37.

38. Fereday J, Muir-Cochrane E. The role of performance feedback in the self-assessment of competence: a research study with nursing clinicians. Collegian. 2006;13(1):10-5.

39. Cowan DT, Norman I, Coopamah VP. Competence in nursing practice: a controversial concept-a focused review of literature. Nurse Educ Today. 2005;25(5):355-62.

40. Konttila J, Siira H, Kyngas H, Lahtinen M, Elo S, Kaariainen M, et al. Healthcare professionals' competence in digitalisation: A systematic review. J Clin Nurs. 2018.

41. Irvine S, Williams B, McKenna L. Near-peer teaching in undergraduate nurse education: An integrative review. Nurse Educ Today. 2018;70:60-8

42. Regulation (EU) 2016/679 of the European Parliament and of the Council of 27 April 2016 on the protection of natural persons with regard to the processing of personal data and on the free movement of such data, and repealing Directive 95/46/EC (General Data Protection Regulation), (2018).

43. Etikan I, Musa SA, Alkassim RS. Comparison of convenience sampling and purposive sampling. American Journal of Theoretical and Applied Statistics. 2016;5(1):1-4.

44. AZW. Arbeid in Zorg en Welzijn 2016 Eindrapport. The Hague: 2016. 
45. Backhaus R, van Rossum E, Verbeek H, Halfens RJ, Tan FE, Capezuti E, et al. Relationship between the presence of baccalaureate-educated RNs and quality of care: a cross-sectional study in Dutch long-term care facilities. BMC Health Serv Res. 2017;17(1):53.

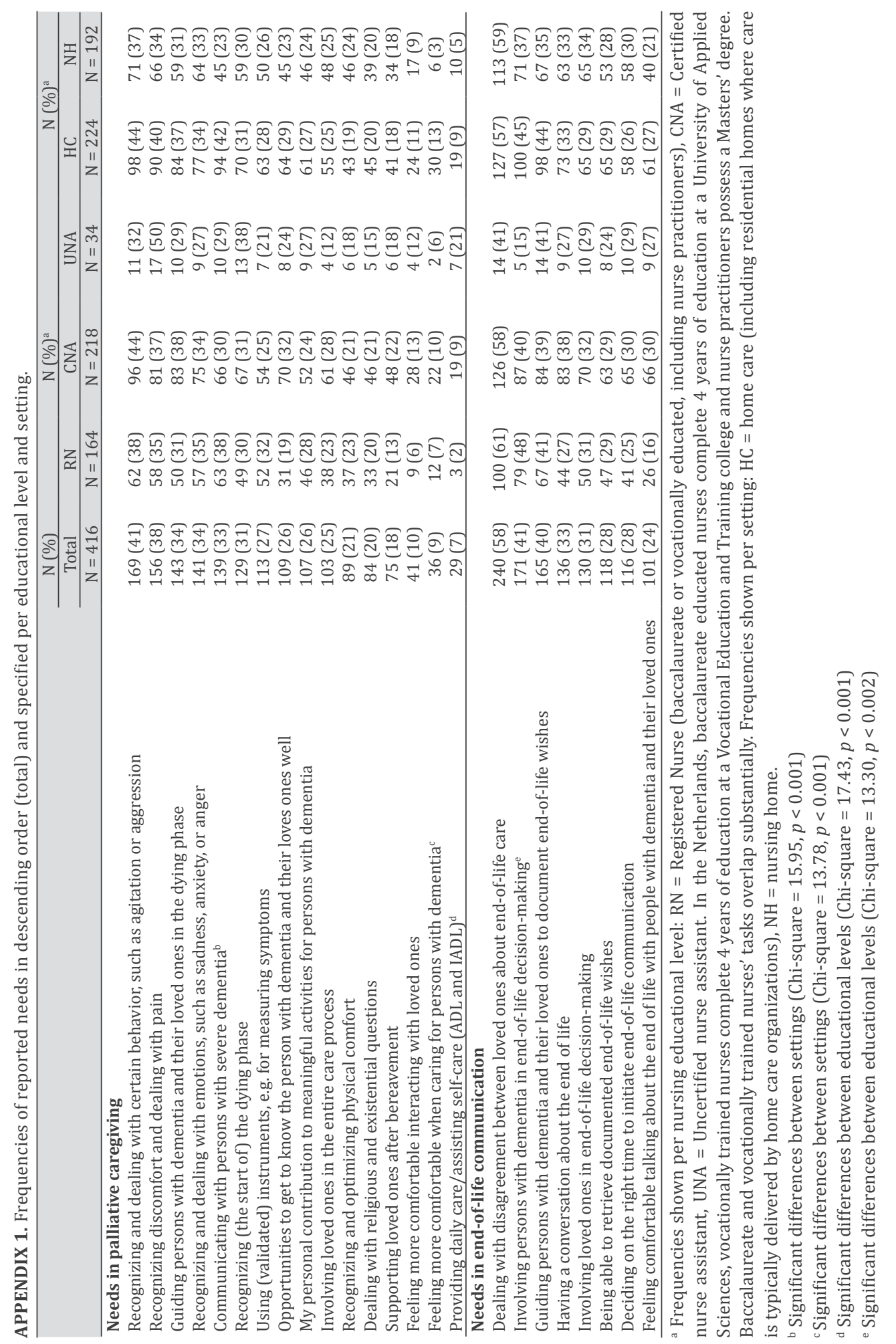

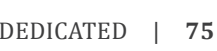




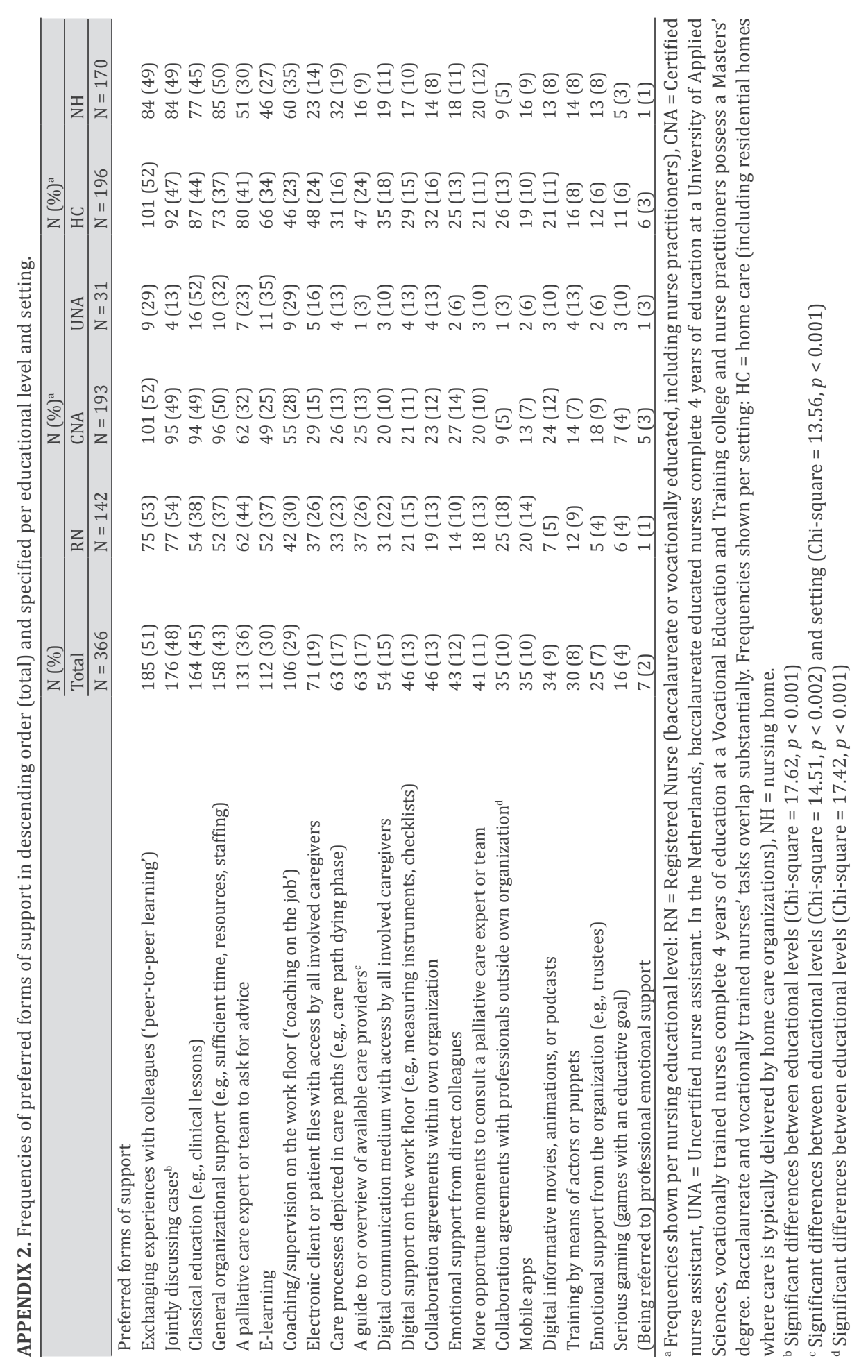

76 | CHAPTER 3 


\section{CHAPTER 4}

\section{Practical nursing recommendations}

for palliative care for people with dementia living in long-term care facilities during the COVID-19 pandemic: A rapid scoping review Jenny $T$ van der Steen Irma Mujezinović

Daisy JA Janssen

Jos MGA Schols Sandra MG Zwakhalen

Chandni Khemai

Els PAGM Knapen

Lara Dijkstra

Judith MM Meijers 


\section{ABSTRACT}

\section{Background}

The acute nature of COVID-19 and its effects on society in terms of social distancing and quarantine regulations affect the provision of palliative care for people with dementia who live in long-term care facilities. The current COVID-19 pandemic poses a challenge to nursing staff, who are in a key position to provide high-quality palliative care for people with dementia and their families.

\section{Objective}

To formulate practice recommendations for nursing staff with regard to providing palliative dementia care in times of COVID-19.

\section{Design and method}

A rapid scoping review following guidelines from the Joanna Briggs Institute. Eligible papers focused on COVID-19 in combination with palliative care for older people or people with dementia and informed practical nursing recommendations for longterm care facilities. After data extraction, we formulated recommendations covering essential domains in palliative care adapted from the National Consensus Project's Clinical Practice Guidelines for Quality Palliative Care.

\section{Data sources}

We searched the bibliographic databases of PubMed, CINAHL and PsycINFO for academic publications. We searched for grey literature using the search engine Google. Moreover, we included relevant letters and editorials, guidelines, web articles and policy papers published by knowledge and professional institutes or associations in dementia and palliative care.

\section{Results}

In total, 23 documents ( 7 (special) articles in peer-reviewed journals, 6 guides, 4 letters to editors, 2 web articles (blogs), 2 reports, a correspondence paper, and a position paper) were included. The highest number of papers informed recommendations under the domains 'advance care planning' and 'psychological aspects of care'. The lowest number of papers informed the domains 'ethical care', 'care of the dying', 'spiritual care', and 'bereavement care'. We found no papers that informed the 'cultural aspects of care' domain.

\section{Conclusion}

Literature that focuses specifically on palliative care for people with dementia in longterm care facilities during the COVID-19 pandemic is still largely lacking. Particular challenges that need addressing involve care of the dying and the bereaved, and ethical, cultural and spiritual aspects of care. Moreover, we must acknowledge grief and moral distress among nursing staff. Nursing leadership is needed to safeguard the quality of care and nursing staff should work together within an interprofessional care team to initiate advance care planning conversations in a timely manner, to review and document advance care plans, and to adapt goals of care as they may change due to the COVID-19 situation. 


\section{INTRODUCTION}

In recognition of the global outbreak of COVID-19, the World Health Organization (WHO) declared a COVID-19 pandemic on March 11, 2020. ${ }^{1}$ The world population is at risk due to the rapid spread of the virus. As of July 15 , over 580,000 deaths have been reported from 215 countries. $^{2}$ The case fatality rate is highest among frail older adults. ${ }^{3,4}$ Current estimates of the case fatality rate from COVID-19 are below $0.2 \%$ for people aged under 60 , and up to $9.3 \%$ among people aged over 80 years..$^{5}$ Older people with dementia are generally frail and they are more likely to have comorbid conditions such as cardiovascular disease, diabetes and pneumonia compared to older individuals without dementia. ${ }^{6}$ Hence, they constitute a particularly vulnerable group that is at risk for negative health outcomes of COVID-19.7 The population of people living with dementia is expected to show more severe illness and higher mortality as a result of COVID-19, due to their comorbidities and other characteristics of dementia. ${ }^{8}$ Even as an independent risk factor, Atkins and colleagues found that pre-existing dementia was the strongest risk diagnosis for developing severe symptoms of COVID-19 in communitydwelling adults aged over $65 .{ }^{9}$ Although this may be different for older people living in facilities, once a virus enters a facility, it is difficult to control and likely to spread rapidly. ${ }^{10}$ Residents with dementia may be more at risk of contracting and transmitting COVID-19 resulting from difficulties to understand and remember infection prevention regulations such as isolation, social distancing, and general hygiene regulations such as hand sanitizing. ${ }^{8,11}$

In most western countries, the majority of people living in long-term care facilities have some form of dementia. ${ }^{12-14}$ The institutional nature of long-term care facilities facilitates the spread of the virus and adds to the risk of COVID-19 among residents. ${ }^{7}$ The double challenge of dementia combined with the COVID-19 pandemic raises concerns for residents living with dementia, their families, and their caregivers. ${ }^{8,15}$ In addition to the increased risk of COVID-19, societal regulations and the organization of healthcare in response to COVID-19 affect the usual provision of care for all people with dementia living in long-term care facilities. Social distancing regulations and visiting restrictions compromise their social contacts and engagement with other residents, physical exercise and meaningful or joint activities undertaken within facilities. These changes may elicit anxiety, agitation, and depression in residents with dementia, as well as loneliness, distress, and confusion. ${ }^{16}$ Loneliness and social isolation are linked to poorer mental and physical health outcomes and a higher mortality risk. ${ }^{17,18}$ In addition, reduced sensory stimulation due to social isolation and physical distancing from others may lead to boredom, sedentary behavior or behavioral disturbances such as agitation or apathy in people with dementia. ${ }^{8,19}$ Nonpharmacological treatments of neuropsychiatric behaviors such as distraction, engagement in activities or going out for a walk are more difficult to apply due to contagion prevention regulations. ${ }^{20}$
This may increase the risk of use of physical restraints and inadequate psychotropic medications in long-term care facilities to manage isolation and distancing regulations, particularly in the case of wandering behaviors. ${ }^{16,20,21}$

Maintaining quality of life and optimizing comfort are important goals of care for people with moderate to severe dementia. ${ }^{22}$ In many western countries, the most common place of death of people with dementia is a long-term care facility, ${ }^{23}$ which highlights the need for palliative and end-of-life care for people with dementia who live in these facilities. Palliative care aims to improve the quality of life by responding to physical, psychosocial and spiritual needs. Early end-of-life conversations and advance care planning are cornerstones of high-quality palliative care, as are the management of pain and other burdensome symptoms, the pursuit of a comfortable death, and support for families before and after bereavement. ${ }^{22}$ There is increasing recognition of the need for the integration of palliative care with care for people with dementia. Nonetheless, palliative care for people with dementia is challenging even in more stable circumstances. For instance, people with dementia are more likely to have unmet needs, to receive poor treatment of pain and other symptoms, to face inappropriate aggressive medical treatments and to be transferred to acute care at the end of life. ${ }^{24}$ Professional caregivers such as nurses and physicians report difficulties in palliative dementia care related to lacking or fragmented palliative care services, pain management, psychosocial needs and challenging behaviors, and end-of-life communication and (shared) decisionmaking. ${ }^{25-27}$

During the COVID-19 pandemic, providing palliative care for long-term care residents with dementia (with or without COVID-19) is even more complex. The pandemic particularly challenges nursing staff working in long-term care, who have an important role in providing palliative care for people with dementia and their families. While they need to deliver medical and physical care to the current standard, they also need to preserve human contact, dignity and comfort for people with dementia with or without COVID-19. Physical touch and social interactions are important to enhance the well-being of people with severe dementia, particularly if other forms of communication become difficult. ${ }^{28}$ Social distancing regulations and personal protective equipment deprive people with dementia at the end of life from intimacy and being touched gently by their family members or caregivers. ${ }^{29}$ Moreover, personal protective equipment may be frightening and confusing for people with dementia. ${ }^{16,29}$ It is particularly challenging to respond to psychological symptoms such as anxiety and depression, and to deal with challenging behaviors, as people with dementia are likely to have difficulties understand their current situation. ${ }^{16}$ Palliative care for people with dementia also involves compassionate advance care planning conversations. However, as COVID-19 unfolds rapidly and visiting of families is restricted, there may be insufficient time and occasions for elaborate and personal conversations with persons with dementia and their families. ${ }^{30}$ Families as proxy decision-makers may face difficult and ethically 
challenging decisions, for instance, concerning the desirability of hospitalization. ${ }^{11,31}$ Overall, families must be involved in end-of-life care for people with dementia, which is hindered due to the widespread lockdown regulations in long-term care facilities. ${ }^{32}$ Caring for a person with dementia who is dying of COVID-19 or its complications may raise additional challenges for families and nursing staff. Rapid deterioration of health and a lack of personal protective equipment in long-term care facilities may compromise family involvement in the last phase. These situations may be stressful for families and for nursing staff, ${ }^{8,31}$ who have often cared for a person with dementia and their family for a long period.

The current COVID-19 crisis poses multiple challenges for nursing staff, who are key professionals providing high-quality palliative care for people with dementia residing in long-term care facilities. This paper describes a rapid scoping review to inform practice recommendations for nursing staff with regard to providing palliative dementia care in long-term care facilities in times of COVID-19.

\section{METHODS}

This rapid scoping review is part of the overarching research project 'DEDICATED: Desired Dementia Care Towards End of Life'. The goal of DEDICATED is to improve palliative care for people with dementia and their families. To structure this review, we used the framework proposed by the Joanna Briggs Institute. ${ }^{33}$ The framework builds upon the original framework for scoping reviews by Arksey and O'Malley, ${ }^{34}$ taking into account earlier enhancements by Levac and colleagues. ${ }^{35}$ Thereby, the Joanna Briggs Institute's framework provides a detailed and explicit description for conducting systematic and rigorous scoping reviews. It is a leading source for guiding the conduct of scoping reviews ${ }^{36}$ and it informed the development of the PRISMA Extension for Scoping Reviews checklist. ${ }^{37}$

\section{Search strategy}

We performed weekly literature searches between April and May 2020, with a last search on May 18. The search strategy included four steps, following the Joanna Briggs Institute manual. ${ }^{33}$ In step one, we searched the databases of PubMed, CINAHL, PsycINFO, and the search engine Google (Scholar) to identify relevant keywords related to the subjects (Table 1, view details of the search in Supplementary material 1). In step two, we used these keywords to build elaborated search strings for searching the databases of PubMed, CINAHL, and PsycINFO. We used various combinations of search terms to either broaden or narrow down the search, depending on the results in a specific database. The search string focused on keywords in titles and abstracts. We searched for papers written in English or Dutch and published from December
2019 onwards, as this review focuses on the COVID-19 period. In step three, we handsearched the reference lists of articles that we considered eligible. Finally, in step four we searched for grey literature using the search engine Google. Furthermore, we searched for relevant letters and editorials, guides, web articles, and policy papers published by knowledge and professional institutes or associations in dementia and palliative care. These included: The European Association for Palliative Care, Alzheimer's Disease International, The Gerontological Society of America, International Psychogeriatric Association, The Society for Post-Acute and Long-Term Care Medicine, International Long-Term Care Policy Network, Marie Curie, Dutch professional nurses organization, Palliaweb (Dutch online platform), Dutch Palliative Care Cooperation, Dutch Association of Elderly Care Physicians Verenso.

Table 1. Key subjects and their search terms

\begin{tabular}{ll}
\hline Subject & Search terms \\
\hline People with dementia & $\begin{array}{l}\text { Dementia; Alzheimer's disease; Alzheimer; cognitive impairment; cognitively } \\
\text { impaired }\end{array}$ \\
Palliative care & $\begin{array}{l}\text { Palliative care; terminal care; end-of-life care; comfort care; nursing home; aged } \\
\text { care; long-term care; bereavement; grief }\end{array}$ \\
CovID-19 & Covid-19; Corona; Coronavirus; 2019-nCoV; SARS-CoV-2
\end{tabular}

\section{Study selection process}

Table 2 displays the inclusion criteria for selecting articles and grey literature. Initially, we screened titles and abstracts or summaries and we excluded articles and papers that were irrelevant or beyond the scope of this review. After screening titles and abstracts or summaries, we obtained articles and papers that we deemed eligible as full texts and further scanned them for eligibility. Authors JM and SB contributed to the study selection process by both performing title-abstract and summary screening and full-text screening independently on all potential titles. Afterwards, the authors discussed any discrepancies and reached full agreement on which articles and papers to include in the review.

Table 2. In- and exclusion criteria for selecting articles

Inclusion criteria $\quad$ Exclusion criteria

- Peer-reviewed articles or reviews of primary research. - Not written in Dutch or English. - Grey lisis in guidelines, letters and editorials, newspaper or web retation to pallictve care for older people, or care for

Informing (implicitly or explicitly) recommendation for nursing staff (population) providing palliative care facilities (concept) during the CoviD-19 crisis (context). 


\section{Data synthesis and analysis}

Three authors (JM, SB, and IM) extracted data from the included papers. First, IM and SB extracted descriptive information from the articles to fill in a data extraction form. Extracted descriptive information included authors, date of publication, country, source or organization, type of article, setting, and focus relevant to the review. Further, JM and SB read the included papers thoroughly to become acquainted with the content. Thereafter, JM listed initial relevant findings related to the research question that could inform recommendations for nursing staff working in long-term care facilities. The two authors (JM and SB) discussed the findings and SB formulated practical recommendations using the extracted information from included sources, adapted to our specific goal.

The recommendations were initially categorized according to the domains of palliative care as proposed by the National Consensus Project Clinical Practice Guidelines for Quality Palliative Care. ${ }^{38}$ These domains include physical aspects of care, psychological aspects of care, social aspects of care, spiritual aspects of care, cultural aspects of care, care for the dying, ethical aspects of care, and structure and processes of care. We discussed the recommendations that followed from this process iteratively throughout the analysis. We placed them under what we considered the most appropriate domain. Based on inductive findings from the included articles, we included recommendations on advance care planning and bereavement care. After JM and SB set up a complete list of recommendations, these were discussed with all authors integrating each team member's expertise for further interpretation, practical application, and fine-tuning. The team's areas of expertise cover palliative care (for people with dementia and/or frailty), advance care planning, elderly care medicine, transmural nursing home care, and long-term care and (community) nursing. This process resulted in a final overview of recommendations for nursing staff on how to provide palliative care for people with dementia during the COVID-19 crisis

\section{RESULTS}

Searching CINAHL, PsycINFO, and PubMed databases and searching (non-scientific) websites for eligible grey literature yielded 163 unique titles (Figure 1). Eventually, we obtained full texts from 55 documents based on title/abstract screening, by hand searching eligible articles, and by searching for grey literature. Of these full texts, 23 were eligible. Table 3 shows the included articles and other documents, and their focus relevant to this review. Among the included documents, there were 7 (special) articles published in peer-reviewed journals, ${ }^{8,29,31,39-42} 6$ guides, ${ }^{30,43-47} 4$ letters to editors, ${ }^{48-51} 2$ web articles (blogs), ${ }^{52,53} 2$ reports, ${ }^{54,55}$ one correspondence paper, ${ }^{15}$ and one position paper. ${ }^{11}$ The documents (first authors) were from the UK and Ireland $(n=7)$, Europe $(\mathrm{n}=6)$, the USA $(\mathrm{n}=3)$, Australia $(\mathrm{n}=2)$, Canada $(\mathrm{n}=2)$, and Asia $(\mathrm{n}=2)$. One was an international paper.
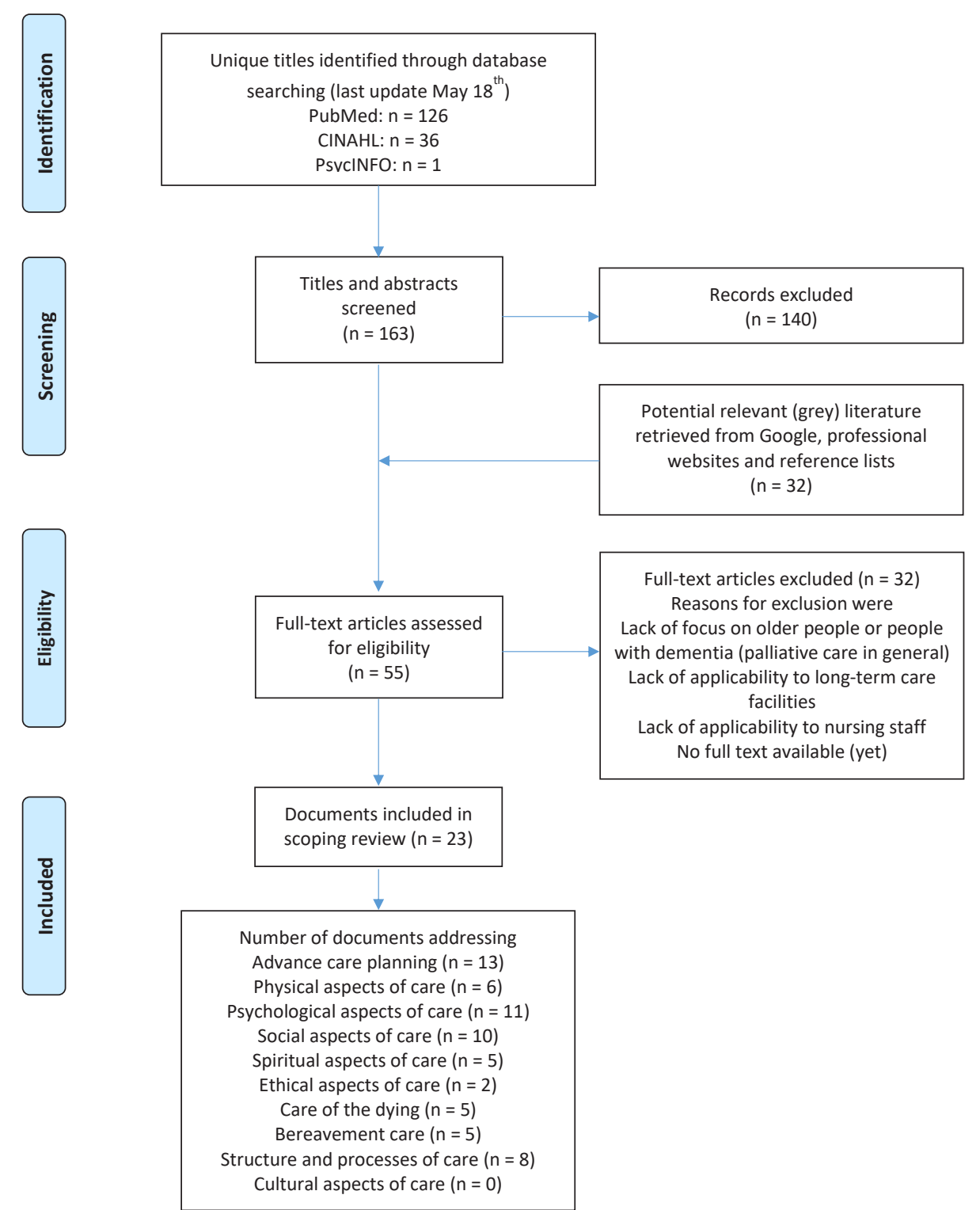

Figure 1. Flowchart of the search and selection process 


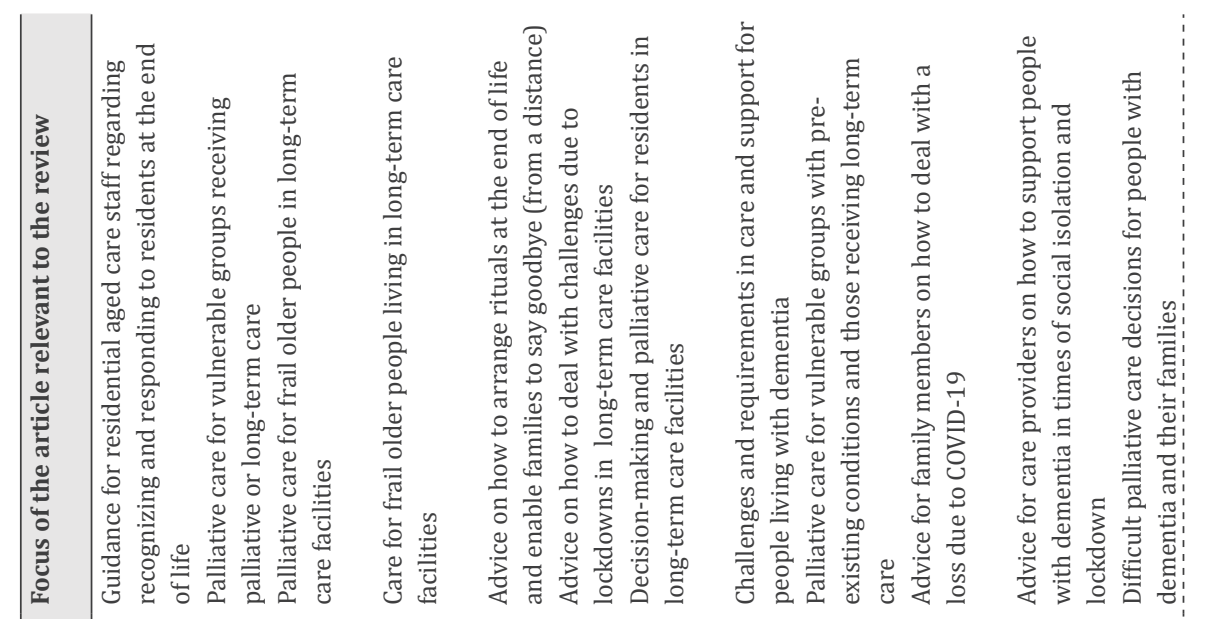

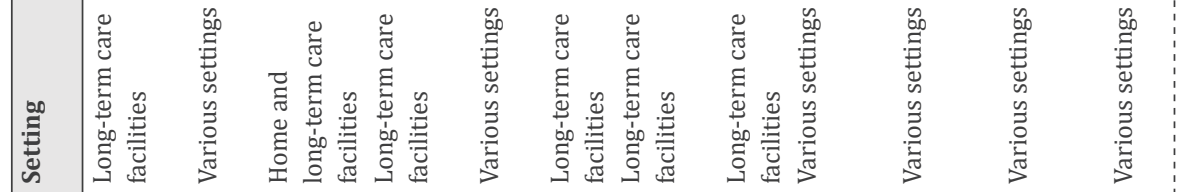

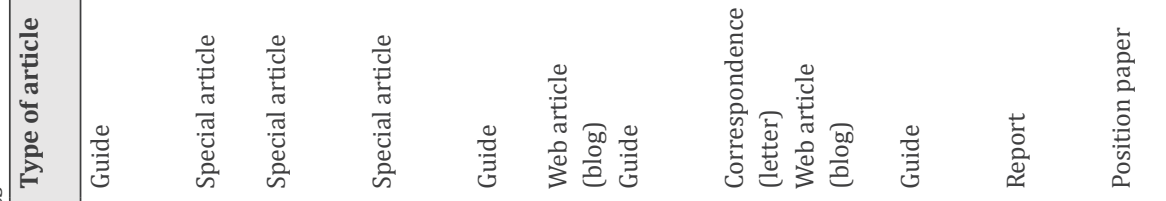

IIIn

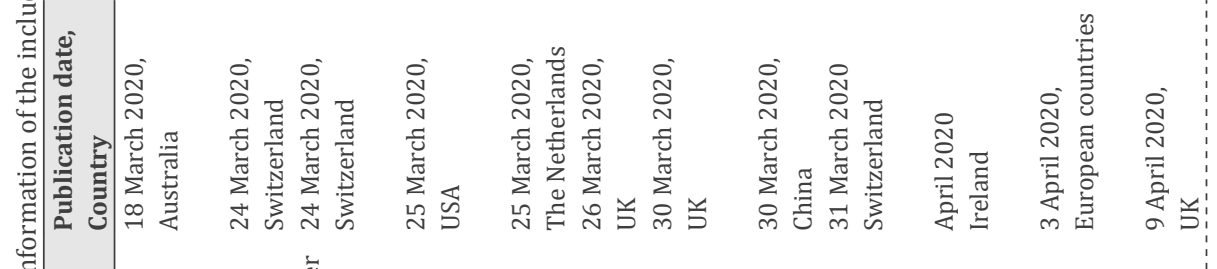

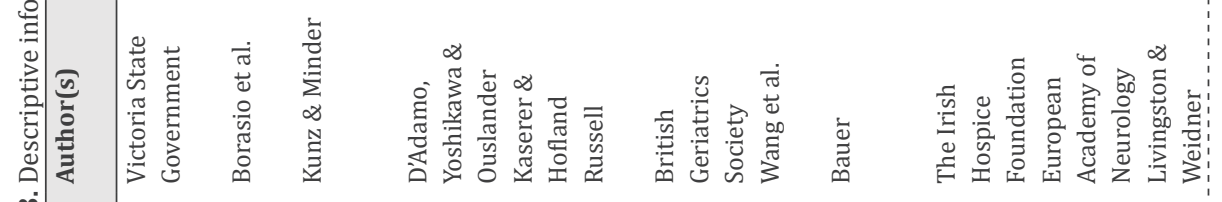
is

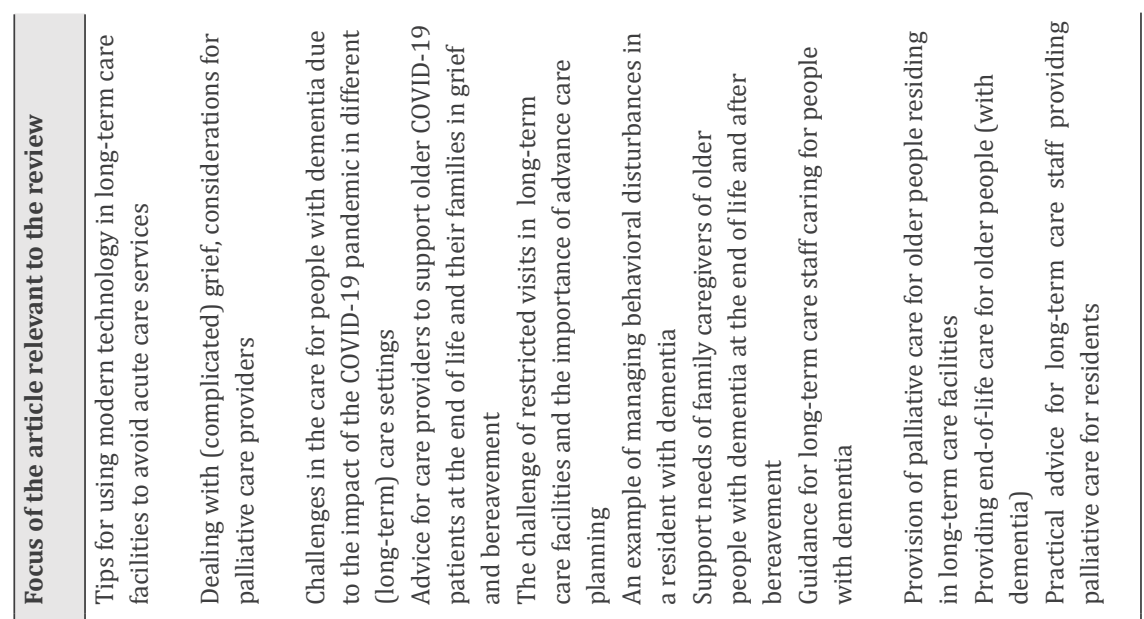

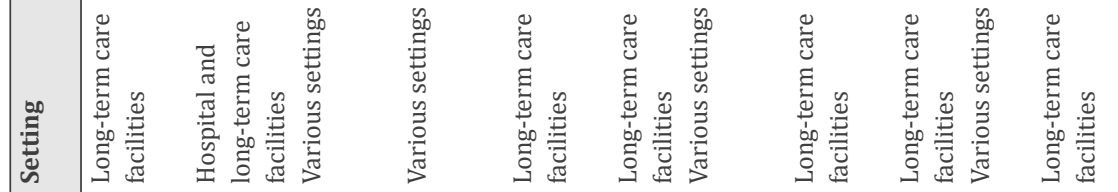

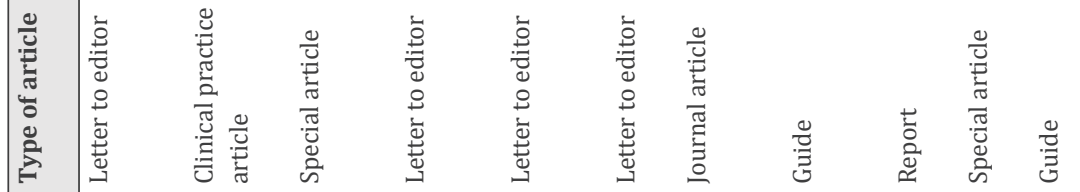

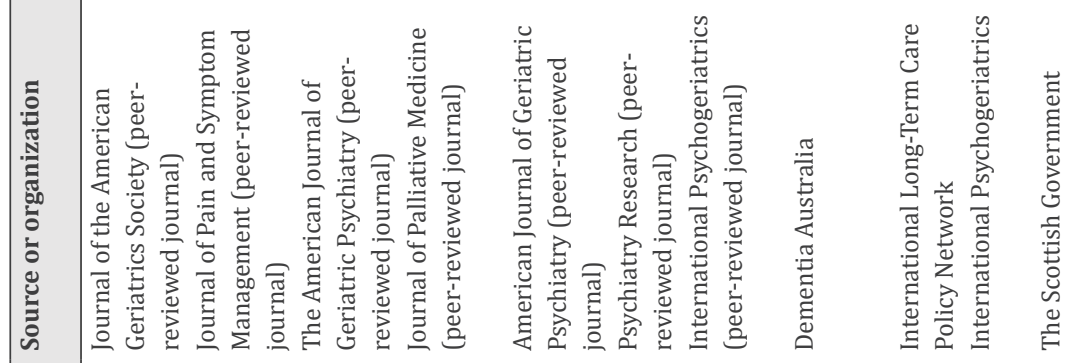

)

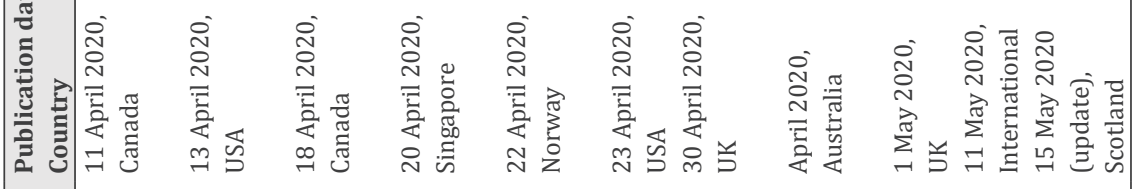

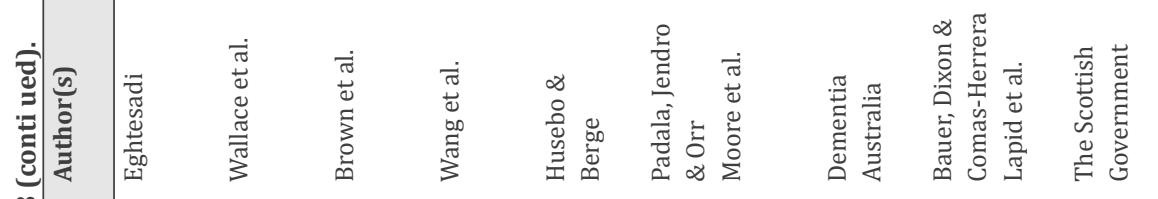

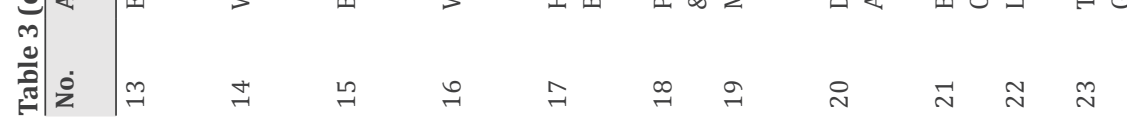


From the included information sources, we extracted original content that informed a list of specific recommendations for nursing staff regarding the provision of palliative care for people with dementia living in long-term care facilities during the COVID-19 pandemic (Table 4). We categorized recommendations under a number of key domains in palliative care adapted from the National Consensus Project Clinical Practice Guidelines for Quality Palliative Care. ${ }^{38}$ Some would fit under multiple domains, though we chose what we considered the most appropriate domain. The domains with the highest number of articles that informed recommendations are 'advance care planning' and 'psychological aspects of care' (Figure 1). The domains with the lowest number of articles that informed recommendations are 'ethical care', 'care of the dying,' 'spiritual care', and 'bereavement care'. We did not find information on 'cultural aspects of care'.

\section{DISCUSSION}

This paper describes a rapid scoping review to formulate practice recommendations for nursing staff with regard to providing palliative dementia care in long-term care facilities in times of COVID-19. The recommendations that followed from the review touch upon most of the key elements of palliative care for people with dementia. Initially, we found papers that mainly addressed advance care planning and physical or medical care of COVID-19 patients. At the time of our first searches, articles on psychological, social, and spiritual care and on nursing care were scarce. However, over time, more papers appeared that described these other domains and the impact of the COVID-19 pandemic on (caring for) people living with dementia. Although we found an increasing number of papers to inform palliative care given to people with dementia in times of COVID-19, papers that explicitly discussed palliative care in dementia specifically in relation to COVID-19 were limited. This illustrates that, although over the past two decades there has been increasing attention for palliative care in dementia, ${ }^{22,56}$ it is not a top priority when a crisis strikes. The current literature emphasizes specific challenges in times of COVID-19 related to advance care planning, family involvement and management of psychosocial needs that may aggravate due to social isolation and residents' limited understanding of the situation. To a lesser extent, the literature addressed the spiritual aspects of care and grief and bereavement. So far, ethical and cultural aspects of palliative dementia care in times of COVID-19 remain under-reported. The available literature on the current pandemic reflects the need for holistic palliative care for people with dementia in long-term care facilities as well as for their families before and after bereavement. Besides improved experiences of people with dementia and their families, a palliative approach to care may contribute to better use of healthcare resources. For instance, advance care planning and setting palliative care goals may reduce hospitalizations and futile medical treatments, and education of healthcare staff may reduce medication administration and costs. ${ }^{57}$ Adequate allocation of healthcare resources is imperative in times of COVID-19. ${ }^{58}$

Although previous papers emphasize the important role of palliative care in times of humanitarian crises and pandemics, ${ }^{59-61}$ the global response to COVID-19 exposes a lack of efficient pandemic palliative care plans and gaps in palliative care training and literature. ${ }^{62}$ In long-term care facilities, which are generally understaffed and under-resourced with regard to providing palliative care, the current pandemic poses particular challenges by further increasing the workload and potential distress of staff. ${ }^{63}$ At this early point, it is difficult to map the adequacy of palliative care in longterm care facilities in the context of COVID-19. However, Bauer and colleagues ${ }^{54}$ wrote that many people at the end of life may have unmet palliative care needs in times of COVID-19, particularly the frail population residing in long-term care facilities. The COVID-19 pandemic raises concerns as it induces a strain on health providers who are under-resourced to provide safe and effective palliative care. ${ }^{64}$ As the number of infected individuals has increased, the potential seriousness and mortality of the infection is becoming more clear, for vulnerable groups and for people with dementia in particular. ${ }^{9}$ Moreover, social isolation regulations may have a detrimental effect on the psychosocial and physical well-being of residents with dementia in long-term care facilities. ${ }^{16}$ These challenges highlight the necessity of adequate palliative care to relieve suffering of people with dementia on the physical, psychological, social, and spiritual domain. ${ }^{64}$ Expectations are that COVID-19 will continue to be a long-lasting global health problem, which underlines the need to provide simultaneous COVIDsensitive and dementia-sensitive care as we transition back from emergency care to regular care. ${ }^{20}$ The current scoping review adds to the knowledge base by providing an overview of relevant literature and practical recommendations.

Over the past few months, the initial response to the pandemic crisis was focused on curing those infected, containing extensive outspread, and preventing intensive care facilities from being overwhelmed by demand. This also reflects the more general, longstanding neglect of the long-term care sector ${ }^{29}$ and weaknesses in its palliative care capacities. ${ }^{54}$ Although the initial response focused on the hospital setting and less on long-term care setting, initiatives that address the psychosocial and spiritual consequences of the pandemic for older people with dementia are on the rise. Longterm care organizations are thinking of innovative ways to deal with social isolation and quarantine regulations to avoid loneliness and social exclusion of older people and persons with dementia. ${ }^{43}$ Nursing staff working in long-term care facilities have a key role in providing psychosocial and spiritual care, especially when face-to-face meetings between families and their relatives with dementia are prohibited.

Literature that addresses domains of palliative dementia care other than the physical domain is increasing. However, a gap remains on some important aspects. The included documents in our review most often addressed advance care planning and 
psychological care, whereas practical information on spiritual care, care of the dying and the bereaved, and ethical aspects of care was sparse. The recommendations that we formulated related to these aspects are underpinned by a smaller body of literature, which suggests that (practical) knowledge on these aspects needs to be expanded. Currently, the most prominent literature gap is in cultural aspects of care, despite the global impact of COVID-19. Another recent review of worldwide guidance documents on palliative care in long-term care facilities also shows that several key aspects, such as holistic symptom management, decision-making, and end-of-life and bereavement care remain under-reported.$^{65}$ Although the recommendations that we formulated provide an initial basis for palliative care provision for people with dementia in times of COVID-19, they are limited to the currently available literature. Ideally, the recommendations should be updated regularly to provide ongoing support and information for nursing staff in long-term care facilities. This should inform contemporary COVID-sensitive and dementia-sensitive practice in long-term care facilities and add to the knowledge base for anticipating possible future crises.

\section{Ethical issues in decision-making}

An important, yet under-reported issue is how to deal with people for whom lifesustaining measures may be inappropriate in the context of COVID-19. In a paper responding to a previous influenza pandemic, Downar and Seccareccia ${ }^{59}$ describe ethical issues related to scarce healthcare resources and medical decision-making. Triage systems and decision-making in times of scarcity may deprive seriously ill people from potentially life-sustaining treatments and cause physical and emotional suffering for patients, their families, and care staff. Advance care planning is a process between healthcare professionals, an individual patient and his or her loved ones. Advance care planning and shared decision-making are core processes in establishing care goals for the end of life of persons with dementia ${ }^{22}$ and may prevent unwanted life-sustaining treatments, which is paramount during this pandemic. Advance care planning conversations are particularly important in times of COVID-19 so that individual wishes for end-of-life care can be discussed in a timely manner and to inform people with dementia and their families about potential risks of hospitalization with the infection. ${ }^{11}$ Families may feel more confident and less guilty about making end-oflife care decisions on behalf of their loved one with dementia if they know the person's wishes.$^{66}$ Particularly in times of COVID-19, it may be difficult and emotive for families of people with dementia who have not previously discussed their wishes to make such decisions. ${ }^{31}$ Although discussing care preferences may help to reduce chances of potentially futile and burdensome treatments and hospitalization, discussions concerning triage for intensive-care treatment under resource scarcity should not be included in the advance care planning process. However, during this pandemic, the autonomy to opt for life-prolonging treatments or a preferred place of death is possibly challenged because of public health directives and scarce resource accessibility.

Lack of a palliative care plan in times of a pandemic raises concerns about the provision of care that is in line with individual wishes of people facing life-limiting conditions and their families. A pandemic palliative care plan should facilitate palliative care services and health organizations to respond quickly and flexibly in times of scarce resources. ${ }^{62}$ As Downar and Seccareccia ${ }^{59}$ described: we need "stuff" (for instance, stockpile medications), staff (education, expertise), space (special wards and units), and systems (triage systems, updated care plans) to provide comprehensive palliative care during a crisis. In times of COVID-19 specifically, older and vulnerable people with cognitive impairment may not receive mechanical ventilation due to their prognosis, even if they wish to. ${ }^{67}$ Residents with COVID-19 may be confined to a room or a special COVID-19 ward that is not of their choosing and regulations of social isolation and quarantine may hamper involvement of family members in the last phase of life of people with dementia. ${ }^{68}$ Even if people with dementia may not qualify for life-sustaining measures or acute care admission, it is a human right that they are not denied palliative care and adequate relief of suffering, regardless of whether they have COVID-19.7,59,69 Stigma increases the risk of certain groups being denied access to health and social services. ${ }^{8}$ In dementia, stigmatization is a pervasive and widespread problem and there have been reports on stigmatization of older people who are at risk for contracting COVID-19. ${ }^{70}$ Hence, people with dementia may face double stigmatization. ${ }^{8}$ Nursing staff have an important role in advocating for people with dementia to shelter them from the negative consequences of stigmatization. During this pandemic, it is a global, public health urgency to apply palliative care knowledge to its best to provide equitable, compassionate and dignified care, to alleviate suffering, and to mitigate the impact on caregiver grief and distress. ${ }^{68}$ In this review, we added advance care planning as a key domain for nursing recommendations. Nursing staff are essential stakeholders advocating for the provision of dignified palliative care for people with dementia. To achieve high-quality palliative care in times of this pandemic, it is crucial to review care plans within the interprofessional care team and to update goals of care through advance care planning conversations with people with dementia and their families. . $^{30,39,41}$

Nursing staff should collaborate diligently with families, and with physicians and other healthcare professionals to provide timely and adequate care that is tailored to individual wishes. Vice versa, healthcare professionals from other disciplines must acknowledge and support nursing staff to facilitate their role. The current pandemic emphasizes the need for nursing leadership in long-term care settings. Especially registered nurses should have a recognized leading role in the delegation and oversight of care tasks, initiation and evaluation of care plans, and assessment of their effectiveness. ${ }^{71}$ They should also function as mentors and supervisors for other care personnel. In the context of COVID-19, decision-making, and care provision may be challenging due to strained resources, which can induce moral distress. Moral distress 
arises when constraints prevent us from doing what we think is morally right, and it may induce unresolved grief and burnout in families and nursing staff. ${ }^{42}$ It is important that nursing staff engage in open communication with their (interprofessional) colleagues and with families about the experience of distress. Nursing staff and family members often place the well-being of the person with dementia above their own feelings. Nonetheless, we need to stimulate self-care and increase self-awareness of families and nursing staff about (negative) emotions and thoughts during care provision in times of the COVID-19 pandemic. Again, this requires leadership skills among nurses to provide peer support and facilitate self-reflection and peer-to-peer coaching.

\section{Grief and bereavement}

In the context of the COVID-19 pandemic, experiences of grief and anticipatory grief are subject to change, which stimulates the need for adapting usual approaches to grief support. ${ }^{42}$ Anticipatory grief is an emotional reaction to imminent losses and occurs before the actual death of oneself or a relative. ${ }^{42}$ Anticipatory grief in relation to dementia is prevalent and complex ${ }^{72}$ given the uncertain and sometimes lengthy illness trajectory, which is accompanied by serial losses on different domains (cognition, autonomy, social relationships). ${ }^{73}$ Severe symptoms of anticipatory grief and low preparedness for the death of a relative are part of a complex network of risk factors for adverse bereavement outcomes, such as complicated grief. $42,74,75$

In this review's recommendations, we included bereavement care as a separate domain, given the unusual circumstances under which people are currently facing the loss of a relative. Given the sudden and rapid decline that a COVID-19 infection may cause, families and nursing staff may feel unprepared for the loss of a person. ${ }^{42,72}$ Along with the possible inability of families to see or have physical contact with their relative at the end of life, this may increase the risk of complicated grief. ${ }^{31}$ It is important to note that nursing staff may equally suffer from grief or moral distress following the deaths of their residents. ${ }^{29,54}$ They may have to communicate distressing news to loved ones, which may be particularly disturbing for care staff who often consider residents (whom they have cared for over an extended period) as a part of their own family. Not being able to say goodbye properly relates to post-bereavement depression and complicated grief. ${ }^{31,76}$ Moreover, the world population is facing multiple potential or actual losses in several other areas due to the COVID-19 pandemic, including the loss of jobs and financial income security, of social, physical and spiritual connections, of physical or mental health, and of autonomy and freedom. A lack of social support relates to increased pre-death grief among family caregivers of people with dementia. ${ }^{72}$ Moreover, social distancing regulations force those who are bereaved in times of COVID-19 to suspend funerals or to arrange an online service instead, with no physical attendance of family members and friends. Thus, bereaved individuals may lack support in terms of physical touch from and closeness to others ('a shoulder to cry on', literally). ${ }^{31}$ All these factors may increase the risk of trauma, posttraumatic stress disorder, feelings of abandonment or loneliness, and a lack of social support to enable coping with the loss of a relative.

The complexity of grief and bereavement in times of COVID-19 emphasizes the role of nursing staff in adequately recognizing and addressing anticipatory grief, in preparing families for bereavement, and in helping families come to terms with their loss as a part of palliative care. ${ }^{42,77}$ We need to optimize the quality of palliative care to reduce potential risk of adverse outcomes for those bereaved of a relative or friend with dementia during the COVID-19 pandemic. To achieve this, it is important that nurses pay attention to possible unmet psychosocial needs of people with dementia and their families, spiritual needs, rituals and family involvement towards the end of life, and signs of anticipatory or complicated grief. Moreover, grief and moral distress among nursing staff in times of COVID-19 should be acknowledged ${ }^{31}$ and long-term care organizations should facilitate (peer) support structures.

Ultimately, humane and empathetic provision of palliative care including grief and bereavement support should prevail, even in times of the COVID-19 pandemic. As Dame Cecily Saunders once said, "how people die remains in the memory of those who live on." Despite the tragedy of the COVID-19 pandemic, its worldwide impact may raise public death literacy and awareness with regard to the need to prioritize integration of palliative care into global health to ensure relief of suffering both before and after death. ${ }^{29,68}$

\section{Limitations}

This rapid scoping review has a few limitations. The goal of this review was to gather relevant information from various resources regarding palliative care and dementia care during the COVID-19 pandemic at short notice. The conduct of the searches was not fully systematic. Relevant documents may have been omitted due to oversight of relevant search terms and due to the rapid increase of both academic and grey literature focusing on COVID-19. Moreover, this review only included documents that were written in English or Dutch. The recommendations were not ranked on their importance. We did not perform a structured quality assessment of the included documents. However, this is in line with the conduct of scoping reviews. ${ }^{33}$

\section{Conclusion}

In times of COVID-19, a pressing need arises for high-quality palliative care for people with dementia living in long-term care facilities and their families. Literature that informs how we should address this need increased over the last months. Nonetheless, an explicit focus on palliative dementia care is still largely lacking in the current academic and grey literature. Although medical and physical care are crucial in times of this pandemic, we need to address spiritual care, and culturally sensitive and ethical 
care. The COVID-19 outbreak and its ensuing societal impact emphasizes a particular need for care of the dying and the bereaved. We must acknowledge grief and moral distress that may arise among staff caring for residents in long-term care facilities. Currently, literature on the spiritual, cultural and ethical aspects and on care of the dying and the bereaved is scarce. The current pandemic raises the need for nursing leadership. Nursing staff should collaborate with their interprofessional teams to establish and document suitable goals of care, tailored to the wishes of patients and their families as these may change in times of COVID-19. Nursing staff are essential to providing palliative care across all domains of care for people with dementia and their families to safeguard a peaceful death and a worthy farewell in these unsettling times.

Table 4. Recommendations for nursing staff on providing palliative care for people with dementia in long-term care facilities in times of COVID-19*

Advance care planning

- Nursing staff should collaborate with geriatricians and family doctors to review (existing) advance car plans of people with dementia. In particular, discuss and evaluate appropriate actions together to anticipate potential COVID-19 (for instance, whether or not life-sustaining treatments and hospital admission are desired).1,7,21

- Note that, ideally, advance care planning starts before a diagnosis of COVID-19 and before the person with dementia loses cognitive capacity 1,3,17,19 $\mathrm{Nuring}$ staff ma provide information and guidance to people with

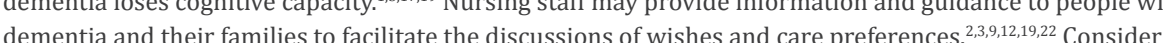
using decision aids as a practical tool to support (proxies in) making difficult decisions.

- Aim to facilitate timely advance care planning conversations by thoughtfully introducing the COVID-19 subject. ${ }^{15}$ Nurses could explain that in the context of COVID-19, it is advisable to discuss potential (realistic) scenarios and end-of-life care options proactively to avoid undesirable treatment (such as unwanted scenarios and end-of-life care options proactively to avoid undesirable trat
hospital admission, life-sustaining treatments or hospitalization), $3,31,1,1922$

- Be aware that, in case advance care planning conversations did not take place before, initiating first conversations in times of COVID-19 may be colored by fears or emotions induced by the current pandemic..$^{22}$ Without in-depth reflection or repeated discussions, certain decisions may be particularly difficult to make. - Consider using advance care planning conversations to identify anticipatory grief and to provide

information on bereavement preparation in times of COVID-19.141,1,19

- For optimal support concerning advance care planning, a follow-up conversation or call is recommended to respond to psychosocial or spiritual needs or questions that may arise from discussing care plans. ${ }^{16}$

Make sure to document wishes clearly in transferable (digital) files that should be available and accessible at all times for different care agencies and care personnel (such as emergency physicians) in acute

- During this pandemic, nursing staff may discuss the preferred place of death with persons with dementia, before potential infection. Keep in mind that a familiar environment is likely preferred over a hospital. ${ }^{3,}$ Additional recommendations for people with dementia who have COVID-19

Complex decisions about hospitalization related to COVID-19 should be discussed jointly within the interprofessional care team (including nurses, family doctors or elderly care physicians, paramedics, palliative care specialists).2,7

For people with dementia who have COVID-19, discuss goals of care with the patient and within the interprofessional care team as soon as possible and revise care goals as the situation changes (involve the person's family or surrogate decision-maker).21

Be sensitive to family members and proxy decision-makers, who may have to make hasty, difficult and

emotive decisions on behalf of their relative ${ }^{19}$
Table 4 (continued)

\section{Physical aspects of care}

Try to stimulate people with dementia to stay active by encouraging movement and (small, at-home) exercises (walking around the room, ward, or outside if possible, changing position (sitting, standing or lying down) regularly. ${ }^{1,11}$

Provide additional support and explanation to residents with dementia, to help them to maintain prope hand hygiene.$^{20}$ Consider the following tips:

Place dementia friendly instruction boards or signs in bathrooms or elsewhere as a reminder to wash one's hands with soap for 20 seconds.

Demonstrate how to execute thorough hand washing.

Use hand sanitizer or anti-bacterial hand wipes as an alternative for people with dementia who cannot easily get to a sink to wash their hands.

Encourage people with dementia to sneeze and cough into a tissue (and discard afterwards) or into their elbow instead of their hands.

Remind them about social and physical distancing and encourage them to stay in their room, for instance by tempting them with indoor hobbies (of their own, or something new that they find interesting).

- Note that other health issues might mask manifestations of COVID-19 in people with dementia or infection may appear asymptomatically (reported symptoms include sudden cough and fever, presence of diminished taste or smell, nausea and diarrhea, shortness of breath, falls, dehydration, delirium or confusion, disordered sleep).23

- Careful identification, documentation and discussion of changes in health status, mood or behavior as potential indicators for infection is advisable, ${ }^{23}$ taking into account that people with dementia may not selfreport such changes., ${ }^{4,1}$

Additional recommendations for people with dementia who have COVID-19

- Pay attention to oral hygiene; this is particularly important for those who contract COVID-19, which may cause a dry mouth.

- Nursing staff may advocate for person-centered procedures to isolate people with dementia who have COVID-19 (especially with behavioral disturbances), that do not involve physical or medical (antipsychotics, sedatives) restraining measures. ${ }^{7,11}$ (see 'Psychological care'). Instead of isolation on one's own room,

consider arranging COVID-19 cohort units, allowing for freedom of movement. 


\section{Table 4 (continued).}

\section{Psychological aspects of care}

Be mindful that regulations of social isolation and distancing followed by experienced loss of social connections and the sight of personal protective equipment on staff may instigate feelings of anxiety, depression, grief and trauma in people with dementia.,1,15,22

- Try to reduce heightened anxiety about COVID-19 among people with dementia. ${ }^{1,11,20}$ Consider the following tips:

Minimize access and exposure to media information

Provide information and explanation to persons with dementia if they express concerns.

Use simple reminders and visual instructions to explain the current situation.

Use reassuring language and gestures to help people with dementia to follow safety regulations. Interact with persons with dementia frequently, ask how they are doing and take time to listen. Validate the person's feelings and provide reassurance.

Avoid using negative language (words such as 'crisis', 'pandemic', 'lockdown' or 'isolation') and do not argue with colleagues about COVID-19 regulations in front of persons with dementia.

- Spend sufficient time with persons with dementia and encourage them to engage in everyday activities and routines to reduce boredom and confusion..$^{20}$

- Report and respond to behaviors that may pose a risk to persons themselves or others (such as ignoring or resisting safety instructions). ${ }^{20}$

- Look for psychosocial interventions to manage such behaviors. ${ }^{711}$ Consider the following tips:11,18

- Use old photographs, objects or songs from the past for distraction.

stimulate movement, exercise and (creative or household) activities (such as painting, cooking, folding towels).

Keep a regular schedule and routine

Be mindful about the effect of social isolation on people with dementia and that it may worsen

symptoms of dementia. Take time to talk to them regularly and thoughtfully explain the situation

taking into account cognitive difficulties, and try not to submit your own anxiety.11

Reach out for family members who may (video)call to reduce distress and confusion in their relative with dementia through interaction. ${ }^{18}$

- Nursing staff should collaborate with mental health professionals and social workers to deliver adequate mental health care.

Additional recommendations for people with dementia who have COVID-19

- Report and respond to behaviors that may pose a risk to others (such as wandering behavior during

isolation)..$^{20}$

Nursing staff should collaborate with mental health and dementia teams to manage wandering behavior of residents who need to be isolated due to infection?

- Pay attention to anticipatory grief work by preparing persons with dementia and their families in case of a nearing death due to COVID-19. Communicate and address anticipatory grief by recognizing and validating emotions. Preferably, use a direct approach and do not avoid or shy away from talking about emotions and grief.14,19

Consider providing (written) information about bereavement preparation in relation to CoviD-19 to people

with dementia and their families 16

\section{Table 4 (continued).}

\section{ocial aspects of care}

Be mindful of the potential adverse effects of isolation from others and the outside world for people with dementia (for instance, loneliness, anxiety, depression, and worsening symptoms of dementia). ${ }^{13}$

- Although COVID-19 patients should be isolated, infection control regulations affect all people living with dementia, in terms of social isolation. When a person is nearing the end of life or when there is an acute need for companionship, staff should weigh the importance of a visit against infection risk. ${ }^{1,17,2}$

- Reduce social isolation and loneliness. ${ }^{11,20}$ Consider the following tips:

Encourage families and friends to drop off letters, drawings or other packages.

Encourage participation in everyday activities (such as listening to music or audiobooks).

Encourage (individual, at a distance) singing, walking outside, doing exercises.

Maintain social support by arranging regular check-ins by family members.

Maintain (small) group activities when possible; play interactive games via overhead speakers, eat in turns at mealtimes.

Encourage the use of technology, such as tablets or smartphones to facilitate online social

engagement (with relatives). Note that the use of technology may require additional explanation and support, and may not be suitable for everyone. . $^{15,19}$

- Invest in creative solutions and alternatives for the restricted visiting. ${ }^{122}$ Consider using advanced technology such as Virtual Reality to offer people with dementia in isolation the opportunity to meet with their family in a simulated, trusted place or to visit special environments (such as music concerts, nature expeditions)..$^{13,17}$

- Virtual networks can also be used as platforms for joint activities and as a virtual visiting lounge for social contacts. ${ }^{6}$

- Nursing staff may advocate for offering family caregivers the opportunity to move in during the COVID-19 period. ${ }^{6}$

\section{ritual aspects of care}

- During advance care planning conversations, it is advisable to pay attention to personal values, desired ritual or spiritual practices surrounding the end of life (which may also include funeral or memorial plans) osing a suitable course of action 14,19

- Connect people with dementia and their families to resources that may support them in their spiritual needs or needs surrounding postdeath planning and that may provide additional (grief) support using telehealth services. ${ }^{1,14}$

- Consider calling in a chaplain or spiritual caregiver to support people with dementia at the end of life and their families during the dying process. ${ }^{5}$ Spiritual support is particularly essential in the complex times of COVID-19, regardless of whether the person with dementia is dying from COVID-19.

Additional recommendations for people with dementia who have COVID-19

- Be mindful of the burden of decision-making for people with dementia who contract COVID-19 themselves their families and their formal caregivers. Feelings of abandonment and moral distress may arise, which may cause complicated grief in families and burnout in nursing staff.2 


\section{Table 4 (continued).}

\section{Care of the dying}

- It is important that nursing staff can identify when a person's death is imminent. ${ }^{1,17}$ Three or more of the

following symptoms likely indicate a terminal phase in persons with COVID-19:

Experiencing rapid day to day and irreversible deterioratio

Completely bedbound, requiring frequent intervention

Becoming less conscious, with lapses into unconsciousness, diminished or absent response to voices Unable to swallow

Diminished or no urine secretion

An acute event happened that required revision of care goals

Profound weakness

Changing breathing pattern

Gurgling or rattly breathing

Changing body temperature (hot and clammy, or cold)

Pale or mottled skin

- If a person with dementia approaches the end of life, nursing staff may advocate for offering families the opportunity to say goodbye in person, despite potential visiting bans due to COVID-19.,21 In the termina phase, talk to the person and his or her family and address the person's comfort. ${ }^{1}$

- If family members are unable to visit in person, use technology to enable a connection between the dying person and his or her family.

- Involve families as much as possible if a person with dementia is nearing the end of life (regardless of whether they have COVID-19), also if they cannot be present in person. Provide information every step of the way and ask for ideas on how to arrange a peaceful death, tailored to the dying person.

- In times of COVID-19, be mindful of rituals that may enable persons with dementia and their families to say goodbye properly (either in person or at a distance). ${ }^{5}$ Nursing staff can contribute to a peaceful death, even in complex times. Consider the following tips:

Rituals for saying goodbye at the end of life should be tailored to the individual to be meaningful. Try to align with the specific life view or religion of the dying person.

You may speak to the dying person, even if they have advanced cognitive impairments and are unaware of the situation. For instance, explain to the person that the moment has come to say goodbye, while trying to maintain a sense of calm and peace.

You may speak to the dying person about their family members and others with whom the person had a conection For instance, ask the dying person to think of or imagine these others. You may ask the dying person what he or she wants to say to them. If a person cannot speak, consider shoring your own thought and feelings. By doing this, you may foster feelings of connectedness, even when family is not present.

family members are present, either in person or via a video call, you may stimulate a joint feeling of connectedness (for instance, by reading a poem, being silent together, saying prayers together singing or humming, listening to music).

\section{Table 4 (continued).}

\section{Bereavement care}

After the death of a person with dementia, inform family members (if they were not present at the momen of death) about the dying process and rituals that were used to foster a peaceful goodbye. ${ }^{5}$ Tell them about any meaningful last words or gestures of their relative. This may enable them to grief their loss in a healthy way.

Consider sharing a dignified photograph of the person with dementia after death with the bereaved family (with their permission). As families may not be present at the time of death, this might be the only visual evidence of the person's death and it may enable emotional relief.

- Nursing staff may advocate for accessing and sharing tools and resources that are needed to mitigate (complicated) grief of families, and to help nursing staff cope with their own grief. For instance, think of communication tools, telehealth services, and nursing staff self-care. ${ }^{14}$

- Be mindful that families bereaved of someone with dementia in times of (and sometimes due to) COVID-19, may feel a range of negative emotions such as abandonment, anger, isolation and loneliness. Families who have not been able to spend time with their relative before death or those who felt unprepared for the loss may have difficulties to come to terms with their loss. ${ }^{10,14,19}$

- Be aware that complicated grief may follow from adverse experiences surrounding the loss. In times of COVID-19, adverse experiences are likely to arise due to the sudden and rapid nature of the infection. ${ }^{10,9}$

- Complicated grief involves recurring intrusive thoughts about the loss, preoccupation with sorrow, ruminating behavior, excessive bitterness, alienation of social contacts, difficulties accepting the loss and information or contact their family doctor if they are concerned about their coping with the loss. ${ }^{10}$

- However, note that not every bereaved family member during the COVID-19 pandemic will experience complicated grief ${ }^{14}$ Nursing staff should explain to families that grieving is normal and that it generally takes time.

- Tell bereaved family members to look after themselves by considering the following tips: ${ }^{10}$

Think of the basics: eat well, stay hydrated, exercise regularly, try to maintain your usual routine. Stay connected (digitally) and talk to others about how you are doing.

Allow yourself to experience nesative emotions: it takes time to come to terms with a loss and the grieving process may fluctuate over time.

Ethical aspects of care

Be aware that in the context of COVID-19, decision-making can be particularly challenging, which may induce moral distress. Moral distress arises when internal or external constraints prevent us from doing what we think is morally right. ${ }^{14}$ Moral and emotional distress may lead to burnout and unresolved grief in professional caregivers and families. ${ }^{14,19}$

- Nurses are often trained to place the patients' well-being above their own feelings. However, self-awarenes in care staff and dealing with one's own emotions and thoughts during care provision in times of the COVID-19 pandemic is imperative to the provision of care that meets ethical standards for persons with dementia and their families. ${ }^{14}$

- To deal with stress and loss during the COVID-19 pandemic, consider the following tips for self-care: ${ }^{14}$ Disconnect from the disaster event by allowing yourself to take breaks (and deep breaths) occasionally.

Facilitate your own role during COVID-19 by making sure you feel prepared and informed. Make sure you know local resources and services to which you may refer for additional suppor a for adequate supervision to facilitate your decisions an responses. 
Table 4 (continued).

\section{Structure and processes of care}

The health condition may deteriorate quickly in COVID-19 patients and people with and without COVID-19 may have unmet palliative care needs as professionals may be unable to prescribe in times of limited resources. It is advisable to consider anticipatory prescription: arrange and document prescriptions in advance. Nursing staff may advocate for collaboration with family doctors and local pharmacists to ensure timely availability of required palliative medication and equipment and to keep anticipatory stocks. ${ }^{3.7}$

- Note that residents with symptoms of COVID-19 must be isolated in a separate room or on a COVID-19 cohort unit immediately. ${ }^{22}$ Nursing staff may advocate for the implementation of strict infection prevention measures in their organization (such as wearing personal protective equipment including masks, goggles, a gown and gloves). $14,4,15$

- It is advisable for nursing staff who have been in contact with infected persons to be tested if they

experience symptoms and to self-quarantine in case they test positive. ${ }^{4}$

- To reduce the chances of viral outspread, it is advisable that nursing staff do not work in multiple facilities and restrict movement between facilities. ${ }^{1}$

- Nursing staff may collaborate with specialized (mobile) palliative care teams, if available, to provide the necessary support and care for persons with dementia. ${ }^{3}$ Consider consulting a palliative care physician or geriatrician via phone or telehealth to assist the identification of the terminal phase.

- Nursing staff may advocate for or contribute personally to the tailoring of information materials (such as behavioral impairments. ${ }^{12}$

- During this pandemic, it is important to have supportive and visible nursing leadership in long-term care. ${ }^{1}$ Nurses should advocate for their role as leaders and supervisors to optimize the quality of care, to increase adherence to prevention and control measures and to support their peers.

- Nursing staff should address their needs with regard to specific information about risks and guidelines on protective measures when providing palliative and end-of-life care under COVID-19.9

- Nursing staff may advocate for setting up a 24-hour palliative care hotline, to give advice and answers to people with dementia and their families. ${ }^{21}$

* Referencing numbers correspond with the overview of included documents in Table 3.

\section{REFERENCES}

1. World Health Organization. Rolling updates on coronavirus disease (COVID-19) 2020 [updated 7 May 2020; cited 8 May 2020]. Available from: https://www.who.int/emergencies/diseases/novelcoronavirus-2019/events-as-they-happen

2. Worldometers. CoviD-19 Coronavirus pandemic 2020 [cited 15 July 2020]. Available from: https://www. worldometers.info/coronavirus/

3. Onder G, Rezza G, Brusaferro S. Case-Fatality Rate and Characteristics of Patients Dying in Relation to COVID-19 in Italy. Jama. 2020.

4. Shams SA, Haleem A, Javaid M. Analyzing COVID-19 pandemic for unequal distribution of tests, identified cases, deaths, and fatality rates in the top 18 countries. Diabetes Metab Syndr. 2020;14(5):953-61.

5. Ferguson N, Laydon D, Nedjati Gilani G, Imai N, Ainslie K, Baguelin M, et al. Report 9: Impact of nonpharmaceutical interventions (NPIs) to reduce COVID19 mortality and healthcare demand. 2020 [cited 6 July 2020]. Available from: https://www.imperial.ac.uk/media/imperial-college/medicine/mrcgida/2020-03-16-COVID19-Report-9.pdf

6. Bauer K, Schwarzkopf L, Graessel E, Holle R. A claims data-based comparison of comorbidity in individuals with and without dementia. BMC Geriatrics. 2014;14(1):10.

7. Clarfield AM, Dwolatzky T, Brill S, Press Y, Glick S, Shvartzman P, et al. Israel ad hoc CovID 19 committee. Guidelines for care of older persons during a pandemic. J Am Geriatr Soc. 2020.

8. Brown EE, Kumar S, Rajji TK, Pollock BG, Mulsant BH. Anticipating and Mitigating the Impact of the COVID-19 Pandemic on Alzheimer's Disease and Related Dementias. Am J Geriatr Psychiatry. 2020.

9. Atkins JL, Masoli JAH, Delgado J, Pilling LC, Kuo C-LC, Kuchel G, et al. Preexisting comorbidities predicting severe COVID-19 in older adults in the UKBiobankcommunity cohort. medRxiv. 2020:2020.05.06.20092700.

10. Gardner W, States D, Bagley N. The Coronavirus and the Risks to the Elderly in Long-Term Care. J Aging Soc Policy. 2020;32(4-5):310-5.

11. Livingston G, Weidner W, Alzheimer's Disease International. COVID-19 and dementia: Difficult decisions about hospital admission and triage. 2020 [cited 15 April 2020]. Available from: https://www.alz.co.uk/ news/adi-releases-position-paper-on-covid-19-and-dementia

12. Doupe M, Brownell M, St. John P, Strang DG, Chateau D, Dik N. Nursing Home Adverse Events: Further Insight into Highest Risk Periods. J Am Med Dir Assoc. 2011;12(6):467-74.

13. Froggatt $\mathrm{K}$, Edwards M, Morbey H, Payne S. Mapping palliative care systems in long term care facilities in Europe. PACE work package. 2016;1 [cited 6 July 2020]. Available from: https://www.eapcnet.eu/ Portals/0/adam/Content/xwkGGSw2ykCLpHNMPZRxkA/Text/WP1_EAPC\%20report\%20Feb_25 2016. pdf

Seitz D, Purandare N, Conn D. Prevalence of psychiatric disorders among older
homes: a systematic review. International Psychogeriatrics. 2010:22(7):1025-39.

. Wang $\mathrm{H}, \mathrm{Li}$ T Barbarin $\mathrm{P}$. Cauthier S. Brodaty $\mathrm{H}$ Molinuevo JL, et al. Dementia care during COVID-19. Lancet. 2020;395(10231):1190-1.

16. Velayudhan $L$ Aarsland $D$. Ballard $C$. Mental health of people living with dementia in care homes during CoviD-19 pandemic. Int Psychogeriatr. 2020:1-2.

17. Leigh-Hunt N, Bagguley D, Bash K, Turner V, Turnbull S, Valtorta N, et al. An overview of systematic reviews on the public health consequences of social isolation and loneliness. Public Health. 2017;152:157-71.

8. Sutin AR, Stephan Y, Luchetti M, Terracciano A. Loneliness and Risk of Dementia. J Gerontol B Psychol Sci Soc Sci. 2018.

19. Kolanowski A, Boltz M, Galik E, Gitlin LN, Kales HC, Resnick B, et al. Determinants of behavioral and psychological symptoms of dementia: A scoping review of the evidence. Nurs Outlook. 2017;65(5):515-29. 20. Canevelli M, Bruno G, Cesari M. Providing Simultaneous COVID-19-sensitive and Dementia-Sensitive Care as We Transition from Crisis Care to Ongoing Care. J Am Med Dir Assoc. 2020;21(7):968-969.

21. Zuidema SU, de Jonghe JF, Verhey FR, Koopmans RT. Environmental correlates of neuropsychiatric symptoms in nursing home patients with dementia. Int J Geriatr Psychiatry. 2010;25(1):14-22.

22. van der Steen JT, Radbruch L, Hertogh CM, de Boer ME, Hughes JC, Larkin P, et al. White paper defining optimal palliative care in older people with dementia: a Delphi study and recommendations from the

23. Reyniers T, Deliens L, Pasman HR, Morin L, Addington-Hall I, Frova L, et al. International Variation in Place 
of Death of Older People Who Died From Dementia in 14 European and non-European Countries. J Am Med Dir Assoc. 2015;16(2):165-71

24. Birch D, Draper J. A critical literature review exploring the challenges of delivering effective palliative care Dith dementia. J Clin Nurs. 2008;17(9):1144-63.

25. Bolt SR, van der Steen JT, Schols JMGA, Zwakhalen SMG, Pieters S, Meijers JMM. Nursing staff needs in providing palliative care for people with dementia at home or in long-term care facilities: A scoping review. Int J Nurs Stud. 2019,96:143-52.

, Manthorpe J, Vernooij-Dassen M, Iliffe S. Barriers to the provision of high-quality palliative care for people with dementia in England: a qualitative study of professionals' experiences. Health Soc Care Community. 2014;22(4):386-94.

27. Ryan T, Gardiner C, Bellamy G, Gott M, Ingleton C. Barriers and facilitators to the receipt of palliative care for people with dementia: The views of medical and nursing staff. Palliat Med. 2012;26(7):879-86.

28. Nicholls D, Chang E, Johnson A, Edenborough M. Touch, the essence of caring for people with end-stage dementia: A mental health perspective in Namaste Care. Aging Ment Health. 2013;17(5):571-8,

9. Lapid MI, Koopmans R, Sampson EL, Van den Block L, Peisah C. Providing quality end of life care to older people in the era of COVID-19: Perspectives from five countries. Int Psychogeriatr. 2020:1-18.

30. British Geriatrics Society. COVID-19: Managing the COVID-19 pandemic in care homes for older people. 2020 [cited 27 March 2020]. Available from: https://www.bgs.org.uk/resources/covid-19-managing-thecovid-19-pandemic-in-care-homes

31. Moore KJ, Sampson EL, Kupeli N, Davies N. Supporting families in end-of-life care and bereavement in the COVID-19 Era. Int Psychogeriatr. 2020:1-10

32. Gordon AL, Goodman C, Achterberg W, Barker RO, Burns E, Hanratty B, et al. Commentary: CovID in Care Homes-Challenges and Dilemmas in Healthcare Delivery. Age Ageing. 2020:afaa113.

33. Peters MD, Godfrey CM, McInerney P, Soares CB, Khali H, Parker D, et al. The Joanna Briggs Institute Reviewers' Manual 2015. Methodology for JBI Scoping Reviews. Adelaide, Australia: The Joanna Briggs Institute; 2015.

34. Arksey H, O'Malley L. Scoping studies: towards a methodological framework. Int J Soc Res Methodol. 2005;8(1):19-32.

35. Levac D, Colquhoun H, O'Brien KK. Scoping studies: advancing the methodology. Implement Sci. 2010;5(1):69.

36. Lockwood C, dos Santos KB, Pap R. Practical Guidance for Knowledge Synthesis: Scoping Review Methods. Asian Nurs Res. 2019;13(5):287-94.

37. Tricco AC, Lillie E, Zarin W, O'Brien KK, Colquhoun H, Levac D, et al. PRISMA Extension for Scoping Reviews (PRISMA-ScR): Checklist and Explanation. Ann Intern Med. 2018;169(7):467-73.

38. Ferrell BR, Twaddle ML, Melnick A, Meier DE. National consensus project clinical practice guidelines for quality palliative care guidelines. J Palliat Med. 2018;21(12):1684-9.

39. Borasio GD, Gamondi C, Obrist M, Jox R, For The Covid-Task Force Of Palliative C. CovID-19: decision making and palliative care. Swiss Med Wkly. 2020;150:w20233.

40. D’Adamo H, Yoshikawa T, Ouslander JG. Coronavirus Disease 2019 in Geriatrics and Long-Term Care: The ABCDs of COVID-19. J Am Geriatr Soc. 2020.

41. Kunz R, Minder M. COVID-19 pandemic: palliative care for elderly and frail patients at home and in residential and nursing homes. Swiss Med Wkly. 2020;150:w20235.

42. Wallace CL, Wladkowski SP, Gibson A, White P. Grief During the CoVID-19 Pandemic: Considerations for Palliative Care Providers. J Pain Symptom Manage. 2020.

43. Dementia Australia. Coronavirus (COVID-19) Tips for residential aged care providers 2020 [cited 29 April 2020]. Available from: https://www.dementia.org.au/files/helpsheets/DA COVID19 Helpsheet 02 residential_care_providers_FA-v4.pdf

44. Kaserer L, Hofland B. Handleiding voor afscheidsrituelen in de buitengewone situatie van de Coronaviruscrisis. 2020 [cited 27 March 2020]. Available from: https.//zingevingondekaart n/ files/200000154 7a4de 7a4e1/RK\%20afscheidsrituelen-7 pdf

45. The Irish Hospice Foundation. Ackowledging and coping with grief from a COVID-19 death. 2020 [cited 30 April 2020]. Available from: https://hospicefoundation.ie/bereavement-2-2/covid19-care-and-inform/ acknowledging-and-coping-with-grief-from-a-covid-19-death/

46. The Scottish Government. National Clinical and Practice Guidance for Adult Care Homes in Scotland during the COVID-19 Pandemic. 2020 [cited 18 May 2020]. Available from: https://www.gov.scot/binaries/ content/documents/govscot/publications/advice-and-guidance/2020/03/coronavirus-covid-19clinical-and-practice-guidance-for-adult-care-homes/documents/clinical-guidance-for-nursing-homeand-residential-care-residents/clinical-guidance-for-nursing-home-and-residential-care-residents/ scot\%3Adocument/National\%2BClinical\%2BGuidance \%2Bfor\%2BCare\%2BHomes\%2BCOVID9\%2BPandemic-\%2BMASTER\%2BCOPY\%2B-\%2BFINAL\%2B-\%2B15\%2BMay\%2B2020.pdf

47. Victoria State Government. Coronavirus disease 2019 (COVID-19): Recognising and responding to a person at the end of life. 2020 [cited 18 May 2020]. Available from: https://www.dhhs.vic.gov.au/recognisingand-responding-at-the-end-of-life-COVID-19

48. Eghtesadi M. Breaking Social Isolation Amidst COVID-19: A Viewpoint on Improving Access to Technology In Long-Term Care Facilities. J Am Geriatr Soc. 2020;68(5):949-950.

49. Husebo BS, Berge LI. Intensive Medicine and Nursing Home Care in Times of SARS CoV-2: A Norwegian Perspective. Am J Geriatr Psychiatry. 2020;28(7):792-793

50. Padala SP, Jendro AM, Orr LC. Facetime to reduce behavioral problems in a nursing home resident with Alzheimer's dementia during COVID-19. Psychiatry Res. 2020;288:113028.

51. Wang SSY, Teo WZY, Yee CW, Chai YW. Pursuing a Good Death in the Time of CoVID-19. J Palliat Med. 2020;23(6):754-755

52. Bauer A. COVID19: Providing palliative care for the many. Article in LTCcovis.org. International LongTerm Care Policy Network, CPEC-LSE. 2020 [cited 17 April 2020]. Available from: https://ttccovid. org/2020/03/31/covid19-proving-palliative-care-for-the-many/

53. Russell S. British Geriatrics Society. 2020 [cited 17 April 2020]. Available from: https://www.bgs.org.uk/ blog/covid-19-supporting-and-caring-from-afar

54. Bauer A, Dixon J, Comas-Herrera A. End-of-life support for people in care homes in the context of CoviD-19: international report. International Long-Term Care Policy Network, CPEC-LSE, 2020 [cited 19 May 2020]. Available from: https://tccovid.org/wp-content/uploads/2020/05/Palliative-care-in-care-homes-andCOVID-1-May-2020.pdf

55. European Academy of Neurology. Dementia Scientific Panel Report - COVID-19 2020 [cited 30 April 2020]. Available from: https://www.eanpages.org/2020/04/03/dementia-scientific-panel-report-covid-19/

56. Hashimie J, Schultz SK, Stewart JT. Palliative Care for Dementia: 2020 Update. Clin Geriatr Med. 2020;36(2):329-39.

57. Senderovich H, Retnasothie S. A systematic review of the integration of palliative care in dementia management. Palliat Support Care. 2019:1-12

58. Barclay L. Age, dementia and the allocation of health resources during and beyond COVID-19. 2020 [cited 6 July 2020]. Available from: https://www.alz.co.uk/sites/default/files/pdfs/Age-dementia-and-theallocation-of-health-resources-during-and-beyond-COVID-19.pdf

59. Downar J, Seccareccia D. Palliating a pandemic: "all patients must be cared for". J Pain Symptom Manage. 2010;39(2):291-5.

60. Powell RA, Schwartz L, Nouvet E, Sutton B, Petrova M, Marston J, et al. Palliative care in humanitarian crises: always something to offer. Lancet. 2017;389(10078):1498-9.

61. Rosoff PM. A central role for palliative care in an influenza pandemic. J Palliat Med. 2006;9(5):1051-3.

62. Etkind SN, Bone AE, Lovell N, Cripps RL, Harding R, Higginson IJ, et al. The Role and Response of Palliative Care and Hospice Services in Epidemics and Pandemics: A Rapid Review to Inform Practice During the COVID-19 Pandemic. J Pain Symptom Manage. 2020;60(1):e31-e40.

63. Arya A, Buchman S, Gagnon B, Downar J. Pandemic palliative care: beyond ventilators and saving lives. Canadian Medical Association Journal. 2020;192(15):E400.

64. The Lancet. Palliative care and the COVID-19 pandemic. Lancet. 2020;395(10231):1168. homes leaves key themes unaddressed. J Pain Symptom Manage. 2020;60(2):e56-e69.

66. Sellars M, Chung D, Nolte L, Tong A, Pond D, Fetherstonhaugh D, et al. Perspectives of people with dementia and carers on advance care planning and end-of-life care: A systematic review and thematic synthesis of qualitative studies. Palliat Med. 2019;33(3):274-90.

67. Parsons JA, Johal HK. Best interests versus resource allocation: could COVID-19 cloud decision-making for the cognitively impaired? J Med Ethics. 2020;46(7):447-450.

68. Radbruch L, Knaul FM, de Lima L, de Joncheere C, Bhadelia A. The key role of palliative care in response to the COVID-19 tsunami of suffering. Lancet. 2020;395(10235):1467-9.

69. Brennan F. Palliative Care as an International Human Right. J Pain Symptom Manage. 2007;33(5):494-9. 
70. Fraser S, Lagace M, Bongue B, Ndeye N, Guyot J, Bechard L, et al. Ageism and CovID-19: What does our society's response say about us? Age Ageing. 2020;49(5):692-695.

71. McGilton KS, Bowers BJ, Heath H, Shannon K, Dellefield ME, Prentice D, et al. Recommendations From the Thernational Consortium on Professional Nursing Practice in Long-Term Care Homes. J Am Med Dir Assoc. (2016;17(2):99-103.

72. Moore KJ, Crawley S, Vickerstaff V, Cooper C, King M, Sampson EL. Is preparation for end of life associated with pre-death grief in caregivers of people with dementia? Int Psychogeriatr. 2020;32(6):753-763.

7. Chan D, Livingston G, Jones L, Sampson EL. Grief reactions in dementia carers. a systematic review. Int Geriatr Psychiatry. 2013;28(1):1-17

74. Nielsen MK, Neergaard MA, Jensen AB, Bro F, Guldin M-B. Do we need to change our understanding of anticipatory grief in caregivers? A systematic review of caregiver studies during end-of-life caregiving and .

75. Stroebe MS, Folkman S, Hansson RO, Schut H. The prediction of bereavement outcome: Development of an integrative risk factor framework. Soc Sci Med. 2006;63(9):2440-51.

76. Otani H, Yoshida S, Morita T, Aoyama M, Kizawa Y, Shima Y, et al. Meaningful Communication Before Death, but Not Present at the Time of Death Itself, Is Associated With Better Outcomes on Measures of Depression and Complicated Grief Among Bereaved Family Members of Cancer Patients. J Pain Symptom Manage. 2017;54(3):273-9.

77. Shore JC, Gelber MW, Koch LM, Sower E. Anticipatory Grief: An Evidence-Based Approach. J Hosp Palliat Nurs. 2016;18(1). 


\section{CHAPTER 5}

Families' experiences with end-of-life care in nursing homes and associations with dying peacefully with dementia 


\section{ABSTRACT}

Objectives

To examine family caregivers' experiences with end-of-life care for nursing home residents with dementia and associations with the residents dying peacefully.

\section{Design}

A secondary data analysis of family caregiver data collected in the observational Dutch End of Life in Dementia (DEOLD) study between 2007 and 2010 .

\section{Setting and Participants}

Data were collected at 34 Dutch nursing homes (2799 beds) representing the nation. We included 252 reports from bereaved family members of nursing home residents with dementia.

\section{Measures}

The primary outcome was dying peacefully, assessed by family members using an item from the Quality of Dying in Long Term Care (QOD-LTC) instrument. Unpleasant experiences with end-of-life care were investigated using open-ended questions. Overall satisfaction with end-of-life care was assessed with the End-of-Life Satisfaction With Care (EOLD-SWC) scale, and families' appraisal of decision-making was measured with the Decision Satisfaction Inventory. Associations were investigated with multilevel linear regression analyses using generalized estimating equations.

\section{Results}

Families' reports of unpleasant experiences translated into two themes: neglect and lack of respect. Neglect involved facing inaccessibility, disinterest, or discontinuity of relations, and negligence in tailored care and information. Lack of respect involved perceptions of being purposefully disregarded, an insensitive approach towards resident and family, noncompliance with agreements, and violations of privacy. Unpleasant experiences with end-of-life care were negatively associated with families' perceptions of the resident dying peacefully. Families' assessment of their relative dying peacefully was positively associated with satisfaction with end-of-life care and decision-making.

\section{Conclusions/Implications}

Families' reports of unpleasant experiences with end-of-life care may inform practice to improve perceived quality of dying of their loved ones. Humane and compassionate care and attention from physicians and other staff for resident and family may facilitate recollections of a peaceful death.

\section{INTRODUCTION}

Families of people with dementia fulfil an important caregiving role that usually continues after nursing home admission. ${ }^{1}$ Dementia may inflict anticipatory grief in families before actual bereavement because of the cognitive and functional deterioration associated with the disease. ${ }^{2,3}$ Families' grief reactions before and after bereavement are influenced by the extent to which families are satisfied with end-of-life care and their experiences around the final days of life of their relative with dementia. ${ }^{2,3}$ Caregiver burden and distress in family caregivers have been described mainly in relation to earlier stages of dementia and community settings.,

In most Western countries, the majority of people with dementia eventually die in nursing homes or other long-term care facilities. ${ }^{6}$ Families of people with dementia are often involved in healthcare decision-making because of their relatives' cognitive impairments. ${ }^{7}$ Especially at the end of life, surrogate decision-makers may face ethical challenges receiving insufficient guidance from health care professionals and experiencing uncertainty regarding the wishes of their loved one..$^{8}$ Offering emotional support and information to families is particularly important in caring for individuals with dementia at the end of life. ${ }^{9-11}$

An indicator for quality of dying in long-term care settings is dying peacefully. ${ }^{12}$ Peaceful dying involves spiritual well-being and meaningfulness of life, ${ }^{12}$ which may be reflected in calmness, nearness to one's beloved, and experiences of inner harmony. ${ }^{13}$ Spiritual and emotional support may offer consolation and aid families to find comfort and peace beyond the painfulness of losing a loved one with dementia. ${ }^{14}$

Previous research indicated that only half of the people with dementia in long-term care facilities died peacefully according to their relatives. ${ }^{13,15}$ De Roo and colleagues ${ }^{13}$ found that dying peacefully was related to the residents' optimism and families' perception that enough nurses were available in the nursing home. However, families' own experiences with the provision of care may contribute to their perceptions of a peaceful death of their loved one and have not been studied extensively. ${ }^{11,15}$ Therefore, the current study aims to investigate unpleasant experiences with end-oflife dementia care and associations with dying peacefully.

\section{METHODS}

A secondary data analysis was performed using data from the Dutch End of Life in Dementia (DEOLD) study. ${ }^{16}$ This study investigated families' and physicians' perceptions of the quality of dying of nursing home residents with dementia, families' satisfaction with end-of-life care and decision-making, and the factors associated with these outcomes. The protocol of the DEOLD study received approval from the Medical 


\section{Study design, setting and data collection}

A purposive sample of nursing homes was recruited across all provinces to represent the nation, seeking variability in family caregivers' publicly available ratings of quality of care. ${ }^{16}$ Data were collected between 2007 and 2010, by physician teams of 17 Dutch nursing home organizations. The teams covered 34 facilities (2799 beds). Questionnaires were completed by families 2 months after the death of the resident.

\section{Population}

Family caregivers were eligible if (1) their relative resided on a psychogeriatric ward in a participating nursing home, (2) their relative was diagnosed with dementia by a physician, and (3) they were able to understand and write Dutch or English. ${ }^{16}$

\section{Measures}

Demographic variables included resident's age at death, gender, and type of dementia, participant's age, gender, and level of education, family relationship, and time spent (by the family member) with the resident in the final week of life.

Dying peacefully was a primary outcome, measured with an item from the Quality of Dying in Long-Term Care instrument. ${ }^{13,17}$ This item concerned the last month of life and was measured on a 5-point Likert-type scale, with higher scores indicating a more peaceful death. Analyzing associations with comfort measured with the Comfort Assessment in Dying (EOLD-CAD) scale had been planned, as it is a valid and reliable measure for quality of dying. ${ }^{18}$ However, we refrained from the analysis because when the family was not present at the moment of death, a skip pattern resulted in missing values and low power.

Two open-ended questions were used inquiring about the occurrence of insufficient care or any unpleasant experiences in the care during the last week of life:

1) If anything else was missing in the care provided to your loved one and to you, could you describe what was most important? Did this (also) concern care in the last week of life?

2) Did you have any unpleasant experiences with the care provided to your loved one and to you? (Yes, namely: ...) Did this (also) concern care in the last week of life?

Independent variables included families' after-death appraisal of the decision-making process and decisions that were made within the last 6 months before death, measured with the Decision Satisfaction Inventory, and satisfaction with care in the last week of life assessed with the End-of-Life Satisfaction With Care (EOLD-SWC) scale. ${ }^{16}$ The Decision Satisfaction Inventory is a reliable and valid instrument ${ }^{19}$ and the EOLD-SWC scale $^{20}$ has shown excellent psychometric properties. ${ }^{18}$ On both instruments, higher

\section{Analyses}

Descriptive statistics of demographic data and the other variables of interest were generated using IBM SPSS statistics version 24.0 (IBM Corp, Armonk, NY). Answers to the open-ended questions were analyzed using thematic analysis. ${ }^{21}$ Two authors (L.V. and J.T.S.) read answers thoroughly to familiarize themselves with the data. The authors initially performed open coding and independently coded the answers. Next, the authors compared their independent coding series, broadening initial codes. Any discrepancies were discussed to reach consensus and to fine-tune individual codes and categories. Lastly, axial coding clustered the main categories into the ultimate themes. A native English speaker checked the translation of themes and citations.

Multilevel linear regression analyses were conducted using the generalized estimating equations method to investigate associations between families' unpleasant experiences with care, their overall satisfaction with care, and their satisfaction with the decisionmaking process and care decisions, and dying peacefully. Population-average models were estimated, ${ }^{22}$ using an independent correlation structure, and clustering of residents within different care facilities was accounted for. If less than one third of the items on the SWC or Decision Satisfaction Inventory missed, the resident's total score was calculated after imputation with the resident's mean item score. Missing values in the control variables were handled using multiple imputation. ${ }^{23}$ Five datasets were imputed using a fully conditional specification method. Demographic variables were entered into adjusted models to control for possible confounding. We performed sensitivity analyses to examine if associations were stable over time by also adjusting for time of death. For the adjusted models, pooled estimates were calculated from the imputed data sets.

\section{RESULTS}

In total, family members of 252 residents completed the after-death assessment (Table 1). The participants' mean age was 60.8 (standard deviation $=11.1$, range 35.8, 90.0); $61.1 \%$ were female. The mean age at death of their relatives with dementia was 85.6 (standard deviation $=7.2$, range $46.5,100.9$ ); $66.3 \%$ were female .

Of the 252 family members, $42(17.0 \%)$ reported 1 or more unpleasant experiences with care during the last week of their relative's life. Two main themes represented the experiences. Theme 1, "neglect", emerged from 34 (13.5\% of the total) cases. Theme 2, "lack of respect", emerged from 16 (6.3\%) cases. 
Table 1. Characteristics of family members and residents

\begin{tabular}{|c|c|c|c|}
\hline & Count (n) & Percentage (\%) & Missing (\%) \\
\hline \multicolumn{4}{|l|}{ Family characteristics } \\
\hline Gender & & & 0 \\
\hline Female & 154 & 61.1 & \\
\hline Male & 98 & 38.9 & \\
\hline Highest completed education & & & 1.6 \\
\hline None or primary/elementary school & 16 & 6.5 & \\
\hline (high school preparing for) Technical/trade school & 130 & 51.6 & \\
\hline High school preparing for BSc or MSc & 27 & 10.7 & \\
\hline BSc or MSc degree & 75 & 29.8 & \\
\hline Family relation with resident & & & 1.2 \\
\hline Son or daughter & 153 & 61.0 & \\
\hline Partner or spouse & 49 & 19.5 & \\
\hline Cousin & 15 & 6.0 & \\
\hline Brother or sister & 6 & 2.4 & \\
\hline Representative & 3 & 1.2 & \\
\hline Grandson or daughter & 2 & 0.8 & \\
\hline Other & 23 & 9.2 & \\
\hline Time spent with resident during the last week of life & & & 0 \\
\hline None & 8 & 3.2 & \\
\hline$\leq 7$ hours & 46 & 18.3 & \\
\hline 8 to 14 hours & 34 & 13.5 & \\
\hline 15 to 21 hours & 39 & 15.5 & \\
\hline $22-28$ hours & 37 & 14.7 & \\
\hline$\geq 28$ hours & 88 & 34.9 & \\
\hline \multicolumn{4}{|l|}{ Resident characteristics } \\
\hline Gender & & & 0 \\
\hline Female & 167 & 66.3 & \\
\hline Male & 85 & 33.7 & \\
\hline Type of dementia & & & 2.4 \\
\hline Alzheimer's & 100 & 40.7 & \\
\hline Vascular & 67 & 27.2 & \\
\hline Alzheimer and vascular & 42 & 17.1 & \\
\hline Lewy body & 15 & 6.1 & \\
\hline Other combinations & 22 & 8.9 & \\
\hline Dying peacefully ${ }^{13}$ & & & 7.5 \\
\hline Completely & 72 & 30.9 & \\
\hline Quite a bit & 59 & 25.3 & \\
\hline A moderate amount & 42 & 18.0 & \\
\hline A little & 35 & 15.0 & \\
\hline Not at all & 25 & 10.7 & \\
\hline Measures* & M & SD & \\
\hline EOLD-SWC, Satisfaction with care † & 32.5 & 5.4 & 2.8 \\
\hline \multicolumn{4}{|l|}{ DSI \# } \\
\hline Satisfaction with decision-making process & 67.7 & 18.7 & 8.7 \\
\hline Satisfaction with decisions & 75.6 & 19.7 & 9.0 \\
\hline
\end{tabular}

Table 2 shows examples of family caregivers' reports that formed the main themes and subthemes. Neglect refers to families' experiences of professional caregivers' negligence in providing tailored care for their relative and providing information about their relatives' disease or process of dying. Moreover, this theme entails a perceived lack of contact with professional caregivers, perceptions of not being properly informed to understand care or treatment, dissatisfaction with communication between staff, and perceptions of shortages on staff and time. Reports regarding this theme of neglect often involved physicians being considered inaccessible and uninvolved or physicians' shift changes. The second theme, lack of respect, involves families' experiences of their relative or themselves not being treated respectfully, or insensitively by health care staff, their relatives' and their own privacy being violated, noncompliance of staff with agreements about care and treatment, and perceptions of being purposefully disregarded.

Table 3 shows that there were significant associations between dying peacefully and families' satisfaction with care $(B=.09, p<.001)$, satisfaction with the decision-making process $(B=.04, p=.002)$, satisfaction with decisions $(B=.15, p=.001)$, and unpleasant experiences with care in the final week of the residents' life $(B=-.74, p=.016)$. In the adjusted models, significant associations remained between the variables of interest and dying peacefully. When all variables of interest were entered to compete in a fully adjusted model, only the significant association with overall satisfaction with care with dying peacefully remained $(B=.10,95 \%$ confidence interval $=.05, .16$, standard error $=.03, p<.001$ ). The coefficients were similar in the sensitivity analyses, which suggests the associations did not change over time. 
Table 2. Example quotes from participants per theme and subtheme describing insufficient care or unpleasant experiences with care.

\section{Main theme and subthemes}

Neglect

Care or treatment not understood Example quotes from participants

"We think that the morphine should have been increased earlier."

"A night shift [nurse] was a bit too casual (in my opinion] about structurally administering morphine."

Not properly informed

"Better counselling regarding people with dementia, further explanations about medication." [missed from physicians]

Poor communication between healthcare professionals/staff between shifts

"It is a very delicate matter that everyone receives and provides the same information. This might be tricky at times, but it is important."

"The one thing that bothers me is that there had been no information transfer from Sunday night to Monday that my mother was dying."

Suboptimal care and treatment

"In the final days, mother became extremely dehydrated; dry and painful mouth, I had to buy Q-tips with glycerin and lemon myself."

My mother in law experienced a lot of pain during the final months; the physician had difficulty finding out why; [resident] received painkillers but that was not enough."

Lack of contact with care providers

"The only time I met the physician associated with [name of

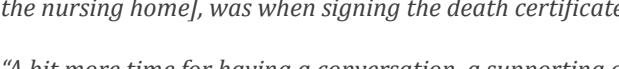
kind word. They tried very hard, but more staff is required."

Shortage on staff/time

\section{Lack of respect}

Violation of privacy

"My father had to share his room with someone else. It was only on Saturday night, prior to the Monday he passed away, that he was given a separate room."

"This was shared with us in the hallway, in the presence of other visitors."

"Communicating with some more respect and compassion." "In the final week of my father's life, a deputy physician the fact that it was previs that this would not happen anymore.

"I indicated several times that my father in law did not handle medication such as haloperidol well at all, following previous experiences with the consequences. It was
Table 3. Adjusted and unadjusted associations with dying peacefully

\begin{tabular}{|c|c|c|c|}
\hline & Unadjusted & \multicolumn{2}{|l|}{ Adjusted } \\
\hline & $\mathrm{B}(95 \% \mathrm{CI})$ & $\mathrm{B}(95 \% \mathrm{CI})$ & $\mathrm{N}$ \\
\hline \multicolumn{4}{|l|}{ Satisfaction with care } \\
\hline (EOLD-SWC)* & $.09(.06 ; .12) \dagger$ & $.08(.05 ; .11) \dagger$ & 228 \\
\hline Satisfaction with decisions (DSI)* & $.15(.07 ; .24) \neq$ & $.16(.07 ; .24) \dagger$ & 122 \\
\hline Satisfaction with the decision-making process & & & \\
\hline$(\mathrm{DSI})^{*}$ & $.04(.01 ; .06) \neq$ & $.04(.01 ; .07) \ddagger$ & 121 \\
\hline Any unpleasant experiences & $-.75(-1.34 ;-.14) \S$ & $-.73(-1.37 ;-.09) \S$ & 229 \\
\hline - Neglect & $-.66(-.1 .22 ;-.11) \S$ & $-.66(-1.22 ;-.09) \S$ & 229 \\
\hline - Lack of respectful treatment & $-.83(-1.54 ;-.13) \S$ & $-.65(-1.47 ; .16)$ & 229 \\
\hline
\end{tabular}

\section{CI: Confidence Interval}

The adjusted models included the variables: resident's age at death, gender, and type of dementia, participant's age, gender, and level of education, family relationship, and time spent (by the family member) with the resident in the final week of life. The outcome measure dying peacefully involves the final month of life. EOLD-SWC scores involve satisfaction with care during the final week of the resident's life. DSI scores involve satisfaction with the decision and the decision-making process when a decision was being made in the final 6 months of the resident's life (57.8\%). Any unpleasant experiences refer only to the final week of the resident's life.

* The coefficient estimates are per unit increase of the independent variable.

$\dagger$ Significant at $p<.001$

$¥$ Significant at $p<.005$

$\S$ Significant at $p<.05$

\section{DISCUSSION}

Families of nursing home residents with dementia essentially complained about 2 issues in the care of their loved one at the end of life: a feeling that they or -mostly- their loved one was being neglected, and a feeling they were treated in a disrespectful manner. Families reporting unpleasant experiences were more likely to believe that their relative did not die peacefully. Slightly more than half of the family members indicated that their relative had died peacefully. ${ }^{13}$ Our findings suggest that satisfaction with care and decision-making and experiencing neglect or a lack of respect in the last week of life impact on how peaceful dying had been according to bereaved family caregivers. Families' satisfaction with care was strongly associated with dying peacefully and as a broad measure assessed with the EOLD-SWC, with excellent psychometric properties, ${ }^{18}$ likely incorporates experiences with care and decision-making.

In line with our findings, Hennings and colleagues ${ }^{11}$ found in their review that families witnessing the end of life of a loved one with dementia in nursing homes need supportive communication, adequate information, and sufficient attention from professional caregivers. Furthermore, although perceived staff shortage is a source of concern, ${ }^{13,24}$ families tend to sympathize with nursing staff. ${ }^{24,25}$ In our study, unpleasant experiences with care often involved physicians' inaccessibility and changes in physicians responsible for the care. Boogaard and colleagues ${ }^{26}$ found that satisfaction 
with care relates to families' trust in professional caregivers in Israel, and that families trust physicians more than nurse aides. Perhaps families' strong trust in physicians and their expectations cause disappointment when their needs for guidance and support are not met, especially at the end of life. ${ }^{25}$ Conversely, available and easily accessible physicians may allow for developing a relationship, promoting more pleasant experiences with care. This corresponds with previous findings indicating that Dutch and US physicians who are present longer in the nursing home are more likely to be aware of family preferences and to honor these preferences. ${ }^{27}$

Perceived abandonment of people with dementia living in nursing homes may not be limited to the final phase, and preserving personhood in dementia care is a virtuous pursuit. ${ }^{28}$ Families may experience emotional disruption and helplessness when sensitive, humane attention for a dying loved one is missed. Dedicated, involved physicians and other staff; genuine, respectful and sensitive attention; and continuity in care and communication may facilitate families of nursing home residents dying with dementia experience peace for both themselves and their loved ones. At the end of caring for a loved one with dementia and having dealt with multiple losses, recollections of a peaceful death may offer consolation.

\section{Strengths and limitations}

There is a dearth of literature on factors contributing to people with dementia dying peacefully. ${ }^{15}$ To our knowledge, this is the first study to investigate families' specific experiences with end-of-life care in relation to their judgment of a relative with dementia dying peacefully. It is important to understand families' needs in their own right. The DEOLD data represented nationwide data from nursing home residents with dementia. ${ }^{16}$ Four researchers were involved in the analysis. We used a single item from the Quality of Dying in Long-term Care instrument as the outcome measure. The outcomes represent families' judgment only. The qualitative analysis in this study was limited to analysis of open-ended items in an otherwise large questionnaire; and some responses were brief.

\section{Conclusion and implications}

Families' unpleasant experiences with end-of-life care relate to perceptions of a less peaceful death of their loved one with dementia. Overall, these unpleasant experiences concern disappointment through the absence of humane, compassionate care and attention for a loved one nearing death. Evaluating family members' experiences with end-of-life care is valuable in both research and practice, as their perspectives may create awareness among healthcare professionals and inform strategies for improving care provision in nursing homes. Responding to the families' needs may improve perceived quality of dying of residents with dementia.

\section{REFERENCES}

1. Brodaty H, Donkin M. Family caregivers of people with dementia. Dialogues Clin Neurosci. 2009;11(2):217 28

2. Kiely DK, Prigerson H, Mitchell SL. Health care proxy grief symptoms before the death of nursing home residents with advanced dementia. Am J Geriatr Psychiatry. 2008;16(8):664-73.

3. Arruda EH, Paun O. Dementia Caregiver Grief and Bereavement: An Integrative Review. West J Nurs Res. 2017;39(6):825-51.

4. Davies N, Maio L, Rait G, Iliffe S. Quality end-of-life care for dementia: What have family carers told us so far? A narrative synthesis. Palliat Med. 2014;28(7):919-30.

5. Gessert CE, Forbes S, Bern-Klug M. Planning end-of-life care for patients with dementia: roles of families and health professionals. Omega (Westport). 2000;42(4):273-91.

6. Houttekier D, Cohen J, Bilsen J, Addington-Hall J, Onwuteaka-Philipsen BD, Deliens L. Place of death of older persons with dementia. A study in five European countries. J Am Geriatr Soc. 2010;58(4):751-6.

7. Shanley C, Fetherstonhaugh D, McAuliffe L, Bauer M, Beattie E. Providing support to surrogate decisionmakers for people living with dementia: Healthcare professional, organisational and community responsibilities. Health Soc Care Community. 2017;25(5):1563-70

8. Givens JL, Kiely DK, Carey K, Mitchell SL. Healthcare proxies of nursing home residents with advanced dementia: decisions they confront and their satisfaction with decision-making. J Am Geriatr Soc. 2009;57(7):1149-55.

9. van der Steen JT, Radbruch L, Hertogh CM, de Boer ME, Hughes JC, Larkin P, et al. White paper defining optimal palliative care in older people with dementia: a Delphi study and recommendations from the European Association for Palliative Care. Palliat Med. 2014;28(3):197-209.

10. Durepos P, Wickson-Griffiths A, Hazzan AA, Kaasalainen S, Vastis V, Battistella L, et al. Assessing Palliative Care Content in Dementia Care Guidelines: A Systematic Review.J Pain Symptom Manage. 2017;53(4):804-

11. Hennings J, Froggatt K, Keady J. Approaching the end of life and dying with dementia in care homes: the accounts of family carers. Rev Clin Gerontol. 2010;20(2):114-27.

12. van Soest-Poortvliet MC, van der Steen JT, Zimmerman S, Cohen LW, Munn J, Achterberg WP, et al. Measuring the Quality of Dying and Quality of Care When Dying in Long-Term Care Settings: A Qualitative Content Analysis of Available Instruments. J Pain Symptom Manage. 2011;42(6):852-63.

13. De Roo ML, van der Steen JT, Galindo Garre F, Van Den Noortgate N, Onwuteaka-Philipsen BD, Deliens L, et al. When do people with dementia die peacefully? An analysis of data collected prospectively in long-term care settings. Palliat Med. 2014;28(3):210-9.

14. Slape J. Dementia and palliative care: The spiritual needs of family members. J Relig Spiritual Aging. 2014;26(2-3):215-30.

15. De Roo ML, Albers G, Deliens L, de Vet HC, Francke AL, Van Den Noortgate N, et al. Physical and Psychological Distress Are Related to Dying Peacefully in Residents With Dementia in Long-Term Care Facilities. J Pain Symptom Manage. 2015;50(1):1-8.

16. van der Steen JT, Ribbe MW, Deliens L, Gutschow G, Onwuteaka-Philipsen BD. Retrospective and prospective data collection compared in the Dutch End Of Life in Dementia (DEOLD) study. Alzheimer Dis Assoc Disord. 2014;28(1):88-94.

17. Munn JC, Zimmerman S, Hanson LC, Williams CS, Sloane PD, Clipp EC, et al. Measuring the Quality of Dying in Long-Term Care. J Am Geriatr Soc. 2007:55(9):1371-9.

18. van Soest-Poortvliet MC, van der Steen JT, Zimmerman S, Cohen LW, Reed D, Achterberg WP, et al. Selecting the best instruments to measure quality of end-of-life care and quality of dying in long term care. J Am Med Dir Assoc. 2013;14(3):179-86

19. Barry MJ, Walker-Corkery E, Chang Y, Tyll LT, Cherkin DC, Fowler FJ. Measurement of overall and diseasespecific health status: does the order of questionnaires make a difference? J Health Serv Res Policy. 1996;1(1):20-7.

20. Volicer L, Hurley AC, Blasi ZV. Scales for evaluation of End-of-Life Care in Dementia. Alzheimer Dis Assoc Disord. 2001;15(4):194-200 
21. Braun V, Clarke V. Using thematic analysis in psychology. Qual Res Psychol. 2006;3(2):77-101.

22. Hubbard AE, Ahern J. Fleischer NL, Van der Laan M, Lippman SA, Jewell N, et al. To GEE or not to GEE: comparing population average and mixed models for estimating the associations between neighborhood risk factors and health. Epidemiology. 2010;21(4):467-74.

23. Eekhout I. Don't Miss Out! Incomplete data can contain valuable information (Doctoral dissertation, Vrije Universiteit Amsterdam). 2015.

24. Givens JL, Lopez RP, Mazor KM, Mitchell SL. Sources of stress for family members of nursing home residents with advanced dementia. Alzheimer Dis Assoc Disord. 2012;26(3):254-9.

25. Shield RR, Wetle T, Teno J, Miller SC, Welch L. Physicians “Missing in Action”: Family Perspectives on Physician and Staffing Problems in End-of-Life Care in the Nursing Home. J Am Geriatr Soc. 2005;53(10):1651-7.

26. Boogaard JA, Werner P, Zisberg A, van der Steen JT. Examining trust in health professionals among family caregivers of nursing home residents with advanced dementia. Geriatr Gerontol Int. 2017;17(12):2466-

27. Helton MR, Cohen LW, Zimmerman S, van der Steen JT. The Importance of Physician Presence in Nursing Homes for Residents with Dementia and Pneumonia. J Am Med Dir Assoc. 2011;12(1):68-73.

28. Gjødsbøl IM, Koch L, Svendsen MN. Resisting decay: On disposal, valuation, and care in a dementia nursing home in Denmark. Soc Sci Med. 2017:184:116-23. 


\section{CHAPTER 6}

What do relatives value most in end-oflife care for people with dementia?

Sascha R Bolt Jenny T van der Steen Jos MGA Schols Sandra MG Zwakhalen Judith MM Meijers 


\section{ABSTRACT}

\section{Background}

End-of-life care for older people with dementia is often sub-optimal. Understanding the experiences of the relatives involved in the care of the person with dementia may help to improve care practice.

Aims

To investigate relatives' experiences with end-of-life care for people with dementia, comparing the nursing home and home setting.

\section{Methods}

In-depth interviews were conducted with 32 individuals who were bereaved of someone with dementia. Thematic analysis was performed to identify main themes from the data.

\section{Findings}

Experiences translated into four themes: acknowledging human dignity; being recognized as an important caregiver; (not) talking about death and dying, and making decisions together. A lack of person-centered care was mainly evident in nursing homes. Relatives took on a more prominent role in the care of the older person with dementia when the relative was cared for in a home setting and this involvement in the care of the older person was something that the relatives valued. Surrogate decision-making induced similar challenges in both settings.

\section{Conclusion}

It is important that healthcare professionals inform and support relatives to help them make decisions about end-of-life care and preferences. Nursing homes should learn to offer the same standard of person-centered care as a home care setting, and ensure that relatives are still involved in the care of the person with dementia.

\section{INTRODUCTION}

Comfort goals of care for older people with dementia, congruent with a palliative approach $^{1}$ contribute to greater satisfaction with end-of-life care among family caregivers. ${ }^{2}$ Comfort care goals are primarily aimed at maintaining the well-being and quality of life of the individual. In the Netherlands, a palliative approach to care is generally accepted for people with dementia and the majority of residents with dementia in Dutch nursing homes have comfort care goals. ${ }^{3}$

However, palliative care for people with dementia is often suboptimal ${ }^{4,5}$ as poor symptom management, little attention for psychosocial and spiritual needs, and burdensome treatments are widespread. ${ }^{6-8}$

Due to cognitive decline which is associated with dementia, family caregivers often become surrogate decision-makers. ${ }^{9}$ They may feel unequipped if they are unaware of their loved one's wishes and uninformed about both the disease and its prognosis. ${ }^{10-12}$ Early communication with an individual that involves their relatives is essential for people with dementia in palliative care. Discussing the individual's wishes for future care may support end-of-life decision-making ${ }^{13}$ decreasing the burden on surrogate decision-makers. ${ }^{14}$ It is fundamental to consider loves ones' satisfaction with end-of-life care, as this may affect the extent, duration and intensity of their grief. ${ }^{15}$ Moreover, their experiences may reveal areas for improvement for the palliative care team.

In many Western countries, the deaths of people with dementia often occur in longterm care facilities. ${ }^{16}$ At the same time, policies encourage older people to live in their own homes for as long as possible. ${ }^{6}$ The relatives of older people with dementia have a crucial caregiving role at home ${ }^{17}$ which continues after the person with dementia has moved to a nursing home. ${ }^{18}$ Given practical, organizational, and emotional differences between the home and nursing home settings, relatives' experiences with care in general may differ. ${ }^{19}$ Whereas home care professionals visit at specified times, nursing home staff (and other residents) are constantly nearby, and all must adhere to the institute's policy. Nursing home residences which have 24 hour surveillance and controlled outdoor access may increase residents' perceptions of safety, but this security may also raise concerns about the autonomy of the people who are being cared for ${ }^{20}$ and their connection to other people, which is the opposite of social isolation and loneliness. ${ }^{21}$

This study explores relatives' experiences with care for people with dementia in the final months of life to identify similarities and differences between experiences in the nursing home and home setting. This has received minimal attention in the literature at present. Understanding relatives' experiences with end-of-life care may support tailored future practices. 


\section{METHODS}

The study is part of the Desired Dementia Care Towards End of Life (DEDICATED) project carried out in The Living Lab in Ageing and Long-Term Care in South Limburg. ${ }^{22}$ Data collection involved semi-structured, in-depth interviews. A critical realist approach was adopted using Fletcher's framework to explore participants' subjective experiences of objective, real-world events. ${ }^{23}$ Adopting critical realism, initially theory and literature regarding end-of-life care guided the research question, data collection and analysis. In analyzing data and reporting results, the authors sought for elements that supported, elaborated or denied the theoretical starting point.. ${ }^{23}$ The consolidated criteria for reporting qualitative research (COREQ) checklist was used for reporting in the study. ${ }^{24}$

\section{Sample}

Combined criterion and snowball sampling ${ }^{25}$ was used to recruit relatives of people with dementia who had received (nursing home or home) care from one of three longterm care organizations in South Limburg, the Netherlands. The authors aimed to attain a sample that varied in terms of the participants' gender, age, and level of education.

\section{Recruitment}

Nurses from the collaborating organizations approached eligible participants (Table 1). With the participant's consent, the researcher called to provide information and to ask permission to send an elaborate information letter. A second phone call followed one week after they had received the letter to ask if the individual was interested and to schedule the face-to-face interview. Ethical approval was obtained before undertaking this study from the Research Ethics Committee (Zuyderland, METCZ20180026). All participants gave written informed consent for taking part in this study.

\section{Table 1. Eligibility criteria}

\begin{tabular}{|c|c|}
\hline Inclusion & Exclusion \\
\hline $\begin{array}{l}\text { - Bereaved of someone with dementia } \\
>6 \text { weeks }<12 \text { months before giving consent to } \\
\text { participate }\end{array}$ & $\begin{array}{l}\text { - Aged }<18 \\
\text { - Insufficient understanding of the Dutch language or } \\
\text { Dutch dialect } \\
\text {. Physically/psychologically incapable to particinate in }\end{array}$ \\
\hline $\begin{array}{l}\text { - First contact person/most closely involved } \\
\text { - Age at death of loved one with dementia } \geq 65\end{array}$ & $\begin{array}{l}\text { - Physically/psychologically incapable to participate in } \\
\text { an interview }\end{array}$ \\
\hline
\end{tabular}

\section{Data collection}

Instruments/measures

An interview guide was developed incorporating questions concerning end-of-life care based on existing guidelines for palliative (dementia) care and relevant literature. 1,26,27
A working group of healthcare professionals and patient representatives judged face validity and evaluated interview questions. Three pilot interviews were conducted with representatives who had once lost a loved one with dementia to test feasibility. With the participant's consent, these interviews were merely used as a rehearsal for the study and were not included in the analysis. Background demographic variables were collected at the start of each interview. Additional information on whether the person with dementia had transitioned from one care setting to another and whether death was expected was collected during the interview.

\section{Procedure}

We conducted interviews from March through June 2018. The interviews took place at the participant's home, the care organization or the university, according to the participant's preference. Three (female, MSc) researchers trained in performing qualitative interviews (SP and LV with a nursing background, SB with a background in neuropsychology) took turns interviewing. One researcher led the interview; the second researcher observed and asked additional questions. The interviews were audio-recorded.

\section{Data analyses}

IBM SPSS Statistics 25 was used for descriptive statistics. Interview recordings were transcribed verbatim. Transcripts were not returned to participants for correction. Interview data was managed and stored using NVivo 11. Thematic analysis adopting Braun \& Clarke's paradigm ${ }^{28}$ was used to analyze the data. Fletcher's framework ${ }^{23}$ informed the application of critical realism in the analysis. Accordingly, a combined theory-driven and data-driven approach was used to extract content from the transcripts. Provisional codes drawn from the literature underlying our research question were changed, elaborated, or discarded through data-driven coding. ${ }^{23}$ One third of the transcripts were coded independently by three researchers (LV, SB and SP) to create an initial overview. Codes were compared and discussed to create a refined list of aggregate codes. Subsequently, two authors (SB and SP) continued coding independently. Coding was constantly compared, allowing cross-validation in the interpretation and to cluster codes into categories. The authors discussed and refined categories to form overarching themes. Triangular analysis and researchertriangulation increased rigor and credibility. ${ }^{29}$ Data saturation was reached when no additional codes emerged to inform new categories..$^{30}$ Finally, all authors agreed on the detailed description of themes. Participants were not approached to check findings considering the specificity of their experiences and possible lack of exposure to the other care setting. 


\section{RESULTS}

A total of 32 participants were interviewed (Table 2). Another 13 individuals refused, with reasons: 'not interested' or that the 'topic was too sensitive'. Participants' mean age was 62 $(\mathrm{SD}=9.3$, range 44-87). The mean age at death of the persons with dementia was 87 (SD = 6.3, range 70-97). The average duration of interviews was 92 minutes (range 64-139).

Table 2. Characteristics of participants

\begin{tabular}{|c|c|c|}
\hline & $\mathrm{N}^{\mathrm{a}}$ & $\%$ \\
\hline \multirow{2}{*}{\multicolumn{3}{|c|}{ Participant characteristics }} \\
\hline & \multicolumn{2}{|c|}{ Gender } \\
\hline Male & 10 & 31 \\
\hline Female & 22 & 69 \\
\hline \multicolumn{3}{|l|}{ Familial relation } \\
\hline Partner & 3 & 9 \\
\hline Son or daughter (in law) & 23 & 72 \\
\hline Brother or sister (in law) & 1 & 3 \\
\hline Niece or nephew & 3 & 9 \\
\hline Ex husband & 1 & 3 \\
\hline Friend & 1 & 3 \\
\hline \multicolumn{3}{|l|}{ Highest level of education } \\
\hline (High school preparing for) Technical/trade school & 20 & 62 \\
\hline High school preparing for BSc or MSc & 4 & 13 \\
\hline BSc or MSc degree & 8 & 25 \\
\hline Characteristics resident/client & $\mathrm{N}^{\mathrm{a}}$ & $\%$ \\
\hline \multicolumn{3}{|l|}{ Gender } \\
\hline Male & 9 & 28 \\
\hline Female & 23 & 72 \\
\hline \multicolumn{3}{|l|}{ Primary place of care } \\
\hline Nursing home & 24 & 75 \\
\hline Home & 8 & 25 \\
\hline \multicolumn{3}{|l|}{ Place of death } \\
\hline Nursing home & 25 & 78 \\
\hline Home & 4 & 13 \\
\hline Hospital & 3 & 9 \\
\hline \multicolumn{3}{|l|}{ Transfer in last 3 months of life } \\
\hline No & 20 & 62 \\
\hline Yes & 12 & 38 \\
\hline \multicolumn{3}{|l|}{ Death expected } \\
\hline No & 11 & 34 \\
\hline Yes & 21 & 66 \\
\hline \multicolumn{3}{|l|}{ Duration of care/length of stay } \\
\hline $0-6$ months & 8 & 25 \\
\hline 7-12 months & 3 & 9 \\
\hline 1 to 2 years & 12 & 38 \\
\hline 2 to 5 years & 9 & 28 \\
\hline
\end{tabular}

${ }^{a}$ Frequencies of most characteristics were approximately equal in both settings. Substantial differences included inverted ratios of female-male resident/client (males prevailed in home care), death being expected ('not expected' prevailed in home care), and any transitions in the final three months ('yes' prevailed in home care). Moreover, half of all home care clients eventually died elsewhere.

'The duration of care refers to the actual period of care received at home from a formal home care organization. Length of stay refers to the period of care received in the nursing home, from admission until death.
Interview data translated into four themes (Table 3). This section describes relatives' experiences supported by quotations and concludes with a brief comparison between the nursing home $(\mathrm{NH})$ and home care $(\mathrm{HC})$ setting.

\section{Acknowledging human dignity}

Perceived authentic, personal attention

Interviewees in both settings valued a personal approach in the care provided to their relative. This involved professional caregivers' effort to offer individualized care and to take account of their relative's preferences.

'Well, this pudding, she really enjoyed, so they would immediately put five more in the fridge, you know.' (Niece, $\mathrm{NH}$ )

Dealing with the person with dementia when they resisted care or showed restlessness in a comforting manner was regarded as important, and participants valued the professionals' undivided attention and efforts to connect with their loved one.

'The nursing staff really sat down to talk (...) he had plenty of stories about

Africa, where he had lived and worked for ten years.' (Niece, $H C$ )

Other positive accounts involved professionals' understanding of subtle individual care needs.

'This - I would say - 'friend' of mom, she talked to her like "are you in pain, madam? Do we need to increase it [medication]?" and the look in her eyes said enough, and then medication was increased.' (Daughter, $\mathrm{NH}$ )

Losing sight of the unique person

An impersonal approach in nursing homes sometimes troubled relatives. Perceptions involved an absence of compassionate care and negligence in comfort and personal hygiene.

My mother was basically blind and deaf, so suddenly being grabbed and dressed without knowing what's going on, well, I would find that very unpleasant.' (Daughter, $\mathrm{NH}$ )

Further, relatives were also disappointed at a lack of meaningful activities for residents and professionals' inattention to personal impairments. Sometimes inattention raised concerns about nutrition and hydration. However, relatives of individuals who were being cared for at home were mostly positive about professionals approaching their 


\section{Being acknowledged as an important caregiver}

Being informed, involved, and heard

Positive accounts of the care that a person with dementia received featured collaboration with the healthcare professionals delivering the care, such as receiving information and feedback. Especially in the nursing home, relatives mentioned that they appreciated that they were being kept informed. The relatives of individuals who were receiving home care mostly spoke of satisfying collaboration with nursing staff and mentioned examples of ways that the nursing staff were focused on individualized care.

'So there was this book, the file, in which everyone wrote their findings. (...) so you could always check, ah, this and that has happened.'(Daughter-in-law, HC)

Being involved in care and feeling heard by healthcare professionals was valued in both home care and residential care settings for relatives. Although participants appreciated being respected as a contributor to care, in both settings, some indicated that they were not the ones 'in charge' of care as they respected the expertise of professionals.

Being emotionally supported

In both settings, the importance of receiving emotional support from professionals was addressed. According to the interviewees, feeling emotionally supported depended on professionals' personal characteristics. Participants from nursing homes particularly valued emotional support surrounding the death of their relative.

I started crying out and immediately, a nurse would take me in her arms, hold me and say: "it's alright, I understand, let it go'”' (Daughter, NH)

As informal caregivers, participants from home care felt supported when professionals kept an eye on their well-being.

I have to say, a few times a week they really took time to talk to me, saying "you should go walk the dog; we are here now."' (Wife, HC)

Feeling set aside as a member of the care team

Perceptions of being left out as a caregiver were predominantly an issue in the nursing home, reflected by dissatisfaction about involvement in care and not being heard. Furthermore, some felt frustrated about not receiving information.

I think we were insufficiently informed about the running of things, what
The weight of informal caregiving

Most participants, in both settings, acknowledged that they fulfilled a substantial role in caregiving.

'You are in it 24/7, thinking "what will tomorrow bring?" Or "will they call today?" That is way more tiring than ploughing soil.' (Ex-husband, NH)

Half of the participants from nursing homes reported that they had to put in disproportionate effort to get things done. Overall, relatives from home care were more neutral or positive about their role and did not mind taking initiative. Some experienced pride with what they had accomplished in their caring role.

"For my father, I have been a caregiver for 3 years and 3 months, 24/7, so I

have lived through it all." (Son, $H C$ )

\section{(Not) talking about death and dying}

A note unsaid

Almost half the participants indicated that their loved one had not spoken about death and dying with them in the past.

'He -with L., that was not something to discuss. You could not talk about death with L.' (Wife, HC)

Different reasons were mentioned for not discussing end-of-life wishes. Some stated that it was their relatives' generation not to discuss the end of life, or that they 'were just not thinking about it'. One woman did not talk with her husband about the end of his life to protect him.

I have never spoken with him about it. Also, I never told him he had dementia

I just couldn't, you know. I would just leave him be.' (Wife, HC)

Besides unclear end-of-life communication among relatives, there were accounts of unclear communication by professionals in both settings. This led to relatives lacking information or experiencing miscommunication about palliative care and the dying process, causing feelings of uncertainty, frustration, or disappointment. Some felt unprepared for the death of their loved one.

'It would have been nice if at some point they had explicitly said "your mother 
is in this stage and this is what we can offer." (...) May be others appreciate such indirect communication, but not me.' (Daughter, $\mathrm{NH}$ )

Clear messages concerning death

A majority of participants indicated that at some point, their loved one expressed having had 'enough of it', referring to a desire for the end of life. Some voiced this over a longer period or had living wills.

'We had a euthanasia request, my husband and I, a living will. (...) My husband himself declared [later on, in the nursing home] that he was done with it.' (Wife, $\mathrm{NH}$ )

However, for others involved in the study, wishes were declared 'in the heat of the moment', when a care decision had to be made. Most of the participants recalled discussing resuscitation or other treatment options among themselves or with professionals. In both settings, clear end-of-life communication with professionals involved being sufficiently informed about what to expect in the final phase and being actively engaged in decision-making:

II was there with my youngest sister when the medication [morphine] was administered and he [physician] explained very sensibly how it [sedation] worked (...). A very pleasant young man.' (Niece, $\mathrm{NH}$ )

\section{Making decisions - together}

\section{Confidence at decision-making}

In both settings, open discussion with professionals aided decision-making about endof-life care. Therein, participants refer to 'being on the same page' with professionals, other relatives, or the persons with dementia themselves.

All of us simply agreed, and that is what she [mother] wanted as well, saying "there is no need for that." At some point, she was done with living anyway. (Son, NH)

Some experienced confidence in decision-making because their loved one had explicitly expressed end-of-life wishes previously. Nonetheless, even when end-of-life wishes had never been discussed, some still felt confident with decision-making.

'So I discussed this with my brothers and sister, and they were all in tune, so we decided no, let's just focus on comfort now, we will not put her through that [medical treatment].' (Daughter, $\mathrm{NH}$
What is the right thing to do?

The difficulty that relatives faced when making surrogate decisions was addressed by healthcare professionals in both the nursing home and home care setting. This mostly concerned relatives who indicated they had not discussed end-of-life wishes with the person with dementia, which led them to questioning the 'moral rightness' of their decisions. Nonetheless, in some instances, even though wishes were expressed, relatives still doubted the morality of their decision.

And then it all starts: what do you do? Do you want to... you know? She had chest pain, which is really agonizing, so actually you would want to help her get rid of that. But she had this living will saying no life-prolonging treatments. (Son, $\mathrm{NH}$ )

Never wished for this

Some relatives (mainly from nursing homes) experienced frustration when, despite knowing their relatives' wishes or their own wishes for them, these were not fulfilled. Some thought this negatively affected the quality of life of their loved one. Institutional policy or perceived incompetence of healthcare professionals sometimes caused frustration. Some referred to existing living wills that were deemed invalid.

'I said, "she filled in a euthanasia declaration once", but that was not valid anymore. Well, that's tragic. You can't just leave someone lying there, right?' (Daughter, $\mathrm{NH}$

\section{Comparison}

Overall, a personal approach to care was valued by relatives. However, person-centered care was not as apparent in the nursing home setting as it was to the relatives of someone being cared for at home. Nevertheless, in both settings, participants valued an acknowledgement of their caregiving role by healthcare professionals. Relatives took on a more prominent role and position within the care team at home and appreciated their caregiving role more compared to relatives of someone who was being cared for at a nursing home. When the person with dementia was cared for in a nursing home, relatives could feel left out of the care team. End-of-life communication and decisionmaking brought forth similar (moral) challenges for both settings. In such circumstances, clear and ongoing communication with healthcare professionals was valued and this facilitated relatives' confidence in decision-making. Particularly in nursing homes, frustration arose from occasional non-compliance with end-of-life wishes. 
Table 3. Overview of main themes and subthemes

\begin{tabular}{|c|c|c|c|}
\hline $\begin{array}{l}\text { Acknowledging human } \\
\text { dignity }\end{array}$ & $\begin{array}{l}\text { Being recognized as an } \\
\text { important caregiver }\end{array}$ & $\begin{array}{l}\text { (Not) talking about death } \\
\text { and dying }\end{array}$ & $\begin{array}{l}\text { Making decisions } \\
\text { together }\end{array}$ \\
\hline $\begin{array}{l}\text { Perceived authentic, } \\
\text { personal attention } \\
\text { - Losing sight of the unique } \\
\text { person }\end{array}$ & $\begin{array}{l}\text { Being informed, } \\
\text { involved, and heard } \\
\text { - Being emotionally } \\
\text { supported } \\
\text { - Feeling set aside as a } \\
\text { member of the care } \\
\text { team } \\
\text { - The weight of informal } \\
\text { caring }\end{array}$ & $\begin{array}{l}\text { - A note unsaid } \\
\text { Clear messages } \\
\text { concerning death }\end{array}$ & $\begin{array}{l}\text { - Confidence at decision- } \\
\text { making } \\
\text { - What is the right thing } \\
\text { to do? } \\
\text { - Never wished for this }\end{array}$ \\
\hline
\end{tabular}

\section{DISCUSSION}

This study investigated relatives' experiences with end-of-life care for people with dementia and compared the nursing home and home setting. Overall, it is clear that participants in the study experienced predominately positive end-of-life care for their relative, as healthcare professionals were sympathetic to their needs when caring for the person with dementia.

Both in the nursing home and home setting, relatives valued authentic, compassionate attention. This is in line with previous work that emphasizes the importance of personcentered dementia care. ${ }^{1,31}$ Person-centered care involves acknowledging personhood and addressing needs through understanding the unique individual. ${ }^{32}$ Although this also involves addressing physical or medical needs, ${ }^{1}$ the interviewees' reports primarily concerned psychosocial aspects of care.

However, participants reported that there was a perceived lack of personcenteredness in the nursing home. Nursing home residents' personal living space is continuously accessible for staff. As a result of this, privacy can be limited. Nursing homes may be perceived as institutions housing people, rather than true homes by the relatives of people with dementia. ${ }^{33}$ Moreover, families may perceive meaningful activities matching the residents' prior interests - which enhanced quality of life at home, to be lacking in comparison. ${ }^{34}$ Recent studies emphasize the need for professionals to familiarize themselves with residents with dementia to enhance engagement in activities tailored to individual backgrounds. ${ }^{35}$ Our findings underline that a personalized approach in the nursing home should receive more attention.

Another difference between the two settings concerned the caregiving role of the relatives interviewed. Being acknowledged as a part of the care team was valued in both settings. Yet, relatives providing care at home were generally more positive, considering themselves the primary caregiver and as though they fulfilled a central role within the care team. In the nursing home, relatives attempted to advise, steer, or assist the primary care team. Feelings of being responsible for adequate caregiving sometimes caused frustration, and relatives experienced feelings of defeat when their efforts to increase the resident's well-being were discarded. Relatives' transition to a new role once the person with dementia has been admitted into a care home may be challenging. ${ }^{36}$ Nonetheless, some interviewees experienced feeling grateful to have a reduced burden of care and being able to trust the nursing home professionals. Correspondingly, previous findings on the effect of nursing home placement on caregiver burden are equivocal. ${ }^{18,37}$ This study found that relatives appreciated being emotionally supported by professionals. Nurturing trustful and supportive care relationships may increase staffs' positive attitudes towards family involvement. ${ }^{38}$ Moreover, improving relationships stimulates personalized care, as relatives are an important source of information about 'the person behind the disease'. ${ }^{35}$

Relatives from both home and nursing home settings emphasized the importance of healthcare professionals providing sufficient information at the end of life, alongside providing ongoing discussions of the situation, which corresponds to previous findings..$^{39,40}$ This is in line with advance care planning (ACP) defined as a continuous, dynamic conversation. ${ }^{41}$ ACP for people with dementia may reduce burdensome interventions and unnecessary medical treatments. ${ }^{42}$ However, in this study, almost half of the relatives who participated found that they could not discuss death and dying with the person with dementia. Prior research emphasizes early end-of-life communication with people with dementia. ${ }^{41}$ Not discussing end-of-life care in a timely manner may ultimately disenable surrogate decision-makers. ${ }^{9}$ From the results of this study, this was found to apply only in some cases. Moreover, not talking about death with the person with dementia did not always induce uncertainty in decision-making for relatives. Further, moral challenges surrounding decision-making sometimes remained even if wishes had been discussed. This suggests that the relationship between endof-life communication and decision-making is not straightforward. At least from the relative's perspective, having supportive and informative conversations with healthcare professionals may compensate for the absence of pronounced wishes of the person with dementia. This notion requires further research.

Indirect or incomplete communication by professionals did raise uncertainty, and left some participants in the study feeling unprepared for bereavement. Professionals may feel uncomfortable talking about the impending death, or feel that it is not their responsibility. ${ }^{12}$ Insufficient explanation from healthcare professionals and a resulting lack of knowledge for relatives about dementia and the dying process have been noted previously as encumbering surrogate decision-making. ${ }^{11}$ In this study, the failure of healthcare professionals or the nursing home setting to comply with endof-life wishes sometimes caused frustration. Open communication about expectations and clarification of what care can and cannot be offered might aid understanding and reduce feelings of frustration. 


\section{Limitations}

A relatively large number of participants who were invited to be part of the study ultimately refused participation. This may have caused selection bias, suggesting that individuals who did participate, were not fully representative of the population under investigation. Nonetheless, reasons for refusal were not distinctly negative or positive. Some of the persons with dementia were transferred to a different care setting for a short period, and four of them died there. Thus, experiences with end-of-life care in these cases were not limited to one setting. However, the interviews and the analysis focused on the nursing home or home setting as the primary place of care in the last three months. The distribution of participants who were recruited from either a home care or nursing home setting was uneven. Nonetheless, sufficient data saturation was achieved for both settings. The researchers' own backgrounds and viewpoints may have influenced interviewing, analysis and interpretation of findings. However, triangulation and frequent discussion between the researchers strengthened the rigor of the analysis.

\section{Conclusion}

This study suggests that lessons can be learned from comparing the nursing home and home setting concerning relatives' experiences with end-of-life care for people with dementia. Nursing home policies should facilitate enhancing care relationships between the healthcare professional, resident and their family, as well as prioritizing person-centered care. Healthcare professionals from both settings should invest time in adequately informing relatives about the disease and dying trajectory and openly discuss care decisions. This may facilitate surrogate decision-making, even in the absence of expressed end-of-life wishes. The impact of a changed role for relatives after a person with dementia has moved to a nursing home should be emphasized in research and practice, discussing their expectations and making clear agreements on the division of caregiving roles. Acknowledging relatives as important members of the healthcare team may facilitate person-centeredness and create a more pleasant caring relationship for both parties.

\section{REFERENCES}

1. van der Steen JT, Radbruch L, Hertogh CM, de Boer ME, Hughes JC, Larkin P, et al. White paper defining optimal palliative care in older people with dementia: a Delphi study and recommendations from the European Association for Palliative Care. Palliat Med. 2014;28(3):197-209.

2. van Soest-Poortvliet MC, van der Steen JT, de Vet HC, Hertogh CM, Deliens L, Onwuteaka-Philipsen BD. Comfort goal of care and end-of-life outcomes in dementia: A prospective study. Palliat Med. 2015;29(6):538-46.

3. Hendriks SA, Smalbrugge M, Deliens L, Koopmans R, Onwuteaka-Philipsen BD, Hertogh C, et al. End-of-life treatment decisions in nursing home residents dying with dementia in the Netherlands. International Journal of Geriatric Psychiatry. 2017;32(12):e43-e9.

4. Dempsey L, Dowling M, Larkin P, Murphy K. The unmet palliative care needs of those dying with dementia. Int J Palliat Nurs. 2015;21(3):126-33.

5. Erel M, Marcus EL, Dekeyser-Ganz F. Barriers to palliative care for advanced dementia: a scoping review. Ann Palliat Med. 2017;6(4):365-79.

6. Lloyd-Williams M, Mogan C, Dening KH. Identifying palliative care needs in people with dementia. Curr Opin Support Palliat Care. 2017;11(4):328-33.

7. Sachs GA, Shega JW, Cox-Hayley D. Barriers to excellent end-of-life care for patients with dementia. J Gen Intern Med. 2004;19(10):1057-63.

8. Volicer L. Medical Issues in Late-Stage Dementia. Alzheimers Care Today. 2005;6(1):29-34.

9. Givens JL, Kiely DK, Carey K, Mitchell SL. Healthcare proxies of nursing home residents with advanced dementia: decisions they confront and their satisfaction with decision-making. J Am Med Dir Assoc. 2009;57(7):1149-55.

10. Caron CD, Griffith J, Arcand M. End-of-life decision making in dementia:The perspective of family caregivers. Dementia (London). 2005;4(1):113-36.

11. Forbes S, Bern-Klug M, Gessert C. End-of-Life Decision Making for Nursing Home Residents with Dementia. J Nurs Scholars. 2000;32(3):251-8.

12. Saini G, Sampson EL, Davis S, Kupeli N, Harrington J, Leavey G, et al. An ethnographic study of strategies to support discussions with family members on end-of-life care for people with advanced dementia in nursing homes. BMC Palliat Care. 2016;15(55):1-12.

13. van der Steen JT. Dying with dementia: what we know after more than a decade of research. J Alzheimers Dis. 2010;22(1):37-55

14. Shanley C, Fetherstonhaugh D, Mcauliffe L, Bauer M, Beattie E. Providing support to surrogate decision-makers for people living with dementia: Healthcare professional, organisational and community responsibilities. Health Soc Care Community. 2017;25(5):1563-70.

15. Kiely DK, Prigerson H, Mitchell SL. Health Care Proxy Grief Symptoms Before the Death of Nursing Home Residents With Advanced Dementia. Am J Geriat Psychiatry. 2008;16(8):664-73.

16. Houttekier D, Cohen J, Bilsen J, Addington-Hall J, Onwuteaka-Philipsen BD, Deliens L. Place of death of older persons with dementia. A study in five European countries. J Am Geriat Soc. 2010;58(4):7516.

17. Laporte Uribe F, Heinrich S, Wolf-Ostermann K, Schmidt S, Thyrian JR, Schäfer-Walkmann S, et al. Caregiver burden assessed in dementia care networks in Germany: findings from the DemNet-D study baseline. Aging Ment Health. 2017;21(9):926-37.

18. Brodaty H, Donkin M. Family caregivers of people with dementia. Dialogues Clin Neurosci. 2009;11(2):217-28

19. Beerens HC, Sutcliffe C, Renom-Guiteras A, Soto ME, Suhonen R, Zabalegui A, et al. Quality of life and quality of care for people with dementia receiving long term institutional care or professional home care: the European RightTimePlaceCare study. J Am Med Dir Assoc. 2014;15(1):54-61.

20. Evans EA, Perkins E, Clarke P, Haines A, Baldwin A, Whittington R. Care home manager attitudes to balancing risk and autonomy for residents with dementia. Aging Ment Health. 2018;22(2):261-9.

21. Nikmat AW, Hawthorne G, Al-Mashoor SH. The comparison of quality of life among people with mild dementia in nursing home and home care--a preliminary report. Dementia. 2015;14(1):114-25. 
22. Verbeek H, Zwakhalen SM, Schols JM, Hamers JP. Keys to successfully embedding scientific research in nursing homes: a win-win perspective. J Am Med Dir Assoc. 2013;14(12):855-7.

23. Fletcher AJ. Applying critical realism in qualitative research: methodology meets method. Int J Soc Res Methodol. 2017;20(2):181-94

24. Tong A, Sainsbury P, Craig J. Consolidated criteria for reporting qualitative research (COREQ): a 32-item checklist for interviews and focus groups. International Journal for Quality in Health Care. 2007;19(6):349-57.

25. Palinkas LA, Horwitz SM, Green CA, Wisdom JP, Duan N, Hoagwood K. Purposeful sampling for qualitative data collection and analysis in mixed method implementation research. Adm Policy Ment Health. 2015;42(5):533-44.

26. IKNL/Palliactief. Kwaliteitskader palliatieve zorg Nederland. 2017.

27. Perrar KM, Schmidt H, Eisenmann Y, Cremer B, Voltz R. Needs of people with severe dementia at the end-of-life: a systematic review. J Alzheimers Dis. 2015;43(2):397-413.

28. Braun V, Clarke V. Using thematic analysis in psychology. Qual Res Psychol. 2006;3(2):77-101.

29. Barbour RS. Checklists for improving rigour in qualitative research: a case of the tail wagging the dog? BMJ. 2001;322(7294):1115-7.

litatief onderzoek: denken en doen: Boom Koninklijke Uitgevers; 2005.

31. Kim SK, Park M. Effectiveness of person-centered care on people with dementia: a systematic review and meta-analysis. Clin Interv Aging. 2017;12:381-97.

32. Kitwood T, Bredin K. Towards a theory of dementia care: personhood and well-being. Ageing Soc. 1992;12:269-87.

33. van Hoof J, Verbeek H, Janssen BM, Eijkelenboom A, Molony SL, Felix E, et al. A three perspective study of the sense of home of nursing home residents: the views of residents, care professionals and relatives. BMC Geriatr. 2016;16:169.

34. Seiger Cronfalk B, Ternestedt B-M, Norberg A. Being a close family member of a person with dementia living in a nursing home. J Clin Nurs. 2017;26(21-22):3519-28.

35. Boumans I, van Boekel LC Baan CA, Luijkx KG. How Can Autonomy Be Maintained and Informal Care Improved for People With Dementia Living in Residential Care Facilities: A Systematic Literature Review. Gerontologist. 2018:gny096.

36. Afram B, Verbeek H, Bleijlevens MHC, Hamers JPH. Needs of informal caregivers during transition from home towards institutional care in dementia: a systematic review of qualitative studies. Int Psychogeriatr. 2015;27(6):891-902.

37. Bleijlevens MH, Stolt M, Stephan A, Zabalegui A, Saks K, Sutcliffe C, et al. Changes in caregiver burden and health-related quality of life of informal caregivers of older people with Dementia: evidence from the European RightTimePlaceCare prospective cohort study. J Adv Nurs. 2015;71(6):1378-91.

38. Maas ML, Reed D, Park M, Specht JP, Schutte D, Kelley LS, et al. Outcomes of family involvement in care intervention for caregivers of individuals with dementia. Nurs Res. 2004;53(2):76-86.

39. Cresp SJ, Lee SF, Moss C. Substitute decision makers' experiences of making decisions at end of life for older persons with dementia: A systematic review and qualitative meta-synthesis. Dementia. 2018;0(0):1-28.

40. McCleary L, Thompson GN, Venturato L, Wickson-Griffiths A, Hunter P, Sussman T, et al. Meaningful connections in dementia end of life care in long term care homes. BMC Psychiatry. 2018;18(1):307.

41. Piers R, Albers G, Gilissen J, De Lepeleire J, Steyaert J, Van Mechelen W, et al. Advance care planning in dementia: recommendations for healthcare professionals. BMC Palliat Care. 2018;17(1):88.

42. Brinkman-Stoppelenburg A, Rietjens JA, van der Heide A. The effects of advance care planning on end-of-life care: a systematic review. Palliat Med. 2014;28(8):1000-25. 


\section{CHAPTER 7}

Trends in quality of care and dying perceived by family caregivers of nursing home residents with dementia between 2005-2019

Maartje S Klapwijk Sascha R Bolt Jannie A (Nienke) Boogaard

Maud ten Koppel Marie-José HE Gijsberts Carolien van Leussen Anne-Mei The Judith MM Meijers Jos MGA Schols Roeline W Pasman, Bregje D Onwuteaka-Philipsen Luc Deliens Lieve Van den Block Bart Mertens Henrica CW de Vet Monique AA Caljouw Wilco P Achterberg Jenny T van der Steen 


\section{ABSTRACT}

\section{Background}

Dementia palliative care is increasingly subject of research and practice improvement initiatives.

\section{Aim}

To assess any changes over time in the evaluation of quality of care and quality of dying with dementia by family caregivers.

\section{Design}

Combined analysis of eight studies with bereaved family caregivers' evaluations 20052019.

\section{Setting/participants}

Family caregivers of nursing home residents with dementia in the Netherlands ( $\mathrm{n}=1189$ ) completed the End-of-Life in Dementia Satisfaction With Care (EOLD-SWC; quality of care) and Comfort Assessment in Dying (EOLD-CAD, four subscales; quality of dying) instruments. Changes in scores over time were analysed using mixed models with random effects for season and facility, and adjustment for demographics, prospective design, and urbanized region.

\section{Results}

The mean total EOLD-SWC score was 33.40 (SD 5.08) and increased by 0.148 points per year ( $95 \%$ CI, 0.052 to 0.244 ; adjusted 0.170 points $95 \% \mathrm{CI}, 0.055$ to 0.258 ). The mean total EOLD-CAD score was 30.80 (SD 5.76) and, unadjusted, there was a trend of decreasing quality of dying over time of -0.175 points ( $95 \% \mathrm{CI},-0.291$ to -0.058$)$ per year increment. With adjustment, the trend was not significant (-0.070 EOLD-CAD total score points, $95 \% \mathrm{CI},-0.205$ to 0.065 ) and only the EOLD-CAD subscale 'Well being' decreased.

\section{Conclusion}

We identified divergent trends over 14 years of increased quality of care, while quality of dying did not increase and well-being in dying decreased. Further research is needed on what well-being in dying means to family. Quality improvement requires continued efforts to treat symptoms in dying with dementia.

\section{INTRODUCTION}

In Western European countries such as the UK and the Netherlands, most people with dementia eventually move to a nursing home, where they reside until death. ${ }^{1-3}$ Nursing home residents may benefit from palliative care with a focus on comfort and quality of life ${ }^{4,5}$ The cognitive impairment associated with moderate or advanced dementia often leads to limited verbal expression of needs. This complicates the assessment of specific palliative care needs and addressing of symptoms. ${ }^{6,7}$ Family caregivers of people with dementia fulfill important roles as spokespersons, care partners, informants, and proxy decision-makers..$^{8-11}$ Their role continues after nursing home admission. ${ }^{12,13}$ Staff should acknowledge the family caregivers' role in the care for people with dementia, especially at the end of life. ${ }^{14-16}$ Families' experiences with end-of-life care and their interactions with professional caregivers potentially influence their post-bereavement outcomes. ${ }^{17}$ "How people die remains in the memories of those who live on" is a famous quote in palliative care literature. ${ }^{18}$ Memories of family members reflect the dying experience and may expose specific points for improvement in end-of-life care. ${ }^{19}$ Family caregivers are important judges of the quality of end-of-life care provided to residents with dementia and of their quality of dying. ${ }^{20,21}$ Validated instruments are available to measure quality of care and quality of dying from the family perspective. ${ }^{22,23}$

A small study that investigated data from 2005 to 2010 showed a positive trend in families' reports of quality of end-of-life care for nursing home residents with dementia. ${ }^{24}$ Exploring such trends can aid our understanding of how the experiences of family caregivers with end-of-life care may have changed, which informs future initiatives to improve palliative and end-of-life care. The present study examines trends in quality of care and quality of dying up to 2019 as judged by family caregivers of residents with dementia in Dutch nursing homes. Various national initiatives aimed to improve knowledge on palliative care in the Netherlands over the last decade. Therefore, the hypothesis is that these trends over a period in which development of dementia palliative care continued, are positive.

\section{METHODS}

\section{Study population}

Data from eight studies conducted in the Netherlands in overlapping time windows between 2005 and 2019 were combined for trend analyses (Table 1). ${ }^{22,24-30}$ For seven of the studies, it concerned a secondary analysis of data collected to address various research questions (Supplement). The main goal of the eighth and most recent study was to enhance assessment of trends over time. Some studies employed nationally representative sampling, whereas other studies were regional. All studies collected 
data retrospectively, and one study also collected data prospectively (Table 1). ${ }^{22,24-30}$ Data collected during any intervention condition were excluded. The data concern 1189 persons with dementia who died in 117 nursing home facilities. One facility contributed to two studies (studies 1 and 3, Table 1). The family caregivers who were the primary contact persons were invited to complete a questionnaire; within 1.5 to 2 months after death in most studies, and up to about a year after death in two studies (studies 6 and 8, Table 1). All nursing home residents included in these studies received medical care by a certified elderly care physician. ${ }^{31}$

\section{Instruments}

Quality of end-of-life care was measured with the End-of-Life in Dementia Satisfaction With Care (EOLD-SWC) instrument. ${ }^{20}{ }^{23}$ It has the most favourable psychometric properties as compared to other such instruments and it comprises 10 items regarding experiences on quality of care from the perspective of the family caregiver ${ }^{22}$ The items cover decision-making, communication, understanding the resident's condition and medical care. The response options are: strongly disagree, disagree, agree, and strongly agree. Three items are negatively phrased statements, which require reverse coding before summing to total scores that range from 10 to 40 . A higher score indicates better quality of end-of-life care.

The End-of-Life in Dementia Comfort Assessment in Dying (EOLD-CAD) ${ }^{20}$ was used to measure quality of dying. ${ }^{23,32}$ The EOLD-CAD comprises 14 items on symptoms such as pain, shortness of breath, choking, and fear. It also includes three positive items in a 'Well being' subscale. This subscale consists of items serenity, peace, and calm, which require reverse coding. The three response options are: a lot, somewhat, and not at all. Total scores range from 14 to 42 , a higher score indicating a better perceived quality of dying. Most studies ( 6 out of 8 ) referred to the last week of life. One study used a skip pattern for the EOLD-CAD if the relative was not present during dying, setting a higher bar with regard to actual presence to observe comfort (Table 1).

\section{Cognition}

All residents had a physician's diagnosis of dementia and resided on a psychogeriatric unit. Studies 1, 2, 3 and 5 (Table 1) included staff assessment using the Bedford Alzheimer Nursing Severity-Scale (BANS-S) to measure the severity of the dementia in the months before death. BANS-S scores range from 7 to 28 . A score of 17 or higher represents severe dementia. ${ }^{33,34}$ In studies 1 to 5 , staff assessed whether residents were fully dependent in eating. Full eating dependence indicates very severe cognitive impairment and is equal to the highest level of impairment on the Cognitive Performance Scale (CPS 6). ${ }^{35,36}$

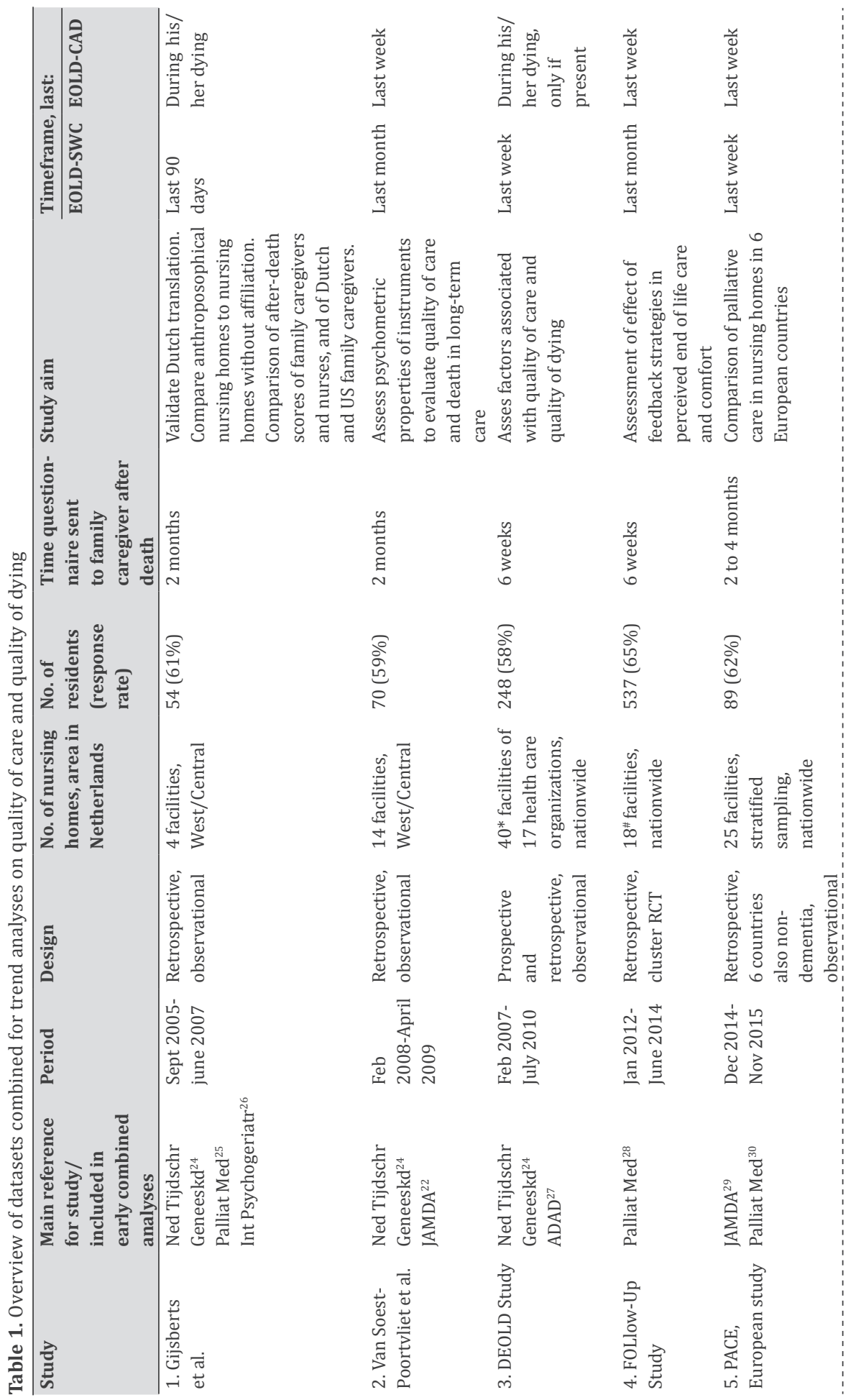

DEDICATED | 145 


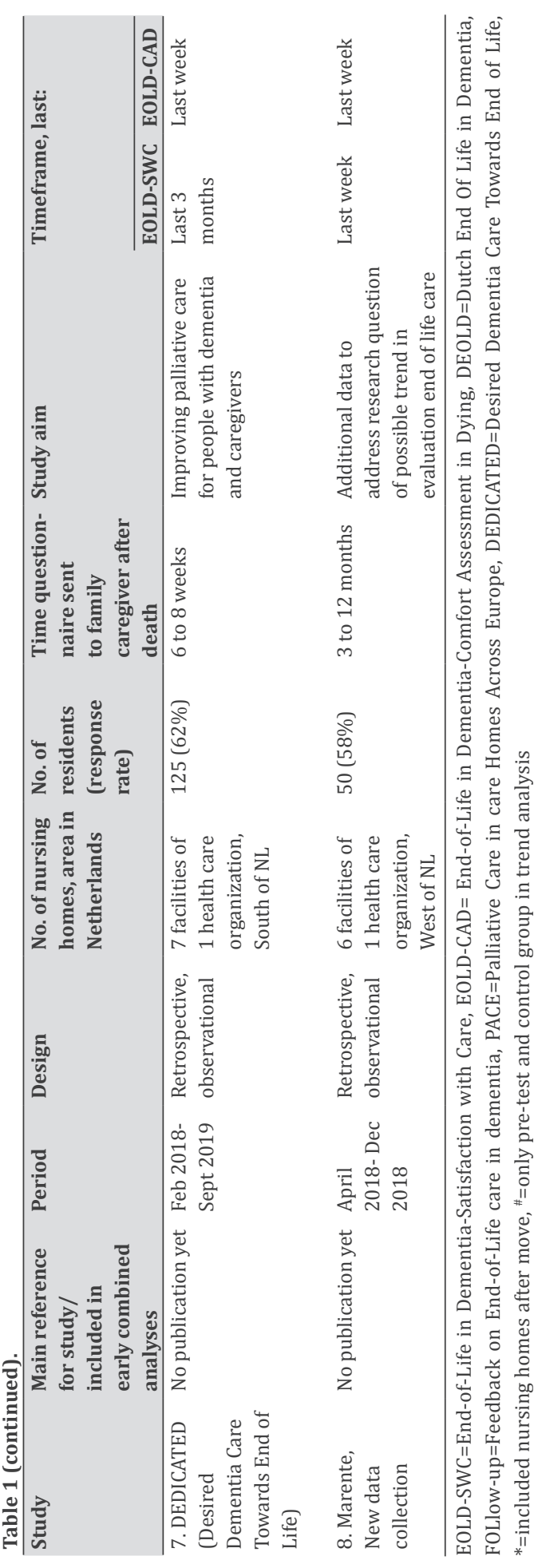

Trend analysis

The EOLD-SWC and EOLD-CAD scores in the combined dataset were analysed with mixed models, using time of death relative to the first death in the first study as the independent variable. The models included random effects for season (as seasonality in cause of death might vary between years) and for clustering of residents within nursing homes. ${ }^{37,38}$ In study 7 , only the month of death was available due to privacy regulations, and we imputed the $14^{\text {th }}$ for February and the $15^{\text {th }}$ for other months. We provide $95 \%$ confidence intervals around the estimate for time. Models were adjusted for characteristics of residents (age and gender), and family caregivers (gender, relationship to resident), region (urbanised Western and central region of the country with greater staffing problems versus other region), and design (prospective enrolment of residents versus retrospectively after death). We conducted sensitivity analyses with additional adjustment for severity of dementia measured with the BANS-S or the eating dependence item (CPS 6) and family caregiver's age. We also added a quadratic term for time to assess the fit of a non-linear model.

Descriptive statistics were used for respondent characteristics. If less than one third of EOLD items missed, the items were imputed with the patient item mean to generate a total score. All analyses were performed in SPSS Inc, version 25, 2017, IBM, USA.

\section{RESULTS}

The mean age of the residents was 85.5 years; $67.9 \%$ were female (Table 2). A little over half $(53.7 \%)$ had severe dementia and almost a third (29.4\%) were fully dependent in eating (no data available for the studies covering 2018 and 2019). Distributions of age, gender and dementia severity were fairly homogeneous between the eight studies (Table 2). Of the family caregivers, the majority were female (62.8\%), and most were sons or daughters (in-law) of the resident (65.8\%). The EOLD-SWC (quality of care) mean total ranged from 31.9 to 34.1 , and the EOLD-CAD (quality of dying) mean total score ranged from 27.2 to 33.3 across studies (Table 3). The correlation between the EOLD-SWC and the EOLD-CAD for quality of dying was weak $(+0.27, \mathrm{P}<0.001)$

Figure 1a shows unadjusted quality of care means per 2 years; the curve is steeper in earlier years and flattens over time when variable error bars are taken into consideration. The EOLD-SWC total score significantly increased by 0.148 points per year ( $\mathrm{CI}, 0.052$ to 0.244 ), and in the adjusted model the trend was 0.170 points per year (CI, 0.055 to 0.285 ) (Table 4 ). The EOLD-CAD total score significantly decreased by -0.175 points per year (CI, -0.291 to -0.058 ; Table 4 and Figure $1 \mathrm{~b}$ ) but in the adjusted model the trend was not significant with a decrease of -0.070 points per year $(\mathrm{CI},-0.205$ to 0.065$)$. The difference of EOLD-CAD with the adjusted model $(-0.070$ versus -0.175 unadjusted; Table 4) was driven by adjustment for prospective versus retrospective 
design. The subscale 'Well Being' significantly decreased by -0.076 points per year (CI, -0.114 to -0.039 ) in the unadjusted model, and in the adjusted model by -0.073 points per year ( $\mathrm{CI},-0.119$ to -0.028 ). The other subscale scores showed no significant trend. Trend models in EOLD-SWC and EOLD-CAD for separate studies are shown in Supplementary figures 1 and 2.

The sensitivity analyses showed similar estimates. A quadratic term for time was significant for the EOLD-SWC in both the unadjusted $(\mathrm{P}=0.002)$ and the adjusted model

$(\mathrm{P}<0.001$; Supplementary figure 3$)$. A quadratic term for change over time was not significant in the unadjusted model for EOLD-CAD $(\mathrm{P}=0.096)$ or the adjusted model $(\mathrm{P}=0.223)$.
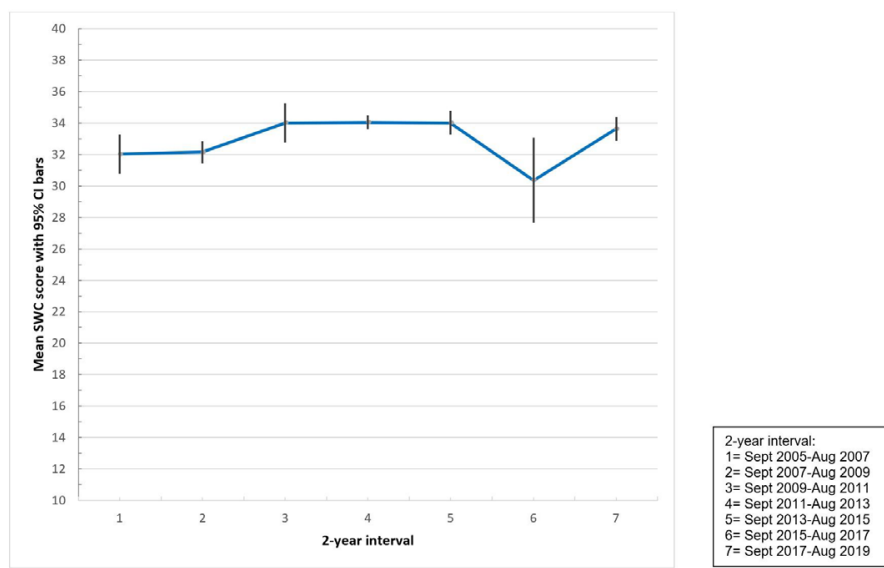

Figure 1a. EOLD-SWC means per 2-year intervals with $95 \% \mathrm{CI}$ bars

EOLD-SWC=End-of-Life in Dementia-Satisfaction with Care, $\mathrm{CI}=$ Confidence Interval

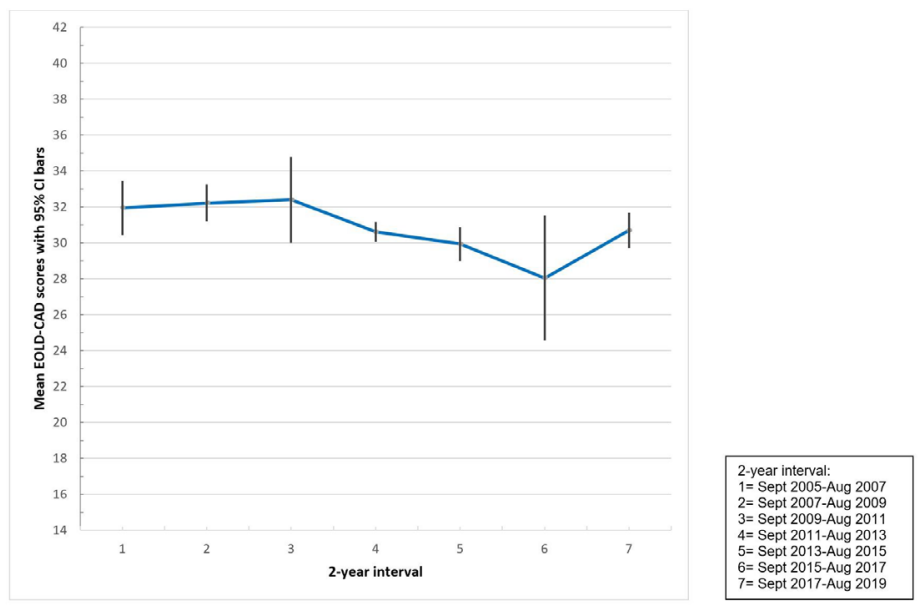

Figure 1b. EOLD-CAD means per 2-year intervals with $95 \% \mathrm{CI}$ bars

EOLD-CAD=End-of-Life in Dementia-Comfort Assessment in Dying, $\mathrm{Cl}=$ Confidence Interva

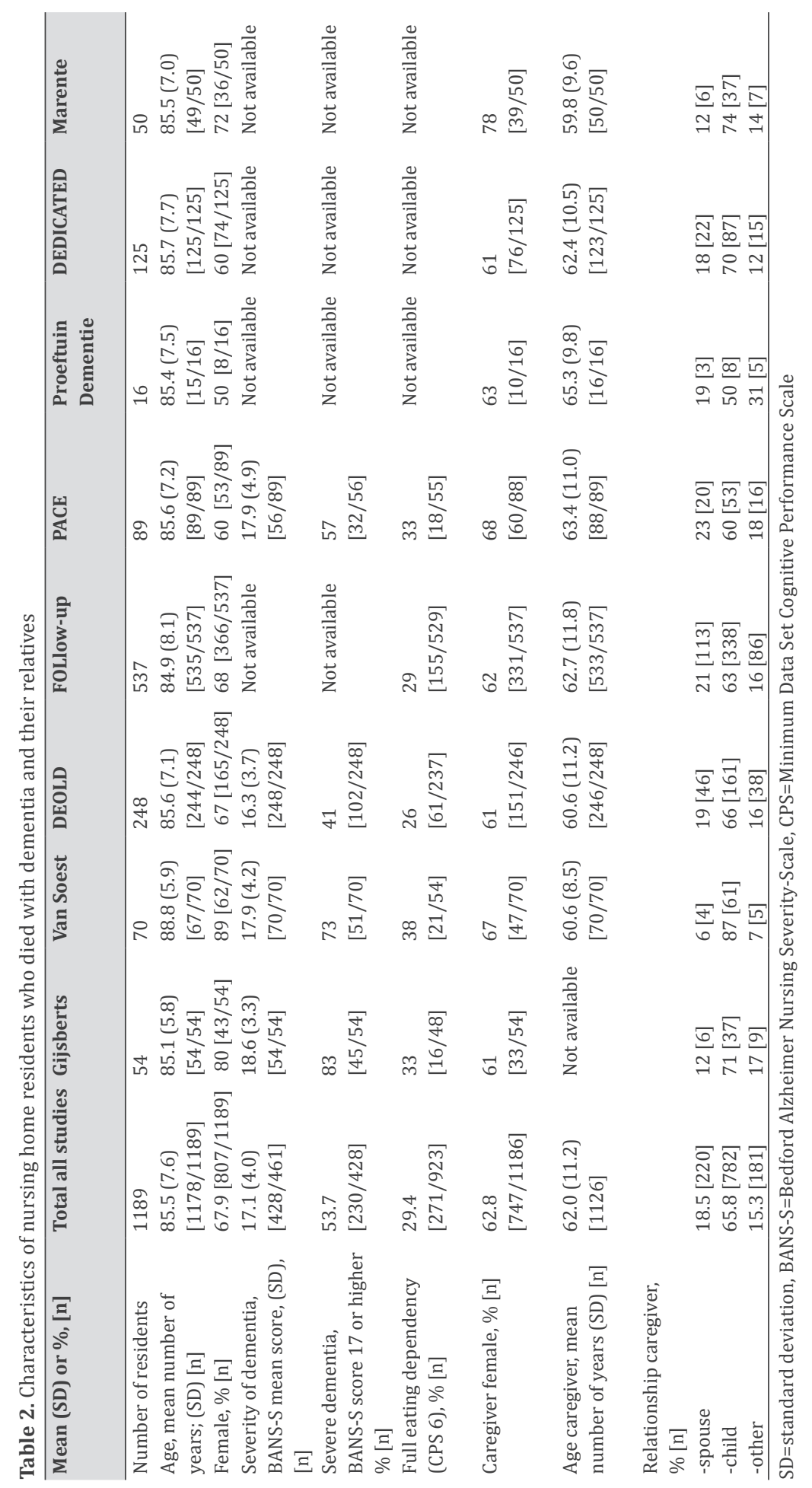

DEDICATED | 149 
Table 3. Total scores for quality of care (EOLD-SWC; $\mathrm{n}=1169$ ) and quality of dying (EOLD-CAD; $\mathrm{n}=903$ )

\begin{tabular}{lllll}
\hline Study/ project, mean (SD) & EOLD-SWC & n/total n & EOLD-CAD & n/total n \\
\hline 1. Gijsberts & $31.9(4.7)$ & $54 / 54$ & $32.0(5.4)$ & $52 / 54$ \\
2. Van Soest-Poortvliet & $32.1(5.8)$ & $68 / 70$ & $30.7(5.3)$ & $59 / 70$ \\
3. DEOLD & $32.6(5.3)$ & $242 / 248$ & $33.3(5.9)$ & $88 / 90$ \\
4. FOLlow-up & $34.1(4.8)$ & $535 / 537$ & $30.6(5.6)$ & $466 / 537$ \\
5. PACE & $33.8(5.2)$ & $86 / 89$ & $29.7(5.6)$ & $80 / 89$ \\
6. Proeftuin Dementie & $30.2(6.3)$ & $16 / 16$ & $27.2(7.2)$ & $13 / 16$ \\
7. DEDICATED & $33.7(5.0)$ & $118 / 125$ & $30.6(6.2)$ & $101 / 125$ \\
8. Marente & $33.4(4.8)$ & $50 / 50$ & $30.8(5.5)$ & $44 / 50$ \\
\hline
\end{tabular}

EOLD-SWC=End-of-Life in Dementia-Satisfaction with Care, EOLD-CAD= End-of-Life in Dementia-Comfort Assessment in Dying

Table 4. Trends in total and item quality of care scores (EOLD-SWC) and in total and subscale quality of dying scores (EOLD-CAD)

\begin{tabular}{|c|c|c|c|}
\hline & $\begin{array}{c}\text { Mean (SD) } \\
{[\mathrm{n}]}\end{array}$ & $\begin{array}{l}\text { Trend; coefficient } \\
\text { (95\%-CI) unadjusted }\end{array}$ & $\begin{array}{l}\text { Trend; coefficient } \\
\text { (95\%-CI) adjusted }\end{array}$ \\
\hline EOLD-SWC total $^{2}$ & $\begin{array}{l}33.40(5.08) \\
{[1169]}\end{array}$ & $0.148(0.052$ to 0.244$)$ & 0.170 (0.055 to 0.285$)$ \\
\hline $\begin{array}{l}\text { a. I felt fully involved in all decision } \\
\text { making }\end{array}$ & $\begin{array}{l}3.41(0.66) \\
{[1171]}\end{array}$ & $0.017(0.005$ to 0.029$)$ & 0.017 (0.002 to 0.032$)$ \\
\hline $\begin{array}{l}\text { b. I would probably have made different } \\
\text { decisions if I had had more information }\end{array}$ & $\begin{array}{l}3.30(0.73) \\
{[1137]}\end{array}$ & $0.006(-0.008$ to 0.019$)$ & 0.011 (-0.006 to 0.027$)$ \\
\hline $\begin{array}{l}\text { c. All measures were taken to keep my } \\
\text { relative comfortable }\end{array}$ & $\begin{array}{c}3.47(0.66) \\
{[1167]}\end{array}$ & 0.024 (0.012 to 0.037$)$ & 0.030 (0.016 to 0.045$)$ \\
\hline $\begin{array}{l}\text { d. The health care team were sensitive } \\
\text { to my needs and feelings }\end{array}$ & $\begin{array}{l}3.35(0.65) \\
{[1146]}\end{array}$ & $0.019(0.007$ to 0.031$)$ & 0.015 (0.001 to 0.030$)$ \\
\hline $\begin{array}{l}\text { e. I did not really understand my } \\
\text { relative's condition }\end{array}$ & $\begin{array}{l}3.35(0.78) \\
{[1150]}\end{array}$ & $0.011(-0.002$ to 0.024$)$ & $0.010(-0.005$ to 0.026$)$ \\
\hline $\begin{array}{l}\text { f. I always knew which doctor or nurse } \\
\text { was in charge of my relative's care }\end{array}$ & $\begin{array}{l}3.03(0.78) \\
{[1165]}\end{array}$ & 0.014 (-0.000 to 0.029$)$ & $0.011(-0.006$ to 0.029$)$ \\
\hline $\begin{array}{l}\text { g. I felt that my relative got all necessary } \\
\text { nursing assistance }\end{array}$ & $\begin{array}{l}3.42(0.66) \\
{[1170]}\end{array}$ & $0.019(0.007$ to 0.031$)$ & $0.026(0.011$ to 0.040$)$ \\
\hline $\begin{array}{l}\text { h. I felt that all medication issues were } \\
\text { clearly explained to me }\end{array}$ & $\begin{array}{l}3.27(0.71) \\
{[1155]}\end{array}$ & $0.016(0.004$ to 0.029$)$ & $0.021(0.005$ to 0.036$)$ \\
\hline $\begin{array}{l}\text { i. My relative was receiving all } \\
\text { treatments or interventions that he or } \\
\text { she could benefit from }\end{array}$ & $\begin{array}{c}3.38(0.66) \\
{[1164]}\end{array}$ & 0.015 (0.004 to 0.027$)$ & $0.016(0.002$ to 0.030$)$ \\
\hline $\begin{array}{l}\text { j. I feel that my relative needed better } \\
\text { medical care at the end of his or her life }\end{array}$ & $\begin{array}{l}3.42(0.76) \\
{[1159]}\end{array}$ & $0.005(-0.008$ to 0.019$)$ & $0.010(-0.006$ to 0.026$)$ \\
\hline EOLD-CAD total ${ }^{b}$ & $\begin{array}{c}30.80(5.76) \\
{[903]}\end{array}$ & $-0.175(-0.291$ to -0.058$)$ & $-0.070(-0.205$ to 0.065$)$ \\
\hline $\begin{array}{l}\text { 1. Physical distress } \\
\text { (item } 1,2,3,4 \text {, score range 4-12) }\end{array}$ & $\begin{array}{c}8.34(2.09) \\
{[935]}\end{array}$ & $-0.037(-0.079$ to 0.004$)$ & $\begin{array}{c}0.00001(-0.048 \text { to } \\
0.048)\end{array}$ \\
\hline $\begin{array}{l}\text { 2. Dying symptoms }{ }^{\mathrm{d}} \\
\text { (item } 4 \text { (part of two subscales), 5, 6, 7, } \\
\text { score range 4-12) }\end{array}$ & $\begin{array}{l}8.85(2.20) \\
\quad[922]\end{array}$ & $-0.017(-0.059$ to 0.025$)$ & $0.017(-0.032$ to 0.067$)$ \\
\hline $\begin{array}{l}\text { 3. Emotional distress } \\
\text { (item } 8,9,10,11 \text {, score range } 4-12 \text { ) }\end{array}$ & $\begin{array}{c}9.54(2.19) \\
{[904]}\end{array}$ & $-0.061(-0.104$ to -0.019$)$ & $-0.026(-0.077$ to 0.025$)$ \\
\hline $\begin{array}{l}\text { 4. Well being } \\
\text { (item } 12,13,14 \text {, score range 3-9) }\end{array}$ & $6.14(1.98)$ & $-0.076(-0.114$ to -0.039$)$ & $-0.073(-0.119$ to \\
\hline
\end{tabular}

(item 12, 13, 14, score range 3-9) Assessment in Dying,

Cl=confidence interval, italics and bold $=\boldsymbol{p}<0.05$

Cronbach's $\alpha$ : ${ }^{a}=$ EOLD-SWC total: $0.90,{ }^{b}=$ EOLD-CAD total: $0.83,{ }^{c}=$ EOLD-CAD subscale Physical distress: 0.62 ,

$=$ EOLD-CAD subscale Dying symptoms: 0.68 ,

$=$ EOLD-CAD subscale Emotional distress: $0.78, \mathrm{f}=$ EOLD-CAD subscale Well being: 0.9

150 | CHAPTER 7

\section{DISCUSSION}

\section{Main findings}

This study investigated trends in family caregivers' assessments of quality of end-of-life care and quality of dying of nursing home residents with dementia in the Netherlands. From 2005 to 2019, quality of care improved, in particular in the earlier years. Quality of dying did not significantly change in adjusted analyses that included adjustment for prospective design, but scores on the subscale 'Well being' nevertheless decreased, also after adjustment.

The statistically significant changes are relevant long-term changes as they may represent ongoing change, and a 2.4 increase in EOLD-SWC total scores, for example, nears 3 used in power calculations. ${ }^{39}$ The progressive and terminal nature of dementia and the complex care needs that accompany dementia underpin a palliative approach to care. ${ }^{5,40}$ The evidence-base for palliative dementia care is still small but will expand over the coming years. ${ }^{41}$ The early increase in quality of care in the Netherlands may be related to political developments in palliative care from the late 1990s onward. ${ }^{42} \mathrm{~A} 1997$ policy programme aimed to integrate palliative care into the regular healthcare system, to increase practitioners' skills and knowledge. ${ }^{43}$ In Dutch national dementia plans, however, palliative or end-of-life care is not mentioned..$^{44}$ Treatments for symptom relief in nursing home residents with dementia increased in 2006-2007 compared to the late 1990 s. $^{45}$ Reasons for this increase, according to physicians, included growing attention and awareness regarding symptom relief, clearer treatment goals and a focus on quality of life..$^{45}$ Palliative care specialists are consulted for residents in Dutch nursing homes with dementia, in only $2.5 \%$ of the cases.$^{46}$ Compared to five other European countries, however, the treating physician in Dutch nursing homes is involved in palliative care more often (in $98.8 \%$ of the cases). ${ }^{30,47}$

In the context of increasing quality of end-of-life care as perceived by family and increasing awareness regarding palliative care as perceived by physicians, ${ }^{45}$ finding no improvement on the quality of dying scale and a decline on the 'Well being' subscale is counterintuitive. Further, scores on the quality of care items, regarding measures taken to improve comfort and regarding nursing assistance showed the highest increase. Other studies also found weak to moderate associations between quality of care evaluated by families and perceived quality of dying. ${ }^{48,49}$ An interesting artefact may have been introduced by a design issue, with a negative trend for a prospective design (Supplement figures 1 and 2). Repeated completion of questionnaires on symptom burden in the prospective study may also have increased family caregivers' awareness of symptoms in the dying phase. These family caregivers may have been prompted to report more symptoms.

Nevertheless, controlled for design, the trend was also negative for the subscale 'Well being' that comprises the items 'serenity', 'peace', and 'calm'. Family caregivers 
may hold negative perceptions about the end of life with dementia as being undignified, especially in Western societies where autonomy is highly valued..$^{50}$ Increasing media exposure and public campaigns on 'living well with dementia', in combination with the Dutch debate on the acceptability of euthanasia in dementia in recent years might influence such perceptions. Lemos Dekker found that family caregivers of nursing home residents with dementia may feel powerless due to a lack of control over relief of their relatives' suffering. ${ }^{50}$ Higher expectations and standards of care, and increased focus on control and dignity might explain a decrease in their assessment of well-being in dying, while their assessment of concrete symptoms remained unchanged. Future research is needed to disentangle what well-being in dying means to families.

\section{Strengths and limitations}

This study used perspectives from more than one thousand family caregivers of nursing home residents with dementia, over a period of 14 years. It does not evaluate a single reform, as there were various initiatives to improve palliative care. Identifying of individual items that did or did not change further enhances the study's relevance to clinical practice. The EOLD-SWC has strong psychometric properties, whereas there is some ambiguity about the psychometric properties of the EOLD-CAD regarding feasibility, validity, and reliability. ${ }^{22,51}$ Although the EOLD-CAD items all assess aspects of quality of dying, the instrument does not cover the full concept of quality of dying, which may include aspects that are more difficult to assess such as retaining identity or dignity. ${ }^{52}$ Nonetheless, other such measures do not perform better or properties are unknown. The EOLD-SWC and EOLD-CAD scales have been widely used after an early comparison of psychometric properties, ${ }^{22}$ which facilitates comparison between countries. ${ }^{30,53}$ This study was limited to the Netherlands, but its EOLD scores are fairly representative for recent European research. ${ }^{30}$ Sample sizes, recruitment methods, and the period before death referred to in the EOLD instruments varied between the individual studies in the analyses. There may be residual confounding by unmeasured confounders. However, any confounding by dementia severity is unlikely, as adjusted estimated were unchanged in sensitivity analyses.

\section{Conclusion}

This study observed a positive trend in family caregivers' assessments of the quality of end-of-life care for nursing home residents with dementia over a period of 14 years. Family caregivers' assessments of quality of dying did not change with regard to symptoms during dying, but according to their assessments the well-being during dying decreased over time. There may be a growing gap between family caregivers' expectations and actual symptoms and well-being at the end of life. These observations call for further monitoring of quality perceived by family and research to investigate contemporary ideas about what constitutes a 'good and comfortable death' at the end of life with dementia.

\section{Contribution}

SRB wrote parts of the paper, in close collaboration with the first and last author. SRB mainly drafted the introduction and discussion sections. All other authors have critically reviewed the paper's content, after which MSK, SRB and JTS revised the manuscript. SRB collected data, and contributed to conceiving and designing the data analysis and interpreting the findings. 


\section{REFERENCES}

1. Honinx E, van Dop N, Smets T, et al. Dying in long-term care facilities in Europe: the PACE epidemiological study of deceased residents in six countries. BMC public health 2019;19(1):1199.

2. Reyniers T, Deliens L, Pasman HR, et al. International variation in place of death of older people who died from dementia in 14 European and non-European countries. J Am Med Dir Assoc. 2015;16(2):165-71.

3. Joling KJ, Janssen O, Francke AL, et al. Time from diagnosis to institutionalization and death in people with dementia. Alzheimers Dement. 2020;16(4):662-71

4. Froggatt K, Payne S, Morbey H, et al. Palliative Care Development in European Care Homes and Nursing Homes: Application of a Typology of Implementation. J Am Med Dir Assoc. 2017;18(6):550.e7-50.e14.

5. van der Steen JT, Radbruch L, Hertogh CM, et al. White paper defining optimal palliative care in older people with dementia: a Delphi study and recommendations from the European Association for Palliative Care. Palliat Med. 2014;28(3):197-209.

6. Erel M, Marcus EL, Dekeyser-Ganz F. Barriers to palliative care for advanced dementia: a scoping review. Ann Palliat Med. 2017;6:365-79.

7. Blackstone KA, Cobbs EL. Palliative care for persons with dementia. J Am Geriatr Soc. 2021.

8. Graneheim UH, Johansson A, Lindgren BM. Family caregivers' experiences of relinquishing the care of a person with dementia to a nursing home: insights from a meta-ethnographic study. Scand J Caring Sci. 2014;28(2):215-24.

9. Bern-Klug M, Forbes-Thompson S. Family members' responsibilities to nursing home residents: "she is the only mother I got". J Gerontol Nurs. 2008;34(2):43-52.

10. Lord K, Livingston G, Cooper C. A systematic review of barriers and facilitators to and interventions for proxy decision-making by family carers of people with dementia. Int Psychogeriatr. 2015;27(8):1301-12.

11. Givens JL, Kiely DK, Carey K, et al. Healthcare proxies of nursing home residents with advanced dementia: decisions they confront and their satisfaction with decision-making. J Am Geriatr Soc. 2009;57(7):114955.

12. Brodaty H, Donkin M. Family caregivers of people with dementia. Dialogues Clin Neurosci. 2009;11(2):21728.

13. Ross MM, Carswell A, Dalziel WB. Family caregiving in long-term care facilities. Clin Nurs Res. 2001;10(4):347-63

14. Boogaard JA, van der Steen JT, de Boer AH, et al. How Is End-of-Life Care With and Without Dementia Associated With Informal Caregivers' Outcomes? Am J Hosp Palliat Care. 2019;36(11):1008-15.

15. Bolt S, van der Steen J, Schols J, et al. What do relatives value most in end-of-life care for people with dementia? Int J Palliat Nurs. 2019;25(9):432-42.

16. Reid RC, Chappell NL. Family Involvement in Nursing Homes: Are Family Caregivers Getting What They Want? J Appl Gerontol. 2017;36(8):993-1015.

17. Shuter P, Beattie E, Edwards H. An Exploratory Study of Grief and Health-Related Quality of Life for Caregivers of People With Dementia. Am J Alzheimers Dis Other Demen. 2014;29(4):379-85.

18. Saunders. Pain and impending death. Textbook of Pain New York, NY: Churchill Livingstone 1984:pp. 4728.

19. Teno JM, Clarridge BR, Casey V, et al. Family perspectives on end-of-life care at the last place of care. Jama. 2004;291(1):88-93

20. Volicer L, Hurley AC, Blasi ZV. Scales for evaluation of End-of-Life Care in Dementia. Alzheimer Dis Assoc Disord. 2001;15(4):194-200

21. McPherson CJ, Addington-Hall JM. Judging the quality of care at the end of life: can proxies provide reliable information? Soc Sci Med. 2003;56(1):95-109.

22. van Soest-Poortvliet MC, van der Steen JT, Zimmerman S, et al. Selecting the best instruments to measure quality of end-of-life care and quality of dying in long term care. J Am Med Dir Assoc. 2013;14(3):179-86.

23. van Soest-Poortvliet MC, van der Steen JT, Zimmerman S, et al. Psychometric properties of instruments to measure the quality of end-of-life care and dying for long-term care residents with dementia. Qual Life Res. 2012;21(4):671-84.

24. van der Steen JT, van Soest-Poortvliet MC, Gijsberts MJ, et al. [Improved end-of-life care for patients with dementia: greater family satisfaction and possibly greater end-of-life comfort]. Ned Tijdschr Geneeskd. 2013;157(17):A5324.

25. van der Steen JT, Gijsberts MJ, Knol DL, et al. Ratings of symptoms and comfort in dementia patients at the end of life: comparison of nurses and families. Palliat Med. 2009;23(4):317-24.

26. van der Steen JT, Gijsberts MJ, Muller MT, et al. Evaluations of end of life with dementia by families in Dutch and U.S. nursing homes. Int Psychogriatr. 2009;21(2):321-9.

27. van der Steen JT, Ribbe MW, Deliens L, et al. Retrospective and prospective data collection compared in the Dutch End Of Life in Dementia (DEOLD) study. Alzheimer Dis Assoc Disord. 2014;28(1):88-94.

28. Boogaard JA, de Vet HC, van Soest-Poortvliet MC, et al. Effects of two feedback interventions on end-of-life outcomes in nursing home residents with dementia: A cluster-randomized controlled three-armed trial. Palliat Med. 2018;32(3):693-702.

29. Van den Block L, Smets T, van Dop N, et al. Comparing Palliative Care in Care Homes Across Europe (PACE): Protocol of a Cross-sectional Study of Deceased Residents in 6 EU Countries. I Am Med Dir Assoc.

30. Pivodic L, Smets T, Van den Noortgate N, et al. Quality of dying and quality of end-of-life care of nursing home residents in six countries: An epidemiological study. Palliat Med. 2018:269216318800610.

31. Koopmans RT, Lavrijsen JC, Hoek JF, et al. Dutch elderly care physician: a new generation of nursing home physician specialists. J Am Geriatr Soc. 2010;58(9):1807-9.

32. Stewart AL, Teno J, Patrick DL, et al. The concept of quality of life of dying persons in the context of health care. J Pain Symptom Manage. 1999;17(2):93-108.

33. Appollonio I, Gori C, Riva G, et al. Assessing early to late stage dementia: the TSI and BANS-S scales in the nursing-home. Int J Geriatr Psychiatry. 2005;20(12):1138-45.

34. Volicer L, Hurley AC, Lathi DC, et al. Measurement of severity in advanced Alzheimer's disease. J Gerontol. 1994;49(5):M223-6.

35. Morris JN, Fries BE, Mehr DR, et al. MDS Cognitive Performance Scale. J Gerontol. 1994;49(4):M174-82.

36. van der Steen JT, Volicer L, Gerritsen DL, et al. Defining severe dementia with the Minimum Data Set. Int J Geriatr Psychiatry. 2006;21(11):1099-106.

37. Fitzmaurice GM, Laird, NM, Ware, JM. Applied Longitudinal Analysis. 2012. John Wiley \& Sons, New Jersey.

38. Molenberghs G, Verbeke, G. A review on linear mixed models for longitudinal data, possibly subject to dropout. Stat Model. 2001;1:235-69.

39. Boogaard JA, van Soest-Poortvliet MC, Anema JR, et al. Feedback on end-of-life care in dementia: the study protocol of the FOLlow-up project. BMC Palliat Care. 2013;12:29.

40. van der Steen JT, Lemos Dekker N, Gijsberts MHE, et al. Palliative care for people with dementia in the terminal phase: a mixed-methods qualitative study to inform service development. BMC Palliat Care. 2017;16(1):28

41. Murphy E, Froggatt K, Connolly S, et al. Palliative care interventions in advanced dementia. Cochrane Database Syst Rev. 2016;12(12):Cd011513.

42. Soest v. De organisatie van de palliatieve zorg in Nederland. In: Berendsen A., van Soest F. (eds) Inzichten in de palliatieve zorg. Bohn Stafleu van Loghum, Houten.

3. Francke AL, Kerkstra A. Palliative care services in The Netherlands: a descriptive study. Patient Educ Couns. 2000;41(1):23-33

44. Nakanishi M and van der Steen JT. National dementia plans to address escalating global palliative care needs. Palliat med. 2020;34:966-7.

45. van der Steen IT, Meuleman-Peperkamp I, Ribbe MW. Trends in treatment of pneumonia among Dutch nursing home patients with dementia. J Palliat Med. 2009;12(9):789-95.

46. van der Steen JT. Deliens $L$ Koopmans $R$, et al. Physicians' perceptions of suffering in people with dementia at the end of life. Palliat Support Care. 2017;15(5):587-99.

47. Ten Koppel M, Onwuteaka-Philipsen BD, Van den Block L, et al. Palliative care provision in long-term care facilities differs across Europe: Results of a cross-sectional study in six European countries (PACE). Palliat Med. 2019:269216319861229

48. Liu LM, Guarino AJ, Lopez RP. Family satisfaction with care provided by nurse practitioners to nursing home residents with dementia at the end of life. Clin Nurs Res. 2012;21(3):350-67.

49. Engel SE, Kiely DK, Mitchell SL. Satisfaction with end-of-life care for nursing home residents with advanced 
dementia. J Am Geriatr Soc. 2006;54(10):1567-72.

. 2017:1-7.

51. Kupeli N, Candy B, Tamura-Rose G, et al. Tools Measuring Quality of Death, Dying, and Care, Completed after Death: Systematic Review of Psychometric Properties. Patient. 2019;12(2):183-197.

52. Nishimura M, Dening, K.H., Sampson, E.L., Vidal, E.I.O., Abreu, W.C., Kaasalainen, S., Eisenmann, Y., Dempsey, L., Moore, K.J., Davies, N., Bolt, S.R., Meijers J.M.M., Lemos Dekker, N., Miyashita, M., Nakanishi, M., Nakayama, T., \& van der Steen, J.T. Cross-cultural conceptualisation of a good end of life with dementia: A meta-qualitative study. The Alzheimer Disease International Conference 2020 Abstract book 2020:64-65.

53. Cohen LW, van der Steen JT, Reed D, et al. Family perceptions of end-of-life care for long-term care residents with dementia: differences between the United States and the Netherlands. J Am Geriatr Soc. 2012;60(2):316-22.
APPENDIX 1. Description of each study on inclusion of residents and study aims

Study 1 Gijsberts et al. ${ }^{1-3}$

The 54 residents enrolled after death in this study were living in 4 nursing homes in the Western and central regions of the Netherlands. All deaths occurred between September 2005 and June 2007. The first study aim was to translate and validate the End of Life in dementia (EOLD) scales, the second aim was to compare anthroposophical nursing homes with nursing homes without religious or spiritual affiliation on quality of care, dying and symptom burden. The third aim was to compare after-death scores of family caregivers and nurses in the Netherlands and the US. Nurses identified family caregivers who had been most involved in the last months of life of residents diagnosed with dementia. An informed consent form was sent by postal mail 6 weeks after the death of their relative. After receiving consent, a printed questionnaire was mailed and was completed around 2 months after death. The response rate was $61 \%$. The study protocol was approved in 2005 by the Medical Ethics Committee of VU University Medical Center in Amsterdam (number 05/098).

Study 2 Psychometric instrument study, Van Soest-Poortvliet et al. ${ }^{4}$

In this study, 70 residents were included after death. They had resided in 8 nursing homes and had been admitted at least 30 days before death between February 2008 and April 2009. This psychometric properties study was designed to test and compare all available instruments to measure quality of care and quality of death with dementia in long-term care. All residents had a physician's diagnosis of dementia and were admitted to a psychogeriatric unit (units with almost all patients having dementia) in nursing homes and residential homes. Informed consent was provided by family caregivers. The response rate was 59\%. The Medical Ethical Committee of VU University Medical Center, Amsterdam, reviewed the protocol in 2008 as an extension of study 3. (number $06 / 179,2006$ ), and provided advice, declaring that the extension also did not fall under the Medical Research Involving Human Subjects Act (WMO).

Study 3 DEOLD= Dutch End Of Life in Dementia, van der Steen et al. ${ }^{15}$

The 491 residents in 19 nursing home organizations covering 34 facilities, enrolled in this study were included using a prospective design in 28 facilities ( 17 organizations) and a retrospective design in 6 other facilities ( 2 organizations, after-death questionnaires only). Family after-death questionnaires were returned for 183 residents who resided in the facilities involved in the prospective data collection, and 65 were returned for residents of facilities based on retrospective data collection only. Some residents moved and so the completed after-death questionnaires concerned 6 more facilities, resulting in a total of 40 facilities. Residents with completed after-death questionnaires died between February 2007 and July 2010. The main study aim was to assess factors 
associated with quality of care and quality of dying. Other aims were to described comfort, symptom burden, pain, decision making and treatment at the end of life. A total of 26 nursing home organizations were invited to participate, 17 agreed, representing a response rate of $65 \%$ ( 2 more nursing home organizations participated after taking the initiative and expressing an interest in participating). The family caregiver received a questionnaire around 2 months after the death of their relative. The response rate was $58 \%$. The study protocol was judged not to fall under the scope of the Medical research Involving Human Subjects Act (WMO), as declared by the Medical Ethics Committee of VU University Medical Center in Amsterdam, in 2006 (number 06/179 (2006).

Study 4 FOLlow-Up= Feedback on End-of-Life care in dementia

The 537 residents enrolled in this study all died on a psychogeriatric ward in 18 different nursing homes and were admitted at least 16 days in the last month of life. The time of death was between January 2012 and June 2014. The study aim was to assess the effect of (patient or generic) feedback strategy on perceived end-of-life care and comfort and the study design was a cluster-randomized 3-armed trial. For this trend analysis the residents who resided in the facilities assigned to the control condition (pre-intervention phase and intervention phase) and all residents who died in the preintervention period of the intervention groups (patient and generic feedback strategy) were included for analyses. Residents were included if they had stayed in the nursing home at least 16 days in the last month of life and had a dementia diagnosis in their medical file. Around 6 weeks after death the family caregiver received an information letter and questionnaire; the response rate was $65 \%$. This cluster-randomized controlled trial is registered in the Netherlands Trial Registration, NL3777 (NTR3942). The research protocol of the Follow-up study was reviewed by the Medical Ethics Review Committee of VU University Medical Center (number 2012/173; judged to not fall under the scope of the Medical research Involving Human Subjects Act (WMO))

\section{Study 5 PACE $=$ Palliative Care in Care Homes Across Europe ${ }^{78}$}

This study conducted in 6 countries included 329 people of whom 143 were residents of 25 nursing homes on a psychogeriatric unit (mostly for people with dementia) at the time of death and 89 family caregivers returned the questionnaires, response rate $62 \%$. These residents died between December 2014 to November 2015. The organizations were invited to participate through a random sampling procedure in each country, based on at least region/province and facility size (number of beds). The aim of the PACE study was to compare palliative care in nursing homes in 6 European countries. The study was funded in the European Commission FP7 program. Consent to participate was obtained when the questionnaire was returned. The Medical Ethics Review Committee of the VU University Medical Center Amsterdam provided a waiver from review as it was judged to not fall under the scope of the Medical Research Involving Human Subjects Act (WMO), 2015.
Study 6 Proeftuin Dementie

This study aimed at setting up palliative care team specialized in palliative care for people with dementia and evaluate it effects in 4 nursing homes. Family caregivers of nursing home residents completed questionnaires before the intervention was pilot tested, and the mobile team was consulted only for home-dwelling persons with dementia. The 16 residents with dementia included in this study (response rate 43\%) had been admitted to a psychogeriatric ward of one of four nursing homes in the region where the study was conducted and died between February 2017 and September 2017. Relatives were contacted in March 2018 and asked to complete the questionnaire. Ethical review for the research protocol was provided by the Medical Ethics Review Committee of the Leiden University Medical Center (number (P17.214; judged to not fall under the scope of the Medical research Involving Human Subjects Act (WMO))

\section{Study 7 DEDICATED = Desired Dementia Care Towards End of Life}

Between February 2018 and September 2019, 206 residents were included in this ongoing end-of-life study. The DEDICATED project aims to improve palliative care for people with dementia. The researchers collect quality of care and quality of dying data over time in one of the participating organizations. The current dataset includes 126 residents who resided on a psychogeriatric unit. For this analysis, we included 125 residents, excluding one resident with a missing date of death from the analysis. The family caregivers in this study received an information letter and questionnaire between 6 to 8 weeks after the residents' death, as part of the routine post-death assessment of the organization. The response rate was $61 \%$. The study protocol was approved by the Medical Ethics Committee of the Maastricht University Medical Center (number METCZ20180026), judged to not fall under the scope of the Medical research Involving Human Subjects Act (WMO)

\section{Study 8 Marente}

This study was conceived for the purpose of addressing the research question about trends in family perspectives on quality of care and quality of dying. All caregivers who served as contact persons for staff received questionnaires if their family who resided on a psychogeriatric (mostly dementia) unit and died between first of March 2018 and $31^{\text {st }}$ of December 2018 in one of six facilities of a care organization in the west of the Netherlands. The questionnaires were sent end of March 2019, to 86 relatives and 50 were returned between the first of April and $25^{\text {th }}$ of May 2019, response rate $58 \%$. We enquired with the Medical Ethics Review Committee of the Leiden University Medical Center; because of use of the same questionnaire as used in study 6 , they regarded the ethics review for study 6 as leading and study 8 as an extension with more facilities of the observational part of study 6 . 


\section{Reference List}

1. van der Steen IT, van Soest-Poortvliet MC, Gijsberts MI, et al. [Improved end-of-life care for patients with dementia: greater family satisfaction and possibly greater end-of-life comfort]. Nederlands tijdschrift voor geneeskunde 2013;157(17):A5324.

2. van der Steen JT, Gijsberts MJ, Knol DL, et al. Ratings of symptoms and comfort in dementia patients at the end of life: comparison of nurses and families. Palliative medicine 2009;23(4):317-24. doi:

3. van der Steen JT, Gijsberts MJ, Muller MT, et al. Evaluations of end of life with dementia by families in Dutch and U.S. nursing homes. International psychogeriatrics / IPA 2009;21(2):321-9. doi: 10.1017/ s1041610208008399

4. van Soest-Poortvliet MC, van der Steen JT, Zimmerman S, et al. Selecting the best instruments to measure quality of end-of-life care and quality of dying in long term care. Journal of the American Medical Directors Association 2013;14(3):179-86. doi: 10.1016/j.jamda.2012.09.019

5. van der Steen JT, Ribbe MW, Deliens $\mathrm{L}$, et al. Retrospective and prospective data collection compared in the Dutch End Of Life in Dementia (DEOLD) study Alzheimer disease and associated disorders 2014:28(1):8894. doi: 10.1097/WAD.0b013e318293b380

6. Boogaard JA, de Vet HC, van Soest-Poortvliet MC, et al. Effects of two feedback interventions on end-of-life outcomes in nursing home residents with dementia: A cluster-randomized controlled three-armed trial. Palliative medicine 2018:32(3):693-702. doi: 10.1177/0269216317750071

7. Van den Block L, Smets T, van Dop N, et al. Comparing Palliative Care in Care Homes Across Europe (PACE): Protocol of a Cross-sectional Study of Deceased Residents in 6 EU Countries. Journal of the American Medical Directors Association 2016;17(6):566.e1-7. doi: 10.1016/j.jamda.2016.03.008

8. Pivodic L, Smets T, Van den Noortgate N, et al. Quality of dying and quality of end-of-life care of nursing home residents in six countries: An epidemiological study. Palliative medicine 2018:269216318800610. doi: $10.1177 / 0269216318800610$

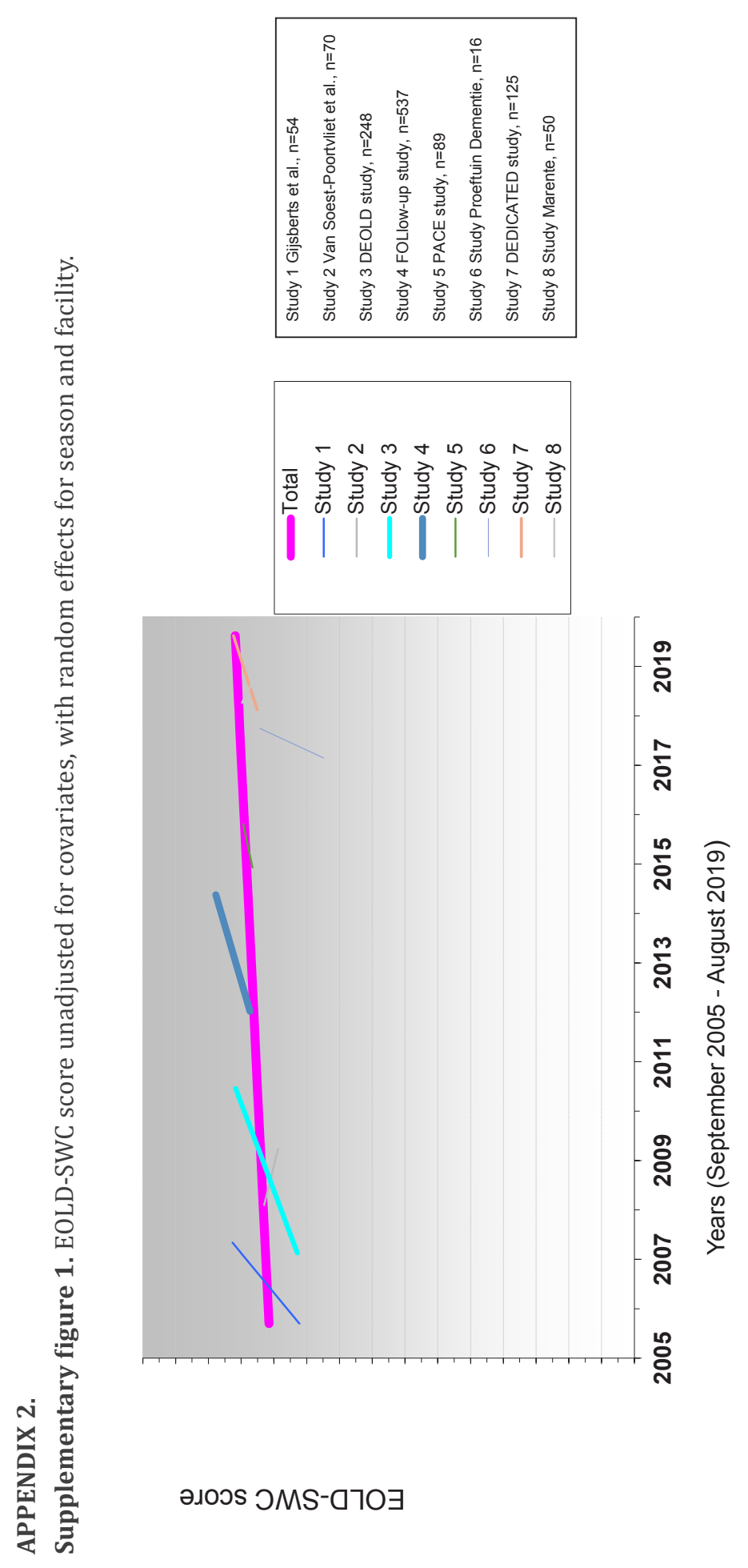




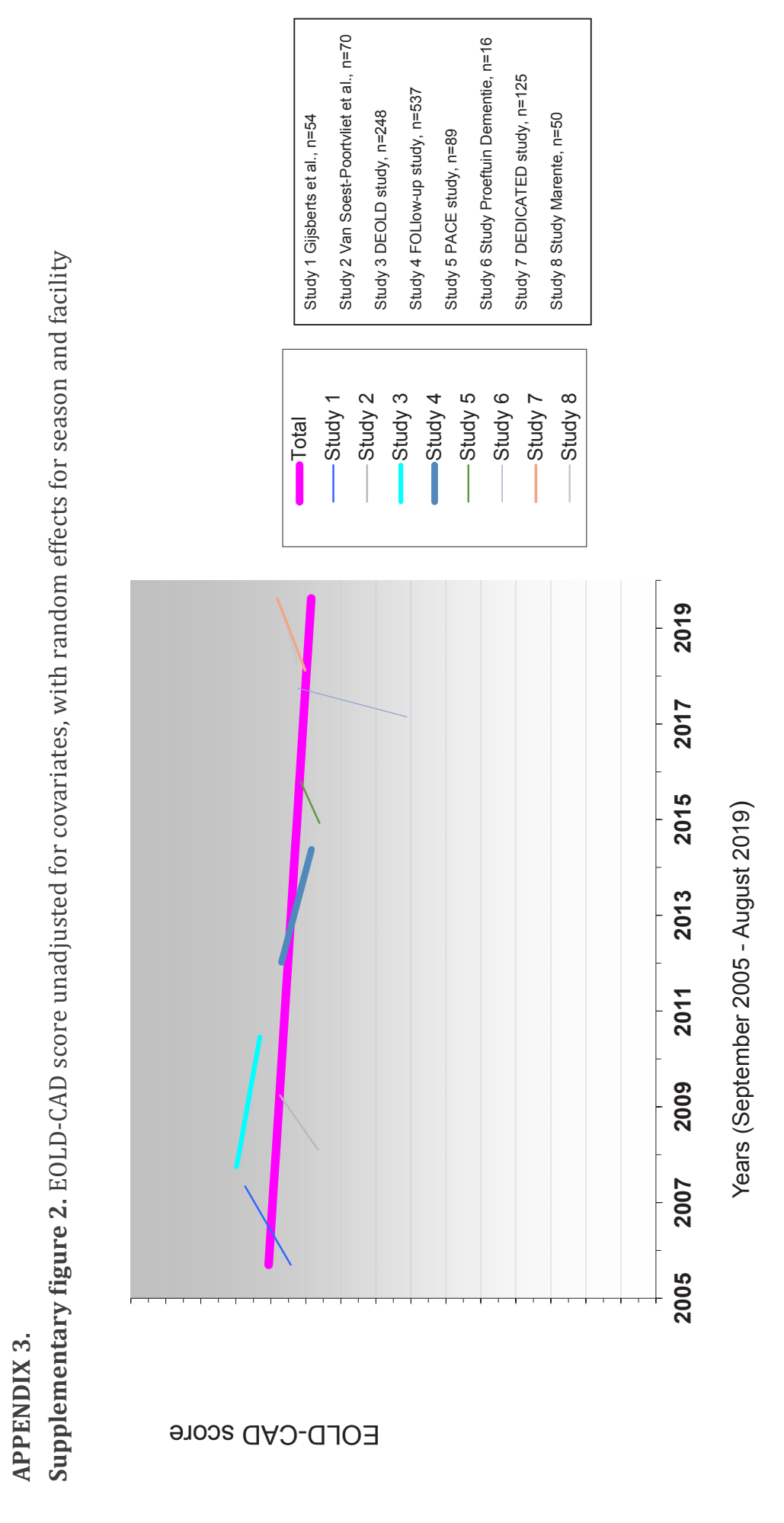

APPENDIX 4.

Supplementary figure 3. Quality of care (EOLD-SWC=End-of-Life in Dementia Satisfaction With Care) adjusted model with additional quadratic term for time

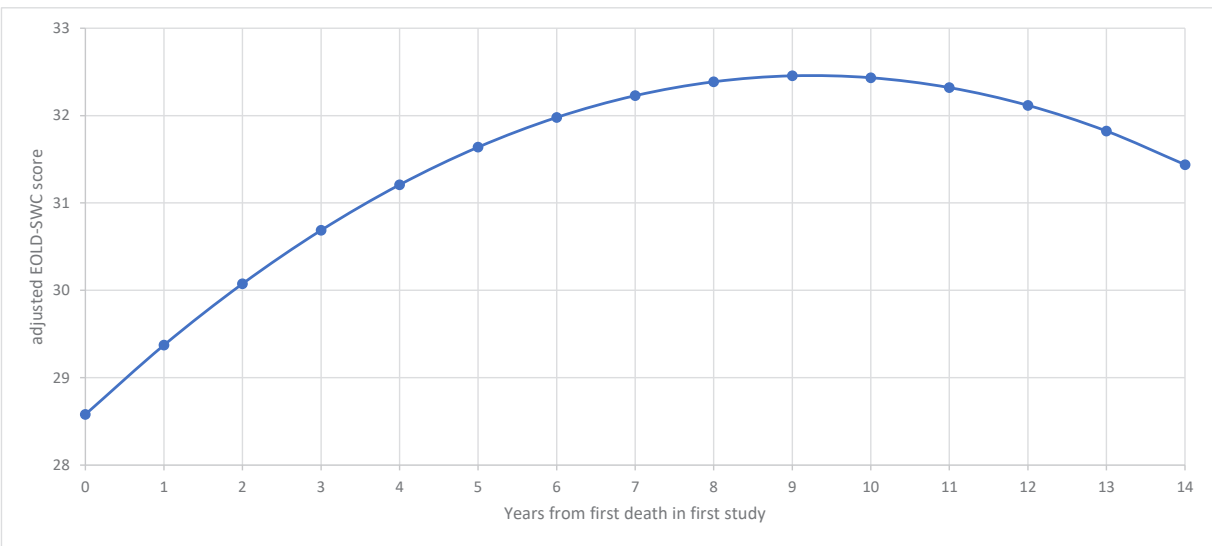




\section{CHAPTER 8}

The perspectives of people with dementia on their future, end of life, and on being cared for by others: A qualitative study

Sascha R Bolt enny T van der Steen Chandni Khemai Jos MGA Schols Sandra MG Zwakhalen Judith MM Meijers 


\section{ABSTRACT}

Aims and objectives

To explore the perspectives of people with dementia on being cared for by others, on the future, and on the end of life, and to evaluate the capability and willingness of participants to have these conversations.

\section{Background}

Awareness about perspectives of people with dementia should decrease stigmatization and improve their quality of life. Applying palliative care principles from an early stage is important to address diverse needs and to anticipate the future. Few studies investigate perspectives of people with dementia regarding palliative care, including advance care planning.

\section{Design}

Qualitative descriptive design.

\section{Methods}

We performed in-depth interviews with 18 community-dwelling persons with dementia in South-Limburg, the Netherlands. Transcripts were analyzed using an inductive content analysis. Two authors coded the data and regularly compared coding. All authors discussed abstraction into categories and themes. We followed the COREQ reporting guidelines.

\section{Results}

Five overarching themes derived from the interviews were as follows: (a) My life still has value and meaning, (b) I am my own unique individual, (c) I place my trust in other people, (d) The future worries me, and (e) I accept and embrace what life brings.

\section{Conclusions}

Participants' thoughts about the future and the end of life involved feelings of ambiguity and anxiety, but also of contentment and resignation. Despite worrying thoughts of decline, participants primarily demonstrated resilience and acceptance. They expressed appreciation and trust towards those who care for them. They wished to be recognized as unique and worthy humans, until the end of life.

\section{Relevance to clinical practice}

This study demonstrates capability and willingness of people with dementia to discuss the future and end-of-life topics. Public and professional awareness may facilitate opportunities for informal end-of-life discussions. Healthcare professionals should promote belongingness of persons with dementia and strive to build equal, trustful care relationships with them and their families. 


\section{INTRODUCTION}

Societies may prioritize enabling the increasing number of people with dementia to 'live well' with their condition. ${ }^{1}$ People with dementia face multiple losses in their personal and social life, which disrupts their connection to others and the world around them. ${ }^{2}$ We need societal awareness and understanding to support people with dementia and their families, to increase their quality of life and to reduce stigma. ${ }^{1}$ Dementia is a lifelimiting illness. ${ }^{3}$ Especially the moderate to advanced stages require care goals focusing on comfort and quality of life. ${ }^{4}$ Integrated care services are a cornerstone of high-quality palliative care for people with dementia and should be adapted to specific needs that arise throughout the course of the disease. ${ }^{1}$ It is essential to study the perspectives of people with dementia themselves to optimize the quality of care provided to them, until the end of life.

\section{BACKGROUND}

Although the provision of palliative care particularly applies to the more advanced stages of dementia, a white paper states that 'recognizing its eventual terminal nature is the basis for anticipating future problems and an impetus to the provision of adequate palliative care.. ${ }^{4}$ Therefore, an early palliative approach to care is recommended. In a palliative approach, professionals apply palliative care knowledge and principles to meet the needs of people with a life-limiting illness, regardless of their prognosis. ${ }^{5}$ Palliative care emphasizes timely recognition and addressing of needs of a physical, psychosocial and spiritual or existential nature, and involves care for families. ${ }^{4}$ Healthcare professionals such as nurses and physicians have an important role in discussing needs for future care with people with dementia and their families. ${ }^{6}$ Nonetheless, healthcare professionals may postpone or avoid end-of-life conversations to avert distress of persons with dementia or themselves. ${ }^{7,8}$ Care staff sometimes perceive end-of-life topics (e.g., death) as a taboo, and they may find it uncomfortable to discuss the end of life ${ }^{9}$ or feel that such conversations are threatening to people with dementia. ${ }^{7}$ Early conversations on future care in the context of advance care planning are important, as cognitive and language impairments may obstruct people with advanced dementia to make active decisions and to express their wishes. ${ }^{10}$ Palliative care knowledge and communication skills among healthcare professionals are needed to improve symptom management and to reduce burdensome treatments and avoidable hospitalizations at the end of life of people with dementia. ${ }^{11,12}$

To offer adequate, personalized and timely palliative care, we must consider the perspectives of people with dementia on what it means to live with dementia and to be cared for by others. ${ }^{13}$ However, studies investigating perspectives on palliative care rarely include the perspectives of people with dementia themselves. ${ }^{14}$ Although proxy ratings are an important source of information in the care for people with cognitive impairments, they cannot replace older adults' self-report of aspects of health and well-being. ${ }^{15}$ Reports on experienced health differ systematically between proxies (i.e., informal or family caregivers and professional caregivers) and persons with dementia. Self-rated quality of life of people with dementia is often higher than the ratings of proxies. ${ }^{16-18}$ This implies that people with dementia may value different aspects or have a different conceptualization of quality of life. ${ }^{18}$ Another study found low to moderate agreement between people with early-stage dementia and their families on preferences for future treatments in hypothetical end-of-life situations. ${ }^{19}$

In contemporary policy, practice and research, it is acknowledged that perspectives of people with dementia cannot be omitted when investigating their care needs. A few studies have described expectations of people with dementia regarding the future and end-of-life care, ${ }^{20-22}$ their needs in early palliative care, ${ }^{23}$ and their perspectives on decision-making. ${ }^{24}$ Little research is currently available that elicits perspectives of people with early-stage dementia on receiving palliative care, on the approaching end of life and on discussing these issues. More awareness is needed of how people with dementia feel about their future, being cared for by others and discussing their end of life to adjust care provision to match their standards. The research question of the current study is: what are the perspectives of people with early-stage dementia on being cared for by others now and in the future and on the end of life? Simultaneously, the study explores the flow of conversations with people with dementia about the future and the end of life.

\section{METHODS}

This study is part of a larger project entitled DEDICATED (Desired Dementia Care Towards End of Life). The goal of DEDICATED is to develop a method for long-term care staff, which aims to improve person-centered palliative care for people with dementia. The current study belongs to a series of studies that investigate the needs in palliative dementia care from different perspectives. It builds on previous findings from a scoping review $^{25}$ and a survey ${ }^{26}$ on the needs of nursing staff, a secondary data analysis ${ }^{27}$ and an interview study on families' experiences with end-of-life care. ${ }^{28}$

\section{Research design}

We used a qualitative descriptive design and adopted a general naturalistic inquiry approach. ${ }^{29}$ Data collection involved individual, semi-structured, in-depth interviews. We followed the Consolidated criteria for reporting qualitative research (COREQ ${ }^{30}$; see checklist in Appendix 1). 


\section{Participants and recruitment}

We recruited a criterion-based (Table 1), purposive sample of people with early-stage dementia. We aimed for a group comprising both males and females with varying ages above 64. Care professionals who collaborate in the DEDICATED project (i.e., dementia case managers, homecare nurses, a geriatrician, and a nurse practitioner in elderly care) recruited participants in the Southern Netherlands. Recruiters made a clinical judgment about participants' cognitive abilities and whether an individual would be competent to engage in an interview and to judge their own willingness to do so. In case of doubt, they approached a legal representative and asked their permission to approach the person with dementia. Recruiters verbally informed eligible participants and (if applicable) their legal representative about the study and asked consent to be contacted by the researcher. If interested, participants and (if applicable) their representative obtained an information letter and a flyer.

Table 1. Eligibility criteria for participation

\begin{tabular}{ll}
\hline Inclusion criteria & Exclusion criteria \\
\hline - At least 65 years old & - Insufficient understanding of the Dutch language \\
- Diagnosed with dementia & or dialect \\
- Living in the community or supported housing & - Living in a nursing home \\
- Informed about the study and willing to participate & Judged by healthcare professional (recruiter): \\
& - Unable or unwilling to participate in an \\
- Receiving varbe consent) & interview \\
Judged by healthcare professionanal (recruiter): & \\
- Sufficient awareness of having dementia & \\
- Competent to engage in an interview & \\
- Can judge own willingness to engage in an interview & \\
\hline
\end{tabular}

After one week, the researcher phoned the participant or the legal representative. They were then given the opportunity to ask additional questions and to indicate their interest in participating. Upon agreement, the researcher scheduled an appointment. The recruiters, who knew the participants well, were asked to inform the researchers beforehand about particularities that should be taken into account during the interview (such as sensitive topics or questions that could cause distress). The Research Ethics Committee (METCZ20180085) approved this study before its start. All participants verbally agreed to be interviewed. All participants or their legal representative provided written informed consent before the start of the interview. The recruiters had judged most participants to be competent to state their willingness to engage in the interview. A few participants who had a legal representative signing the informed consent form, gave verbal consent themselves. Participation was strictly voluntary and participants were free to withdraw their participation at any moment, for any reason. The recruiters approached 22 individuals. Four were not willing to participate. Main reasons for refusal were being occupied with other things (e.g., recovering from a fall, reorganizing the house) or legal representatives not wanting to overburden their relative. Table 2 depicts the 18 participants; 11 males and 7 females. Their mean age was 82 (SD, 9) years and ranged from 65 to 94 . The average duration of the interviews was 53 minutes (SD, 19) and ranged from 31 to 108 minutes.

\section{Data collection}

A topic list was used flexibly to structure the interviews (Appendix 2). It included questions about receiving care from others, the future and the end of life. It also included questions about interprofessional collaboration and transitions of care, however, these topics are not the focus of the current article. The topic list was informed by expert views (i.e., dementia case managers), relevant literature ${ }^{4,14}$ and results from our previous studies. ${ }^{25-28}$ For instance, the experts and our previous interview study with family caregivers emphasized the need for familiarity, which led to the question 'What do others need to know about you, to care for you properly?' To improve the topic list, we presented it to a working group of nurses, nurse managers, dementia case managers, and patient representatives. We conducted two rehearsal interviews to obtain feedback. These interviews were held with, respectively, a family caregiver and a woman with dementia. Both gave written informed consent confirming the official procedure. The latter interview was transcribed and used in the final analysis, with permission. Minor, mainly textual, adaptations were made based on comments from the working group and rehearsal interviews. For instance, we replaced some factual questions, such as 'who cares for you at home?' and 'how often do they come here?' with more general questions, such as 'do or did you receive help from other people?' and 'how do you feel about that?' Whereas the topic list remained unchanged throughout the further data collection period, experiences from previous interviews contributed to nuances in subsequent conversations (e.g., focus on specific topics, the introduction of topics, use of examples for clarification). Recruiters provided participants' demographic information including age, gender, and relationship with the informal caregiver (if present) before the interview.

Interviews were held between August 2018 and October 2019 and took place at the participants' own home at a time of their preference. Informal caregivers were allowed to be present in case this was preferred, though they were not actively involved in the interview. Two female researchers (SB and CK) with a background in respectively neuropsychology and biomedical sciences took turns leading the interviews. Both researchers were trained in qualitative interviewing as a part of their academic education and both had led in-depth interviews before. In addition, they received a short training on interviewing people with dementia (e.g., make participants feel at ease, adapt to participant's level of understanding) from a nurse practitioner in elderly care. During each interview, the leading interviewer was accompanied by a 
co-interviewer (SB, CK, or another member of the research team). The accompanying member observed and sporadically asked additional questions for clarification. Before the start of each interview, the researchers used reassuring communication ('small talk') to establish a trustful connection with the participant. The purpose of the interview was explained in clear language, guiding the participant through the consent form before obtaining written consent. The researchers emphasized that there were no right or wrong answers, and that they merely wished to learn from the perspectives of the person with dementia. Interviews were audio-recorded with the participants' permission. The researchers closely monitored the well-being and potential overburdening of participants during the interview by paying attention to signals of exhaustion, confusion, or negative emotions. When considered appropriate, the interviewer asked whether the participant needed a break or wanted to end the conversation. The leading interviewer shortly debriefed participants and (if present) their legal representative, and asked how they had experienced the conversation and how they felt about the interview topics. The researchers wrote brief field notes after the interviews regarding the atmosphere or particularities during the conversation. The scheduled duration of the interviews was 30-45 minutes.

The process of interviewing was guided by reflective bracketing. ${ }^{31}$ Before initiating data collection, reflective discussions took place between the researchers, dementia care professionals and informal caregivers about the process of interviewing people with dementia and the content of the interviews. Moreover, two rehearsal interviews and the subsequent feedback promoted reflection. Reflection helped to identify preexisting knowledge and it contributed to the researchers' awareness of their own role as interviewers, potential internal biases (e.g., prejudices about frail older people) and their own and others' assumptions and preconceptions on how persons with dementia perceive the end of life and on how they would respond to being interviewed. For instance, such assumptions included the idea that certain questions would be too complex (e.g., questions about potential future situations could be too cognitively challenging) or too confronting (e.g., questions about the future and end of life could induce distress in persons with a progressive illness).

To achieve openness, the interviewers used the attained self-awareness to set aside assumptions and preexisting knowledge about the study topic and about the participants. They applied specific interviewing skills to enable a vulnerable group to speak in an open and trustful environment. For instance, they applied principles of active listening. ${ }^{32}$ This involved nonverbal communication (e.g., adjusting one's height to level the other, adopt an open and attentive posture), reinforcement (e.g., encouraging the other to share their own opinion), open-ended questioning, paraphrasing and reflecting (e.g., checking whether one's interpretation is correct, referring to past statements). The interviewers used feedback obtained immediately after the interviews, their notes and (fragments of) the audio recordings to reflect on their own interviewing style and on the attainment of an open atmosphere.

\section{Data analysis}

Descriptive statistics for demographic variables (e.g., age, sex) were calculated in Microsoft Excel. All interviews were transcribed clean verbatim for analyses. An inductive content analysis was performed, as the phenomenon under study requires more comprehensive knowledge. ${ }^{33}$ The analysis was assisted by NVivo 12 software. Two researchers (SB and $\mathrm{CK}$ ) read the interview transcripts to familiarize with the participants' stories. The unit of analysis involved the transcripts and meaning units were fragments of texts (words, phrases or paragraphs), which were labelled with codes. Both researchers conducted inductive open coding separately on all transcripts and they met during regular analytical sessions to compare and discuss their coding. After analysis and discussion of the first three transcripts, the researchers used an agreed upon coding sheet with initial codes as a guide. In the continuing process, they labelled text fragments with initial codes when appropriate, altered initial codes, or formed additional inductive codes. After each next five interviews, the researchers compared their coding, discussed and refined codes that were added or altered, and revised the coding sheet accordingly. Coding continued until data saturation was reached, at which point labelling text fragments did not require new codes. To confirm this, the lead author reread all transcripts to ensure the codes covered all content related to being cared for by others, the future and the end of life. Next, the researchers grouped codes together based upon resemblances to create categories. The final step in the analysis involved abstraction by collapsing categories into broader themes that reflected the underlying meaning (i.e., latent content) of categories and relationships between them. ${ }^{33}$

The analysis process was iterative and involved multiple analytical sessions during which the researchers compared their codes and code descriptions. In case of controversy, the researchers went back to the text fragments to check which definition captured its meaning. They moved back and forth reflectively between code definitions and text fragments. Data abstraction was an iterative process as well. The coders discussed the grouping of codes into categories and the subsequent grouping of categories into themes. The coders used their analytic sessions to confirm the interpretation of patterns. The lead author (SB) met with the co-authors to seek agreement in data abstraction and the designation and interpretation of themes. This researcher-triangulation increased rigor of the analysis. All authors agreed upon an illustration that was developed inductively from the themes to depict how the themes interrelate. 
Table 2. Interview participant

\begin{tabular}{|c|c|c|c|c|}
\hline \multirow[t]{2}{*}{ Pseudonym } & \multirow[t]{2}{*}{ Sex } & \multirow{2}{*}{ Age } & \multicolumn{2}{|l|}{ Informal caregiver } \\
\hline & & & $\begin{array}{l}\text { Present? } \\
\end{array}$ & (Familial) relationship \\
\hline Vincent & Male & 80 & Yes & Unrelated informal caregiver \\
\hline Leonard & Male & 81 & Yes & Partner \\
\hline Benjamin & Male & 83 & Yes & Partner \\
\hline Oliver & Male & 83 & Yes & Partner \\
\hline Anna & Female & 85 & No & - \\
\hline James & Male & 77 & Yes & Partner \\
\hline Lucas $\dagger$ & Male & 86 & No & - \\
\hline Teddy $\ddagger$ & Male & 93 & Yes & Son \\
\hline Thomas & Male & 93 & No & - \\
\hline Nora & Female & 89 & Yes & Niece \\
\hline Joseph & Male & 73 & Yes & Partner \\
\hline Lucy & Female & 94 & Yes & Daughter \\
\hline David & Male & 72 & No & - \\
\hline John & Male & 65 & No & - \\
\hline Caroline & Female & 88 & Yes & Daughter \\
\hline Eva & Female & 87 & Yes & Daughter \\
\hline Julia & Female & 67 & Yes & Daughter \\
\hline Sophie & Female & 82 & Yes & Unrelated informal caregiver \\
\hline
\end{tabular}

$\dagger$ A formal caregiver (case manager) was present during this interview

\# The interviewee just moved to a residential care home and had more advanced dementia

\section{RESULTS}

The following section tells the participants' story using pseudonyms (Table 2). Each theme consists of underlying categories, which were formed from the coded interview transcripts (Table 3). Figure 1 shows interrelations between the five themes and visualizes tension between holding on and letting go, and resistance and resignation.

\begin{tabular}{|c|c|c|}
\hline Theme & Categories & Codes \\
\hline \multirow[t]{3}{*}{$\begin{array}{l}\text { My life still has value } \\
\text { and meaning }\end{array}$} & I want to engage in meaningful activities & $\begin{array}{l}\text { Keeping busy } \\
\text { Spending time purposefully }\end{array}$ \\
\hline & I want to be an active part of society & $\begin{array}{l}\text { Social engagement } \\
\text { Getting involved } \\
\text { Being put aside and forgotten }\end{array}$ \\
\hline & I want them to look at me as a human being & $\begin{array}{l}\text { Say my piece } \\
\text { Respect my dignity }\end{array}$ \\
\hline \multirow[t]{2}{*}{$\begin{array}{l}\text { I am my own unique } \\
\text { individual }\end{array}$} & I want to manage myself & $\begin{array}{l}\text { Do it myself } \\
\text { Do not want to be a burden }\end{array}$ \\
\hline & What defines me is what matters & $\begin{array}{l}\text { My own environment and habits } \\
\text { Memories that shaped me } \\
\text { Relationship to religion }\end{array}$ \\
\hline
\end{tabular}

\begin{tabular}{|c|c|c|}
\hline Theme & Categories & Codes \\
\hline \multirow{7}{*}{$\begin{array}{l}\text { I place my trust in other } \\
\text { people }\end{array}$} & \multirow[t]{4}{*}{ I appreciate professionals who care for me } & Valuing caregivers \\
\hline & & Having a connection \\
\hline & & Unburden loved ones \\
\hline & & Providing information \\
\hline & Others will know what is best for me & Others will know \\
\hline & \multirow[t]{2}{*}{ What would I do without them? } & Directed by others \\
\hline & & What to do without them \\
\hline \multirow[t]{5}{*}{ The future worries me } & \multirow[t]{3}{*}{ I am in a tough spot } & Confronted by decline \\
\hline & & It is about me now \\
\hline & & Tough world for older people \\
\hline & \multirow[t]{2}{*}{ I am keeping the future at a distance } & At a safe distance \\
\hline & & Staying at home for now \\
\hline \multirow{10}{*}{$\begin{array}{l}\text { I accept and embrace } \\
\text { what life brings }\end{array}$} & \multirow[t]{3}{*}{ I am letting go } & Acceptance \\
\hline & & Ways to cope \\
\hline & & Nothing more to ask for \\
\hline & \multirow[t]{4}{*}{ This is all I hope for } & Hope \\
\hline & & Content with this life \\
\hline & & The future is now \\
\hline & & Carrying on \\
\hline & \multirow[t]{3}{*}{ It ends for all of us some day } & Not a taboo topic \\
\hline & & The future will tell \\
\hline & & All taken care of \\
\hline
\end{tabular}

\section{My life still has value and meaning}

When thinking about the future, the participants emphasized the importance of living a worthy and valuable life. As the dementia progressed, they insisted to hold on to activities that have meaning to them. They wanted to stay part of society and the social world. They wished for others to see their worth as a fellow, equal human being.

I want to engage in meaningful activities

It was important for participants to engage in activities that were meaningful and pleasant. For instance, particular hobbies in and around their own house, such as walking, reading the newspaper or doing the laundry, or activities organized by others (e.g., day care services)

Well, we usually walk around outside. Gives you something to do, gives you the feeling that you can still do something valuable. (Vincent)

Meaningful activities were activities that the person had been used to doing throughout his or her life. Sometimes trying new activities was appreciated, though there was a lot of variety in personal interests and in the type of activities that individuals (would) want to engage in, either in the community or in a facility. It was important for the participants that (future) caregivers considered these preferences. 
I am passionate about music. Yes, having the opportunity [to make music], that would be ideal. (David)

I want to be an active part of society

Besides engaging in purposeful activities, participants emphasized that they wanted to stay an active member of society. They did not want to be set aside, even when the dementia got worse.

Well, that I can still do what I do, and that I am not put into a corner like an old doll. (Vincent)

Ways of staying an active and involved member of society included following the news, going out in public or joining clubs or committees. Most importantly, participants wanted to maintain social connections. They valued spending time with family members, friends, or other people who share the experience of living with dementia.

I like living here, and I am also, I am not lonely. I get a lot of visitors and [daughter] picks me up every weekend, sometimes. (Lucy)

I want them to look at me as a human being

Thinking about other people who care for them, one of the most important things for participants was that they could speak up and that they were heard.

Well, for starters, talk to me like an equal, you know, I always appreciate that very much. (Lucas)

Some of the participants mentioned that it bothered them to think that other people, mainly professional caregivers, were not taking them seriously. Moreover, it was important for participants to maintain their dignity, particularly when other people took over certain (intimate) care tasks. Thinking about the future, if the dementia got worse, some participants feared losing their dignity. Being treated carefully and with respect may help to accept others' assistance while maintaining a feeling of self-worth.

Well, you will simply get used to it [being cared for by others], you can accept it more easily when they explain to you 'see, I am here to care for you', and that they respect a person's dignity. (Vincent)

\section{I am my own unique individual}

The participants wanted to be seen as full-fledged members of human society. They wanted others to see them for autonomous, unique individuals, with their own wishes, uses and particularities that define them.

I want to manage myself

All participants appreciated doing things in their own way and independently of others. Throughout their lives, they had been independent individuals and they were still very keen on managing themselves.

No, I am not that dependent, I prefer to manage myself, actually. And I prefer to make my own decisions. (Thomas)

Some of them found it difficult to accept assistance from others. Moreover, some disliked the feeling of being a burden to others, or that they had to depend on others to fulfil their needs. They tried to do as much as they could by themselves, as long as they were still capable. It annoyed some of the participants when people took over tasks that they could easily do by themselves.

Well, I always say that everything that I can do myself, they should not do that for me, I want to do that myself. That is training. If you do sports, you have to practice every day as well. (Eva)

They thought that professional caregivers should be kept at bay as long as possible, or at least their assistance should be kept to a minimum. The thought of becoming more dependent in the future bothered or even scared some of the participants.

That I cannot, that I will become dependent on other people. That I will have to wait until someone gets there to wash me and I don't know what else, argh, that seems terrible to me. (Anna)

What defines me is what matters

All participants were keen on their own environment and routines. They liked to be at home, surrounded by their own things and the people that are familiar to them. Most of them knew their neighborhood and hoped to stay in this familiar place in the future. Participants were inclined to talk about their memories: particular moments or situations that shaped them through the course of life. These private, unique stories had sometimes had an impact on their stance towards others and their view on life.

The first thing that comes to mind is that, if you have been a teacher for years, standing in front of a class full of teenagers, you are armed. Yes, I think, by being a teacher, I have learned about all these different characters, and you have those here [day care] as well. (Lucas) 
Another factor that helped shape the participants' perspectives on life was religion. Most of them still found support in religion or religious activities such as saying prayers.

\section{I still pray every day. And I pray every night before I go to bed. (Lucy)}

Some had mixed feelings about religion. One participant had a special interest in Buddhism. A few others had distanced themselves from the church or showed little interest in religion. Most participants barely felt the need to discuss this topic with professional caregivers; it was more of a private matter to them.

\section{I place my trust in other people}

Although the participants preferred to do things by themselves, most of them also trusted other people who cared for them then or who might care for them in the future. They typically spoke warmly about these others. Most seemed prepared to put their trust in others to care for them, to make decisions for them, or to manage other aspects of their life.

I appreciate professionals who care for me

Talking about professional caregivers such as the family doctor, the case manager and homecare workers, participants primarily expressed gratefulness and admiration. Most of them recognized that they need care or support in certain aspects of life, or that they might need more care and support someday. Their expectations of having professionals caring for them were partly based on experiences in other situations (e.g., receiving care in the hospital, witnessing professionals caring for a family member). Some participants did receive homecare themselves and they praised professional caregivers for being hardworking and skillful.

Well, in the first place that they are very good at what they do (...). They are skillful. They are really doing an excellent job. (James)

Moreover, some participants recognized that professional caregivers may help to unburden family caregivers. It was very important to the participants to build a trustful, empathetic care relationship with professional caregivers. Therein, it is important to get to know each other and to invest in an honest, harmonious connection.

[Case manager] treats me very well. As if we are two close friends. (Oliver)

Yes, they enjoy being here, we always make it a pleasant occasion, I always have coffee ready (...). If you trust each other, everything else will be better too. (Eva)
Getting familiar and building rapport were considered essential for a good care relationship. Also, humor was valuable to some of the participants.

Well, sometimes it is simply hilarious, (...) a somewhat older person who, well, who also held the opinion that a good laugh was very welcome, as we were no at the funeral yet, you know. And this [humor] was applied, which was very pleasant. (Leonard)

Others will know what is best for me

Although participants valued making their own decisions and speaking up for themselves; when it comes to making decisions surrounding the end of life they placed a lot of trust in others. Even when they had not explicitly talked about their wishes, participants trusted their loved ones to be aware of what they would or would not want.

Well, I think that it means that, without having discussed it, we believe that we naturally know these things about each other. In good faith. (Lucas)

These 'trusted others' were generally partners, family members or other informal caregivers, whereas a few participants mentioned physicians. For some of the participants, their trust in others was linked to the absence of clear advance directives and not having formally discussed end-of-life decisions.

No, but I think that doctors are very good at foreseeing how a patient will recover from anesthesia or whatever they have to recover from. (Eva)

Yeah well, what should I be thinking about that [the future]? I leave myself to others, you know. (Teddy)

What would I do without them?

Most of the participants recognized that other people played an increasingly important role in their lives. Participants needed help and support in certain areas of life, as some things were not as easy as they used to be.

You take this into account of course, that you cannot do everything by yourself anymore, so you have to hire other people to do things for you, so to speak (Vincent)

Most participants accepted this and they welcomed loved ones and other individuals entering their life and providing support. Nonetheless, a few of them noted that it was hectic at times. Especially when multiple unfamiliar faces got involved within a short period. 
participants witnessed others with dementia in later stages and they considered that the same might be waiting for them, which was a confronting thought.

Most importantly, loved ones often took on a prominent supporting role and participants appreciated them for helping out and taking over tasks. What would I do without them? Although this question reflected gratefulness, for some participants it also reflected anxiety.

I say this a hundred times a day. What would I do if she was not here? She does everything for me. (Benjamin)

\section{The future worries me}

All participants experienced, in one way or another, confrontation by decline. Former activities were becoming more and more difficult to pursue and some participants already had to give up on them. For some, observing this deterioration made it uneasy or unpleasant to think about the future, knowing that things might 'get worse'. This triggered a sense of resistance.

\section{I am in a tough spot}

The participants were aware of their condition and they recognized that they did not function in their daily lives the way they used to. A few of them also disliked the quick digitalization of society and their inability to follow along. It bothered most of the participants that seemingly simple abilities that they used to take for granted, were now challenging them in their daily routines.

Well, it is not pleasant, I can tell you. I have always done everything by myself, and then suddenly, it is all gone. (Nora)

I stood there with my $t$-shirt in my hands and I just did not know where to start. What do I do with this thing? What is this? Well, that was not a pretty sight (Joseph)

Most of them were also aware of the likeliness that their memory and overall functioning would decline further, which was an unsettling thought. Some participants expressed worries about having to leave their own home.

Yes, that scares me. If I would not know what is going on anymore, that I would have to leave this place [home]. (Lucy)

Thinking about the future, participants were uncertain and it was hard for them to imagine what awaits. This uncertainty raised concerns for some of them. Some of the
I do not want to end up walking around a ward with a doll, like my mother in law. Or like people that are rattling at the door because they want to go home, to their children or to their mommy or daddy. (Julia)

I am keeping the future at a distance

Thinking about the future and potential scenarios in case the dementia would get worse was unpleasant and therefore, most participants preferred keeping the future 'at bay'.

I am not going to wrap my head around it [the future]. I am living right now, and how things will be in the future, well, I will see when I get there. (John)

Some of them recognized this as an avoidant way of coping with unpleasant thoughts about the future. Others stated that they did not care about the future or the end of life and therefore did not bother to talk about it.

See, people talking about dying, for instance. I do not care about that at all

(...). I assume that I will stay alive, period. (Thomas)

A few of the participants never considered discussing end-of-life wishes before and they wondered whether it might be useful. Some of them recognized that it is something that they would need to think or talk about at some point, but they mostly stated that now is not the time.

If I have to suffer, there is still plenty of time to talk about it. For now, just leave me be. (Eva) leave their own home caused distress and was therefore preferably avoided.

\section{I accept and embrace what life brings}

In contrast to the ominousness and, at times, anxiety experienced by participants when thinking about the future, they also expressed hope, acceptance, and contentment with life. Most participants lived day by day and tried to make the most out of their lives. They accepted losses, dealt with challenges and found ways to cope with their condition. Most participants expressed contentment with the life they had lived and that they were living. Also, most were rather down-to-earth about the end of life, regarding it as something that all of us will have to deal with someday and that we have no control over.
For some, thinking or talking about the future or specifically thinking about having to 
I am letting go

The participants had developed ways to deal with and adapt to their gradual losses. They tried to seize the days while they last and most of them expressed gratitude for things that they were still able to do. Besides living their life as it was now, there was not much more for them to ask for

You know, so, you just have to learn to live with it and be grateful that you can still do things. (Vincent)

Most of them were aware that there was nothing that they could do about their decline and some stated that acceptance is key to still living a pleasurable life. As most things in life, living with dementia is something that one had to get used to.

Everything is still alright, as long as you do not put up a fight. (Caroline)

\section{This is all I hope for}

The participants expressed contentment with the life they were currently living and the life they had lived. They did not hope for a lot more in the future and mainly wished that things would stay the way that they were now for as long as possible.

Yes, I am a very content person. Where I am, what I do, honestly. As long as she is here with me, nothing bad can happen to me. (Joseph)

They primarily hoped to stay healthy for a bit longer and most of them had a positive stance towards the days that were to come in the near future. Some of the participants believed that there was no future beyond these days; their time had come and gone, and that was alright.

I do not really have much of a future anymore, I have lived through it all, I have lived a very good and pleasant life. (Eva)

It ends for all of us someday

The end of life is an ambiguous topic and most of the participants expressed mixed feelings when talking about it. The end of life was somewhat mysterious and although thinking or talking about death was upsetting for a few of them, most participants also expressed resignation and regarded death as something inevitable that awaits all humans one day.

Yes, well, it [dying] can happen and it can happen to anyone, and the older you get, the higher the odds, I presume. (Sophie)
Accordingly, most participants 'had taken care of' certain arrangements surrounding the end of life, such as creating a living will or discussing or documenting wishes about after their death.

I am very down to earth when it comes to that. (...) My children know what needs to happen, they know where I wish to be cremated and they know where I want them to scatter my ashes. (Anna)

No one knows what the future will bring. Therefore, some participants were skeptical about 'directing' the end of life, even though death was not necessarily a taboo topic.

You can, look how things will work out in the end... Anyway, that will mainly unfold as it happens, when or wherever that is, I think. (Leonard)

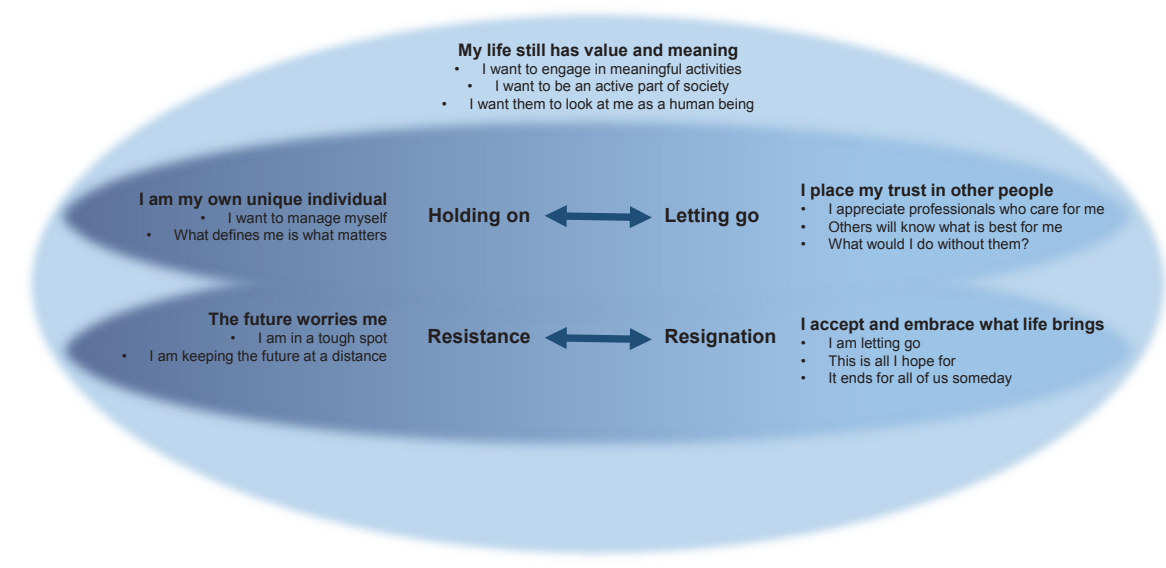

Figure 1. Conceptual illustration of the interrelations between the five main themes, abstracted from categories. The illustration visualizes tension between holding on and letting go, and resistance and resignation

\section{DISCUSSION}

This study shows the perspectives of people with dementia on being cared for by others, on their future, and on the end of life. It shows that not only the participants were capable of having a conversation about the future and the end of life; they were also willing to share their thoughts. They offered valuable insight into their perspectives. The participants expressed a strong wish to live a meaningful life and to be seen by others 
as worthy and unique humans. They wanted to stay active and involved as a member of society for as long as possible. Nonetheless, the participants were confronted with their declining functioning, which posed challenges to maintaining their independence in daily routines and activities. The thought of further decline was unpleasant and participants preferred distancing themselves from this worrying future. They were generally content with their current existence and tended to live day by day. They wished for things to stay this way and they did not hope for much more. Although they wished to remain autonomous for as long as possible, they placed a fair amount of trust in others to support them, care for them or make decisions for them about the end of life. They appreciated other people who helped them and they valued trustful and friendly connections. Although ambiguity and sometimes anxiety or denial lingered when thinking about the future, most participants perceived death itself as something inevitable, which involved a sense of resignation.

\section{Meaning of life and personhood}

People with dementia in previous studies expressed aspects that are important to their quality of life, which include overall well-being and functioning, participation in activities, maintaining friendships, and having a sense of belonging. ${ }^{34}$ In their review, de Boer and colleagues ${ }^{34}$ focused on how people with dementia experience living with the condition. Although our study had a different focus, we found a similar desire of people with dementia to stay an active member of society and to be valued by others as an individual, also through the later stages. The need for belongingness and recognition are basic and universal psychological needs. ${ }^{35}$ Fulfilling these needs through engagement in meaningful activities and participation in day-to-day life are important to life meaning and well-being. ${ }^{36}$ In our study, while talking about the future and dependency on others for care towards the end of life, these basic human needs surfaced. The findings point to specific expectations, beliefs or fears that people with dementia hold about their future, in which those needs may be compromised. Similarly, a previous study found that people with dementia fear 'losing control', which involves a fear of dependency, being a burden to others, and loss of role functioning. ${ }^{22}$ The wish to live a worthy and meaningful life might be challenged when one has dementia, as in western society cognitive functions are viewed as core human abilities and prerequisites to maintain self-control, independence, personhood, and meaningful relations with others. ${ }^{37}$ Descartes' famous quote "Cogito ergo sum", "I think, therefore I am" is fundamental in western philosophy and suggests that 'thinking' (i.e., cognition) is inextricably linked to 'being. Person-centered care in dementia promotes personhood and aims to foster a sense of belongingness through empathetic care relationships characterized by recognition, respect, and trust. ${ }^{38}$ Our results underline the importance of empathetic relationships and suggest that 'being seen' by others is highly valuable to people living with early-stage dementia.

\section{(Blindly) trusting others in end-of-life decision-making}

Most participants in our study were willing to talk about their view on the end of life and on discussing care plans, although some declared disinterest or unwillingness to think about, or plan for the future. Shared decision-making and advanced care planning are suggested key elements of palliative dementia care. ${ }^{4}$ In our study, some of the participants reported that they had not discussed future care simply because no one had asked them about it. The provision of information and the initiation of advance care planning is primarily the responsibility of healthcare professionals, albeit tailored to the individual's readiness. ${ }^{8,39}$ Similar to previous findings, ${ }^{21}$ participants in our study who reported to have 'taken care of' end-of-life arrangements often referred to living wills or post-death arrangements rather than details about future care. Moreover, as in our study, people with early-stage dementia may feel it is not yet 'time' to discuss end-of-life wishes formally. ${ }^{40}$ More research is needed to investigate how advance care planning for people with dementia can be implemented into practice and to inform healthcare professionals on proper ways to establish shared-decision making in setting goals of (palliative) care.

The participants in our study commonly trusted their loved ones to make the right decisions on their behalf, even if their wishes had not been discussed. This corresponds to previous findings, which describe confidence of people with dementia in their family members to know and advocate for their wishes at the end of life. ${ }^{21}$ The eminent trust of people with dementia in their family members to manage their care is at odds with experiences of families with end-of-life care, who may feel unprepared. ${ }^{41,42}$ Nonetheless, in a previous study we found that family caregivers of people with dementia sometimes felt confident in making decisions even if the person with dementia had never discussed the end of life with them. ${ }^{28}$ There are many factors that influence experiences with proxy decision-making other than the presence or absence of explicit end-of-life wishes. ${ }^{19,43,44}$ Previous studies emphasize the importance of trust between proxy decision-makers and staff in long-term care. ${ }^{28,45}$ A trustful care relationship contributes to proxies' confidence and an overall positive experience with decision-making.

\section{Coping and the tension between holding on and letting go}

The impact of living with dementia on one's quality of life is influenced by coping strategies used by people with dementia. ${ }^{34}$ Coping strategies show how people come to terms with their condition. In our study, participants merely demonstrated resilience. They aimed to continue living their lives by staying active and socially involved. Some openly struggled with bothersome symptoms, whereas others minimized or normalized having dementia or used humor to cope.Strategies of denial and avoidance mainly applied to (not) thinking about the end of life. Coping strategies used by people with dementia may serve self-maintenance or self-adjustment and the types of coping strategies used by individuals may change as the dementia progresses. ${ }^{46}$ Fetherstonhaugh and 
colleagues $^{24}$ found that people with dementia prefer if others provide 'subtle support', enabling them to maintain feelings of control and independence in their decisions and choices. They experience a tension between letting go and wanting to hold on to their abilities for as long as possible. Our study adds to these findings by demonstrating that the tension between holding on and letting go extends beyond decision-making and coping strategies, and applies to the overall experience of living with, coming to terms with, and thinking about the future with dementia. Future research may explore how specific coping mechanisms relate to readiness for end-of-life communication.

\section{Limitations and strengths}

The study used a purposive, criterion-based sample recruited by care professionals. Recruiters made a judgment about potential participants' willingness and ability to be interviewed based on their knowledge of the individual resulting from an established care relationship. This fact may have biased the results as people that were not considered willing or able to be interviewed may hold different perspectives. The participants' responses may be biased as individuals who are prepared to openly discuss end-of-life topics may be more likely to participate.

During some of the interviews, an informal caregiver was present. Although they were not formally involved and requested not to interfere, some had additional remarks or helped the person with dementia to answer questions. During one interview, a formal caregiver insisted on being present and intervened several times during the conversation (e.g., commenting on the difficulty of questions being asked). One participant had just moved to a care home and had more advanced dementia. Although he did not understand some of the questions, he touched on the same themes. This suggests that the findings may apply to people in different stages of dementia. A predefined topic list guided the interviews; although participants were invited to address additional topics, certain aspects were not questioned nor addressed (e.g., sexuality).

This study's key strength is that it describes the perspective of people with dementia themselves while simultaneously demonstrating the capability of people with dementia to discuss the future and the end of life. During the interviews, the researchers pursued openness, which meant increased self-awareness and setting aside judgments and personal perspectives. This supported a trustful and safe interview environment and researchers' receptiveness to the participants' perspectives. Interview transcripts hold multiple meanings and an interviewer's frame of reference and personal characteristics (e.g., age, gender, education, and religious or spiritual belief systems) may affect data collection and interpretation. ${ }^{47}$ The frequent analytical discussions enabled reflection on the researchers' own position throughout this study (e.g., role as interviewers, possible biases and influence on the research). The reflective nature of the process strengthened the rigor of the analysis and the trustworthiness of the findings.

\section{CONCLUSIONS}

When thinking about the future and the end of life, the people with dementia in this study expressed a variety of feelings, such as ambiguity, anxiety, contentment, and resignation. Despite fear of further decline and dependency, they demonstrated resilience and acceptance towards death. The individuals expressed thankfulness for the life that they had lived and they hoped for things to stay the same for as long as possible. When thinking about being cared for by others, the individuals in this study expressed appreciation and trust. They had a particularly strong wish to live a worthy and meaningful life and to maintain uniqueness and belongingness until the end of life. Others should regard and treat people with dementia as equal and worthy human beings to fulfil their basic human need to 'matter' and to 'belong'.

\section{RELEVANCE TO CLINICAL PRACTICE}

This study holds particular practical value by demonstrating that, when given the opportunity, most participants with dementia showed openness, willingness, and capability to discuss the future and the end of life in a non-medical informal setting. Some of the participants did not recall having been asked about their end-of-life wishes and wondered whether it would be helpful to discuss this some time. Public and professional awareness is needed on the value of (informal) end-of-life conversations. Although this may be particularly relevant with regard to dementia, awareness and normalization of end-of-life communication may also serve other populations with chronic life-limiting conditions. Training and education is needed to equip healthcare professionals to inform people with dementia and their families and to initiate such conversations in a sensitive manner. ${ }^{48}$

The current findings add to the literature as they evoke questions about the appropriateness and desirability of advance care planning for people with dementia. As an important part of an early palliative care approach, conversations in the context of advance care planning should be tailored to an individual's life view, preferences, and readiness to talk. A wish to refrain from talking about the future and to relinquish care decisions to (knowledgeable) others should be respected. Yet, opportunities for conversations about future care and the end of life should be offered regularly, as individuals' readiness to talk may change. The process of advance care planning itself may promote such readiness. ${ }^{39}$ Our study demonstrates that even persons who do not wish to discuss their end of life may be willing to share their thoughts on the future and on why they would or would not bother to discuss or document care wishes in advance. When aiming to discuss the future, it might be helpful to first explore how individuals cope with their condition. 
Healthcare professionals should invest in building equal and trustful care relationships with persons with dementia and their family caregivers. To achieve this, one should acknowledge ('see') the person with dementia and invest in getting to know them. A previously described culture change movement toward person-centered care in nursing homes, ${ }^{49}$ applies to a range of settings in which people with dementia reside, including the community. In adopting a palliative approach to care for persons with dementia and their families, communities and care organizations should promote person-centeredness and relationship-centeredness by fostering belongingness of people with dementia and by involving family caregivers. It is important that longterm care managers facilitate healthcare professionals to apply person-centered and relationship-centered care, for instance by giving them sufficient time and space to build strong relationships. Policy makers may promote person-centeredness by setting up dementia-friendly policies and by funding initiatives that support participation of people with dementia in society.

\section{REFERENCES}

1. World Health Organization. Dementia: a public health priority. World Health Organization, 2012 9241564458 .

2. van Wijngaarden E, Alma M, The AM. 'The eyes of others' are what really matters: The experience of living with dementia from an insider perspective. PLoS One. 2019;14(4):e0214724.

3. Brodaty H, Seeher K, Gibson L. Dementia time to death: a systematic literature review on survival time and years of life lost in people with dementia. Int Psychogeriatr. 2012;24(7):1034-45.

4. van der Steen JT, Radbruch L, Hertogh CM, de Boer ME, Hughes JC, Larkin P, et al. White paper defining optimal palliative care in older people with dementia: a Delphi study and recommendations from the European Association for Palliative Care. Palliat Med. 2014;28(3):197-209.

5. Sawatzky R, Porterfield P, Lee J, Dixon D, Lounsbury K, Pesut B, et al. Conceptual foundations of a palliative approach: a knowledge synthesis. BMC Palliat Care. 2016;15(1):5.

6. Lee RP, Bamford C, Poole M, McLellan E, Exley C, Robinson L. End of life care for people with dementia: The views of health professionals, social care service managers and frontline staff on key requirements for good practice. PLoS One. 2017;12(6):e0179355.

7. Poppe M, Burleigh S, Banerjee S. Qualitative Evaluation of Advanced Care Planning in Early Dementia (ACPED). PLoS One. 2013;8(4):e60412

8. Sinclair JB, Oyebode JR, Owens RG. Consensus views on advance care planning for dementia: a Delphi study. Health \& Social Care in the Community. 2016;24(2):165-74.

9. Livingston G, Pitfield C, Morris J, Manela M, Lewis-Holmes E, Jacobs H. Care at the end of life for people with dementia living in a care home: a qualitative study of staff experience and attitudes. Int J Geriatr Psychiatry. 2012;27(6):643-50.

10. Harrison Dening K, Jones L, Sampson EL. Advance care planning for people with dementia: a review. Int Psychogeriatr. 2011;23(10):1535-51.

11. van der Steen JT. Dying with dementia: what we know after more than a decade of research. J Alzheimers Dis. 2010;22(1):37-55.

12. van Riet Paap J, Mariani E, Chattat R, Koopmans R, Kerherve H, Leppert W, et al. Identification of the palliative phase in people with dementia: a variety of opinions between healthcare professionals. BMC Palliat Care. 2015;14:56

13. Hill SR, Mason H, Poole M, Vale L, Robinson L. What is important at the end of life for people with dementia? The views of people with dementia and their carers. Int J Geriatr Psychiatry. 2017;32(9):1037-45.

14. Perrar KM, Schmidt H, Eisenmann Y, Cremer B, Voltz R. Needs of people with severe dementia at the endof-life: a systematic review. Journal of Alzheimer's Disease. 2015;43(2):397-413.

15. Neumann PJ, Araki SS, Gutterman EM. The use of proxy respondents in studies of older adults: lessons, challenges, and opportunities. J Am Geriatr Soc. 2000;48(12):1646-54.

16. Beerens HC, Zwakhalen SMG, Verbeek H, Ruwaard D, Hamers JPH. Factors associated with quality of life of people with dementia in long-term care facilities: A systematic review. International Journal of Nursing Studies. 2013;50(9):1259-70.

17. Bowling A, Rowe G, Adams S, Sands P, Samsi K, Crane M, et al. Quality of life in dementia: a systematically conducted narrative review of dementia-specific measurement scales. Aging Ment Health. 2015;19(1):13-

18. Griffiths AW, Smith SJ, Martin A, Meads D, Kelley R, Surr CA. Exploring self-report and proxy-report qualityof-life measures for people living with dementia in care homes. Qual Life Res. 2019.

19. Harrison Dening K, King M, Jones L, Vickestaff V, Sampson EL. Advance Care Planning in Dementia: Do Family Carers Know the Treatment Preferences of People with Early Dementia? PLoS One. 2016;11(7):e0159056.

20. Goodman C, Amador S, Elmore N, Machen I, Mathie E. Preferences and priorities for ongoing and end-oflife care: A qualitative study of older people with dementia resident in care homes. International Journal of Nursing Studies. 2013;50(12):1639-47.

21. Poole M, Bamford C, McLellan E, Lee RP, Exley C, Hughes JC, et al. End-of-life care: A qualitative study comparing the views of people with dementia and family carers. Palliat Med. 2018;32(3):631-42.

22. Read ST, Toye C, Wynaden D. Experiences and expectations of living with dementia: A qualitative study. 
Collegian. 2017;24(5):427-32

23. Beernaert K, Deliens L, De Vleminck A, Devroey D, Pardon K, Block LVd, et al. Is There a Need for Early Palliative Care in Patients With Life-Limiting Illnesses? Interview Study With Patients About Experienced Care Needs From Diagnosis Onward. American Journal of Hospice and Palliative Medicine ${ }^{\circledR}$. 2016;33(5):489-97.

24. Fetherstonhaugh D, Tarzia L, Nay R. Being central to decision making means I am still here!: the essence of decision making for people with dementia. J Aging Stud. 2013;27(2):143-50.

25. Bolt SR, van der Steen JT, Schols JMGA, Zwakhalen SMG, Pieters S, Meijers JMM. Nursing staff needs in providing palliative care for people with dementia at home or in long-term care facilities: A scoping review. Int J Nurs Stud. 2019;96:143-52.

26. Bolt SR, Meijers JMM, van der Steen JT, Schols JMGA, Zwakhalen SMG. Nursing Staff Needs in Providing Palliative Care for Persons With Dementia at Home or in Nursing Homes: A Survey. Journal of Nursing Scholarship. 2020;52(2):164-73.

27. Bolt SR, Verbeek L, Meijers JMM, van der Steen JT. Families' Experiences With End-of-Life Care in Nursing Homes and Associations With Dying Peacefully With Dementia J Am Med Dir Assoc. 2019;20(3):268-72.

28. Bolt SR, van der Steen JT, Schols JMGA, Zwakhalen SMG, Meijers JMM. What do relatives value most in endof-life care for people with dementia? Int J Palliat Nurs. 2019;25(9):432-42.

29. Sandelowski M. Whatever happened to qualitative description? Research in Nursing \& Health. 2000;23(4):334-40

30. Tong A, Sainsbury P, Craig J. Consolidated criteria for reporting qualitative research (COREQ): a 32-item checklist for interviews and focus groups. International Journal for Quality in Health Care. 2007;19(6):34957.

31. Tufford L, Newman P. Bracketing in qualitative research. Qualitative Social Work: Research and Practice. 2012;11(1):80-96.

32. Hargie 0. Skilled interpersonal communication: Research, theory and practice (5th ed.): Routledge; 2011.

33. Elo S, Kyngäs H. The qualitative content analysis process. Journal of Advanced Nursing. 2008;62(1):107-

34. de Boer ME, Hertogh CM, Droes RM, Riphagen, II, Jonker C, Eefsting JA. Suffering from dementia - the patient's perspective: a review of the literature. Int Psychogeriatr. 2007;19(6):1021-39.

35. Maslow AH. A theory of human motivation. Psychological review. 1943;50(4):370

35. Maslow AH. A heory o human motivation. Psychological review. $1943,50(4): 370$. test of the meaningful activity and life meaning model. OTJR (Thorofare N J). 2013;33(2):100-9.

37. Post SG. The concept of Alzheimer disease in a hypercognitive society. Concepts of Alzheimer disease: Biological, clinical and cultural perspectives. 2000:245-56.

38. Kitwood TM, Bredin K. Towards a Theory of Dementia Care: Personhood and Well-being. Ageing and Society. 1992;12(3):269-87.

39. Zwakman M, Jabbarian LJ, van Delden J, van der Heide A, Korfage IJ, Pollock K, et al. Advance care planning: A systematic review about experiences of patients with a life-threatening or life-limiting illness. Palliat Med. 2018;32(8):1305-21.

40. Dickinson C, Bamford C, Exley C, Emmett C, Hughes J, Robinson L. Planning for tomorrow whilst living for today: the views of people with dementia and their families on advance care planning. Int Psychogeriatr. 2013;25(12):2011-21.

41. Caron CD, Griffith J, Arcand M. End-of-life decision making in dementia:The perspective of family caregivers. Dementia. 2005;4(1):113-36

42. Forbes S, Bern-Klug M, Gessert C. End-of-Life Decision Making for Nursing Home Residents with Dementia. Journal of Nursing Scholarship. 2000;32(3):251-8.

43. Hirschman KB, Kapo JM, Karlawish JHT. Why Doesn't a Family Member of a Person With Advanced Dementia Use a Substituted Judgment When Making a Decision for That Person? The American Journal of Geriatric Psychiatry. 2006;14(8):659-67.

44. Kwak J, De Larwelle JA, Valuch Ko, Kesler T. Role of Advance Care Planning in Proxy Decision Making Among Individuals With Dementia and Their Family Caregivers. Res Gerontol Nurs. 2016;9(2):72-80.

45. Cresp SJ, Lee SF, Moss C. Substitute decision makers' experiences of making decisions at end of life for older persons with dementia: A systematic review and qualitative meta-synthesis. Dementia (London).
2018:1471301218802127.

46. Steeman $\mathrm{F}$ de Casterle BD, Godderis J, Grypdonck M. Living with early-stage dementia: a review of qualitative studies.J Adv Nurs. 2006:54(6):722-38.

47. Graneheim UH. Lundman B. Qualitative content analysis in nursing research: concepts, procedures and measures to achieve trustworthiness. Nurse Educ Today. 2004;24(2):105-12.

48. Harrison Dening K, Sampson EL, De Vries K. Advance care planning in dementia: recommendations for healthcare professionals. Palliative Care: Research and Treatment. 2019;12:1178224219826579.

49. Koren M]. Person-centered care for nursing home residents: the culture-change movement. Health Aff (Millwood). 2010;29(2):312-7. 
APPENDIX 1. Consolidated criteria for reporting qualitative studies (COREQ)

\begin{tabular}{|c|c|c|c|}
\hline \multicolumn{2}{|c|}{ Item } & Guide Questions/Description & $\begin{array}{l}\text { Reported on Page No. and/ } \\
\text { or description }\end{array}$ \\
\hline \multicolumn{4}{|c|}{ Domain 1: Research team and reflexivity } \\
\hline \multicolumn{4}{|c|}{ Personal Characteristics } \\
\hline 1. & Interviewer/facilitator & $\begin{array}{l}\text { Which author/s conducted the interview } \\
\text { or focus group? }\end{array}$ & Title page + page 6 \\
\hline 2. & Credentials & What were the researcher's credentials? & Both MSc, Title page \\
\hline 3. & Occupation & $\begin{array}{l}\text { What was their occupation at the time of } \\
\text { the study? }\end{array}$ & $\begin{array}{l}\text { Both } \mathrm{PhD} \text { candidates at the } \\
\text { reported affiliation (Title } \\
\text { page) }\end{array}$ \\
\hline 4. & Gender & Was the researcher male or female? & Page 6 \\
\hline 5. & Experience and training & $\begin{array}{l}\text { What experience or training did the } \\
\text { researcher have? }\end{array}$ & Page 6-7 \\
\hline \multicolumn{4}{|c|}{ Relationship with participants } \\
\hline 6. & Relationship established & $\begin{array}{l}\text { Was a relationship established prior to } \\
\text { study commencement? }\end{array}$ & $\begin{array}{l}\text { The researchers did not } \\
\text { established a relationship } \\
\text { with the interviewees before } \\
\text { the study commenced. } \\
\text { Participants were recruited by } \\
\text { their professional caregivers. } \\
\text { Page } 5\end{array}$ \\
\hline 7. & $\begin{array}{l}\text { Participant knowledge of the } \\
\text { interviewer }\end{array}$ & $\begin{array}{l}\text { What did the participants know about } \\
\text { the researcher? e.g. personal goals, } \\
\text { reasons for doing the research }\end{array}$ & $\begin{array}{l}\text { The information letter/ } \\
\text { flyer explained the goal of } \\
\text { the interviews and included } \\
\text { information about the } \\
\text { affiliation of the researchers. } \\
\text { Page } 5 \\
\text { The researchers repeated } \\
\text { their objectives and reasons } \\
\text { for conducting the study on } \\
\text { the interview day, before the } \\
\text { start of the interview. } \\
\text { Page } 7\end{array}$ \\
\hline 8. & Interviewer characteristics & $\begin{array}{l}\text { What characteristics were reported } \\
\text { about the interviewer/facilitator? e.g., } \\
\text { bias, assumptions, reasons and interests } \\
\text { in the research topic }\end{array}$ & $\begin{array}{l}\text { Besides gender, credentials, } \\
\text { occupation and experience } \\
\text { in performing qualitative } \\
\text { interviews, we reported how } \\
\text { we dealt with preexisting } \\
\text { assumptions and possible } \\
\text { biases, in the methods section. } \\
\text { We elaborate on how we } \\
\text { attained an open attitude by } \\
\text { setting aside prior knowledge } \\
\text { and assumptions. } \\
\text { Page 7-8. } \\
\text { We emphasized the reflective } \\
\text { nature of the whole study } \\
\text { procedure in the discussion } \\
\text { section. } \\
\text { Page } 20\end{array}$ \\
\hline
\end{tabular}

Appendix 1 (continued).

Item

Reported on Page No. and/ or description

Domain 2: Study design

Theoretical framework

9. Methodological orientatio and Theory

What methodological orientation

Page 5 and 8

was stated to underpin the study? e.g.

grounded theory, discourse analysis,
ethnography, phenomenology, conten

analysis

Participant selection

10. Sampling

How were participants selected? e.g.

purposive, convenience, consecutive,

Page 5

snowball

11. Method of approach How were participants approached? e.g. Page 5

face-to-face, telephone, mail, email

How many participants were in the

Page 6

13. Non-participation

How many people refused to participate Page 6 or dropped out? Reasons?

Setting

14. Setting of data collection Where was the data collected? e.g. home, Page 6 clinic, workplace

15. Presence of non-participants Was anyone else present besides the Page 6 + Table 2 participants and researchers?

16. Description of sample What are the important characteristics of Page $6+$ Table 2 the sample? e.g. demographic data, date

Data collection

17. Interview guide

Were questions, prompts, guides

provided by the authors? Was it pilot

tested?

18. Repeat interviews Were repeat interviews carried out? If N/A

$\begin{array}{lll}\text { 19. Audio/visual recording } & \text { yes, how many? } \\ \text { Did the research use audio or visual } & \text { Page } 7\end{array}$

recording to collect the data?

Were field notes made during and/or The interviewers tried to after the interview or focus group? establish a trustful bond with the interviewees. Multiple recruiters (case managers, nurse practitioner) advised us not to make notes during the interview as this would potentially disrupt trust and distract participants. Brief notes were made afterwards to indicate the atmosphere and particularities.

21. Duration Page 7

or focus group?

Page 8 


\section{Appendix 1 (continued).

\section{Domain 2: Study design}

Data collection

23. Transcripts returned

Were transcripts returned to participants N/A.

for comment and/or correction? Due to ethical considerations;

the interviewees were

a vulnerable group of

individuals, some of whom

experience memory or other

not want to overburden the

participants.

\section{Domain 3: analysis and findings}

\section{Data analysis}

24. Number of data coders

How many data coders coded the data? Page 8

25. Description of the coding tree Did authors provide a description of the Table 3

coding tree?

Were themes identified in advance or Page 8

derived from the data?

27. Software

28. Participant checking

What software, if applicable, was used to Page 8 manage the data?

findings?

\section{Reporting}

29. Quotations presented

Were participant quotations preseted

to illustrate the themes / findings? Was

each quotation identified? e.g. participan

number

30. Data and findings consistent Was there consistency between the data Yes.

presented and the findings?

Were major themes clearly presented in Throughout the results

the findings? section + Table $3+$ Figure

31. Clarity of major theme

Is there a description of diverse cases or discussion of minor themes?

themes and subthemes we

also describe contradictions,

minor themes and diverse

Developed from: Tong A, Sainsbury P, Craig J. Consolidated criteria for reporting qualitative research (COREQ):

a 32-item checklist for interviews and focus groups. International Journal for Quality in Health Care. 2007.

Volume 19, Number 6: pp. 349 - 357
APPENDIX 2. Questions and prompts on the topic list

\section{Topic}

Questions and prompts

Do (or did) you receive help or care from other people?

- What do they do for you?

How do you feel about them caring for you?

What is important to you when other people are caring for you?

What are things you like or dislike when other people are caring for you?

Do you usually receive care from the

- How do you feel about that?

How do the people that care for you approach you? - How do you feel about that?

- How should they approach you?
Are you concerned with faith/religion/giving meaning?

Are you concerned with faith/religion/giv

- How do you engage in this topic?

- Do you discuss these topics with care professionals?

- (Yes) what does that look like?

- (Yes) how do you feel about that?

(No) how do you feel about that?

(No) would you like to discuss these matters with them? Why (not)?

Can you imagine being (fully) cared for by other people?

- What comes to your mind then?

What makes the thought (un)pleasant?

What would help you to accept such help/care from others?

What do others need to know about you, to care for you properly?

End-of-life

communication

Do you ever think about the future?

- Why is this thought (pleasant/unpleasant/confronting...)?

Do you ever think about the end of life?

- What comes to your mind then?

Why is this thought (pleasant/unpleasant/confronting...)?

(No) What do you think is the reason for that?

Did you ever talk about particular wishes regarding the end of life?

- (Yes) with whom did you discuss this?

- (Yes) how did you feel about discussing the end of life?

What is the reason that it was (easy/difficult/confronting) for you to discuss this?

- (No) how do you feel about discussing the end of life?

- (No) would you like to discuss this with someone (professional)? (Yes) with whom?

What would make it easier to discuss the future?

- What would you need to discuss the future?

Have your wishes for the end of life been documented?

- Do you have a living will?

Who will decide for you if you cannot decide for yourself?

- Have you been ever asked that question before?

- Did you ever discuss this with the GP or notary, for instance?

Has this been documented?

What do you hope for in the future?

With all your life experience, I am really curious...

Wrapping up

What is a lesson you have learned in life that you would teach to a young person like me?

What is your motto? 


\section{CHAPTER 9}

\section{General discussion}


Paul, Millie and Aisha sit at a table in the general living room of nursing home 'Madelief'. Paul sips on a cup of coffee - all black, no sugar - and Millie stares at the bag of tea as it floats silently in a glass of hot water. It has been two weeks since Fiona died. Aisha places her hand on Paul's. 'Fiona will be a tough one to forget, Paul. She has a special place in our hearts.' Paul and Millie look at each other with a tender smile. Both of them feel that Fiona was at peace when she died, surrounded by a loving care team and the people that were closest to her.

This dissertation aimed to explore and describe what constitutes high-quality palliative dementia care, taking into consideration the perspective of nursing staff, family caregivers, and people with dementia. The studies in this dissertation belong to the DEDICATED (Desired Dementia Care Towards the End of Life) project, which aims to improve palliative care for people with dementia and their families. These studies provide the basis for the development of a 'DEDICATED approach' to support nursing staff, working in the community or in nursing homes, in the provision of palliative dementia care.

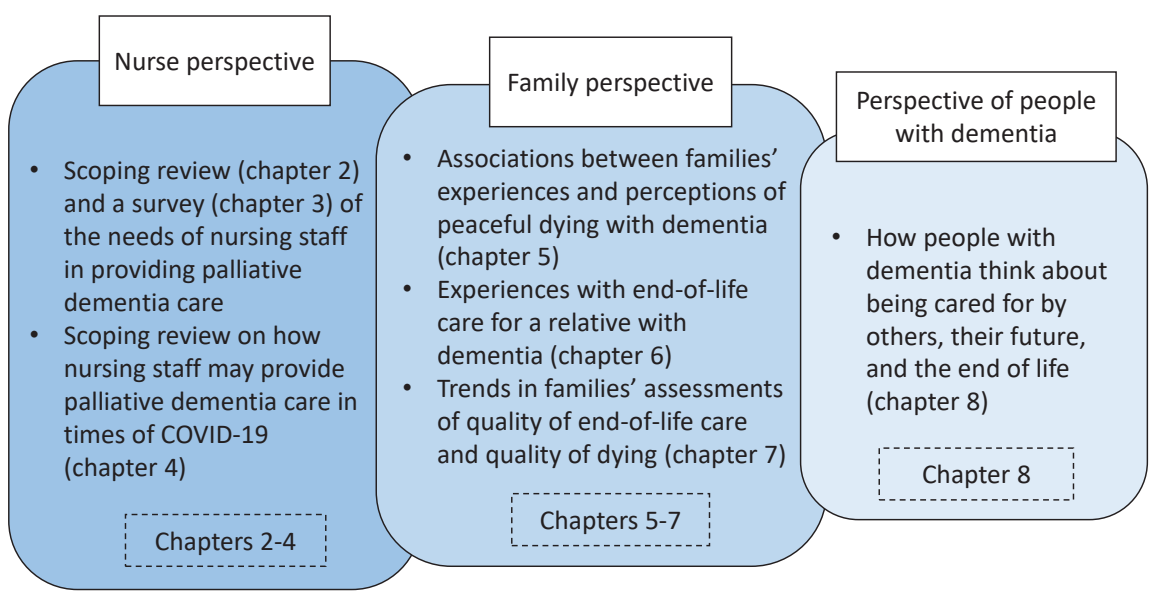

Figure 1. Illustration of what was studied in relation to the different perspectives, with reference to corresponding chapters

The dissertation consists of three parts that represent the perspective of, respectively, nursing staff, family caregivers, and people with dementia (Figure 1). The nursing staff perspective was mapped through a scoping review of nursing staff's needs in palliative dementia care and a survey among Dutch nursing staff to assess their support needs. In response to COVID-19, a rapid scoping review resulted in an overview of available information, translated into practical nursing recommendations on how to provide palliative dementia care during the pandemic. The family caregiver perspective was mapped through analyzing associations between their experiences with care and their perceptions of peaceful dying, and a qualitative exploration of their experiences with care at the end of life of a relative with dementia. Moreover, this part involved an analysis of trends in family caregivers' assessments of quality of end-of-life care and quality of dying over a 14-year period. The perspective of people with dementia was represented by a qualitative study among 18 people with dementia, exploring their perspectives on their future, the end of life, and on being cared for by others.

This chapter summarizes the main findings from these studies, followed by theoretical and methodological considerations. Finally, the chapter includes implications for future research, practice, and policy.

\section{MAIN FINDINGS}

The studies in this dissertation show that a number of elements should be in place for high-quality palliative care for people with dementia as perceived by nursing staff, family caregivers, and people with dementia themselves. Each perspective includes particular elements, and the focus and content may differ between those perspectives. The overarching themes extracted from the three perspectives together provide a comprehensive understanding of the most important elements in palliative dementia care. This section outlines the main findings and a narrative of recurrent themes throughout the dissertation, with references to corresponding chapters.

\section{Familiarity and getting to know each other}

An important element in high-quality palliative care for people with dementia is familiarity between those who are involved. This refers to familiarity between the person with dementia and their professional caregivers, but also between the person's family and professional caregivers. It is essential to build rapport and to invest in trustful and respectful care relationships within the care 'triad' (in this case, the person with dementia, their family caregivers, and the nursing staff).

The scoping review (chapter 2 ) showed that a central need of nursing staff is to invest in getting to know a person with dementia to provide the desired quality of palliative care. In the survey (chapter 3), nursing staff indicated the importance of devoting personal attention to people with dementia and their families. This was referred to in $83 \%$ of the responses to the open-ended question: 'if you had more time to do your work, what would you use it for?' Interviews with family caregivers (chapter 6) showed that for them, getting to know their relative's professional caregivers and building a supportive care relationship is beneficial as it supports them in providing informal 
care and making decisions on behalf of the person with dementia. Acknowledgement of their role by professional caregivers was particularly important for family caregivers of nursing home residents with dementia, whereas family caregivers in the community took on a prominent role by themselves. The comparison between settings in the interview study showed that in nursing homes, family caregivers sometimes felt disregarded and uninvolved by professional caregivers (chapter 6).

The secondary data analysis (chapter 5) showed that negative experiences with end-of-life care in nursing homes, reported by $17 \%$ of the family caregivers, involved feelings of neglect and a lack of respect. From a proxy perspective, family caregivers value a personal approach, attention, and respect by professional caregivers towards their relative with dementia. Family caregivers in nursing homes particularly stressed the importance of dignified and compassionate care and attention, which helped them to relinquish care to trusted staff (chapter 6). Family caregivers indicated a lack of tailored care as a negative experience (chapter 5). A central theme highlighted in the interviews with people with dementia themselves (chapter 8), was the importance of having a sense of belongingness and of being a valued and respected individual (being 'seen' by others). Genuine attention from familiar, trusted and involved professional caregivers may foster such feelings. For nursing staff, knowing a person with dementia helps them to recognize care needs and to respond to those needs in a way that suits the person's preferences (chapter 2). Both interview studies (chapters 6, 8) showed that responsiveness towards personal needs and preferences is in turn valued by persons with dementia themselves and their family caregivers.

Communication about (future) palliative care

Open and ongoing communication is another important aspect, which refers to general communication around care provision and, more specifically, to end-of-life communication as a part of advance care planning (ACP). Communication (about the end of life) within the care triad closely links to the theme of familiarity, as these are reciprocal processes: one may support or restrict the other.

The interviewed family caregivers emphasized the importance of being informed and involved (chapter 6). They valued receiving information and explanation, such as on prognosis and care or treatment options, from familiar professional caregivers. Family caregivers of nursing home residents appreciated being regularly updated on the situation of their relative. Therein, nursing staff have an important role, especially when the person with dementia has limited communication capacities. During the COVID-19 pandemic, as indicated by the scoping review (chapter 4), rapidly growing attention for psychosocial aspects of care led to creative ways to communicate with families outside the nursing home.

In the home and nursing home setting, family caregivers experienced similar challenges in making care decisions on behalf of their relative with dementia (chapter
6). In both settings, adequate communication with nursing staff and being 'on the same page' with professional caregivers and other family members facilitated shared decision-making. Nursing staff, on the other hand, indicated a pressing need for support in dealing with disagreement between family members in end-of-life decision-making. This specific need was selected by $58 \%$ of the survey respondents, with no difference between nursing staff with varying educational backgrounds and from the home and nursing home setting (chapter 3 ). The importance of having timely discussions about care options, also including family caregivers, became yet more obvious through the outbreak of COVID-19 (chapter 4). The scoping review (chapter 2) showed that verbal communication with nursing home residents with dementia poses a challenge for nursing staff. At this stage, the inclusion of persons with dementia in the shared decisionmaking process is difficult. This reflects the value of an early introduction of end-of-life communication as a part of ACP, when people with dementia still live at home. However, the survey (chapter 3 ) suggests that especially home care staff may lack training and education in dementia care. As indicated by the scoping review, the literature on home care staff's specific needs in palliative dementia care is limited (chapter 2). Moreover, both interview studies (chapters 6, 8) indicated that people in an early stage of dementia may be reluctant to talk about the future or the impending end of their life. In addition, the interviews with family caregivers suggest that having discussed the end of life does not guarantee smooth decision-making at the end of life and vice versa: not discussing the end of life does not necessarily hamper later decision-making (chapter 6). Overall, end-of-life communication should be person- and family-centered, taking into account individual characteristics such as coping and readiness to talk about the future.

\section{Management of burdensome symptom}

At the end of life with dementia, a key element of palliative care provision concerns the management of burdensome symptoms. From the scoping review and survey (chapters 2, 3), it appeared that recognizing and managing pain and discomfort in persons with (advanced) dementia is particularly challenging to nursing staff. Moreover, they experience significant difficulties in dealing with responsive behaviors, such as agitation, apathy, and aggression. Nursing staff working in both settings (home and nursing home) and nursing staff with different educational backgrounds equally addressed these issues (chapter 3). During the COVID-19 outbreak, dealing with responsive behaviors received additional attention, mainly in relation to quarantine measures in nursing homes (chapter 4). Not being able to establish comfort for the person with dementia frustrates both families and nursing staff. COVID-19 in particular brought forth accounts of moral distress among nursing staff, who felt incapacitated to deliver care that met their moral standards (chapter 4). The secondary data analysis and interview study (chapters 5, 6) showed that family caregivers from nursing home residents experienced feelings of neglect when their relative's discomfort was 
not heeded. The secondary data analysis showed that for family caregivers, their perception of care at the end of their relative's life significantly influenced how they perceived the eventual death of their relative (chapter 5). Negative experiences with end-of-life care, including perceptions of negligence in comfort care, contributed to the perception of a less peaceful death. The trend study (chapter 7) showed that over the past 14 years, there is a significant positive trend in families' assessments of the quality of end-of-life care, though their assessments of the quality of dying (measured through comfort) did not change over time and their perception of well-being in dying decreased. These divergent trends echo the complex interplay between aspects of care provision, symptom management and perceptions of death and dying. The adequate management of symptoms and responsiveness to individual care needs also closely links to the elements of familiarity and communication.

\section{Awareness of palliative care for people with dementia}

An underlying theme beneath the concrete aspects of palliative dementia care, involves awareness. This refers to a general awareness about the meaning and relevance of applying palliative care principles in the care for people with dementia, and obtaining the right skills and knowledge to put this into practice. Awareness of a palliative approach may serve as a first step towards high-quality palliative dementia care, as it may instigate a more pronounced focus on quality of life and comfort by professional caregivers.

The scoping review concerning COVID-19 confirmed a longstanding societal lack of awareness regarding palliative care for people with dementia specifically (chapter 4). In society, an understanding of a palliative approach and normalization of topics around death and dying may stimulate conversations about quality of life and wishes for the future and the end of life. The interview studies showed that people with dementia, their family caregivers, or both, sometimes regarded talking about the end of life as taboo (chapters 6, 8). Nursing staff may need to become more aware of their own role in palliative dementia care as a first step to developing the right skills and knowledge. The scoping review (chapter 2) and survey (chapter 3 ) suggested that, to mobilize their role in palliative dementia care, nursing staff need adequate time and space to develop the appropriate skills and to deepen their knowledge. For this, they need education and training opportunities (chapter 2), and opportunities for learning with peers (chapter 3). Attention for the development of skills and knowledge on palliative dementia care may be especially lacking in the home setting (chapter 3). Peer-to-peer learning and case discussions were the most frequently selected forms of support sought by nursing staff from both settings (chapter 3). Awareness among nursing staff of their role may facilitate such joint learning and reflection. Moreover, other members of the professional care team (such as physicians) should recognize the important role of nurses and nurse assistants, and include their views in the holistic care plan (chapter 2). The COVID-19 outbreak highlighted the need for nursing leadership within interprofessional care teams to uphold high-quality palliative dementia care (chapter 4).

\section{THEORETICAL CONSIDERATIONS}

The gap in palliative care in dementia: a matter of terminology?

Over the last two decades, attention for palliative care for people with dementia has grown. ${ }^{1-3}$ Yet, there is still a paucity of high-quality research regarding palliative care interventions for people with dementia. ${ }^{4,5}$ Although most westernized countries have developed palliative care services, the accessibility and availability for people with dementia is often inadequate. ${ }^{1}$ In some countries, including the Netherlands, dementia may not be recognized and classified as a terminal condition, raising barriers in terms of healthcare costs and insurance for hospice care and other palliative care services. ${ }^{6}$ Several aspects of palliative dementia care, including its appropriate timing, remain understudied. While there is evidence in favor of early palliative care in patients with cancer, ${ }^{7,8}$ there is a lack of such evidence for people with dementia. ${ }^{9}$ To date, most studies concerning palliative care for people with dementia have focused on the more advanced stages of dementia. ${ }^{9,10}$ Several reviews on effects, ${ }^{5}$ barriers and facilitators, ${ }^{11,12}$ contents in care guidelines ${ }^{13}$ and quality indicators ${ }^{14}$ in relation to palliative dementia care, focused on advanced dementia or end-of-life care. Hanson and colleagues aimed to define an 'extended palliative phase' in dementia. ${ }^{15}$ The authors used 'advanced dementia' as a working definition of this extended phase, which implies that the earlier stages were omitted at the outset. They found no clear definition of advanced dementia and report that the available literature tended to focus on end-of-life dementia care, largely abandoning any prior phases of (palliative) care. ${ }^{15}$

An earlier Delphi study described the views of 64 experts in the fields of palliative care and dementia care, who considered the broadening of palliative care to the entire dementia trajectory as 'too ambitious. ${ }^{16} \mathrm{~A}$ majority of the panelists strongly (56.3\%) or moderately (23.4\%) agreed with the applicability of palliative care to dementia from diagnosis until after death. However, in some panelists this more inclusive definition of palliative care in dementia raised concerns. For instance, they stressed that goals of improving quality of life, maintaining functioning, and optimizing comfort were not specific to palliative care and that labeling dementia care as palliative care could undermine non-palliative care expertise. ${ }^{16}$ There is a great variety in healthcare professionals' opinions concerning the adequate time to start palliative care in dementia. ${ }^{17}$ A lack of consensus on the applicability of palliative care is not limited to dementia. Radbruch and colleagues ${ }^{18}$ also noted a tension between those who think palliative care solely applies to severe illness at the end of life and those who believe it helps to relief suffering for a broader population. Incongruity among experts around 
the applicability of palliative care in dementia potentially explains part of its limited knowledge base. The scoping review about palliative dementia care in response to the COVID-19 outbreak (chapter 4) largely yielded sources that addressed either palliative care or dementia care. This accentuates the limited integration. There is considerable overlap in domains of dementia care and palliative care, although aspects of dementia care are often not labeled as such. ${ }^{19}$ The nursing perspective in this dissertation emphasized the need for awareness of palliative care and its applicability to dementia. A joint understanding of how palliative care relates to dementia care may facilitate training and education of nursing staff to apply palliative care principles in an early stage. Nursing curricula in the Netherlands lack in-depth focus on palliative care, ${ }^{20,21}$ let alone palliative care for people with dementia. The initial scoping review (chapter 2) on nursing staff's needs retrieved only one study that concerned the home care setting. The subsequent survey study (chapter 3 ) showed that particularly nursing staff working in the community lack training on palliative dementia care. Previous studies also described a lack of education opportunities in palliative dementia care at home..$^{22,23}$ Yet, an early palliative approach to care is best initiated when persons still live at home.

To mitigate concerns about undermining dementia care as a separate expertise, it may be useful to regard palliative care as a philosophy of care that is applicable and complementary to dementia care. Thus, 'a palliative approach to dementia care' may be a more appropriate phrasing, which refers to the adoption of palliative care knowledge and principles rather than a specialized service. ${ }^{24}$ Ideally, any healthcare professional with basic education should be able to apply palliative care principles to respond to individual care needs of people with life-limiting conditions. ${ }^{25}$ This is particularly important for nursing staff, given their prominent role in the care for people with dementia and their families. The perspectives of people with dementia (chapter 8) and their family caregivers (chapter 6) reflect the potential value of adopting palliative care principles to respond to their need for holistic and supportive care, and for sensitive communication about the end of life. A recent international report on care needed to improve the lives of people with dementia recognizes the importance of applying a palliative approach to care after diagnosis, throughout the illness trajectory. ${ }^{1}$ Nonetheless, the report's focus was narrowed to the advanced stage and the end of life. This dissertation advocates for the applicability of a palliative approach to care for people with dementia regardless of the stage of dementia (i.e., early, moderate or advanced) and the place of residence (i.e., at home or in a nursing home). This is in line with a novel consensus-based, inclusive definition of palliative care. ${ }^{18}$

\section{Anticipating the future with dementia}

Palliative care, more than dementia care in general, anticipates the end of life and pays attention to timely end-of-life discussions and spiritual and existential needs. ${ }^{19}$ Applying palliative care principles to the care for people with dementia facilitates timely recognition of its eventual terminal nature and the imminent decline of cognitive and functional status. ${ }^{3}$ This recognition, by healthcare professionals as well as by people with dementia and their family caregivers, may support timely discussions and shareddecision making about future goals of care. ${ }^{3,26}$ Previous studies indicate that ambiguity around the responsibilities of different healthcare professionals in advance care planning (ACP) is an important barrier to its implementation. ${ }^{27}$ Medical care planning and the documentation of treatment preferences are part of ACP. Nonetheless, the ACP process should be broader and involve the addressing of physical, psychological, social, and spiritual care needs. ${ }^{28}$ ACP may help to prepare persons with dementia and their families for the end of life, strengthen care relationships, and facilitate discussions on personal fears and values. ${ }^{29}$ The holistic nature of ACP resonates a need for an interdisciplinary approach, in which it becomes a shared endeavor of multiple disciplines. There is growing attention in the literature for the nurse's role in the ACP process. ${ }^{30,31}$ In a recent survey, Dutch nursing staff indicated the absence of proactive care plans as a barrier to ideal palliative care for people with dementia. ${ }^{32}$ Instead of highlighting the potential need among nursing staff themselves to develop skills in facilitating ACP, the authors emphasize that physicians should have ACP conversations and document care plans. As shown in the scoping review and survey (chapters 2, 3), nursing staff need skills in involving people with dementia in shared decision-making. Although ACP was touched upon in the studies in this dissertation, it was not a prominent topic as assessed by nursing staff themselves. This may reflect a general underestimation of nursing staff of their own potential role in ACP and the view that this is outside their scope. ${ }^{33}$ In contrast, the family perspective (chapter 6 ) in this dissertation emphasizes the importance of ongoing, sensible communication with nursing staff regarding the anticipated end of life. This need arose in both the home and nursing home setting. Families need this support to feel confident at making care decisions on behalf of their relative.

This dissertation also addressed end-of-life communication as a part of ACP from the perspective of people with dementia (chapter 8), which raised concerns about the appropriateness of ACP. Although end-of-life discussions may be supporting and reassuring for some, others may not feel 'ready' to talk about the end of life while they are busy trying to cope with their condition in the present. People with dementia may prefer to 'live in the moment', holding off on potential future scenarios which may evoke fear and worries. The literature base on ACP in dementia has grown considerably over the past decade, ${ }^{34}$ potentially reflecting an increasing focus on 'controlling' and 'managing' the end of life in western societies. ${ }^{35}$ The view that a 'good death' involves autonomy and control, however, does not accurately reflect the perspectives of people who are at the end of life themselves. ${ }^{36-38}$ Moreover, the trend study (chapter 7) showed that although families' assessments of quality of care at the end of life increased between 2005-2019, no increase was found in their assessments of quality of dying. Over time, 
their ratings on a subscale that measured well-being during dying even decreased. The increasing focus on control and planning death may increase satisfaction with end-oflife care, yet it may fail to contribute to families' perceptions of a 'good death'.

The interview study (chapter 8) showed that people with dementia did not necessarily fear death; they demonstrated acceptance and resignation. Exerting control over end-of-life care was not highly valued, whereas they emphasized placing their trust in others when it came to making end-of-life decisions for them. The literature on ACP may too often surpass the question of its universal appropriateness, particularly for people with dementia. Although cognitive decline is often raised as an argument for early initiation of $\mathrm{ACP}^{39}$ the uncertainty of living with dementia and facing cognitive decline itself may be a prominent barrier to making proactive end-of-life decisions. Generally, people cannot accurately judge their own attitudes or preferences concerning healthcare in situations that are dissimilar from their current situation. ${ }^{40-42}$ People may demonstrate resilience in the face of serious illness or disability, and learn how to cope with their condition. ${ }^{41}$ People with advanced dementia may still experience good quality of life even though they would not have considered that life meaningful in the past. ${ }^{43}$ Decisions about future care and treatment are thus often made in the context of that particular moment, which is not static, and previous wishes may not hold in future 'selves' and situations. The findings from this dissertation support the idea that endof-life communication may need a focus away from medical decision-making, which is difficult to oversee in advance and often confronting to contemplate. Instead, endof-life communication with people with dementia and their families may focus more on dealing with the condition and its uncertain future, while maintaining personhood and meaningful relationships until the end of life. Therein, nursing staff should play a principal role.

\section{The person behind the dementia}

End-of-life communication should be person-centered, responding to individual needs and readiness to talk about the future. This person-centeredness is not limited to endof-life communication, but covers the entire palliative care approach for people with dementia. Person-centered dementia care, which originated from Kitwood's theory of personhood, ${ }^{44}$ has been well described and is recognized by the international Alzheimer's Association as an essential part of high-quality dementia care. ${ }^{45,46}$ Knowing a person's history and life story supports person-centered care. Yet 'selfhood', which is at the core of person-centered care, stretches beyond a person's autobiography. ${ }^{45}$ Even when cognition declines and memories fade, selfhood can be maintained through interpersonal interaction and social connections. ${ }^{44}$ The studies in this dissertation almost all underline the utter importance of seeing and maintaining 'the person behind the dementia'. The family caregivers' perspective (chapter 6) emphasizes the importance of professional caregivers' acknowledgement of their relative's personal, unique needs. A perceived lack thereof, which mainly occurred in nursing homes, negatively relates to families' perceptions of their relative dying in peace (chapter 5). Family caregivers appreciated being closely involved as partners in palliative care (chapter 6), which aligns with relationship-centered care. ${ }^{47}$ People with dementia themselves, when contemplating the future, have a pronounced desire to still 'matter' and 'belong', and to be treated as a worthy human being (chapter 8). Such needs also reflect important aspects highlighted in the theory of relationship-centered care, ${ }^{47}$ as they largely depend on being 'seen' by others and being treated in a thoughtful way. Through these interactions, people with dementia may uphold their feelings of belongingness, significance and purpose.

Although Kitwood emphasized the importance of interpersonal relationships in dementia care, his terminology of 'person-centered' care received criticism. ${ }^{48}$ This critique mainly concerns the implied focus on the autonomous 'person' and ambiguity regarding what a 'person' is. Relationship-centered care specifically highlights interdependence and interconnectedness, through which a care environment is shaped. ${ }^{47}$ In this care environment, people with dementia, their family caregivers and professional caregivers all have a part to play. Nursing staff have a prominent role in the care for people with dementia at home and in nursing homes. They emphasized a vital need for familiarity: getting to know the person with dementia and paying personal attention to them and their family caregivers (chapter 3). The importance of building trustful care relationships to achieve high-quality palliative care is a common denominator for people with dementia, their families, and nursing staff. In western countries, we may need to focus more on relationships instead of autonomy and control to achieve a good end of life for people with dementia. This notion suits the continuing paradigm shift towards 'relational autonomy', in which interdependence, partnership, and social relations are acknowledged as important factors in shaping human identities and needs. ${ }^{49,50}$ Not only in tailored care provision, but also in preparing for the end of life, choices are made in the context of social networks surrounding the person with dementia ${ }^{38}$

\section{METHODOLOGICAL CONSIDERATIONS}

The studies in this dissertation focused on nursing staff, family caregivers, and people with dementia. The exclusion of people with dementia from research is a widespread problem..$^{51}$ Our study (chapter 8 ) showed that the interviewees with dementia were capable and willing to be interviewed, even about a sensitive topic such as the end of life. The advisory board and working groups (with healthcare and education professionals, patient representatives and policy makers) of the DEDICATED project gave advice on the conduct of the interviews, and suggested to limit the interviews to 
a population of community-dwelling people with dementia who were cognitively able to participate. We decided to refrain from interviewing nursing home residents, as the project's advisory bodies and recruiters considered the interview topic as too complex and potentially distressing for people with dementia who lived in a nursing home. To interview or involve people with more advanced dementia in research otherwise, different methods may be required..$^{52}$ For instance, such alternative methods could involve visual aids or case vignettes to prompt responses. ${ }^{53}$ We chose not to measure cognitive performance, such as with Mini-Mental State Examination (MMSE) scores, and instead asked recruiters (i.e., dementia care professionals) to make a clinical judgment of the individual's capabilities to participate in the interview. The reason for this was that the recruiters felt that MMSE scores were not a proper representation of the ability and willingness to participate in an interview. For instance, a person with poor performance on visuospatial and planning tasks can still have the ability to talk about his or her thoughts and feelings towards the topic. Although recruitment by care professionals may have limited the generalizability to the entire population of people with dementia (e.g., by selecting individuals with rather intact cognitive skills and willingness to talk about care and the end of life), it was considered the most feasible and desirable way to recruit a vulnerable population. To diminish selection bias, we asked recruiters to approach anyone (matching our inclusion criteria) that they deemed cognitively fit to participate, regardless of their attitudes toward the topic. Similarly, for the interviews with family caregivers, we asked recruiters from care organizations to approach any contact person bereaved of a relative with dementia within the last 12 months, regardless of families' alleged experience with care.

In the Netherlands, most people with dementia (79\%) live in the community and receive informal care from their families. ${ }^{54}$ Family caregivers therefore have an important role that is often shared with nursing staff providing home care. Nursing staff also provide most of the 24-hour care in nursing homes, and families continue to fulfill an important role as spokespersons, proxies and informal caregivers after nursing home admission. The nursing perspective included nursing staff from different levels of education (registered nurses, certified nurse assistants (i.e., licensed nurses), and nurse assistants) to grasp the breadth of nursing staff providing most of the daily care for people with dementia and their families. ${ }^{55}$ The survey (chapter 3 ) demonstrated that nurses from these different levels experience similar needs in providing palliative dementia care. The three perspectives - that of people with dementia, their family caregivers, and nursing staff - were considered to provide the most valuable information to inform the question of what constitutes high-quality palliative care in dementia at home and in nursing homes. Nonetheless, palliative care for people with dementia is ideally a shared endeavor of healthcare professionals from multiple disciplines. ${ }^{3}$ Perspectives of physicians, psychologists or spiritual counselors, for instance, could have highlighted additional elements of palliative dementia care that this dissertation does not cover. Moreover, the studies in this dissertation were a part of the larger DEDICATED project and focused specifically on palliative caregiving by nursing staff and on end-of-life communication. The DEDICATED project consists of two parts. The other part focused on different elements of palliative dementia care that relate to interprofessional collaboration and continuity in transfers between home and the nursing home. Adequate interprofessional collaboration and continuous care are also imperative to the establishment of a high-quality and full-system approach to palliative care in dementia. These topics were, however, beyond the scope of this dissertation.

The different studies in this dissertation cover a variety of qualitative and quantitative methods and literature reviews. Two studies integrated qualitative and quantitative data in the analysis (chapters 3,5 ). The use of mixed methods increased the completeness and depth of information retrieved from the data on the topic of interest. ${ }^{56}$ Moreover, results from the earlier studies informed data collection in subsequent studies, which contributed to a mutual validation of findings using different methods. For instance, findings from the first scoping review (chapter 2) informed survey item development (chapter 3) and findings from the family interviews (chapter 6) informed the topic list for interviewing people with dementia (chapter 8). For the qualitative work in this dissertation, rigor of the analyses was strengthened through reflexivity and researcher triangulation (e.g., joint analysis, mutual reflection on findings, reflective discussions on procedures, researcher roles, backgrounds, and internal biases). Both literature reviews applied a systematic scoping review approach and involved multiple researchers in all steps (e.g., literature search, inclusion, and data extraction, analysis, synthesis, and presentation). The studies that used existing data (chapters 5, 7) studied (trends in) the quality of end-of-life care and quality of dying with dementia as judged by family caregivers. The validated measurement instruments used in these studies - the End-of-Life in Dementia Satisfaction With Care (EOLD-SWC) and Comfort Assessment in Dying (EOLD-CAD) - have been widely used and tested at an international level. ${ }^{57,58}$ Although family caregivers are considered important judges of quality of dying, their experiences may not capture the lived experience of the dying person with dementia him or herself. ${ }^{59}$ When interpreting these findings, it is important to keep in mind that the concept of quality of dying with dementia is based entirely on the families' perspective. Yet, proxy assessment is an obvious choice of method when aiming to collect retrospective data on a dying experience.

In the Netherlands, the majority (70\%) of people with dementia die in a nursing home. ${ }^{60}$ To increase generalizability, several studies in this dissertation focused on both the home and nursing home setting, as these are the two prominent settings where palliative care provision for people with dementia takes place. The scoping review (chapter 2) aimed to include studies from both settings, and we identified only one article about the home setting. The apparent paucity of literature in this setting was 
an important finding by itself. We interviewed family caregivers from people with dementia who resided in both settings (chapter 6 ) and nursing staff from both settings filled in the survey (chapter 3 ), and we compared the findings. The scoping review in relation to COVID-19 (chapter 4) initially focused on both settings; however, this focus was narrowed to the nursing home due to a lack of information on community nursing and to provide more specific recommendations for nursing home care. Overall, findings from this dissertation suggest that similar elements should be in place for both settings to establish high-quality palliative care for people with dementia. Specific areas of focus per settings are highlighted throughout the dissertation.

\section{IMPLICATIONS FOR RESEARCH, PRACTICE, AND POLICY}

The results of this dissertation emphasize the need for a person-centered and relationship-centered palliative care approach for people with dementia living at home and in nursing homes. Several aspects constitute high-quality palliative dementia care from the perspectives of people with dementia, their family caregivers, and nursing staff, which has implications for future research, practice, and policy.

\section{Toward a dementia-inclusive and palliative-minded society}

To improve palliative care for people with dementia at its core, a societal culture change may be necessary. In modern western society, there is an emphasis on cognitive abilities as prerequisites to live a meaningful life and to achieve presumable autonomy ${ }^{61}{ }^{\text {There }}$ is a public stigma towards people with dementia and their families. ${ }^{62}$ Negative imagery, prejudice and an 'us versus them' culture contribute to negative emotions such as fear for the future in people who live with dementia. ${ }^{63}$ Especially the end of life with dementia is often considered 'dehumanizing' or 'undignified. ${ }^{64}$ This dissertation reflects all these themes and suggests that the greatest pursuit in palliative dementia care is to maintain the qualities of being human through social connections until the end of life, and that this outweighs control and individualistic autonomy. Practice, policy, research, and the media should strive to reduce stigma and to establish dementia-friendliness by positively framing dementia and by stimulating full participation of people with dementia. Only when dementia-friendliness is achieved, a next step can be taken toward a dementia-inclusive society in which there is no discrimination of people who live with the condition. Future research should invest in the inclusion of people with dementia themselves. As noted by Fletcher, ethics review procedures may hinder the inclusion of people with diminished mental capacity, and suggests that dementia researchers should be aware of these potentially 'unethical ethics'. ${ }^{11}$ As the Dementia Alliance International (i.e., a group representing people living with dementia) states: "Nothing About Us Without Us; No more Us and Them. This is our right." ${ }^{65}$ People with dementia have a human, moral, and legal right to participate in civil society in its broadest sense. To reduce fear and stigma related to dementia, western societies may need to move away from medicalizing, planning and controlling death. From an integrative review of the concept of 'a good death' in western cultures, Cottrell and Duggleby ${ }^{35}$ noted that prevailing perceptions of death have shifted from denial to acceptance. Death is welcomed as something that is swift, tightly controllable and even demandable. Media cultivate this perception of having 'a right to die', ${ }^{35}$ with euthanasia or physician-assisted suicide as ultimate ways to plan and control death. At the same time, the contemporary cultural discourse on the end of life marginalized and largely abandoned the dying process. There is a focus on the negative aspects related to dying, and how these can be mitigated or reduced. Although there is increasing appreciation of end-of-life care by family caregivers, their perceptions of the quality of dying did not improve, and their perception of well-being even decreased (chapter 7). The findings indicate that symptom management at the end of life with dementia did not improve from the families' point of view, despite considerable efforts to improve end-of-life care for people with dementia. Current policy and practice in end-of-life care, including ACP, advance directives and shared decision-making, promote the western view of a good death as a controlled death. These practices may improve the quality of care delivered in anticipation of dying. Nonetheless, the contemporary culture in end-of-life care practice may reduce families' ability to find meaning and acceptance in the dying trajectory of a relative with dementia by placing emphasis on controlling symptoms that families perceive as distressing or burdensome.

Future research should aim to disentangle aspects related to quality in end-of-life care as opposed to quality of dying. To inform practice, researchers may investigate how to uphold the quality of end-of-life care while attaining a less normative stance towards 'the good death'. In addition, culture and religion play an important role in shaping perceptions of a good death and ideas about optimal palliative care. ${ }^{66}$ The COVID-19 review (chapter 4) showed the lack of attention paid to cultural aspects of palliative care in response to the pandemic. The cultural diversity of people with dementia living in the Netherlands calls for future research and practice in the field of palliative care to be culture-sensitive. Ideally, palliative care does not try to prolong life nor to hasten death. It merely focuses on the quality of life for as long as it lasts. Principles of palliative care may thereby guide a cultural discourse about the meaning of death and on how quality can be found in the process of illness and dying. A more 'palliative-minded' society may recognize and address a range of positive and negative aspects, such as hope, distress, relief, compassion, and detachment. This may reduce fear of a dying process in healthcare professionals, people with dementia, and their families, and in the public in general. Attention for all aspects of dying and framing the dying process as a natural part of life may also facilitate discussions about wishes and preferences for the last phase of life, without focusing primarily on control. The 
particular role of nursing staff in having conversations with persons with dementia about what constitutes their quality of life, and on how they perceive the future and the end of life requires recognition. ${ }^{67}$ From their position, which is generally close to the person with dementia and their family caregivers, they can initiate conversations that are relevant to the process of ACP. ${ }^{68}$ Moreover, nurses play a central and connecting role within the interprofessional care team, in which they can function as mediators, messengers and advocates for people with dementia and their families in the ACP process. ${ }^{67}$

Ideally, a dementia-inclusive and palliative-minded society fosters a feeling of significance and belongingness in people with dementia, and supports them to find meaning and quality in the last phase of their life. In practice, despite possible criticism towards labeling the care for people with dementia at least partially as palliative care, acceptance of this term may support education and training of nursing staff. Generalist care staff, and nurses in particular, are at the forefront of establishing a palliative approach to care. ${ }^{69}$ However, current nursing curricula in the Netherlands do not adequately address palliative care for people with dementia. ${ }^{20,21}$ To play their important role in 'primary' palliative care, nurses need specific skills, such as in facilitating conversations about prognosis and care preferences and in addressing social, psychological, and spiritual needs and distress. ${ }^{69}$ Recognizing palliative care as an essential part of dementia care is a first step towards developing suitable nursing education. Additionally, an explicit integration of palliative care principles in dementia care may have benefits in terms of available resources for care providers. For instance, the Netherlands quality framework for palliative care ${ }^{70}$ provides information that can be useful in the care for people with dementia in any stage, such as on ACP and on the addressing of spiritual issues and grief.

Future research and initiatives to improve practice should pay particular attention to the home setting, and to how nursing staff working in the community may introduce a palliative care approach in an early stage of dementia. The education of nursing staff in providing palliative dementia care should include a particular focus on fostering person-centeredness and relationship-centeredness. This dissertation shows that building close care relationships is the common denominator for people with dementia, their family caregivers, and nursing staff. Nursing staff have a strong intrinsic drive to give their undivided attention to people with dementia and their families. Policies on the level of care organizations as well as national policy should take advantage of this intrinsic motivation, and invest in adequate (financial and societal) recognition, and support in terms of time and space for nursing staff to provide the best possible care. For instance, care organizations could receive incentives for facilitating their care staff to spend sufficient time with the persons for whom they care. Moreover, policies should reward efforts to maintain continuity of care relationships. Current policy pressures organizations into limiting staff's time and space, and the financing of palliative dementia care is fragmented. ${ }^{71}$ Both these issues threaten the most essential part of palliative dementia care: bonding within care triads. Although reporting, assessing and controlling can be important tools to improve quality of care, high levels of bureaucracy in healthcare may overshoot the mark by overburdening the individuals that are closest to the person receiving care. Policy makers on all levels should take on a critical stance and continuously question the efficiency and desirability of regulations that intend to support the quality of care.

\section{CONCLUSION}

This dissertation aimed to describe the fundamental elements of palliative care for people with dementia. The combination of the perspectives of people with dementia, their family caregivers, and nursing staff resulted in a comprehensive understanding of the most important elements. These elements concern familiarity and getting to know each other, tailored communication about the future and the end of life, and compassionate management of burdensome symptoms (pain and responsive behavior in particular). An overarching element concerns awareness about the applicability of a palliative approach to care for people with dementia. Together, these four elements form the basis for the development of a DEDICATED approach to care. The DEDICATED approach is developed in co-creation with nurses, dementia case managers, and nurse educators. It includes support materials related to the four elements that are implemented in practice in a stepwise manner. The knowledge developed in this dissertation and the subsequently developed DEDICATED approach are important steps toward more person-centered and relationship-centered palliative care provision for people with dementia living at home or in a nursing home. 


\section{REFERENCES}

1. OECD. Care Needed: Improving the Lives of People with Dementia. Paris: OECD Publishing; 2018.

2. van der Steen JT. Dying with dementia: what we know after more than a decade of research. J Alzheimers Dis. 2010;22(1):37-55.

3. van der Steen JT, Radbruch L, Hertogh CM, de Boer ME, Hughes JC, Larkin P, et al. White paper defining optimal palliative care in older people with dementia: a Delphi study and recommendations from the European Association for Palliative Care. Palliat Med. 2014;28(3):197-209.

4. Miranda R, Bunn F, Lynch J, Van den Block L, Goodman C. Palliative care for people with dementia living at home: A systematic review of interventions. Palliat Med. 2019;33(7):726-42.

5. Murphy E, Froggatt K, Connolly S, O'Shea E, Sampson EL, Casey D, et al. Palliative care interventions in advanced dementia. Cochrane Database of Systematic Reviews. 2016(12).

6. Davies N, Maio L, Vedavanam K, Manthorpe J, Vernooij-Dassen M, Iliffe S. Barriers to the provision of high-quality palliative care for people with dementia in England: a qualitative study of professionals' experiences. Health Soc Care Community. 2014;22(4):386-94.

7. Hannon B, Swami N, Rodin G, Pope A, Zimmermann C. Experiences of patients and caregivers with early palliative care: A qualitative study. Palliat Med. 2017;31(1):72-81.

8. Temel JS, Greer JA, Muzikansky A, Gallagher ER, Admane S, Jackson VA, et al. Early palliative care for patients with metastatic non-small-cell lung cancer. N Engl J Med. 2010;363(8):733-42.

9. Gottesman RT, Blinderman CD. Updated Review of Palliative Care in Dementia. Current Geriatrics Reports. 2021;10(1):42-50.

10. Senderovich H, Retnasothie S. A systematic review of the integration of palliative care in dementia management. Palliative and Supportive Care. 2020;18(4):495-506.

11. Erel M, Marcus EL, Dekeyser-Ganz F. Barriers to palliative care for advanced dementia: a scoping review. Ann Palliat Med. 2017;6(4):365-79.

12. Mataqi M, Aslanpour Z. Factors influencing palliative care in advanced dementia: a systematic review. BMJ Support Palliat Care. 2020;10(2):145-56.

13. Durepos P, Wickson-Griffiths A, Hazzan AA, Kaasalainen S, Vastis V, Battistella L, et al. Assessing Palliative Care Content in Dementia Care Guidelines: A Systematic Review. J Pain Symptom Manage. 2017;53(4):804-13.

14. Amador S, Sampson EL, Goodman C, Robinson L. A systematic review and critical appraisal of quality indicators to assess optimal palliative care for older people with dementia. Palliat Med. 2019;33(4):415-29.

15. Hanson E, Hellström A, Sandvide Å, Jackson GA, MacRae R, Waugh A, et al. The extended palliative phase of dementia - An integrative literature review. Dementia (London). 2019;18(1):108-34.

16. van der Steen JT, Radbruch L, de Boer ME, Jünger S, Hughes JC, Larkin P, et al. Achieving consensus and controversy around applicability of palliative care to dementia. Int Psychogeriatr. 2016;28(1):13345.

17. van Riet Paap J, Mariani E, Chattat R, Koopmans R, Kerhervé H, Leppert W, et al. Identification of the palliative phase in people with dementia: a variety of opinions between healthcare professionals. BMC Palliative Care. 2015;14(1):56.

18. Radbruch L, De Lima L, Knaul F, Wenk R, Ali Z, Bhatnaghar S, et al. Redefining Palliative Care-A New Consensus-Based Definition. Journal of Pain and Symptom Management. 2020;60(4):754-64.

19. Nakanishi M, Nakashima T, Shindo Y, Miyamoto Y, Gove D, Radbruch L, et al. An evaluation of palliative care contents in national dementia strategies in reference to the European Association for Palliative Care white paper. Int Psychogeriatr. 2015;27(9):1551-61.

20. Courtens A, Vaessen G, Bour A, Pol A. Palliatieve zorg in het onderwijs. TVZ-Verpleegkunde in praktijk en wetenschap. 2020;130:42-5.

21. Courtens A, Vaessen G, Bour A, van Pol A, van den Beuken-van Everdingen M. Basiscompetenties palliatieve zorg voor verzorgenden en verpleegkundigen. Onderwijs en Gezondheidszorg. 2019;43:26-9.

22. D’Astous V, Abrams R, Vandrevala T, Samsi K, Manthorpe J. Gaps in Understanding the Experiences f Homecare Workers Providing Care for People with Dementia up to the End of Life: A Systematic Review. Dementia (London). 2019;18(3):970-89.

23. Smith C, Newbury G. Palliative care for community patients diagnosed with dementia: a systematic review. Br J Community Nurs. 2019;24(12):570-5.

24. Sawatzky R, Porterfield P, Lee J, Dixon D, Lounsbury K, Pesut B, et al. Conceptual foundations of a palliative approach: a knowledge synthesis. BMC Palliative Care. 2016;15(1):5.

25. Quill TE, Abernethy AP. Generalist plus specialist palliative care--creating a more sustainable model. N Engl J Med. 2013;368(13):1173-5.

26. Zwakman M, Jabbarian LJ, van Delden J, van der Heide A, Korfage IJ, Pollock K, et al. Advance care planning: A systematic review about experiences of patients with a life-threatening or life-limiting illness. Palliat Med. 2018;32(8):1305-21.

27. Hemsley B, Meredith J, Bryant L, Wilson NJ, Higgins I, Georgiou A, et al. An integrative review of stakeholder views on Advance Care Directives (ACD): Barriers and facilitators to initiation, documentation, storage, and implementation. Patient Educ Couns. 2019;102(6):1067-79.

28. Rietjens JAC, Sudore RL, Connolly M, van Delden JJ, Drickamer MA, Droger M, et al. Definition and recommendations for advance care planning: an international consensus supported by the European Association for Palliative Care. The Lancet Oncology. 2017;18(9):e543-e51.

29. Fleuren N, Depla MFIA, Janssen DJA, Huisman M, Hertogh CMPM. Underlying goals of advance care planning (ACP): a qualitative analysis of the literature. BMC Palliative Care. 2020;19(1):27.

30. Gabbard J, Pajewski NM, Callahan KE, Dharod A, Foley KL, Ferris K, et al. Effectiveness of a NurseLed Multidisciplinary Intervention vs Usual Care on Advance Care Planning for Vulnerable Older Adults in an Accountable Care Organization: A Randomized Clinical Trial. JAMA Intern Med. 2021;181(3):361-9.

31. Houben CHM, Spruit MA, Luyten H, Pennings HJ, van den Boogaart VEM, Creemers J, et al. Clusterrandomised trial of a nurse-led advance care planning session in patients with COPD and their loved ones. Thorax. 2019;74(4):328-36

32. Uitdehaag MJ, Stellato RK, Lugtig P, Olden T, Teunissen S. Barriers to ideal palliative care in multiple care settings: the nurses' point of view. Int J Palliat Nurs. 2019;25(6):294-305.

33. Reinke LF, Shannon SE, Engelberg R, Dotolo D, Silvestri GA, Curtis JR. Nurses' identification of important yet under-utilized end-of-life care skills for patients with life-limiting or terminal illnesses. J Palliat Med. 2010;13(6):753-9.

34. Wendrich-van Dael A, Bunn F, Lynch J, Pivodic L, Van den Block L, Goodman C. Advance care planning for people living with dementia: An umbrella review of effectiveness and experiences. International Journal of Nursing Studies. 2020;107:103576.

35. Cottrell L, Duggleby W. The "good death": An integrative literature review. Palliat Support Care. 2016;14(6):686-712.

36. Goldsteen M, Houtepen R, Proot IM, Abu-Saad HH, Spreeuwenberg C, Widdershoven G. What is a good death? Terminally ill patients dealing with normative expectations around death and dying. Patient Educ Couns. 2006;64(1-3):378-86.

37. Gott M, Small N, Barnes S, Payne S, Seamark D. Older people's views of a good death in heart failure: implications for palliative care provision. Soc Sci Med. 2008;67(7):1113-21.

38. Pollock K, Seymour J. Reappraising 'the good death' for populations in the age of ageing. Age and Ageing. 2018;47(3):328-30.

39. Harrison Dening K, Sampson EL, De Vries K. Advance care planning in dementia: recommendations for healthcare professionals. Palliat Care. 2019;12:1178224219826579.

40. Loewenstein G. Hot-cold empathy gaps and medical decision making. Health Psychol. 2005;24(4s):S49-56.

41. Halpern J, Arnold RM. Affective forecasting: an unrecognized challenge in making serious health decisions. J Gen Intern Med. 2008;23(10):1708-12.

42. Pols J, Limburg S. A Matter of Taste? Quality of Life in Day-to-Day Living with ALS and a Feeding Tube. Cult Med Psychiatry. 2016;40(3):361-82

43. Weidemann EJ. The ethics of life and death: Advance directives and end-of-life decision making in persons with dementia. Journal of Forensic Psychology Practice. 2012;12(1):81-96. 
44. Kitwood TM, Bredin K. Towards a Theory of Dementia Care: Personhood and Well-being. Ageing and Society. 1992;12(3):269-87

45. Fazio S, Pace D, Flinner J, Kallmyer B. The Fundamentals of Person-Centered Care for Individuals With Dementia. The Gerontologist. 2018;58(suppl_1):S10-S9.

46. Fazio S, Pace D, Maslow K, Zimmerman S, Kallmyer B. Alzheimer's Association Dementia Care Practice Recommendations. The Gerontologist. 2018;58(suppl_1):S1-S9.

47. Nolan MR, Davies S, Brown J, Keady J, Nolan J. Beyond person-centred care: a new vision for gerontological nursing. J Clin Nurs. 2004;13(3a):45-53.

48. de Witt L, Fortune D. Relationship-Centered Dementia Care: Insights from a Community-Based Culture Change Coalition. Dementia. 2019;18(3):1146-65.

49. Dove ES, Kelly SE, Lucivero F, Machirori M, Dheensa S, Prainsack B. Beyond individualism: Is there a place for relational autonomy in clinical practice and research? Clinical Ethics. 2017;12(3):150-65.

50. Sherwin S, Winsby M. A relational perspective on autonomy for older adults residing in nursing homes. Health expectations : an international journal of public participation in health care and health policy. 2011;14(2):182-90.

51. Fletcher JR. Unethical governance: capacity legislation and the exclusion of people diagnosed with dementias from research. Research Ethics. 2020;0(0):1747016120982023.

52. Wilkinson H. Including people with dementia in research: methods and motivations. In: Wilkinson $\mathrm{H}$, editor. The Perspectives of People with Dementia: Research Methods and Motivations. London: Jessica Kingsley Publishers; 2002.

53. Samsi K, Manthorpe J. Interviewing people living with dementia in social care research. 2020.

54. Nederland A. Factsheet cijfers en feiten over dementie 2021 [cited 202124 March]. Available from: https://www.alzheimer-nederland.nl/factsheet-cijfers-en-feiten-over-dementie.

55. Backhaus R. Thinking beyond numbers: nursing staff and quality of care in nursing homes. Maastricht: Maastricht University; 2017.

56. Kelle U. Combining qualitative and quantitative methods in research practice: purposes and advantages. Qualitative Research in Psychology. 2006;3(4):293-311.

57. Kupeli N, Candy B, Tamura-Rose G, Schofield G, Webber N, Hicks SE, et al. Tools Measuring Quality of Death, Dying, and Care, Completed after Death: Systematic Review of Psychometric Properties. Patient. 2019;12(2):183-97.

58. van Soest-Poortvliet MC, van der Steen JT, Zimmerman S, Cohen LW, Reed D, Achterberg WP, et al. Selecting the best instruments to measure quality of end-of-life care and quality of dying in long term care. J Am Med Dir Assoc. 2013;14(3):179-86.

59. van Soest-Poortvliet MC, van der Steen JT, Zimmerman S, Cohen LW, Munn J, Achterberg WP, et al. Measuring the quality of dying and quality of care when dying in long-term care settings: a qualitative content analysis of available instruments. J Pain Symptom Manage. 2011;42(6):852-63.

60. Joling KJ, Janssen O, Francke AL, Verheij RA, Lissenberg-Witte BI, Visser PJ, et al. Time from diagnosis to institutionalization and death in people with dementia. Alzheimers Dement. 2020;16(4):662-71.

61. Post SG. The concept of Alzheimer disease in a hypercognitive society. Concepts of Alzheimer disease: Biological, clinical and cultural perspectives. 2000:245-56.

62. Nguyen T, Li X. Understanding public-stigma and self-stigma in the context of dementia: A systematic review of the global literature. Dementia. 2020;19(2):148-81.

63. Low L-F, Purwaningrum F. Negative stereotypes, fear and social distance: a systematic review of depictions of dementia in popular culture in the context of stigma. BMC Geriatrics. 2020;20(1):477.

64. Lemos Dekker N. Moral frames for lives worth living: Managing the end of life with dementia. Death Studies. 2018;42(5):322-8.

65. Dementia Alliance International (DAI). The human rights of people living with dementia: From rhetoric to reality (2nd ed.). 2016

66. Cain CL, Surbone A, Elk R, Kagawa-Singer M. Culture and Pallitive Care. Preferen Meaning, and Mutual Decision Making. J Pain Symptom Manage. 2018;55(5):1408-19.

67. Bolt SR, van der Steen JT, Schols JMGA, Zwakhalen SMG, Janssen DJA, Meijers JMM. De rol van de verzorgende en verpleegkundige in het advance care planning proces. Tijdschrift voor Gerontologie en Geriatrie. 2021;52(1).
68. Ke LS, Huang X, O'Connor M, Lee S. Nurses' views regarding implementing advance care planning for older people: a systematic review and synthesis of qualitative studies. J Clin Nurs. 2015:24(1516):2057-73.

69. Phillips J, Johnston B, Mcllfatrick S. Valuing palliative care nursing and extending the reach. Palliative Medicine. 2020;34(2):157-9

70. IKNL/Palliactief. Netherlands Quality Framework for Palliative Care. 2017.

71. Groeneveld EI, Cassel JB, Bausewein C, Csikós A, Krajnik M, Ryan K, et al. Funding models in palliative care: Lessons from international experience. Palliative Medicine. 2017;31(4):296-305. 


\title{
ADDENDUM
}

\author{
Summary \\ Nederlandse samenvatting \\ Impact \\ Dankwoord
} About the author Publications Living Lab in Ageing and Long-Term Care 


\section{SUMMARY}

Palliative care aims to improve the quality of life of people with life-limiting conditions and their families. Dementia is a progressive and irreversible condition. Hence, people with dementia may benefit from a palliative approach to care. Palliative care is an important element in the delivery of high-quality dementia care and involves personcentered care on the physical, psychological, social, and spiritual domain. Family support and involvement by professional caregivers is another essential part, as family caregivers of people with dementia often fulfill a prominent role. Due to the cognitive decline associated with dementia, eventually family caregivers often take over decisionmaking about care and treatment. Having timely conversations with people with dementia about their wishes and care preferences facilitates shared-decision making on future goals of care. The barriers to high-quality palliative care for people with dementia are plentiful. Ideally, every member of the healthcare team should be able to apply the basic principles of palliative care (such as person-centered and relationshipcentered care, anticipating the future with people with dementia and their family caregivers, a holistic approach to addressing care needs). Nursing staff in particular have an important and central role in caring for people with dementia and their families, at home or in the nursing home. Yet, nursing staff may not feel competent to provide palliative care. To fulfill their key role and to contribute to high-quality palliative care for people with dementia until the end of life, they need to develop specific skills. This dissertation aimed to contribute to a deeper understanding of what constitutes highquality palliative care for people with dementia, taking into account the perspective of nursing staff, family caregivers and people with dementia. This knowledge forms the basis for the development of an intervention aimed to increase the competences of nursing staff in providing palliative dementia care.

Chapter 1 introduces key concepts related to palliative care and dementia. It describes the prominent caregiving role of family members of people with dementia and of nursing staff in the context of Dutch home care and nursing home care. The chapter highlights several challenges in the provision of high-quality palliative care for people with dementia until the end of life. The studies in this dissertation belong to a project entitled DEDICATED (Desired Dementia Care Towards End of Life) project. The first chapter briefly describes the DEDICATED project, and concludes with the overall aims and outline of this dissertation.

Chapter 2 describes a scoping review that aimed to explore what is known from the scientific literature concerning the needs of nursing staff when providing palliative dementia care at home or in the nursing home. A thematic analysis of the 15 included papers resulted in four themes that reflected needs on a direct care-level: 1) recognizing and addressing palliative care needs, 2) verbal and non-verbal communication, 3) dealing with challenging behavior, and 4) familiarity: knowing and understanding the person with dementia. In addition, three more themes were identified that reflected needs on more distant, organizational levels: 5) interdisciplinary collaboration, 6) 
training and education, and 7) organizational support (e.g., time, staffing, opportunities for professional development). The themes informed an integrated conceptualization of nursing staff's needs in providing palliative care for people with dementia. The needs of nursing staff related to direct care-delivery for people with dementia occur within workplace and organizational contexts. The results suggest that interventions aimed at increasing nurses' competences in palliative dementia care should be tailored to their specific needs (e.g., the need for communication skills or tools for signaling pain). Healthcare organizations should play a facilitating role in the implementation of such interventions. Of the 15 included articles, only one concerned the home care setting; thus, palliative dementia care in the community requires particular attention.

Chapter 3 presents the results of a cross-sectional survey study to evaluate the types and forms of support that nursing staff need when providing palliative care for persons with dementia. The study compared nursing staff with different educational levels and nursing staff working in home care or in the nursing home. A sample of Dutch registered nurses $(\mathrm{N}=164)$, certified nurse assistants $(\mathrm{N}=218)$ and uncertified nurse assistants $(\mathrm{N}=34)$ filled in the survey. Of these 416 respondents, 224 worked in a nursing home and 192 worked in home care. Results showed that the highest-ranking needs were in dealing with family disagreement in end-of-life decision making (58\%), dealing with challenging behaviors (41\%), and recognizing and managing pain (38\%). The highest-ranking form of support was peer-to-peer learning (51\%). The survey included an open-ended question asking what respondents would do if they would have more time in their work. Of the 238 responses to this question, 198 concerned devoting personal attention to the person with dementia. Nursing staff from different educational levels and working in the home or nursing home setting largely indicated similar needs. It is vital to understand the needs of nursing staff in order to develop and implement tailored interventions. The findings suggest that interventions aimed at supporting nursing staff in providing palliative care for people with dementia may target similar areas to serve a heterogeneous group of nursing staff from different levels and working in home care or in a nursing home.

Chapter 4 describes a rapid scoping review performed to formulate recommendations for nursing staff on how to provide palliative dementia care in times of COVID-19. The review was carried out in April and May 2020, in response to the worldwide outbreak of COVID-19. The pandemic and its associated societal regulations posed specific challenges to the provision of high-quality palliative care for people with dementia living in long-term care facilities. The scoping review resulted in an overview of contemporary practice recommendations for nursing staff on how to safeguard the quality of palliative dementia care during the pandemic. The recommendations were grouped according to the essential domains in palliative dementia care. The highest number of papers informed recommendations under the domains 'advance care planning' and 'psychological aspects of care'. The lowest number of papers informed the domains 'ethical care', 'care of the dying', 'spiritual care' and 'bereavement care'. No papers were found that informed the 'cultural aspects of care' domain. The scoping review demonstrated that there is a particular need for grief and bereavement support to mitigate adverse outcomes such as complicated grief and trauma. Grief and moral distress among nursing staff requires recognition and attention. Nursing leadership is needed to safeguard the quality of palliative care, interprofessional collaboration and peer support among nursing staff. The results of the review exposed practice and knowledge gaps with regard to palliative dementia care in the global response to COVID-19. The findings reflect the longstanding neglect and weaknesses of palliative care in the long-term care setting.

Chapter 5 presents the results of a secondary data analysis of questionnaires filled in by bereaved family caregivers of nursing home residents with dementia $(\mathrm{N}=252)$. Previous analyses of the data, derived from 34 Dutch nursing homes, showed that only $56 \%$ of the family caregivers had perceived the death of their relative as peaceful. The study presented in this dissertation sought to explore the associations between families' experiences with end-of-life care and their recollection of the person with dementia dying peacefully. Results showed a positive association between families' satisfaction with care and decision-making and dying peacefully. Negative experiences with care were associated with families' perceptions of a less peaceful death. A thematic analysis of answers to an open-ended question asking about the family caregivers' negative experiences resulted in two main themes: 1) neglect and 2) lack of respect. Neglect meant that families faced inaccessibility and disinterest of professional caregivers, discontinuous care relationships, and negligence in tailored care for their relative. Lack of respect involved families' perceptions of being disregarded on purpose, an insensitive approach by professional caregivers towards their relative, noncompliance with agreements, and violations of privacy. Insight into these specific experiences, which negatively relate to dying peacefully, provides meaningful information to improve practice in end-of-life care for people with dementia and their families. The results underline the need for humane and compassionate care and attention until the end of life.

Chapter 6 describes a qualitative study that further explored family caregivers' experiences with care at the end of life of people with dementia. Interviewees had experienced the care for their relative in a nursing home $(\mathrm{N}=24)$ or at home $(\mathrm{N}=8)$. Their experiences translated into four themes: 1) acknowledging human dignity, 2) being recognized as an important caregiver, 3) (not) talking about death and dying, and 4) making decisions together. The comparison between both settings showed that mainly family caregivers from the nursing home setting reported a lack of person-centeredness, which bothered them. They were also more uncertain about their caregiving role in the nursing home, and sometimes felt set aside by the care team. At home, family caregivers took on a more central caregiving role. Family caregivers from both settings valued 
person-centeredness and being actively involved as a member of the care team. They faced similar challenges related to surrogate decision-making, which required ongoing, open communication with familiar professional caregivers. The findings highlight the importance of building close and supportive care relationships to aid end-of-life decision-making by families. Moreover, stimulating person-centeredness and family involvement may be a particular area for improvement in the nursing home setting.

Chapter 7 reports on an analysis of combined, existing datasets to explore trends in family caregivers' evaluations of quality of care and quality of dying of nursing home residents with dementia in the Netherlands. The analysis included reports of 1189 family caregivers and covered a 14-year period from 2005 to 2019. Results showed a trend of increasing quality of care, while quality of dying did not change. Families' evaluations of the well-being while dying subscale decreased over time. These results suggest that, despite the growing attention for palliative dementia care in research and practice, symptom management in dying with dementia needs further improvement. The gap between families' expectations and their actual experiences with the dying process may be increasing. Further research is needed to disentangle the complex interplay between quality of care and quality of dying as perceived by family caregivers of people with dementia. Continuing monitoring of families' perceived quality of care and quality of dying may aid an understanding of contemporary views on what constitutes 'a good death' for people with dementia.

Chapter $\mathbf{8}$ describes the results of a qualitative study that explored the perspectives of people with dementia on their future, the end of life, and on being cared for by others. The interviewees were 18 community-dwelling persons with dementia. Their story was reflected through five overarching themes: 1) my life still has value and meaning, 2) I am my own unique individual, 3) I place my trust in other people, 4) the future worries me, and 5) I accept and embrace what life brings. The interviewees expressed a strong wish to live a meaningful life, to feel that they matter and belong, and to be seen by others as worthy and unique humans. Their stories reflected resilience, despite their feelings of ambiguity and anxiety towards the future and their further decline. Interviewees preferred distancing themselves from a worrisome future and instead intended to 'live in the moment'. They were generally content with the life they had lived, and thinking about death involved feelings of acceptance and resignation. They placed great trust in their family members and others who care for them now or may care for them in the future. Results showed that individuals cope with their condition in different ways. This suggests that conversations about future care in the context of advance care planning should be tailored to an individual's stance towards the future and readiness to discuss it. This study demonstrated that people with dementia, when given the opportunity, are willing and capable of sharing their thoughts on complex and sensitive end-of-life topics. The findings emphasize the need for an inclusive community for people with dementia, in which others facilitate them to fulfil basic human needs: to live a meaningful life and to maintain belongingness and uniqueness until the end of life.

Chapter 9 summarizes the main findings of all studies included in this dissertation, followed by theoretical and methodological considerations. It describes implications for research, practice and policy, following from the results of this dissertation. The knowledge base developed in this dissertation and the subsequent development of the DEDICATED approach are important steps towards advancing person-centered and relationship-centered palliative care provision for people with dementia and their families. 
NEDERLANDSE SAMENVATTING

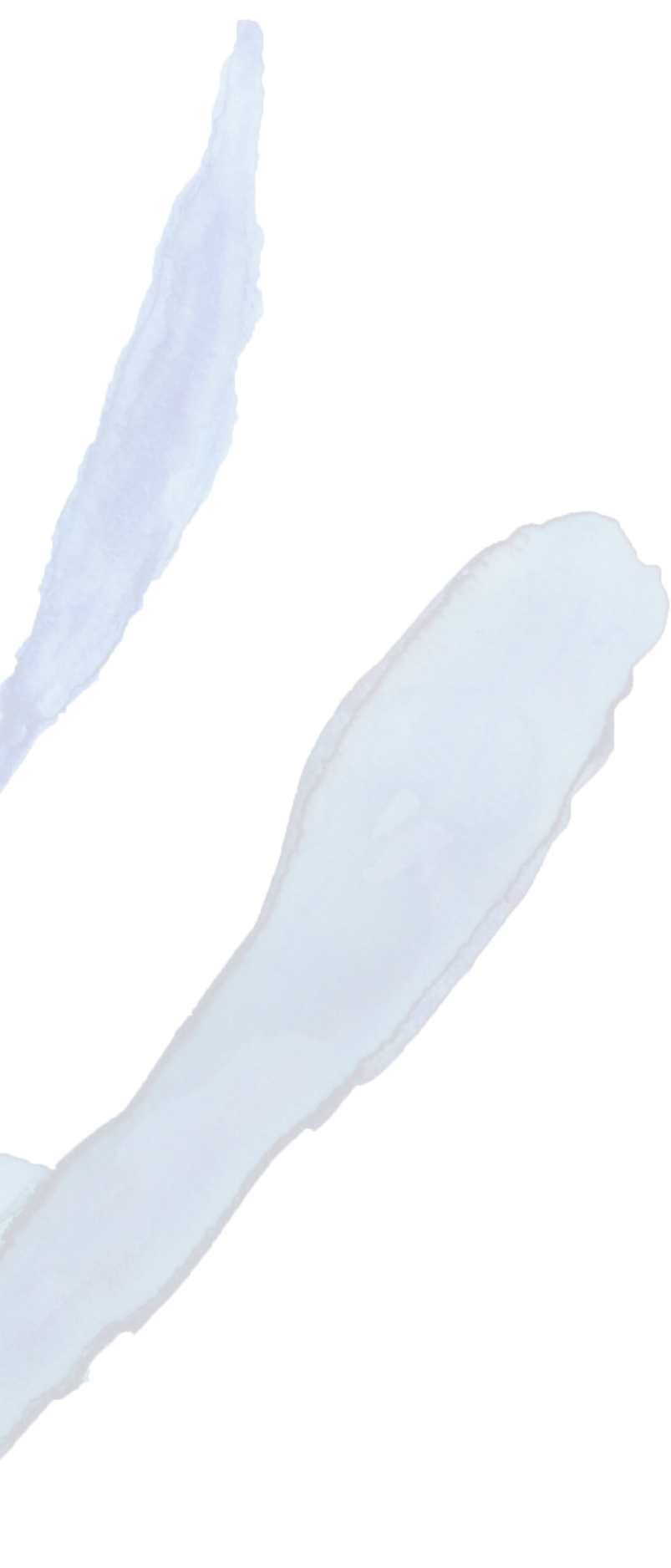

Palliatieve zorg is erop gericht de kwaliteit van leven van mensen met een ongeneeslijke ziekte en hun naasten te verbeteren. Dementie is een progressieve en onomkeerbare aandoening. Mensen met dementie kunnen daarom baat hebben bij een palliatieve benadering van de zorg. Palliatieve zorg is een belangrijk onderdeel van hoogstaande dementiezorg en omvat persoonsgerichte zorg op lichamelijk, psychisch, sociaal en spiritueel vlak. Ook het bieden van ondersteuning aan en het betrekken van familie door zorgprofessionals is een essentieel onderdeel, aangezien mantelzorgers van mensen met dementie vaak een prominente rol vervullen. Door de cognitieve achteruitgang waarmee dementie gepaard gaat, nemen familieleden uiteindelijk vaak de besluitvorming rondom zorg en behandeling over. Tijdige communicatie met mensen met dementie over hun wensen en behandelvoorkeuren faciliteert gezamenlijke besluitvorming over toekomstige zorgdoelen. Er zijn veel factoren die de kwaliteit van de palliatieve zorgverlening aan mensen met dementie in de weg staan. Idealiter zou iedere zorgprofessional in staat moeten zijn om de basisprincipes van de palliatieve zorg toe te passen (zoals persoonsgerichte en relatiegerichte zorg, samen met mensen met dementie en mantelzorgers anticiperen op de toekomst, inspelen op zorgbehoeften vanuit een holistische benadering). Verzorgenden en verpleegkundigen hebben een belangrijke en centrale rol in de zorg voor mensen met dementie en hun naasten, zowel thuis als in het verpleeghuis. Toch voelen verzorgenden en verpleegkundigen zich niet altijd competent om palliatieve zorg te verlenen. Zij hebben specifieke vaardigheden nodig om hun essentiële rol goed te kunnen vervullen en om te kunnen bijdragen aan hoogstaande palliatieve zorg voor mensen met dementie. Het doel van dit proefschrift was om meer inzicht te krijgen in de aspecten die van belang zijn bij goede palliatieve zorg voor mensen met dementie vanuit het perspectief van verzorgenden en verpleegkundigen, mantelzorgers en mensen met dementie. Deze kennis vormt de basis voor de ontwikkeling van een interventie met als doel de competenties van verzorgenden en verpleegkundigen in de palliatieve dementiezorg te verbeteren.

Hoofdstuk 1 introduceert de belangrijkste concepten rondom palliatieve zorg en dementie. Het omschrijft de prominente rol van mantelzorgers van mensen met dementie en van verzorgenden en verpleegkundigen, binnen de context van de thuiszorg en de verpleeghuiszorg in Nederland. Het hoofdstuk belicht verschillende uitdagingen bij het verlenen van goede palliatieve zorg voor mensen met dementie tot aan het levenseinde. De studies in dit proefschrift zijn onderdeel van een project genaamd DEDICATED (Desired Dementia Care Towards End of Life). Het eerste hoofdstuk omschrijft kort wat het project DEDICATED inhoudt en sluit af met een omschrijving van de algehele doelen en de opbouw van het proefschrift.

Hoofdstuk 2 beschrijt een scoping review met als doel te onderzoeken wat er bekend is vanuit de wetenschappelijke literatuur over de behoeften van verzorgenden en verpleegkundigen wanneer zij palliatieve zorg verlenen aan mensen met dementie, thuis en in het verpleeghuis. Een thematische analyse van de 15 geïncludeerde artikelen 
resulteerde in vier thema's rondom behoeften op het niveau van directe zorgverlening: 1) het herkennen van en inspelen op palliatieve zorgbehoeften, 2) verbale en nonverbale communicatie, 3) omgaan met onbegrepen gedrag, en 4) het leren kennen van de persoon met dementie. Daarnaast werden drie aanvullende thema's omschreven rondom behoeften op een meer overstijgend, organisatorisch niveau: 5) interdisciplinaire samenwerking, 6) training en educatie, en 7) ondersteuning vanuit de organisatie (zoals tijd, personeel, mogelijkheden voor professionalisering). Vanuit deze thema's is een geïntegreerde conceptualisatie van verpleegkundige behoeften in de palliatieve dementiezorg ontwikkeld. Behoeften gerelateerd aan de directe zorgverlening aan mensen met dementie ontstaan binnen de context van de werkvloer en organisatie. De resultaten suggereren dat interventies die erop gericht zijn verpleegkundige competenties in de palliatieve dementiezorg te vergroten, moeten worden afgestemd op de specifieke behoeften van verzorgenden en verpleegkundigen (zoals behoeften aan communicatievaardigheden of tools om pijn te signaleren). Zorgorganisaties spelen idealiter een faciliterende rol bij de implementatie van dergelijke interventies. Van de 15 geïncludeerde artikelen had er slechts één betrekking op de thuiszorg; er is daarom specifieke aandacht nodig voor palliatieve dementiezorg in de thuissituatie.

Hoofdstuk 3 presenteert de resultaten van een cross-sectioneel vragenlijstenonderzoek om te evalueren welk type en welke vormen van ondersteuning verzorgenden en verpleegkundigen nodig hebben in de palliatieve zorgverlening aan mensen met dementie. De studie maakte een vergelijking tussen respondenten van verschillende verpleegkundige niveaus en tussen respondenten werkend in de thuiszorg of in het verpleeghuis. De vragenlijst werd ingevuld door een steekproef van Nederlandse verpleegkundigen ( $\mathrm{N}=164)$, verzorgenden $(\mathrm{N}=218)$ en helpenden $(\mathrm{N}=34)$. Van deze 416 respondenten werkten er 224 in het verpleeghuis en 192 in de thuiszorg. De meest onderschreven behoeften betroffen ondersteuning bij conflicten tussen naasten bij de besluitvorming over het levenseinde (58\%), het omgaan met onbegrepen gedrag, zoals onrust of agressie (41\%) en het herkennen van en omgaan met pijn (38\%). De gewenste vorm van ondersteuning die het meest werd onderschreven, was intervisie (51\%). De vragenlijst bevatte een open vraag naar wat respondenten zouden doen indien zij meer tijd zouden hebben in hun werk. Van de 238 antwoorden op deze vraag, hadden er 198 betrekking op het geven van persoonlijke aandacht aan de persoon met dementie. Respondenten van verschillende verpleegkundige niveaus en werkzaam in de thuiszorg of in het verpleeghuis gaven vergelijkbare ondersteuningsbehoeften aan. Het is belangrijk om inzicht te krijgen in de specifieke behoeften van verzorgenden en verpleegkundigen om interventies op maat te kunnen ontwikkelen en implementeren. De bevindingen suggereren dat interventies om competenties te vergroten op het vlak van palliatieve dementiezorg zich voor verpleegkundigen, verzorgenden en helpenden werkzaam in de thuiszorg of in het verpleeghuis op vergelijkbare thema's kunnen richten om gepaste ondersteuning te bieden.
Hoofdstuk 4 omschrijft een 'rapid scoping review' die werd uitgevoerd om praktische aanbevelingen te formuleren voor verpleegkundig personeel met betrekking tot het verlenen van palliatieve dementiezorg in tijden van COVID-19. De review werd uitgevoerd in april en mei 2020, in reactie op de wereldwijde uitbraak van COVID-19. De pandemie en de daaruit volgende maatschappelijke maatregelen leidde tot specifieke uitdagingen in het verlenen van goede palliatieve zorg voor verpleeghuisbewoners met dementie. De review resulteerde in een overzicht van actuele, praktische aanbevelingen voor verzorgenden en verpleegkundigen, over hoe zij de kwaliteit van palliatieve dementiezorg kunnen bewaken tijdens deze pandemie. De aanbevelingen werden gegroepeerd onder de kerndomeinen van palliatieve dementiezorg. De meeste artikelen hadden betrekking op aanbevelingen gegroepeerd onder de domeinen 'advance care planning' (=proactieve zorgplanning) en 'psychologische aspecten van de zorg'. Het minste aantal artikelen hadden betrekking op aanbevelingen gegroepeerd onder de domeinen 'zorgethiek', 'spirituele zorg', 'zorg voor de stervende', en 'zorg voor de nabestaanden'. Er werden geen artikelen gevonden met informatie over het domein 'culturele aspecten van de zorg'. De review liet zien dat er vooral nood is aan ondersteuning rondom verlies en rouw, om potentiële negatieve uitkomsten zoals gecompliceerde rouw en trauma te beperken. Rouw en morele nood onder verzorgenden en verpleegkundigen vraagt om erkenning en aandacht. Verpleegkundig leiderschap is nodig om de kwaliteit van palliatieve zorg, interprofessionele samenwerking en peer support onder verpleegkundigen te waarborgen. De resultaten van de review tonen de praktijk- en kennishiaten met betrekking tot palliatieve dementiezorg in de wereldwijde COVID-19 aanpak. Deze bevindingen weerspiegelen de persisterende uitdagingen rondom palliatieve zorg in de langdurige-zorgsector.

Hoofdstuk 5 presenteert de resultaten van een secundaire data-analyse van vragenlijsten ingevuld door familieleden van overleden verpleeghuisbewoners met dementie $(\mathrm{N}=252)$. Eerdere analyses van deze data, verkregen uit 34 Nederlandse verpleeghuizen, lieten zien dat slechts $56 \%$ van de familieleden de dood van hun naaste als vredig had ervaren. De studie in dit proefschrift onderzocht de associaties tussen de ervaringen van familieleden met de zorg aan het levenseinde en hun herinnering aan een vredig overlijden van de persoon met dementie. De resultaten toonden een positieve associatie tussen tevredenheid van familieleden met de zorg en de besluitvorming aan het levenseinde, en hun herinnering aan een vredig overlijden. Negatieve ervaringen met de zorg waren gerelateerd aan een minder vredig overlijden van de persoon met dementie, zoals bezien door de familie. Een thematische analyse van de antwoorden op een open vraag naar de negatieve ervaringen die familieleden hadden gehad, resulteerde in twee thema's: 1) gebrek aan aandacht en 2) gebrek aan respect. 'Gebrek aan aandacht' hield in dat familieleden aanliepen tegen ontoegankelijkheid en desinteresse van zorgprofessionals, discontinuïteit in zorgrelaties en een gebrek aan zorg op maat voor hun naaste met dementie. 'Gebrek aan respect' hield in dat familieleden het gevoel 
hadden dat zij opzettelijk werden genegeerd en dat zorgprofessionals hun naaste met dementie onsympathiek benaderde. Ook hoorde hierbij het gevoel dat afspraken niet werden nagekomen en dat er onvoldoende aandacht was voor privacy. Inzicht in deze specifieke ervaringen, die negatief samenhangen met een vredig sterfbed, geeft belangrijke informatie op basis waarvan de levenseindezorg voor mensen met dementie en hun naasten kan worden verbeterd. De resultaten onderstrepen het belang van menselijke en compassievolle zorg en aandacht tot aan het levenseinde.

Hoofdstuk 6 beschrijft een kwalitatieve studie om de ervaringen van familieleden met de zorg aan het levenseinde van mensen met dementie verder te verkennen. De geïnterviewden hadden ervaring met de zorg voor hun naaste in een verpleeghuis $(\mathrm{N}=24)$ of thuis $(\mathrm{N}=8)$. Hun ervaringen besloegen vier thema's: 1) waarborgen waardigheid als mens, 2) erkend worden als mantelzorger, 3) (niet) spreken over de dood, en 4) beslissingen maken met elkaar. De vergelijking tussen beide zorgsettingen liet zien dat vooral familieleden die de zorg in het verpleeghuis hadden meegemaakt soms persoonsgerichte zorg hadden gemist en dit als hinderlijk hadden ervaren. Ook waren zij onzekerder over hun rol als mantelzorger in het verpleeghuis en voelden zij zich soms buitengesloten door het zorgteam. Thuis namen familieleden vaak het voortouw in hun rol als mantelzorger. Familieleden uit beide settingen waardeerden een persoonsgerichte benadering en zij werden graag actief betrokken als onderdeel van het zorgteam. In beide settingen werden vergelijkbare uitdagingen ervaren in het maken van surrogaatbeslissingen, waarbij er behoefte was aan structurele en open communicatie met zorgprofessionals. De bevindingen benadrukken het belang van hechte en ondersteunende zorgrelaties om familieleden te faciliteren in de besluitvorming aan het levenseinde van hun naaste met dementie. Verder is het stimuleren van een persoonsgerichte benadering en het betrekken van familieleden mogelijk een specifiek aandachtspunt in de verpleeghuissetting.

Hoofdstuk 7 rapporteert een analyse van gecombineerde, bestaande datasets om trends te onderzoeken in de kwaliteit van zorg en kwaliteit van sterven van verpleeghuisbewoners met dementie in Nederland, zoals beoordeeld door familieleden. In de analyse werden gegevens van 1189 familieleden meegenomen, waarbij een totale periode van 14 jaar werd beslagen (2005-2019). De resultaten toonden een stijgende trend in de kwaliteit van zorg, terwijl de kwaliteit van sterven niet veranderde. De subschaal 'welzijn tijdens het sterven', zoals beoordeeld door familieleden, daalde over de tijd. De resultaten suggereren dat symptoom management aan het levenseinde met dementie nog altijd om verbetering vraagt, ondanks de groeiende aandacht voor palliatieve dementiezorg in onderzoek en praktijk. Mogelijk is er een groeiende kloof tussen de verwachtingen van familieleden en hun daadwerkelijke ervaringen met het stervensproces. Aanvullend onderzoek is nodig om het complexe samenspel tussen de kwaliteit van zorg en kwaliteit van sterven zoals ervaren door familieleden van mensen met dementie te ontrafelen. Het doorlopend monitoren van de ervaren kwaliteit van zorg en kwaliteit van sterven door familie draagt bij aan ons inzicht in hedendaagse perspectieven op wat een 'goede dood' bij mensen met dementie inhoudt

Hoofdstuk 8 beschrijft de resultaten van een kwalitatieve studie naar de perspectieven van mensen met dementie op het ontvangen van zorg door anderen, de toekomst en het levenseinde. De geïnterviewden waren 18 thuiswonende mensen met dementie. Hun verhaal weerspiegelde vijf overkoepelende thema's: 1) mijn leven heeft nog steeds waarde en betekenis, 2) ik ben mijn eigen unieke individu, 3) ik plaats mijn vertrouwen in anderen, 4) de toekomst verontrust me, en 5) ik accepteer en omarm wat het leven brengt. De geïnterviewden uitten een sterke wens om een betekenisvol leven te leiden, om het gevoel te hebben dat ze ertoe doen en 'erbij horen', en om door anderen gezien te worden als volwaardige en unieke mensen. Ondanks een onzekere toekomst die soms angst opwekte, toonden de geïnterviewden veel veerkracht. Bij voorkeur distantieerden zij zich van een zorgwekkende toekomst en richtten zij zich op het 'hier en nu'. Over het algemeen waren ze tevreden met het leven dat zij hadden geleid. Ze ervaarden een gevoel van acceptatie en berusting ten aanzien van het naderende levenseinde. Zij plaatsten veel vertrouwen in hun familieleden en anderen die op dit moment voor hen zorgen of in de toekomst voor hen zullen zorgen. De resultaten lieten zien dat individuen verschillend omgaan met hun ziekte. Dit suggereert dat levenseindegesprekken in het kader van advance care planning afgestemd moeten worden op de manier waarop een individu aankijkt tegen de toekomst, en zijn of haar bereidheid om hierover in gesprek te gaan. Deze studie liet zien dat mensen met dementie in staat en bereid zijn om hun gedachten over complexe en gevoelige zaken rondom het levenseinde te delen, als zij hiertoe de kans krijgen. De bevindingen benadrukken het belang van een inclusieve maatschappij, waarin we mensen met dementie faciliteren om een basale menselijke behoefte te vervullen. Namelijk om een betekenisvol leven te leiden en om zich tot aan het levenseinde gezien, betrokken en gewaardeerd te voelen als mens.

Hoofdstuk 9 vat de belangrijkste bevindingen van alle studies in dit proefschrift samen, gevolgd door de theoretische en methodologische overwegingen. Het omschrijft implicaties voor onderzoek, praktijk en beleid, volgend uit de resultaten van dit proefschrift. De ontwikkelde kennis uit dit proefschrift, en de hieruit volgende ontwikkeling van de DEDICATED-werkwijze, vormen belangrijke stappen om de persoonsgerichte en relatiegerichte palliatieve zorgverlening voor mensen met dementie en hun naasten te bevorderen. 
IMPACT

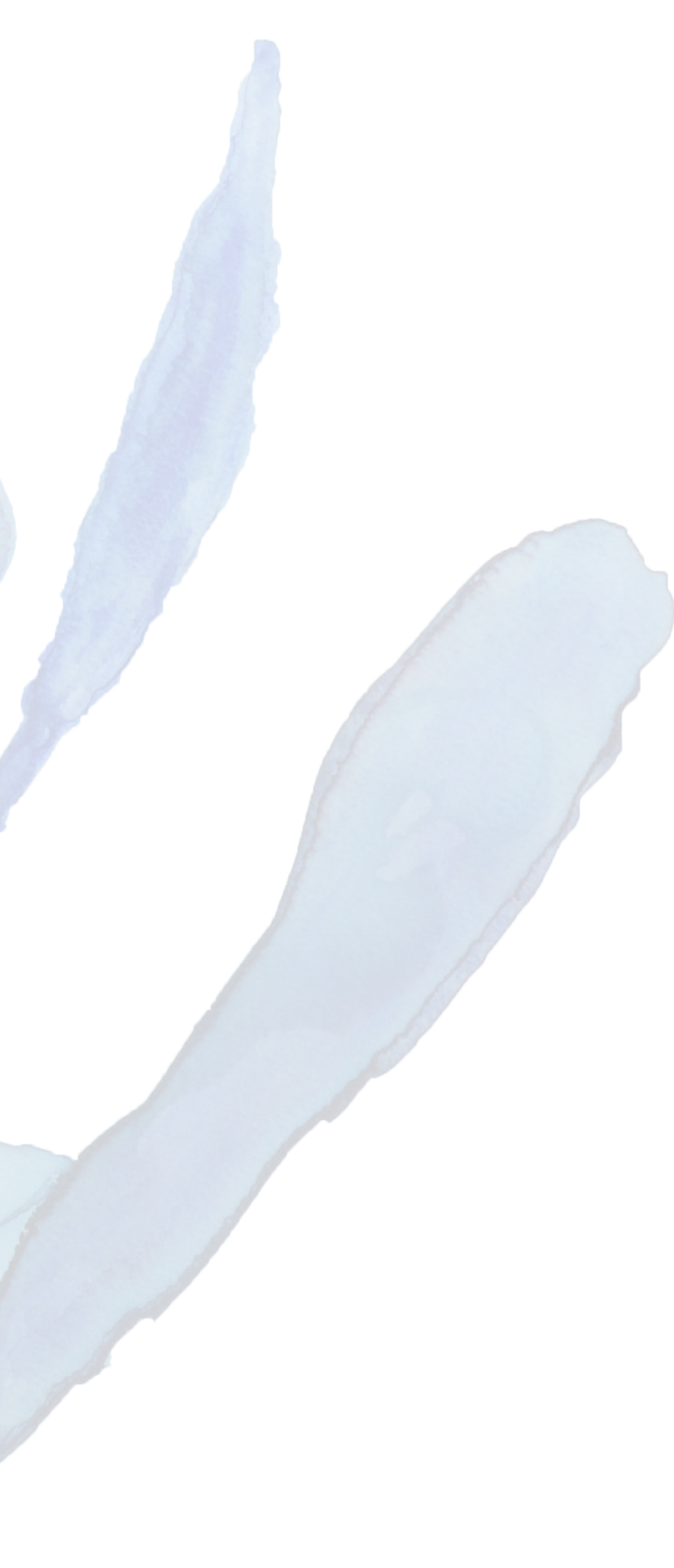

The colleagues are all enthusiastic. We really feel like we can become of greater significance to the client.' (Quote from an interview by the Dutch Nursing Society V\&VN with one of the DEDICATED ambassadors) ${ }^{1}$

This dissertation introduces a contemporary view on the need for integration of palliative nursing care into dementia care. The research provides a comprehensive basis for further development of nursing practice and education in the provision of palliative care for people with dementia. This chapter reflects on the impact of the research described in this dissertation on practice, education, and science. It also describes the societal impact and the future of this DEDICATED project.

\section{PRACTICE AND EDUCATION}

'Stirring up old memories went with a smile and a tear. A beautiful process, doing this together. I learned more about the client, because I heard stories that are not documented in a care plan, and that are not told during an intake. The family caregivers were very enthusiastic as well. We collected a variety of materials to fill the poster: photos, stickers, clippings from magazines. The daughter framed and hanged the poster. The client, his daughter, his wife and I were all very happy with the result. Everyone had to come and see the poster.' (DEDICATED ambassador talking about creating a 'life story poster' with a client with dementia, see photo)

The chapters in this dissertation reflect the thorough groundwork that was carried out to inform the development of practical tools and materials to support palliative dementia care. Since September 2019, parallel to the scientific groundwork described in this dissertation, a design team has been working on the development of the 'DEDICATED approach'. The design team includes nurses working in the home and nursing home setting, nurse educators, dementia case managers, and researchers. Results from the studies in this dissertation informed four of the main themes addressed in the DEDICATED approach. The themes include:

1) Awareness of a palliative care approach in dementia

2) Familiarity (getting to know each other)

3) End-of-life communication

4) Dealing with pain and responsive behaviors

During regular meetings, the design team brainstormed about themes and related challenges. The design team inventoried existing tools, methods, and 'best practices' that related to these themes and that suited the nursing context of the project. When 
needed, the team also developed new support materials. The inventory and development process took into account the organizational context by exploring each organization's current practices, possibilities, and barriers concerning the use of existing and newly developed materials and methods. After finalizing a theme, design team members took the theme's materials into practice to test and evaluate them with their colleagues. This was an ongoing and iterative co-creation process of developing, testing, and adapting materials.

This dissertation came forth from the larger DEDICATED project. DEDICATED consists of two parts. Part 1 focuses on palliative caregiving in dementia by nursing staff and on end-of-life communication. Part 2 focuses on interprofessional collaboration in palliative dementia care, and on continuity in transfers between home and the nursing home. This dissertation is a product of the first part; the second part will result in a separate dissertation. Nonetheless, both parts of the DEDICATED project are complementary and, since April 2020, we worked on the gradual integration of part 1 and 2. The DEDICATED approach therefore incorporates elements from both project parts. The nurses, case managers, and other care professionals who participated in the design team of either project part were designated and trained as 'DEDICATED ambassadors'. Professionals from intermediate and higher vocational nursing education participated in the co-creation process as well. At first, they gave advice on the formats and content of support materials, from a didactic perspective. For instance, they provided feedback on the use of language to facilitate understanding by nursing staff from a variety of educational levels. Moreover, together with the education professionals, we developed a training for DEDICATED ambassadors. The ambassador's training aims to:

1) Introduce palliative care for people with dementia

2) Teach ambassadors how to enthuse and motivate their colleagues

3) Familiarize ambassadors with the DEDICATED approach and materials; teach them how to identify learning goals within their teams; teach them how to match the DEDICATED approach to these learning goals within their organizational contexts

4) Create a peer support and intervision group of ambassadors; teach them how to implement, disseminate, and sustain the DEDICATED approach together.

A DEDICATED ambassador should ideally lead care teams that want to use the DEDICATED materials. The ambassadors have an important role in stimulating awareness about palliative care and dementia, introducing the DEDICATED approach and its belonging materials to their colleagues, and sustaining the use of the DEDICATED approach in practice. The DEDICATED ambassadors have proven to be truly 'dedicated' and they have contributed to increasing recognition of the project. Six care teams in the project's partner organizations (nursing home and home care) are currently using DEDICATED materials as a pilot. Ambassadors and their colleagues can retrieve the developed materials via the webpage of the DEDICATED approach (see dedicatedwerkwijze.nl, or scan QR code).

The DEDICATED webpage guides its users to the appropriate support materials, sorted according to themes as well as according to the place of care (home, nursing home, or in transition). The teams' learning goals function as a basis to navigate the webpage and find the support they need. Most of the materials have digital formats, which users can download and open on their digital device or print. A few of the materials are physical. For instance, we collaborated with 'Bureau MORBidee', an expert business in end-of-life communication, to develop communication aids. The aids consist of a pack of photo cards and a sack of dices with symbols, which can be used to have conversations with persons with dementia about the future, the end of life and related topics (see photo). The aids were well received by our ambassadors and by nursing students. They are currently being used in practice and education to ease (end-of-life) communication with persons with dementia. Another example of a support material, which was developed in response to a contemporary practice need, was a guidance document with practical recommendations for nursing staff on how to provide palliative dementia care in times of COVID-19. These recommendations were retrieved from the scoping review (chapter 4), summarized, and translated into Dutch. Several regional and national project partners (e.g., the Dutch Nursing Society V\&VN, Vilans, Palliative Care Networks, Palliaweb) and a Dutch practice journal of nursing (TvZ) disseminated the formalized guidance document. Thereby, the guidance document reached a broad audience of clinicians in dementia care. Table 1 provides an overview of developed materials within part 1 of DEDICATED.

Nursing staff, including registered nurses and nurse practitioners, certified nurse assistants (i.e., licensed nurses), and nurse assistants, together with dementia case managers, make up the primary target groups for all these materials. Applying the materials in practice should help them to feel more competent and better prepared to deliver high-quality and person-centered palliative dementia care. Moreover, the ambassadors' involvement in the project as co-creators stimulates a general movement within their care teams to think and talk about palliative care and to reflect on what this means in relation to dementia. From anecdotal evidence, the current ambassadors working in nursing homes underscore the usefulness and potential of using DEDICATED materials to support palliative caregiving for people with dementia. For instance, during one of the ambassador's training sessions, an ambassador said that 'The support materials offer guidance and they actually help to establish low-threshold conversations with residents and with their families. It can really help to increase their involvement.' 


\begin{tabular}{|c|c|c|c|}
\hline & $\begin{array}{c}\text { Elaborate } \\
\text { instruction }\end{array}$ & $\begin{array}{l}\text { Overview / } \\
\text { condensed }\end{array}$ & $\begin{array}{c}\text { Physical material } \\
\text { / other }\end{array}$ \\
\hline \multicolumn{4}{|l|}{ Awareness of a palliative care approach in dementia } \\
\hline Case discussions within the care team & $\mathbf{x}$ & $\mathbf{x}$ & \\
\hline Reflection within the care team & $\mathbf{x}$ & $\mathbf{x}$ & \\
\hline 'Chatter jar' ('Kletspot') & & & $\mathrm{x}$ \\
\hline Short movie to stimulate awareness & & & $\mathrm{x}$ \\
\hline $\begin{array}{l}\text { Practical nursing recommendations for palliative dementia } \\
\text { care during COVID-19 }\end{array}$ & & $\mathrm{x}$ & \\
\hline \multicolumn{4}{|l|}{ Familiarity (getting to know each other) } \\
\hline Method life story book & $\mathbf{x}$ & $\mathbf{x}$ & \\
\hline Method life story poster & $\mathbf{x}$ & $\mathbf{x}$ & \\
\hline ‘Good practice example’ life story book & & $\mathrm{x}$ & \\
\hline 'Good practice example' life story poster & & $\mathrm{x}$ & \\
\hline \multicolumn{4}{|l|}{ End-of-life communication } \\
\hline Communication aid: dices & & $\mathrm{x}$ & $\mathbf{x}$ \\
\hline Communication aid: photo cards & & $\mathrm{x}$ & $\mathrm{x}$ \\
\hline Overview of other communication aides & & $\mathrm{x}$ & \\
\hline \multicolumn{4}{|l|}{ Dealing with pain and responsive behaviors } \\
\hline PACSLAC-D: short movie & & & $\mathbf{x}$ \\
\hline PACSLAC-D: poster to stimulate awareness & & $\mathrm{x}$ & $\mathrm{x}$ \\
\hline Overview of other pain signaling instruments & & $\mathrm{x}$ & \\
\hline ABC-method: poster to stimulate awareness & & & $\mathbf{x}$ \\
\hline
\end{tabular}

The investment in a group of dedicated (DEDICATED) ambassadors will facilitate the dissemination and preservation of the approach in the future. In collaboration with the participating educators and the current ambassadors, we will train ambassadors from new care teams and organizations. In a subsequent stage, we will also set up a train-thetrainer program to educate new trainers who can provide the ambassadors' training (and thereby replace the educators that are involved now). Nurses and dementia case managers are the primary target group for the train-the-trainer program. The existing DEDICATED ambassadors can evolve into trainers if they please. This will lead to a solid and self-sustaining network of DEDICATED trainers and DEDICATED ambassadors, who pass on their knowledge and stimulate awareness.

Next to their role in the development of materials and a training program for ambassadors, the education professionals contribute to the uptake of DEDICATED into nurse students' education and curricula. For instance, they are using DEDICATED materials in their classes as a part of palliative care education (see photo). One of the educators reported that 'students felt DEDICATED' after joining a

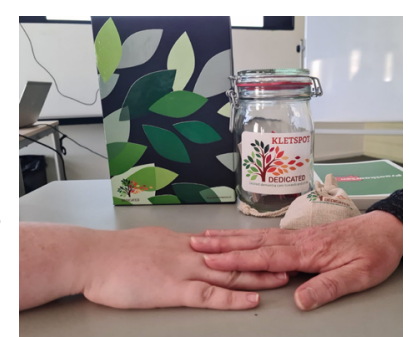

workshop with one of the ambassadors. Another educator noted that the integration of DEDICATED into palliative care education triggers awareness among students about the inextricable link between palliative care and dementia care. This awareness, in turn, rouses their interest in and motivation to further explore the topic. It contributes to the realization that they can still be of great significance to people with dementia, even in the case of severe impairment. Therein, the 'short movie to stimulate awareness' is considered to be a great tool, that speaks to students' imagination and touches their feelings.

At several occasions, the DEDICATED research team itself organized lectures and classes on palliative dementia care for students from intermediate and higher vocational nursing education as well as for employed nursing staff. For instance, we organized a practical lecture at a hospice for nurse students using DEDICATED materials to have a joint case discussion and reflection. One of the ambassadors joint and co-led this meeting. Further, we organized digital lessons about palliative care and dementia for nursing students from higher and intermediate vocational education and for care professionals as part of an interprofessional palliative care course. Such activities contribute to the awareness of nurse students and professional nursing staff about the meaning and importance of a palliative approach to dementia care. Our collaboration with the education section of the Dutch Palliative Care Consortium (Limburg Zuid-Oost Brabant) has led to the inclusion of DEDICATED materials into the current training of 20 lecturers. The educators involved in the DEDICATED project provide this training. By the end of 2021, it is planned that around 200 lecturers from intermediate and higher vocational education will have been trained.

Within the DEDICATED project, 13 students (from BA Health Sciences, MA Healthcare Policy, Innovation and Management and MA Nursing Science) wrote their theses on topics related to palliative care and dementia. Laura Verbeek, a student from the Master of Nursing Science won the scientific Johanna Diepeveen-Speekenbrink award for our publication that was based on her thesis (chapter 5).

\section{SOCIETY}

"Dementia is an incurable and neurodegenerative condition. Persons with dementia experience increasing deterioration and loss of functions. Therefore, a palliative approach, which starts after a diagnosis of dementia, is of importance throughout the dementia trajectory, with the goal of maximizing and preserving quality of life until the end." - Dementia Care Standard 2020

As a research group, DEDICATED played an important role in the integration of palliative care in the newly developed Dutch Dementia Care Standard. ${ }^{2}$ From the studies in this dissertation, we learned that an early adoption of a palliative approach is important in the care provision for people with dementia. Based on our specific expertise, the 
authors of the standard (one of whom is also a member of DEDICATED's advisory board) requested our advice. Draft versions of the standard mentioned palliative care merely in relation to the end of life and dying with dementia. In multiple feedback rounds, we advocated for a clear and explicit early palliative approach to care, which is now adopted throughout the standard, together with recurrent references to the Netherlands Quality Framework for Palliative Care. ${ }^{3}$ Thereby, the work in this dissertation contributed to the advancement of the national vision and knowledge on dementia care. The Dementia Care Standard is an important guideline that supports the organization and delivery of tailored dementia care in integral networks and chains of care. It reaches a broad population of professionals working in the field of dementia, including healthcare providers, policy makers and managers. ${ }^{2}$

The DEDICATED project involved structural groups of stakeholders. Besides the design group, the project involved a working group (with healthcare professionals and managers, educators, patient representatives) and an advisory board (with care directors, representatives from national and regional partners such as from the Dutch Alzheimer's Association, Vilans and the Dutch Nursing Society V\&VN). Figure 1 (in Dutch) depicts all project partners. Co-creation by means of involving stakeholders in several steps of the research process is key to generating societal and practical impact of the results. ${ }^{4}$ The DEDICATED project engaged many stakeholders from a variety of disciplines (e.g., nursing, geriatrics, psychology, spiritual counselling) and participating on different levels. Thereby, the research was highly practice-oriented and responded to needs and demands arising from the field. The swift response to the COVID-19 outbreak by means of performing a scoping review and providing practical recommendations, as shown in this dissertation, clearly demonstrates this practice-sensitivity. Moreover, the advisory board members helped to create visibility of the project and awareness of palliative dementia care among national professional organizations, such as V\&VN and Vilans. The advisory board also involved a representative of a Dutch health insurance company (CZ), which is an important stakeholder when aiming to improve care delivery.

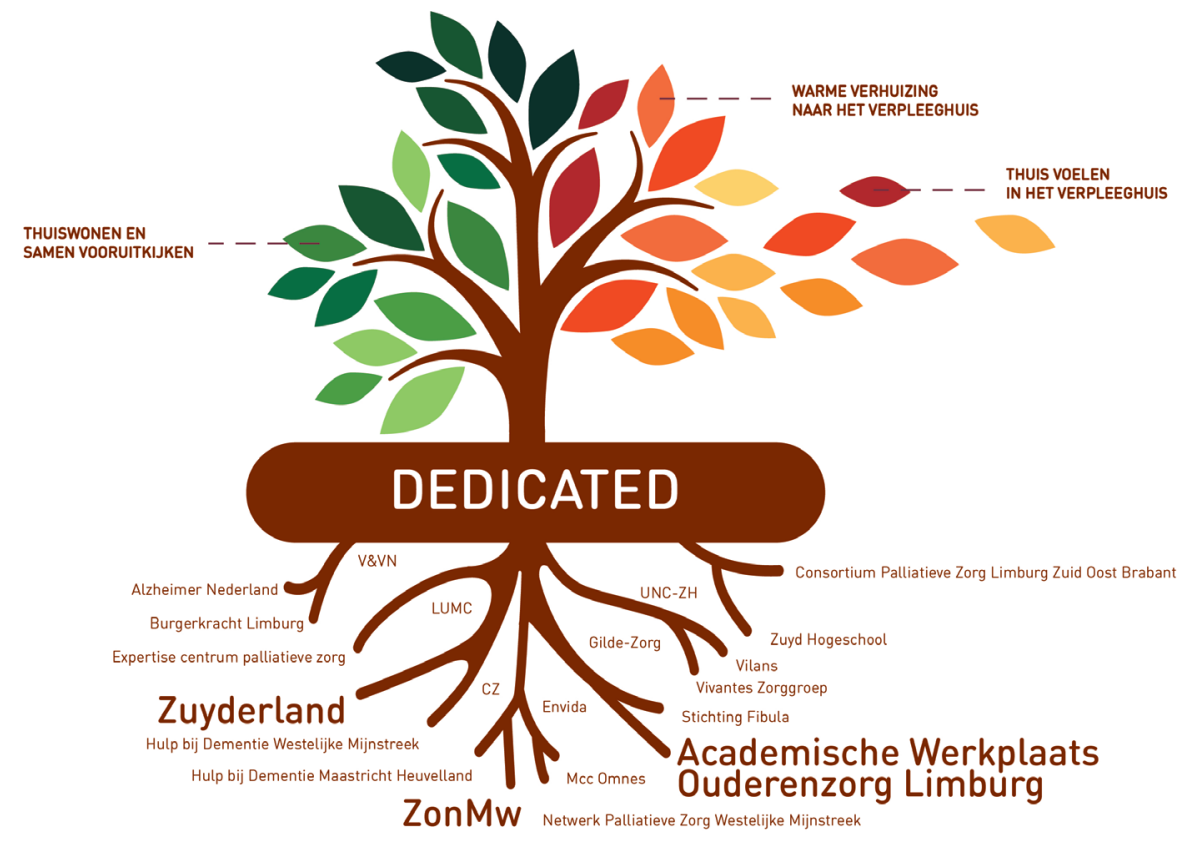

Figure 1. DEDICATED tree depicting project partners as its roots. The leaves say 'living at home and looking ahead together' 'warm transfer to the nursing home', and 'feeling at home in the nursing home'

\section{SCIENCE}

The studies in this dissertation contribute to a more profound scientific knowledge base on palliative care for people with dementia. Although the literature on dementia care and palliative care separately is plentiful, the combination of both requires attention. Over the past two decades, there have been growing efforts to study and to improve palliative care provision for people with dementia. However, the timing of palliative care in relation to dementia and its applicability to earlier stages remain questionable. Previous studies generally focused on palliative care at the end of life with dementia, or on palliative care for people with advanced dementia. This dissertation advocates for a clearer and more explicit integration of palliative care and dementia care, both in research and in practice.

The knowledge base on palliative dementia care in the community is particularly limited, even though the majority of people with dementia live at home. ${ }^{5}$ This dissertation targeted both the nursing home and community setting. Thereby, it delivers valuable knowledge for further advancement of palliative dementia care in both settings. In addition, the dissertation described comparisons between both settings. This novel insight into possible differences and similarities between the settings regarding the provision of palliative dementia care may inform future research, practice, and policy. Further, nursing staff from different levels represented the nursing perspective in 
the thesis. Thereby, the identified themes apply to a large, heterogeneous group of caregivers that are at the forefront of providing dementia care. Insight into this group's perspective and the finding that the variety of nursing staff have many mutual needs brings forth implications for further research and practice.

The studies in this dissertation reflect a thorough enquiry using a mix of research methods and including three important perspectives to inform palliative dementia care. The perspectives of family caregivers and nursing staff, as the primary care providers for people with dementia, are a valuable source of information. Nonetheless, the involvement of people with dementia themselves is indispensable when aiming to improve the care provided to them. The inclusion of people with dementia in this dissertation sets it apart from most other studies investigating perspectives on palliative dementia care. Moreover, it demonstrates that people with dementia are fit to participate in scientific research. In line with a societal shift towards dementiainclusivity, research should follow this movement and aim to involve people with dementia as potential study participants. In addition, future efforts should be made to involve people with dementia not only as participants, but also as partners in the research process. ${ }^{6}$

Data collected as a part of the DEDICATED project have been used or shared to use in other scientific studies. Sharing data and combining data from different studies is an important factor to create research impact. For instance, it may help to verify and strengthen findings, and it supports the building of meaningful collaborations with other researchers. ${ }^{7}$ First, our data were used in a national study looking at trends of families' assessments of quality of care and quality of dying. This particular study, which included 1189 family assessments, is also a chapter in this dissertation (chapter 7). Our data also informed other studies and articles that are not part of this dissertation, but that do contribute to the advancement of the palliative care knowledge in dementia. For instance, we participated in an international, meta-qualitative study to derive a crosscultural conceptualization of a 'good end of life' with dementia. Researchers from eight countries in Europe, the Americas, and Asia participated in this study using results from each of their original qualitative studies. Another study involved a combination and secondary analysis of data from our interviews and ethnographic fieldwork to explore how advance care planning for people with dementia is experienced and perceived in practice. Both manuscripts are under review. Lastly, during the project period, a travel grant was obtained to visit the TREC (Translating Research in Elder Care) research group at the University of Alberta in Edmonton, Canada. The visit strengthened our international collaboration and broadened our view in the DEDICATED project to consider aspects of nursing staff's work life (e.g., psychological empowerment, work engagement, job satisfaction) in relation to their care provision.

\section{DISSEMINATION OF FINDINGS}

The collaboration with national and regional partners contributed to the recognition and reputation of the DEDICATED project, which aided the dissemination of our research findings. For instance, it led to our involvement in the revision of the Dementia Care Standard and to the reach of our COVID-19 recommendations via professional networks. Moreover, we disseminated regular newsletters to our partners (e.g., work group participants and advisory board members who further distributed to their colleagues), and within the Living Lab in Ageing and Long-Term Care. The Living Lab, located in the southern part of the Netherlands, is a formal and structural collaborative between Maastricht University, nine long-term care organizations, and three higher and intermediate education institutes. The embedding of DEDICATED within the Living Lab, with its large reach and strong connections between education and practice, provides opportunities to disseminate the DEDICATED approach and to generate impact. We shared public summaries and occasional vlogs of our research findings with our associates after publication of scientific articles. In 2019, we organized a DEDICATED symposium to share our findings and progress with our project partners and others who were interested. The project also received attention in communications from other (partner) organizations. Among others, DEDICATED appeared in newsletters from the Netherlands Organization for Health Research and Development (ZonMw, the funder of the project), in an annual report of the Living Lab in Ageing and Long-Term Care and in an article in the M\&G (Society \& Health) magazine from the Dutch Nurses' Association $\mathrm{V} \& \mathrm{VN}$

Of the seven articles in this dissertation, six were published in peer-reviewed, international journals and the seventh has been accepted for publication. Two articles were published in special issues on dementia care and one article was designated by the journal as a 'continuing education article'. The general introduction of this dissertation was based on an accepted book chapter that will be published in 'The practical handbook of dementia'; an informative book for people with dementia, their family caregivers, and professional caregivers. Three of the articles were translated and published in Dutch practice journals. Apart from the studies included in this dissertation, we wrote a commentary about the nurses' role in advance care planning in the Dutch, practice-oriented 'Tijdschrift voor Gerontologie en Geriatrie' (i.e., journal of gerontology and geriatrics). ${ }^{8}$ We contributed to another book chapter about the conduct of scoping review in a Dutch educative book describing study designs for nurses and nurse students ('Onderzoek langs de meetlat').

We presented study findings at several national and international scientific conferences, such as at the congress of the European Association for Palliative Care (EAPC) and during the Dutch National Congress of Palliative Care. The DEDICATED project and its findings were also disseminated during a number of events for a variety of non-academic audiences. For instance, DEDICATED was presented as part of a guest 
lecture at a symposium organized by a catholic bond for older people, which hosted an audience of approximately 100 people with an average age of 80 years. Other events involved keynote lectures and workshops during seminars for care professionals and a presentation at a trade fair in healthcare. On World Alzheimer's Day 2020, we launched a short movie to stimulate awareness about palliative care for people with 可 dementia (see https://youtu.be/qWz8VBNCa0Y or scan QR code)

\section{TO CONCLUDE: Desired Dementia Care Towards End of Life}

This dissertation forms an important basis for the advancement of palliative dementia care and for the development of a DEDICATED approach. This 'work in progress' involves iterative co-creation with dementia care professionals and nurse educators. After the pilot phase, new DEDICATED ambassadors will be selected from test teams at the participating organizations and they will be trained to implement the finalized approach within their teams. New ambassadors will be linked to former ambassadors and together, they will create a network to support, inform, and motivate each other in their ambassador's role. Originally, the DEDICATED project ran from September 2017 to September 2021. The Netherlands Organization for Health Research and Development (ZonMw) approved extension of the project by one year and we obtained additional funding to carry forward the implementation and further dissemination of the project's deliverables. The test phase will start from September 2021 and involve an effect and process evaluation of the implemented DEDICATED approach. Moreover, together with the educators from higher vocational nursing education (Zuyd, University of Applied Sciences), we will develop a train-the-trainer program. Through this program, we will prepare ambitious care professionals to become DEDICATED trainers, who are responsible for training new DEDICATED ambassadors after the end of the project's term. The goal is to disseminate the DEDICATED approach within the Living Lab in Ageing and Long-Term Care first. Eventually, a rich pool and strong network of DEDICATED trainers and ambassadors facilitates dissemination to other organizations and regions.

\section{REFERENCES}

1. Bosman A, Kooijman H. 'Maak palliatieve fase bij dementie eerder bespreekbaar'. V\&VN Maatschappij \& Gezondheid. 2020;20(1):18-20.

2. Dementiezorg voor Elkaar. Zorgstandaard Dementie: Samenwerken op maat voor personen met dementie en mantelzorgers. 2020.

3. IKNL/Palliactief. Netherlands Quality Framework for Palliative Care. 2017.

4. van Dijk-de Vries A, Stevens A, van der Weijden T, Beurskens AJHM. How to support a co-creative research approach in order to foster impact. The development of a Co-creation Impact Compass for healthcare researchers. PLOS ONE. 2020;15(10):e0240543.

5. Nederland A. Factsheet cijfers en feiten over dementie 2021 [cited 202124 March]. Available from: https://www.alzheimer-nederland.nl/factsheet-cijfers-en-feiten-over-dementie.

6. Gove D, Diaz-Ponce A, Georges J, Moniz-Cook E, Mountain G, Chattat R, et al. Alzheimer Europe's position on involving people with dementia in research through PPI (patient and public involvement). Aging Ment Health. 2018;22(6):723-9.

7. Vicente-Saez R, Martinez-Fuentes C. Open Science now: A systematic literature review for an integrated definition. Journal of Business Research. 2018;88:428-36.

8. Bolt SR, van der Steen JT, Schols JMGA, Zwakhalen SMG, Janssen DJA, Meijers JMM. De rol van de verzorgende en verpleegkundige in het advance care planning proces. Tijdschrift voor Gerontologie en Geriatrie. 2021;52(1). 


\section{DANKWOORD}

Vier jaar geleden, juni 2017, was ik druk met het afronden van een leerzame wetenschapsstage bij de Militaire GGZ. Ik wist toen inmiddels al dat ik na de zomer zou starten als promovendus in Maastricht. Een spannende nieuwe stap na mijn studiejaren in Utrecht. Het onderwerp van mijn promotieonderzoek ligt mij nauw aan het hart. De vier jaren zijn voorbijgevlogen en ik ben (gelukkig) nooit het gevreesde diepe dal tegengekomen waar in de 'PhD wereld' regelmatig over wordt gerept. Er zijn een aantal mensen die ik in het speciaal wil bedanken voor de ondersteuning, fijne gesprekken, afleiding, of gewoon het 'er zijn' gedurende mijn $\mathrm{PhD}$ avontuur.

Mijn promotieteam, Judith, Jenny, Jos en Sandra, ik wil jullie bedanken voor de prettige samenwerking in de afgelopen jaren. Vanaf de start heb ik me door jullie gesteund gevoeld. Ik kon met mijn vragen en ideeën altijd terecht. Tijdens de promotieoverleggen hebben we veel interessante en leuke discussies gevoerd. Jullie vullen elkaar als begeleiders enorm goed aan, allemaal met jullie eigen blik en kwaliteiten.

Judith, van jou als dagelijks begeleider heb ik enorm veel geleerd, op professioneel en persoonlijk vlak. Je hebt altijd vertrouwen getoond in mij en mijn werk, wat me heeft geholpen om ook zelf op mijn 'eigen kunnen' te vertrouwen. Je hebt vanaf het begin geleid, maar ook gefaciliteerd, zodat ik mezelf kon ontwikkelen en mijn eigen koers kon varen. Je leerde me dat niks vast staat en dat controle - grotendeels - een illusie is, zeker in praktijkgericht onderzoek. Dankzij jou heb ik in 2019 een prachtige (werk) reis naar Canada gemaakt. Samen hadden we in Kananaskis een inspirerend 'werk'weekend, inclusief paardrijden door de Rockies. We zijn een goed team en ik werk met veel plezier met je samen.

Jenny, als externe copromotor was jij enorm toegewijd en betrokken. Jouw waardevolle input heeft ons werk naar een hoger niveau getild. Vaak weet jij de zaken nét wat mooier te formuleren. Ook heb je enorm veel kennis, waar ik vaak uit kon putten. Regelmatig hebben wij samen interessante gesprekken gevoerd over onze bevindingen, waarbij we een laagje verder de diepte in konden gaan. Ik heb veel bewondering voor jou als wetenschapper en ik hoop dat we elkaar in de toekomst nog vaak tegenkomen.

Jos, jouw enthousiasme en energie werken aanstekelijk. Op Dub30 kon je flink door de gang racen, en diezelfde snelheid nam je mee in de promotie-overleggen. Ook heb ik nooit lang hoeven wachten op reactie via de mail. Soms kwam de reactie binnen enkele minuten, niet zelden uitgedrukt in enkel hoofdletters ('TOP!!!'). Toch deed je snelheid niet af aan je oplettendheid en betrokkenheid. Hoewel de onderzoekswereld je zeker gaat missen, hoop ik dat je binnen afzienbare tijd kunt gaan genieten van een welverdiend pensioen. 
Sandra, je keek vaak van een afstandje mee en hielp me regelmatig door als 'onafhankelijk expert' kritische vragen te stellen. Ik ben blij dat ik getuige mocht zijn van een nieuwe stap in jouw loopbaan, toen je benoemd werd als hoogleraar. Je bent een toegewijd onderzoeker en daarnaast een fijne begeleider met (volgens mij) een flink portie droge humor en relativeringsvermogen.

Professor Verhey, professor van den Beuken-van Everdingen, professor Teunissen, en professor Verbeek, leden van de beoordelingscommissie, hartelijk dank voor het lezen en beoordelen van mijn proefschrift. Professor Cummings, a special thank you for joining the assessment committee from wonderful Edmonton. Moreover, thank you for having me as a trainee within your faculty at the University of Alberta. Professor Verbeek, Hilde, bedankt voor al je tips en adviezen over het 'werken in de academie', je voorbeeld, inspiratie en ideeën.

Het DEDICATED-team, ook wel bekend als 'DB' of'DEDICATED-dames': Lara, Els, Saskia en Chaan (en Judith, natuurlijk), ik wil jullie bedanken voor de fijne samenwerking, de humor, de leuke momenten, de minder leuke momenten die we samen doorkwamen, en meer! Hoewel de gespreksstof mij soms wat zweverig werd, ben ik over de jaren heen wat milder en (ietsje) minder sceptisch geworden.

Lara, als projectmanager was jij vanaf het begin af aan al mijn 'go-to' voor praktische zaken, vragen en regeldingen. Vaak liep onze samenwerking als een geoliede machine. Hoewel we best wel op elkaar lijken in veel opzichten, vullen we elkaar ook mooi aan. In de afgelopen jaren hebben we een goede band opgebouwd en ik ben superblij dat je mij tijdens de verdediging van m'n proefschrift bijstaat als paranimf :-

Els, 'de moeder van de club', heel erg bedankt voor jouw warme betrokkenheid. Als adviseur van het project keek je mee vanuit het kraaiennest en hield je het overzicht. Je was niet alleen adviseur, maar vaak ook raadgever en vertrouwenspersoon.

Saskia, als trouwe en harde werker was jij een super onderzoeksassistent. Door jouw werk 'achter de schermen' konden Chaan en ik ons focussen op het onderzoek. Samen met Lara heb je ons veel werk uit handen genomen en je was altijd bereid in te springen waar nodig. Je bent (stiekem) ook nog eens heel creatief!

Chaan, je bent er ruim een jaar na de start van DEDICATED bijgekomen en hebt 'de achterstand' in sneltreinvaart ingehaald. Je kwam met nieuwe ideeën, een frisse blik en vooral een hele hoop energie. Je was de afgelopen jaren een fijne 'roomie' (voor Corona dan) en we zijn steeds nauwer gaan samenwerken aan ons project. Heel veel succes met het afronden van jouw proefschrift het komende jaar, you can do it!
Sabine, het eerste jaar van DEDICATED mocht ik samen met jou meemaken, als mede-PhD. Het was fijn om met iemand in hetzelfde schuitje te zitten en om samen voorzichtig de onderzoekswereld te verkennen. Ik zal ook niet snel ons tripje naar ons eerste congres, in Bern, vergeten. Blinde paniek toen we in de verkeerde trein bleken te zitten... Ik ben blij dat je vanuit jouw rol als docent bij Zuyd hogeschool nauw bij ons en bij DEDICATED betrokken bleef!

Alle deelnemers, partners en andere betrokkenen bij het project: zonder jullie inzet was er geen DEDICATED. Vanaf het begin hebben de leden van de werkgroepen en de adviesraad hun waardevolle input gegeven. Jullie waren zelfs betrokken bij het bedenken van de naam van het project, tijdens de allereerste bijeenkomst. Jullie hebben altijd kritisch meegekeken, advies gegeven, landelijke en lokale ontwikkelingen aan ons teruggekoppeld, behoeften uit de praktijk meegenomen, en nog veel meer. Het ontwikkelteam, ik wil jullie enorm bedanken, Renate, Hannie, Thea, Patricia, Björn, Wendy, Inge en Elke, voor jullie enthousiasme als DEDICATED-ambassadeurs en alle hulp bij de vertaling van onderzoek naar de praktijk. Ook Peter, Ingrid, Laura en Kitty, dank voor jullie vertegenwoordiging vanuit de casemanagers! Daarnaast, veel dank aan alle andere betrokkenen vanuit de zorgorganisaties Zuyderland, Vivantes en Envida, dat jullie dit project mogelijk hebben gemaakt. Henk, Jeanny en Sabine, vanuit Zuyd hogeschool hebben jullie een waardevolle bijdrage geleverd aan het ontwikkelen van de training voor onze ambassadeurs. Veel dank voor de fijne samenwerking. Nicole, heel veel dank voor jouw enthousiasme, vertegenwoordiging voor Gilde Opleidingen, en voor het meenemen van de DEDICATED-materialen in jouw onderwijsactiviteiten. Ook wil ik alle deelnemers aan ons onderzoek bedanken. Uw deelname maakt het mogelijk om onderzoek te doen en onze kennis te vergroten. Ik heb hier niet alle namen genoemd, want er hebben veel mensen een mooie bijdrage geleverd. Ook voor alle andere betrokkenen: veel dank!

Collega's van HSR, veel dank voor de gezellige momenten tijdens de (digitale) lunch, inspirerende (Zoom)gesprekken, leuke uitjes en meer. Leden van de 'Thuiswerk vrijmibo', Svenja, Anne, Ines, Lise, Robin, Katya en Rose, dankzij jullie werd het gemis van collega's door het thuiswerken wat verzacht, zeker in het begin van de crisis.

Teuni, wij begonnen tegelijk aan ons PhD-avontuur en konden elkaar op verschillende momenten mooi een beetje op weg helpen. Beide woonachtig in Brabant, wat niet altijd ideaal is voor het werken in Maastricht. Een werkplek dichter bij huis leek ons allebei soms toch ook wel wat! Dankjewel voor het sparren, tips en adviezen en (in het laatste COVID jaar) sporadische telefoongesprekjes. Ik wens jou veel succes met de laatste loodjes, en hoop dat je proefschrift ook af is tegen de tijd dat je dit leest $\odot$ 
Anne, ook jij hoorde bij de 'lichting van september 2017' en we hebben de ups en downs in ieders traject doorstaan. Het einde is nu in zicht en we kunnen straks genieten van onze welverdiende doctorstitels. In of na deze zomer zullen we elkaar hopelijk weer eens zien, al is het heen-en-weer sturen van kudo's op Strava ook gezellig.

Katya, de afgelopen jaren heb ik veel van je geleerd en stiekem een beetje afgekeken hoe jij 'de dingen' deed. Ik kon altijd met vragen bij je terecht. Ook in de trein tussen Maastricht en Eindhoven was je regelmatig een fijn gezelschap (als er niet meer gewerkt moest worden, tenminste). Ik wens jou en Simon heel veel geluk met jullie mooie dochtertje Hannah en we zullen elkaar binnenkort vast weer zien.

Svenja, dank voor de leuke en interessante gesprekjes en ook bedankt voor je vele vermakelijke 'Insta stories' met katten in de hoofdrol. We hebben elkaar een beetje gevonden in een gedeelde interesse voor onderzoek naar dieren in de zorg voor mensen met dementie. Ik hoop dat we hier in de toekomst vervolg aan kunnen geven en dit samen op de kaart kunnen gaan zetten.

Annick, inmiddels al even geen collega meer, maar wel een fijne vriendin. Als psycholoog in het verpleeghuis zit je goed op je plek, en wie weet worden we ooit opnieuw collega's. Of gaan we toch samen een zorgboerderij opzetten? Ik kom graag een keertje loeren in Best of zwemmen in de Haagse Beemden.

Graag bedank ik de ondersteunende collega's van HSR, Joanna, Brigitte, Bernike, Judith Urlings. Jullie zijn de duizendpoten van de afdeling en ik bewonder jullie betrokkenheid en organisatievermogen. Suzanne, veel dank voor de spellingscheck van mijn proefschrift. Ook wil ik Arnold bedanken voor zijn ondersteuning bij ICTzaken, waar ik hem regelmatig voor nodig had. Bijvoorbeeld toen in Canada de bliksem insloeg en mijn laptop overleed, in mijn eerste week daar. Er zijn nog veel meer collega's (Bram, Angela, Stephanie, Cindy, Vivienne, ...) met wie ik fijn heb samengewerkt, die me waardevolle tips hebben gegeven en met wie ik leuke momenten heb beleefd. Ook als je naam hier niet bij staat, super bedankt!

Colleagues from the University of Alberta; Yuting, Trina, Kyle, Adam, Leo, Judith, Alvina and others, thank you for the wonderful time in Edmonton. You all made me feel very welcome and I had lots of fun working with you, going to the (huge) shopping mall, going out for diner and going to typically Canadian festivals. Yuting, thank you for supervising my work (still) and for the collaboration on TREC projects. I hope we can continue to work together in the future! Carole and Greta, thank you for having me as a TREC trainee and for the opportunity to visit your university and faculty. David, thank you for sharing your house with me from June to August 2019. You were truly a great 'landlord', and you instantly made me feel at home. I appreciated your warm welcome, also for my parents and Niels when they visited. Having such a nice home (full of cats!!!) in Edmonton further elevated the total 'abroad experience'. If I ever return to Edmonton, I hope I can stay at your place again

Ook wil ik alle studenten die hebben geholpen met de data verzameling/data-analyse bedanken. Laura, het was fijn om met je te werken en je hebt enorm geholpen bij de interviews. Mede dankzij jou is het artikel over de secundaire analyse tot stand gekomen (hoofdstuk 5). Irma, heel erg bedankt voor je hulp bij de scoping review over COVID-19 (hoofdstuk 4). Kirsten en Daan, fijn dat ik jullie in het laatste jaar nog heb kunnen begeleiden bij de scriptie. Twee interessante stukken, die we hopelijk ook binnenkort kunnen publiceren!

Maartje, dankjewel voor de fijne samenwerking in het schrijven van ons 'trend artikel' (hoofdstuk 7) en voor de vele gezellige Zoom overleggen. Ik ben ook erg dankbaar voor je doorzettingsvermogen (en vooral de analyse en alles wat daaraan voorafging met al die verschillende datasets). Heel veel succes met de laatste loodjes van jouw promotie en ik ben er zeker bij als je gaat verdedigen! Natashe, al vanaf het begin van mijn PhD traject heb jij input gegeven en je kennis gedeeld, en het laatste jaar zijn we ook samen een 'projectje' begonnen. Superleuk om met jou te schrijven en regelmatig inspirerende Zoom-brainstormsessies te hebben. Alieke, ook jij mag in mijn dankwoord niet ontbreken. Als stagebegeleider bij de MGGZ heb je me enorm geholpen en klaargestoomd om als $\mathrm{PhD}$ te beginnen.

Tot slot wil ik mijn lieve vrienden en familie bedanken. Hoewel fijne collega's belangrijk zijn; zonder mijn 'naasten' was het leven toch maar saai geweest.

Ginny, mijn lieve vriendinnetje die ik al bijna 20 jaar ken. In groep 4 kwamen we bij elkaar in de klas, werden beste maatjes, en 'the rest is history'. Wat hebben wij in ons leven een hoop lol gehad, en lief en leed gedeeld. Eindeloze logeerpartijen, kattenkwaad waar ik me vandaag de dag nog voor schaam, fantasieverhalen die alleen wij begrepen, liefdesverdriet en andere drama's. Hoewel onze levenspaden nogal verschillend zijn, vinden we elkaar altijd terug. We hebben zo veel mooie, hilarische, spannende, gestoorde en leuke herinneringen; daar zou ik een boek minstens zo lang als dit proefschrift over kunnen volschrijven.

Tessa, ook wij gaan al even mee en ik denk nog vaak terug aan onze mooie tijd op het St. Antoniuscollege. Samen het VWO met succes afgemaakt, beide een natuurprofiel en een gruwelijke hekel aan scheikunde, natuurkunde en biologie, haha. Maar we hebben elkaar er doorheen gesleept! Examentraining was een uitkomst, in combinatie met 
een luxe hotelverblijf in Noordwijk. Na het VWO beide gaan studeren in Utrecht, en inmiddels beide bijna doctor. Hoewel ons contact de afgelopen jaren minder intensief was dan ervoor (kan ook moeilijk anders), is het heel fijn om ook deze fase van ons leven te delen. Heel veel succes met het afronden van jouw proefschrift Tes!

Regina, vanaf de brugklas hebben we een hechte vriendschap opgebouwd, die door weer en wind standhoudt. We zien elkaar niet vaak, maar als we elkaar zien, is het meteen weer als vanouds. Ik kan nog steeds genieten van onze droge humor samen, die in de brugklas al een goede match bleek te zijn. Ik ben trots op jou en hoop dat we nog vaak samen bloemkool met spinazie-kaas schnitzel zullen eten en pouring paintings zullen maken. :)

Amber, wij leerden elkaar kennen tijdens onze studie psychologie in Utrecht. Eigenlijk pas in het laatste jaar van de bachelor, met het schrijven van de scriptie. Inmiddels ben je een goede vriendin geworden. Ik waardeer de filosofische gesprekken, jouw goede raad, en onze sporadische kook- of borrelsessies. Snel weer eens doen?

Lieve Sandra en Maurice, over de jaren hebben we samen pieken en dalen meegemaakt, en elkaar door en door leren kennen. Dat moet ook wel, met al onze toffe en soms bizarre reizen en avonturen samen. Met als ultieme top de Uhuru peak van de Kilimanjaro. Een reis om nooit te vergeten, net als al onze wintersportavonturen, vakanties en ontelbare uitjes. Wat begon toen Niels, Sandra en ik nog samen op het Salamancapad in Utrecht woonden, is uitgegroeid tot een hechte, waardevolle vriendschap met jullie. We zijn vereerd om volgende zomer getuige te mogen zijn bij jullie bruiloft. En Sandra, ik ben super blij dat je mij ook bijstaat als paranimf straks (in elvenkostuum toch?)

Lieke, Lucas, Mark, Hannah, Tom, Jasmijn, dank jullie wel voor de gezellige spelletjesavonden, vriendenweekenden en wintersportvakanties de afgelopen jaren!

Lieve schoonpa en schoonma, Coert en Nelleke, jullie voelen inmiddels als een 'tweede setje ouders' en jullie staan altijd voor ons klaar. Wel zo makkelijk dat we tegenwoordig op een kleine 3 kilometer door het bos van elkaar wonen. We zijn regelmatig bij elkaar over de vloer en jullie hebben daarom de afgelopen jaren ook het nodige meegekregen van mijn promotie. Aangezien jullie beide professionals in de ouderenzorg zijn, werden de thema's in dit proefschrift regelmatig aan de eettafel besproken. Dank voor jullie support en voor alle gezellige en fijne momenten samen!

Lieve Carolien, als mijn schoonzusje ken ik je al een heel tijdje! Wat een transformatie naar 'volwassenheid' hebben we beide doorgemaakt in die tijd. Mooi om te zien hoe jij je pad uitstippelt; super trots op jou als jongste psycholoog i.o. tot gz-psycholoog die ik ken $\odot$ Ik wens je samen met Philippe heel veel plezier in jullie eerste 'echte' huis!
Lieve Luus, mijn grote zus. Jij bent er al heel mijn leven en ik kan me geen betere zus indenken. Met uitzondering van enkele puberale periodes zijn we altijd ook hartsvriendinnen geweest. Je hebt me vroeger beschermd tegen gemene kinderen, stomme ex-vriendjes en ander gespuis. Wat voelde het veilig om bij jou op dezelfde middelbare school te komen! En ook een beetje stoer, zo'n grote zus. Je was en bent nog steeds mijn grote voorbeeld en ik ben bewonder allerlei eigenschappen in jou die ik zelf wat minder bezit. Ik hoop dat we samen, en natuurlijk met de schone broeders Niels en Diederik, veel gezellige dingen blijven ondernemen. En dat we nog vaak in flitsende WOOBI-pakjes zullen fietsen!

Lieve pap en mam, ik kan jullie niet genoeg bedanken voor alles dat jullie me hebben (mee)gegeven in mijn leven. Onvoorwaardelijke liefde, ondersteuning, vertrouwen, wijze raad (en tegenwoordig is dat soms ook andersom), een warm thuis, hulp met klussen, en nog ontelbaar veel meer. Ik kan altijd bij jullie terecht met vragen, over kopzorgen, voor een gezellig spelletje, een lange wandeling of gewoon voor een knuffel (laatste jaar wat minder helaas). In mijzelf herken ik steeds meer van jullie beide, wat ik een leuke en interessante gewaarwording vind (al blijven die slechte ogen toch lastig hoor... :). Ik ben super dankbaar en trots dat ik jullie dochter mag zijn!

Lieve Niels, mijn lief, tot slot wil ik jou bedanken. Want zoals ik je vertelde, is het vrij gebruikelijk om je partner een prominente plek te geven in het dankwoord. Daar moest je een beetje om grinniken. Maar hee, logisch toch?? Al zo'n 9 jaar lang zijn wij samen, in de volste zin van het woord. We hebben elkaar ontmoet in ons studentenhuis in Utrecht en woonden direct samen. Niet zo gek dus, dat we elkaar door en door kennen. We houden elkaar dan ook regelmatig een spiegel voor, waar ik persoonlijk steeds weer van leer (en waar we soms ook erg om kunnen lachen). Fijn dat ik samen met jou dit 'pad naar volwassenheid' mocht en nog steeds mag doorlopen. Je bent mijn lief, mijn soulmate, mijn beste vriend. We delen onze liefde voor wielrennen, voor zelfgebakken pizza, voor de katjes Guinness en Lizzy, voor films, voor onze families. Dankjewel dat je er altijd voor me bent en weet dat ik er altijd voor jou zal zijn. Dat we nog een geweldig leven lang samen mogen delen, mijn lief! $<3$ 


\section{ABOUT THE AUTHOR}

Sascha Rianne Bolt was born on October 26, 1993 in Zwolle, the Netherlands. She completed secondary education in 2012 at the St. Antoniuscollege in Gouda. In 2015, she obtained a Bachelor's degree in Clinical and Health psychology, at Utrecht University. Sascha obtained Master's degrees in Neuropsychology (2016) and in Clinical psychology (2017, Cum Laude), at Utrecht University. In 2016, she was an intern at the memory clinic of the Radboudumc in Nijmegen, where she obtained the Psychodiagnostics Basic Registration certificate (BAPD). She conducted her thesis research at the Donders Institute for Brain, Cognition and Behavior. During her second Master, Sascha was a research intern at the research department of Military Mental Health (MGGZ). Alongside her studies, she worked as a domestic help for older people.

In September 2017, Sascha started her PhD research at the department of Health Services Research at Maastricht University. As a PhD, she has been working on the DEDICATED (Desired Dementia Care Towards End of Life) project within the Living Lab of Ageing and Long-Term Care. The goal of DEDICATED is to improve the quality of palliative care for people with dementia and their families. To that end, Sascha developed a 'DEDICATED approach' in close collaboration with healthcare professionals and education experts. In the summer of 2019, Sascha traveled to Edmonton, Canada, to work as a trainee at the University of Alberta within the TREC (Translating Research in Elder Care) program. She obtained a travel grant from Alzheimer Nederland to support her work trip to Canada. Today, she still works on several projects with Canadian colleagues. Alongside her work as a $\mathrm{PhD}$ candidate, Sascha participated in various extracurricular activities. She was a PhD representative for the Care and Public Health Research Institute (CAPHRI) within the Netherlands School of Public Health and Care Research (CaRe) and a member of the CAPRHI PhD panel from 2018-2021. She currently chairs a newly developed, international network for early-career researchers within the International Psychogeriatrics Association (IPA) and she is part of the organization committee of the 2021 IPA congress. Sascha was elected for the CAPHRI 'Research Talent Program' of 2021: a program for early-career researchers with high potential. From August 2021, Sascha will be working as a senior researcher and research broker at Tranzo Scientific Center for Care and Wellbeing, Tilburg University. She will also continue to work on the DEDICATED project. Over the next coming years, Sascha aspires to further develop as a practice-oriented researcher and to contribute to person-centered care for older people. 


\section{PUBLICATIONS}

\section{INTERNATIONAL PUBLICATIONS}

Bolt, SR, van der Steen, JT, Schols, JMGA, Zwakhalen, SMG, Pieters, S, Meijers, JMM. Nursing staff needs in providing palliative care for people with dementia at home or in long-term care facilities: a scoping review. International Journal of Nursing Studies, 2019; 96: 143-152

Bolt, SR, Verbeek, L, Meijers, JMM, van der Steen, JT. Families' experiences with endof-life care in nursing homes and associations with dying peacefully with dementia. Journal of the American Medical Directors Association, 2019; 20(3): 268-272

Bolt, SR, van der Steen, JT, Schols, JMGA, Zwakhalen, SMG, Meijers, JMM. What do relatives value most in end-of-life care for people with dementia? International Journal of Palliative Nursing, 2019; 25(9): 432-442

Bolt, SR, Meijers, JMM, van der Steen, JT, Schols, JMGA, Zwakhalen, SMG. Nursing Staff Needs in Providing Palliative Care for Persons With Dementia at Home or in Nursing Homes: A Survey. Journal of Nursing Scholarship, 2020; 52(2): 164-173

Khemai, C, Janssen, DJA, Schols, JMGA, Naus, L, Kemper, S., Jole, I, Bolt, SR, Meijers, JMM. Nurses' needs when collaborating with other healthcare professionals in palliative dementia care. Nurse Education in Practice, 2020; 48: 102866

Bolt, SR, van der Steen, JT, Mujezinović, I, Janssen, DJA, Schols, JMGA, Zwakhalen, SMG, Khemai, C, Knapen, EPAGM, Dijkstra, L, Meijers, JMM. Practical nursing recommendations for palliative care for people with dementia living in long-term care facilities during the COVID-19 pandemic: A rapid scoping review. International Journal of Nursing Studies, 2020; 113: 103781

Bolt, SR, van der Steen, JT, Khemai, C, Schols, JMGA, Zwakhalen, SMG, Meijers, JMM. The perspectives of people with dementia on their future, end of life and on being cared for by others: A qualitative study. Journal of Clinical Nursing, 2021: Epub ahead of print

Klapwijk, MS, Bolt, SR, Boogaard, JA, ten Koppel, M, Gijsberts, MHE, van Leussen, C, The, AM, Meijers, JMM, Schols, JMGA, Pasman, RW, Onwuteaka-Philipsen, BD, Deliens, L, Van den Block, L, Mertens, B, de Vet, HCW, Caljouw, MAA, Achterberg, WP, van der Steen, JT. Trends in quality of care and dying perceived by family caregivers of nursing home residents with dementia between 2005-2019. Palliative Medicine. Accepted

\section{NATIONAL PUBLICATIONS}

Willems, A, Pieters, S, Bolt, SR, Knapen, E, Dijkstra, L, Meijers, JMM. Palliatieve zorg 
bij mensen met dementie in Nederland. Nederlands-Vlaams Tijdschrift voor Palliatieve Zorg, 2019; 16(2): 54-59

Bolt, SR, Meijers, JMM, van der Steen, JT, Schols, JMGA, \& Zwakhalen, SMG. Behoeften in het verlenen van palliatieve zorg aan mensen met dementie, thuis of in het verpleeghuis. Verpleegkunde. 2020; 3: 13-21

Bolt, SR, van der Steen, JT, Mujezinovíc, I, Janssen, DJA, Schols, JMGA, Zwakhalen, SMG, Khemai, C, Knapen, E, Dijkstra, L, Jochem, I, Timmermans, J, \& Meijers, JMM. Palliatieve dementiezorg verlenen tijdens COVID-19. TVZ. 2020; 4: 44-47

Bolt, SR, van der Steen, JT, Schols, JMGA, Zwakhalen, Janssen, DJA, \& Meijers, JMM. De rol van de verzorgende en verpleegkundige in het advance care planning proces. Tijdschrift voor Gerontologie en Geriatrie. 2021; 52(1)

Bolt, SR, van der Steen, JT, Khemai, C, Schols, JMGA, Zwakhalen, SMG, Meijers, JMM. Hoe mensen met dementie aankijken tegen hun toekomst, het levenseinde en de zorg die zij ontvangen van anderen. GERON. Accepted

\section{IN SUBMISSION}

Nishimura M, Dening, KH, Sampson, EL, Vidal, EIO, Abreu, WC, Kaasalainen, S, Eisenmann, Y, Dempsey, L, Moore, KJ, Davies, N, Bolt, SR, Meijers JMM, Lemos Dekker, N, Miyashita, M, Nakanishi, M, Nakayama, T, \& van der Steen, JT. Cross-cultural conceptualisation of a good end of life with dementia: A meta-qualitative study. Submitted

Lemos Dekker, N., Bolt, SR. Relating to the future through advance care planning: expectations and experiences of people with dementia and their family caregivers. Submitted

\section{BOOK CHAPTERS}

Meijers, JMM, Bolt, SR. De waarde van scoping reviews. In: Eskes, AM \& van Oostveen, CJ, eds. Onderzoek langs de meetlat: Onderzoekdesigns voor verpleegkundigen. 2021. Bohn Stafleu van Loghum

Bolt, SR, Meijers, JMM, van der Steen, JT. Palliative care options in dementia. In: Austin, R \& Hopfenbeck, MS, eds. The practical handbook of dementia. Monmouth: PCCS Books. Submitted to publisher

\section{CONFERENCE CONTRIBUTIONS AND PUBLISHED ABSTRACTS}

Meijers, JMM, Bolt, SR, Pieters, S, Van der Steen, JT, Janssen, D, Zwakhalen, SMG, Hamers,
J, Schols, J. Desired End of Life Care for People with Dementia and their Loved Ones. 10th World Research Congress of the European Association for Palliative Care (EAPC), Bern, Switzerland. Palliative Medicine, 2018; 32: 1 (suppl. 1): 3-330. [Abstract only]

Bolt, SR, van der Steen, JT, Schols, JMGA, Zwakhalen, S, Pieters, S, Meijers, JMM. What nursing staff needs in providing palliative care for people with dementia: a scoping review. 17th European Doctoral Conference in Nursing Science (EDCNS), Maastricht, the Netherlands. Verpleegkunde. 2018; 33: 3: 31-35 [Oral presentation]

Meijers, JMM, Bolt, SR. Let's talk about death. 5th Nursing Home Research International Working Group, 2018, Rome, Italy. [Oral presentation]

Bolt, SR, Verbeek, LMH, Meijers, JMM, van der Steen, JT. De ervaringen van naasten met zorg aan het levenseinde van verpleeghuisbewoners met dementie en de samenhang met vredig sterven. Nationaal Congres Palliatieve Zorg, 2018, Lunteren, the Netherlands. [Oral presentation]

Bolt, SR, Verbeek, LMH, Meijers, JMM, van der Steen, JT. Families' experiences with endof-life care in nursing homes and associations with dying peacefully with dementia. 4th Sigma postgraduate virtual conference, Tau Omega Chapter, 2018, Gothenburg, Sweden. [Oral presentation]

Bolt, SR, Meijers, JMM. 'Palliatieve zorg voor mensen met dementie en hun naasten' Themed meeting palliative care network, Sittard, the Netherlands, 2018. [Invited lecture]

Bolt, SR. 'Palliatieve zorg voor mensen met dementie'. Dementiezorg congres, Veenendaal, the Netherlands, 2019. [Key note presentation]

Bolt, SR, Dijkstra, L. 'Palliatieve zorg voor mensen met dementie'. Dementiezorg congres, Veenendaal, the Netherlands, 2019. [Workshop]

Bolt, SR. 'Palliatieve zorg voor mensen met dementie'. Zorgtotaal Event, Jaarbeurs, Utrecht, the Netherlands, 2019. [Oral presentation]

Bolt, SR, van der Steen, JT, Schols, JMGA, Zwakhalen, S, Meijers, JMM. What Is Valued Most in End-of-Life Care for People with Dementia? A Qualitative Exploration of their Loved Ones' Experiences. Abstracts of the 16th World Congress of the European Association for Palliative Care (EAPC), Berlin, Germany. Palliative Medicine. 2019; 33: 1: 118-589. [Oral presentation] 
Bolt, SR, Verbeek, LMH, Meijers, JMM, van der Steen, JT. Families' Experiences with Endof-Life Care in Nursing Homes and Associations with Dying Peacefully with Dementia. Abstracts of the 16th World Congress of the European Association for Palliative Care (EAPC), Berlin, Germany. Palliative Medicine. 2019; 33: 1:118-589. [Poster presentation]

Bolt, SR, Khemai, C. 'Gewenste zorg in de laatste levensfase van ouderen'. Symposium Werken met thuiswonende kwetsbare ouderen, Ede, the Netherlands, 2019. [Workshop]

Bolt, SR. 'Leven toevoegen aan de jaren: een positieve benadering van palliatieve zorg'. KBO (catholic bond for older people) Symposium Zo gezond mogelijk oud worden op je eigen wijze, Oirsbeek, the Netherlands, 2019. [Key note presentation]

Bolt, SR, van der Steen, JT, Schols, JMGA, Zwakhalen, S, Meijers, JMM. Palliatieve zorg voor mensen met dementie thuis en in het verpleeghuis: wat hebben verzorgenden en verpleegkundigen nodig? Nederlands Vlaamse Wetenschapsdagen Palliatieve Zorg, 2019, Antwerpen, Belgium. [Oral presentation]

Bolt, SR, van der Steen, JT, Schols, JMGA, Zwakhalen, S, Meijers, JMM. Hoe waarderen naasten van mensen met dementie de zorg aan het levenseinde? Nederlands Vlaamse Wetenschapsdagen Palliatieve Zorg, 2019, Antwerpen, Belgium. [Poster presentation, nominated as one of the best three posters]

Bolt, SR. 'Kwaliteitsverbetering van palliatieve zorg'. Studiedag Wat kun je doen aan dementie? Utrecht, 2020. [Key note presentation]

Bolt, SR, van der Steen, JT, Schols, JMGA, Zwakhalen, S, Meijers, JMM. Palliative care for people with dementia at home or in the nursing home: what do nursing staff need? 11th World Research Congress of the European Association for Palliative Care (EAPC), Online. Palliative Medicine, 2020; 34: 1 (suppl. 1): 1-280. [Poster presentation, digital]

Nishimura M, Dening, KH, Sampson, EL, Vidal, EIO, Abreu, WC, Kaasalainen, S, Eisenmann, Y, Dempsey, L, Moore, KJ, Davies, N, Bolt, SR, Meijers JMM, Lemos Dekker, N, Miyashita, M, Nakanishi, M, Nakayama, T, \& van der Steen, JT. Cross-cultural conceptualisation of a good end of life with dementia: A meta-qualitative study. The Alzheimer Disease International Conference 2020 Abstract book. 2020: 64-5.

Bolt, SR, Meijers, JMM, van der Steen, JT, Schols, JMGA, Zwakhalen, S. Nursing Staff Needs in Providing Palliative Care for Persons With Dementia at Home or in Nursing Homes: A Survey. 2021 Alzheimer's Association International Conference, Denver, USA and online. [Accepted poster presentation] 
LIVING LAB IN AGEING AND LONG-TERM CARE

\section{LIVING LAB IN AGEING AND LONG-TERM CARE}

This thesis is part of the Living Lab in Ageing and Long-Term Care, a formal and structural multidisciplinary network consisting of Maastricht University, nine long-term care organizations (MeanderGroep Zuid-Limburg, Sevagram, Envida, Cicero Zorggroep, Zuyderland, Vivantes, De Zorggroep, Land van Horne \& Proteion), Intermediate Vocational Training Institutes Gilde and VISTA college and Zuyd University of Applied Sciences, all located in the southern part of the Netherlands. In the Living Lab we aim to improve quality of care and life for older people and quality of work for staff employed in long-term care via a structural multidisciplinary collaboration between research, policy, education and practice. Practitioners (such as nurses, physicians, psychologists, physio- and occupational therapists), work together with managers, researchers, students, teachers and older people themselves to develop and test innovations in longterm care.

\section{ACADEMISCHE WERKPLAATS OUDERENZORG LIMBURG}

Dit proefschrift is onderdeel van de Academische Werkplaats Ouderenzorg Limburg, een structureel, multidisciplinair samenwerkingsverband tussen de Universiteit Maastricht, negen zorgorganisaties (MeanderGroep Zuid-Limburg, Sevagram, Envida, Cicero Zorggroep, Zuyderland, Vivantes, De Zorggroep, Land van Horne \& Proteion), Gilde Zorgcollege, VISTA college en Zuyd Hogeschool. In de werkplaats draait het om het verbeteren van de kwaliteit van leven en zorg voor ouderen en de kwaliteit van werk voor iedereen die in de ouderenzorg werkt. Zorgverleners (zoals verpleegkundigen, verzorgenden, artsen, psychologen, fysio- en ergotherapeuten), beleidsmakers, onderzoekers, studenten en ouderen zelf wisselen kennis en ervaring uit. Daarnaast evalueren we vernieuwingen in de dagelijkse zorg. Praktijk, beleid, onderzoek en onderwijs gaan hierbij hand in hand. 
PHD-THESES LIVING LAB IN AGEING AND LONG-TERM CARE / PROEFSCHRIFTEN ACADEMISCHE WERKPLAATS OUDERENZORG LIMBURG

Sascha Bolt. The fundamentals of a DEDICATED palliative approach to care for people with dementia. 2021

Angela Mengelers. To risk or to restrain? Involuntary treatment use in people with dementia living at home. 2021

Katya Sion. Connecting Conversations. Experienced quality of care from the resident's perspective: a narrative method for nursing homes. 2021

Linda Hoek. Change begins with choice. Supporting the autonomy of nursing home residents with dementia through partnership. 2020

Mirre den Ouden. Every step counts. Daily activities of nursing home residents and the role of nursing staff. 2018

Theresa Thoma-Lürken. Innovating long-term care for older people. Development and evaluation of a decision support app for formal caregivers in community-based

dementia care. 2018

Eveline van Velthuijsen. Delirium in older hospitalised patients: diagnosis and management in daily practice. 2018

Bram de Boer. Living at a green care farm. An innovative alternative for regular care in nursing homes for people with dementia. 2017

Nienke Kuk. Moving forward in nursing home practice. Supporting nursing staff in implementing innovations. 2017

Irma Everink. Geriatric rehabilitation. Development, implementation and evaluation of an integrated care pathway for older patients with complex health problems. 2017

Ramona Backhaus. Thinking beyond numbers. Nursing staff and quality of care in nursing homes. 2017

Martin Van Leen. Prevention of pressure ulcers in nursing homes, a big challenge. 2017

Mariëlle Daamen-Van der Velden. Heart failure in nursing home residents. Prevalence, diagnosis and treatment. 2016

Armand Rondas. Prevalence and assessment of (infected) chronic wounds. 2016

Hanneke Beerens. Adding life to years. Quality of life of people with dementia receiving long-term care. 2016 (Cum Laude)

Donja Mijnarends. Sarcopenia: a rising geriatric giant. Health and economic outcomes of community-dwelling older adults with sarcopenia. 2016

Tanja Dorresteijn. A home-based program to manage concerns about falls. Feasibility, effects and costs of a cognitive behavioral approach in community-dwelling, frail older people. 2016

Basema Afram. From home towards the nursing home in dementia. Informal caregivers' perspectives on why admission happens and what they need. 2015

Noemi Van Nie-Visser. Malnutrition in nursing home residents in the Netherlands, Germany and Austria. Exploring and comparing influencing factors. 2014
Esther Meesterberends. Pressure ulcer care in the Netherlands versus Germany 0-1. What makes the difference? 2013

Math Gulpers. EXBELT: expelling belt restraints from psychogeriatric nursing homes. 2013

Hilde Verbeek. Redesigning dementia care. An evaluation of small-scale homelike care environments. 2011

Judith Meijers. Awareness of malnutrition in health care, the Dutch perspective. 2009 Ans Bouman. A home visiting program for older people with poor health. 2009

Monique Du Moulin. Urinary incontinence in primary care, diagnosis and interventions. 2008

Anna Huizing. Towards restraint free care for psychogeriatric nursing home residents. 2008

Pascalle Van Bilsen. Care for the elderly, an exploration of perceived needs, demands and service use. 2008

Rixt Zijlstra. Managing concerns about falls. Fear of falling and avoidance of activity in older people. 2007

Sandra Zwakhalen. Pain assessment in nursing home residents with dementia. 2007 

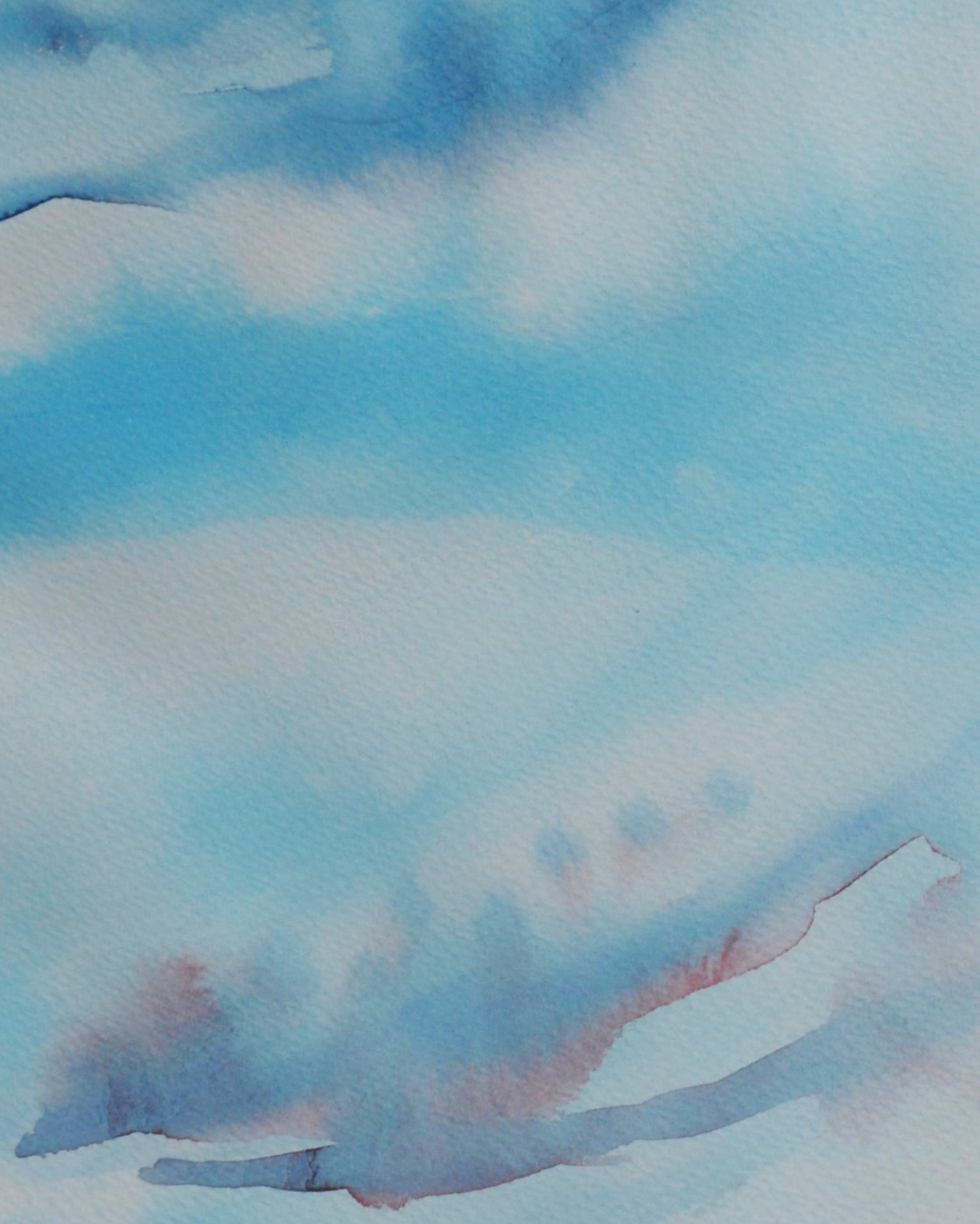